EDITED BY CRAIG JOHNSON, NOAH TOLY, HEIKE SCHROEDER

\title{
The Urban Climate Challenge
}

Rethinking the Role of Cities in the

Global Climate Regime
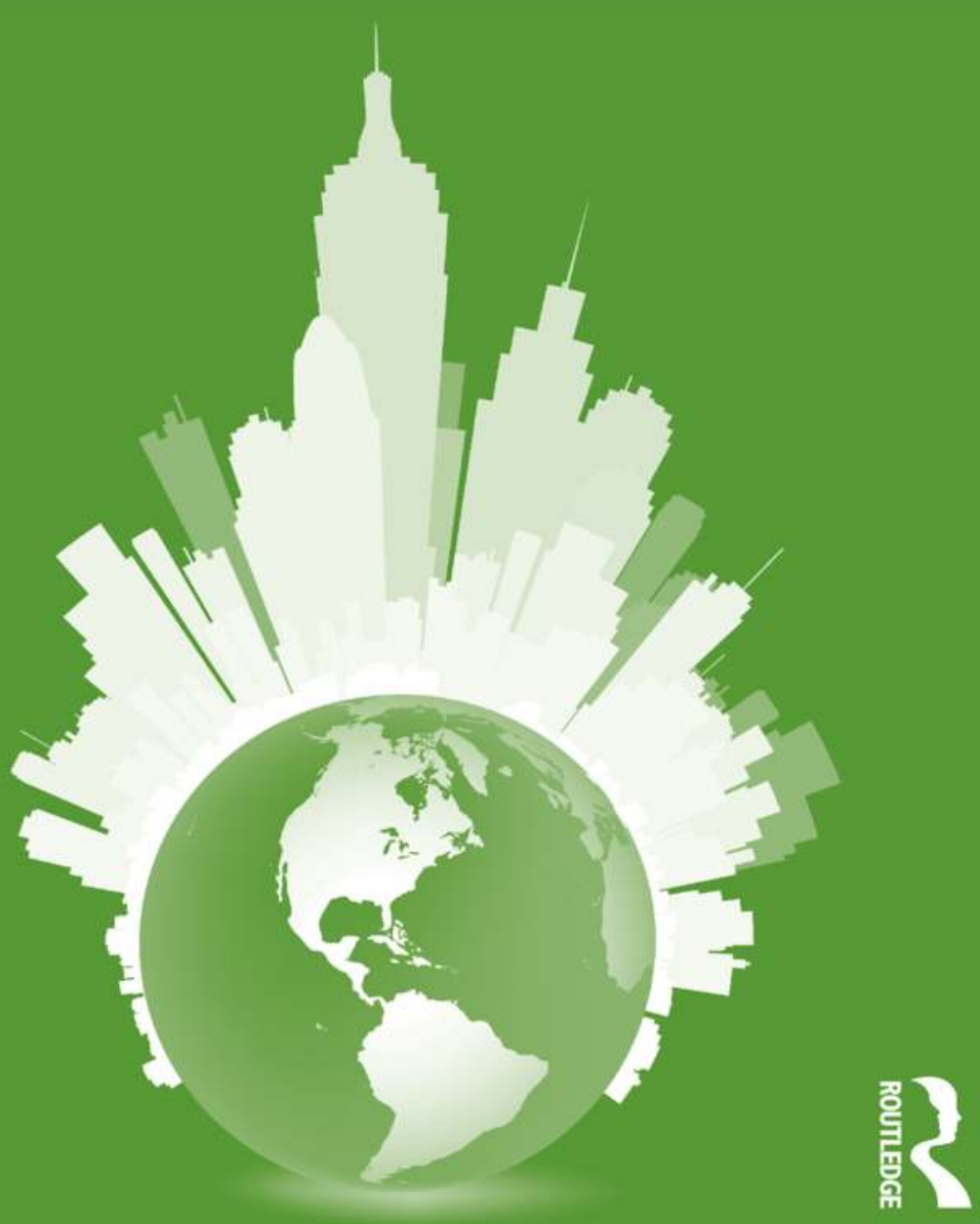


\title{
The Urban Climate Challenge
}

\begin{abstract}
"This volume takes readers on a comprehensive tour through the world of urban carbon governance research and is sure to set the agenda for a new generation of cities and climate change researchers.” - Michele M. Betsill, Colorado State University
\end{abstract}

"If dangerous climate change is to be avoided, we need both adaptation and mitigation to be incorporated into urban investments, policies and planning everywhere. This needs strong engagement with local stakeholders (especially those most at risk) and strong support from national governments and global climate governance regimes. This book provides a valuable contribution to how this can be done and where responsibilities for this lie." —David Satterthwaite, International Institute for Environment and Development (IIED)

Drawing upon a variety of empirical and theoretical perspectives, The Urban Climate Challenge provides a hands-on perspective about the political and technical challenges now facing cities and transnational urban networks in the global climate regime. Bringing together experts working in the fields of global environmental governance, urban sustainability and climate change, this volume explores the ways in which cities, transnational urban networks and global policy institutions are repositioning themselves in relation to this changing global policy environment.

Focusing on both Northern and Southern experience across the globe, three questions that have strong bearing on the ways in which we understand and assess the changing relationship between cities and global climate system are examined.

- How are cities repositioning themselves in relation to the global climate regime?

- How are cities being repositioned-conceptually and epistemologically?

- What are the prospects for crafting policies that can reduce the urban carbon footprint while at the same time building resilience to future climate change?

The Urban Climate Challenge will be of interest to scholars of urban climate policy, global environmental governance and climate change. It will be of interest to readers more generally interested in the ways in which cities are now addressing the inter-related challenges of sustainable urban growth and global climate change.

Craig Johnson is Associate Professor of Political Science and International Development Studies at the University of Guelph in Canada. His research focuses on questions of land and resource governance in the context of urbanization, globalization and climate change.

Noah Toly is Director of Urban Studies and Associate Professor of Politics and International Relations at Wheaton College in the United States (IL). His research and teaching interests are at the intersections of urban and global environmental governance, with particular interests in the participation of cities as sites and municipalities as actors in climate governance regimes.

Heike Schroeder is a Senior Lecturer in Climate Change and International Development at the School of International Development, University of East Anglia. Her areas of work include global environmental politics, urban climate governance, the role of non-state actors in international cooperation on climate change and forest governance. 


\title{
Cities and Global Governance
}

\author{
Edited by Noah Toly, Wheaton College
}

The Routledge series Cities and Global Governance is composed of contributed volumes covering key areas of study at the intersection of urbanism and global governance. Each title explores dimensions of the relationship between the local and the global, between urban landscapes and global dynamics. Authors in the series make empirical and theoretical contributions that advance our understanding of the role of cities as sites and actors in global governance.

1 Cities, Networks, and Global Environmental Governance

Spaces of Innovation, Places of Leadership

Sofie Bouteligier

2 The Power of Cities in International Relations

Edited by Simon

Curtis
3 Global Cities and Climate Change The Translocal Relations of Environmental Governance Taedong Lee

4 The Urban Climate Challenge Rethinking the Role of Cities in the Global Climate Regime Edited by Craig Johnson, Noah Toly and Heike Schroeder 


\section{The Urban Climate Challenge Rethinking the Role of Cities in the Global Climate Regime}

\section{Edited by Craig Johnson, Noah Toly and Heike Schroeder}


First published 2015

by Routledge

711 Third Avenue, New York, NY 10017

and by Routledge

2 Park Square, Milton Park, Abingdon, Oxon, OX14 4RN

Routledge is an imprint of the Taylor \& Francis Group, an informa business

(C) 2015 Taylor \& Francis

The right of the editors to be identified as the authors of the editorial material, and of the authors for their individual chapters, has been asserted in accordance with sections 77 and 78 of the Copyright, Designs and Patents Act 1988.

With the exception of Chapters 9 and 11, no part of this book may be reprinted or reproduced or utilised in any form or by any electronic, mechanical, or other means, now known or hereafter invented, including photocopying and recording, or in any information storage or retrieval system, without permission in writing from the publishers.

Chapters 9 and 11 of this book is available for free in PDF format as Open Access at www.tandfebooks.com. It has been made available under a Creative Commons Attribution-Non Commercial-No Derivatives 3.0 license.

Trademark Notice: Product or corporate names may be trademarks or registered trademarks, and are used only for identification and explanation without intent to infringe.

\section{Library of Congress Cataloging-in-Publication Data}

The urban climate challenge : rethinking the role of cities in the global climate regime / edited by Craig Johnson, Noah Toly, Heike Schroeder. pages $\mathrm{cm}$. - (Cities and global governance ; 4)

Includes index.

1. Urban ecology (Sociology) 2. Climatic changes. 3. Environmental policy. 4. Urban policy-Environmental aspects. I. Johnson, Craig (Craig Anthony) II. Toly, Noah. III. Schroeder, Heike.

HT241.U694 2015

$307.76-\mathrm{dc} 23$

2014036428

ISBN: 978-1-138-77688-3 (hbk)

ISBN: 978-1-315-77298-1 (ebk)

Typeset in Sabon

by Apex CoVantage, LLC

This research was supported by the Social Sciences Humanities Research Council (Canada) under Grant 430-2012-0827. 


\section{Contents}

List of Figures and Tables

\section{PART I}

Governing the Urban Climate Challenge: Understanding the Role of Cities in the Global Climate Regime

1 Introduction: Urban Resilience, Low Carbon Governance and the Global Climate Regime

CRAIG JOHNSON, HEIKE SCHROEDER AND NOAH TOLY

2 Bringing Cities into the Global Climate Framework SASKIA SASSEN

3 Closed Cycles-Open City

KATLEEN DE FLANDER

\section{PART II}

Going Global? The Changing Face of Urban Climate Governance

4 If Cities Are the Solution, What Are the Problems?

The Promise and Perils of Urban Climate Leadership

DAVID GORDON AND MICHELE ACUTO

5 Multinational Companies and Urban Climate Governance: Market Making or Successful Policy Innovation? 


\section{PART III}

Domestic Policy Responses: Integrating Mitigation and Adaptation into Urban Climate Governance

6 Combining Local and Transnational Action in the Adoption and Implementation of Climate Policies in the City of São Paulo

JOANA SETZER, LAURA VALENTE DE MACEDO AND

FERNANDO REI

7 Urban Climate Governance through a Sustainability

Lens: Exploring the Integration of Adaptation and

Mitigation in Four British Columbian Cities

SARAH BURCH, ALISON SHAW, FREYA KRISTENSEN, JOHN ROBINSON AND ANN DALE

8 Climate Change Adaptation in Mumbai, India

EMILY BOYD, ADITYA GHOSH AND MAXWELL

T. BOYKOFF

9 Relational Agency and the Local Governance of Climate Change: International Trends and an American Exemplar ALEXANDER AYLETT

\section{PART IV}

Regional Policy Perspectives: Comparing Policies and Outcomes across Regional Policy Regimes

10 Multilevel Governance and Institutional Capacity for Climate Change Responses in Latin American Cities

PATRICIA ROMERO-LANKAO, JORGELINA HARDOY, SARA HUGHES, ANGÉLICA ROSAS-HUERTA, ROXANA BÓRQUEZ AND DANIEL M. GNATZ

11 Climate Change Adaptation and African Cities: Understanding the Impact of Government and Governance on Future Action 
PART V

Governing the Urban Climate Challenge: New Directions in Theory, Policy and Research

12 Conclusion: Governing the Urban Climate Challenge

CRAIG JOHNSON, HEIKE SCHROEDER AND NOAH TOLY

Contributor Bios 245

Index 253 
$\Longrightarrow$ Taylor \& Francis

Taylor \& Francis Group

http://taylorandfrancis.com 


\section{Figures and Tables}

\section{FIGURES}

1.1 Urban and rural population growth trends and projections: 1950-2050.

3.1 Matching demand and supply. 39

3.2 Closed energy cycle (grey area) in an abstract system. 40

3.3 Reduce and increase size of closed cycle area in an abstract system.

3.4 Reduce density in closed cycle area in an abstract system. $\quad 41$

3.5 Increase size of closed cycle area in an abstract system. 42

3.6 Increase density in closed cycle area in an abstract system. 42

3.7 Resource deserts. 44

3.8 Different densities in closed cycle area in an abstract system. 44

3.9 Dynamic interdependent parameters. 47

3.10 Tree structure. $\quad 48$

3.11 Semi-lattice structure. 48

3.12 Social structure of a neighbourhood. 49

3.13 Lilypad Floating Ecopolis. $\quad 51$

3.14 Masdar City. $\quad 52$

3.15 Masdar City. $\quad 52$

3.16 Short-cut path. 53

7.1 Diverse case study selection in 11 communities across

7.2 Different responses and levels of integration in

9.1 Portland GHG emissions by sector, 1990 and 2008.

11.1 Home with secondary wall, Tandale Ward, Dar es Salaam. 206

11.2 River in Tandale Ward, with houses near river. 206 
$\mathrm{x}$ Figures and Tables

\section{TABLES}

7.1 Summary of drivers of sustainability-oriented urban climate change governance and specific innovations

10.1 Selected socioeconomic, demographic and climatic indicators 
Part I

Governing the Urban
Climate Challenge

Understanding the Role of Cities

in the Global Climate Regime 
$\Longrightarrow$ Taylor \& Francis

Taylor \& Francis Group

http://taylorandfrancis.com 


\title{
1 Introduction
}

\section{Urban Resilience, Low Carbon Governance and the Global Climate Regime ${ }^{1}$}

\author{
Craig Johnson, Heike Schroeder \\ and Noab Toly
}

\section{INTRODUCTION}

Urbanization has emerged as a major theme in world politics. For the first time on record, the number of people living in urban areas has exceeded the world's rural population (Satterthwaite et al., 2010: 2809). According to the United Nations, the world's urban population is projected to grow by another 3 billion people by the year 2050, increasing demand for clean air, water, land and essential public services, and putting unprecedented pressure on these and other resources (McDonald et al., 2011: 1). Most of the growth in urban population is expected to occur in the developing world (Figure 1.1). ${ }^{2}$

By virtue of the fact that they concentrate significant resources and numbers of people, cities are highly vulnerable to climatic hazards, such as floods, heat waves, storms and water-borne disease, especially in low elevation areas (McGranahan et al., 2007; Munslow and O'Dempsey, 2011; McDonald et al., 2011; Adamo, 2010; Romero-Lankao and Dodman, 2011). According to the 2011 Revision of the World Urbanization Prospects (UN/DESA, 2012: 18), 39 of the 63 urban areas with populations greater than 5 million are located in areas with a high risk of flooding, cyclones or drought; 72 percent are located "on or near the coast," two-thirds are in Asia. $^{3}$

At the same time, cities are also major emitters of greenhouse gases. According to the International Energy Agency (IEA, cited in World Bank, 2010), cities now account for 74 percent of the world's carbon consumption. ${ }^{4}$ Left unchecked, rapid urbanization will have a profound effect on the world's demand for renewable resources, creating new forms of vulnerability within cities, but also far beyond the urban footprint (IPCC, 2014: Chapter 8). Indeed, it is no stretch to suggest that processes of urbanization are the most significant forces shaping the global environment.

Improving the ability of cities to mitigate and adapt to climate change is therefore a pressing global priority. This book is about the ways in which cities, transnational urban networks and global governance institutions 


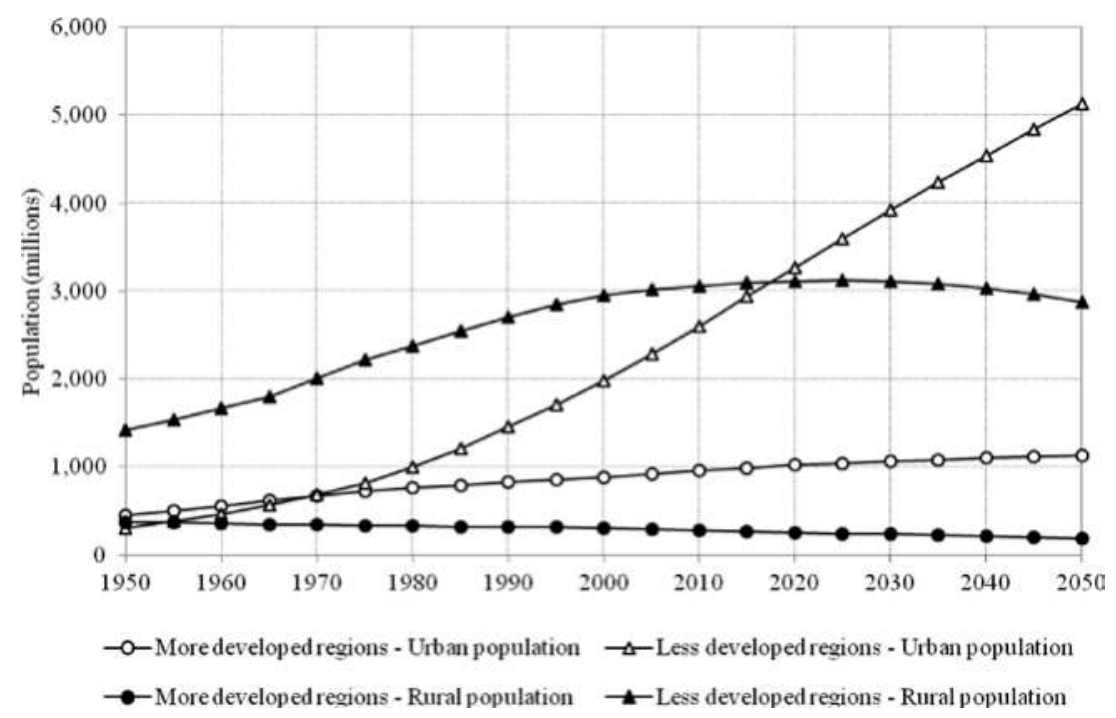

Figure 1.1 Urban and rural population growth trends and projections: 1950-2050. Source: UN/DESA (2012).

have repositioned themselves in the context of urbanization and global climate change. It starts from the premise that urban engagement with international climate policy discourses has influenced new forms of urban and global climate governance that are as yet poorly understood. Drawing upon contributions from scholars working in the fields of global environmental governance, urban sustainability and climate change, the volume explores four questions that have strong bearing on the ways in which we understand and assess the changing relationship between cities and the global climate regime.

- First, how and in what ways are cities incorporating climate change into urban planning and policy?

- Second, what is the impact of international climate change norms on urban and domestic climate policy?

- Third, how are cities and transnational urban networks engaging with global climate governance politics?

- And fourth, what are the implications for the study of international relations and global climate governance?

This chapter introduces the volume by reviewing the state of existing knowledge about the ways in which cities have been conceptualized in the field of urban and global climate governance. In so doing, it explores the ways in which climate change considerations have been articulated and 
disseminated through the global climate regime, a term we use to describe the rules, norms and procedures that have been established through the UN Framework Convention on Climate Change (hereafter UNFCCC). This is not to suggest that the international climate regime is only or primarily a function of the UNFCCC. Rather, it implies that urban engagement in international climate policy discourses has been framed by the norms and institutions established by the UNFCCC, an assumption we explore more critically in due course.

First, however, we begin by describing the urban climate challenge.

\section{THE URBAN CLIMATE CHALLENGE}

Empirical insights about the impact of urban systems on global emissions raise important questions about the extent to which cities can act autonomously and collectively to develop alternative industries, technologies and institutions that may encourage more sustainable patterns of consumption and production. At the international level, considerable attention has been paid to the capabilities of national governments to forge new commitments to support deep and meaningful cuts in emissions while at the same time investing in adaptation measures (Bulkeley and Betsill, 2005; Betsill and Bulkeley, 2006; Toly, 2008; Kern and Bulkeley, 2009; Bulkeley, 2010; World Bank, 2010; IPCC, 2014: Chapter 8). In recent years, cities like Toronto, New York and Seattle and transnational urban alliances, like the C40 and the International Council on Local Environmental Initiatives, have forged new commitments of their own, often in parallel to the post-2012 framework.

Whether cities will make a difference in terms of actually reducing emissions and vulnerability to climate change will depend on the will and ability of municipalities, corporations and civil society organizations to effect meaningful change at the local level by investing in infrastructure and institutions that can be replicated and maintained in the face of future social and environmental stress (World Bank, 2010; Atkins, 2012). But it will also depend on the ability of cities to support policy initiatives that work with a wider range of state and non-state actors whose diverse interests, actions and institutions have important bearing on the ability to engage in mitigation and adaptation at wider scales of interaction.

In theory, new sources of international funding (like the Green Climate Fund) will provide an important means of investing in adaptation and mitigation measures that may reduce emissions and vulnerability to climate change (World Bank, 2010; Kennedy, 2011). However, the ability of cities to invest in "climate smart" technologies that can lower emissions while at the same time building resilience to climate change is limited. Urban infrastructure, for example, often persists for decades and sometimes lasts for centuries. Overcoming the rigidities put in place by years of investment (or lack thereof) in particular modes of transportation, electricity generation, 
sanitation, water treatment and so forth entails an ability to understand the costs and potential risks of maintaining the status quo and an ability to mobilize (public and private) resources in the name of (long-term) infrastructural development (cf. Moser and Luers, 2008; World Bank, 2010; Kennedy, 2011; IPCC, 2014: Chapter 8). In some cases (e.g., raising transmission boxes and insulating electrical cables in New York), investing in resilience can be relatively straightforward (Klinenberg, 2013). In others (e.g., building the 10,000ha Marina and Barrage Reservoir in Singapore or the Delta Works/Climate Proof Program in Rotterdam), it can span generations (Klinenberg, 2013).

Promoting higher-density settlement is often advanced as a means of reducing urban emissions, especially in transportation and building systems (World Bank, 2010: 19; IPCC, 2014: Chapter 8). However, higher-density living can also exacerbate traffic congestion if personal car ownership is high, which leads to further emissions. ${ }^{5}$ Moreover, the factors affecting urban demand for land, energy and resources are arguably part of a wider political process that both frequently transcends the formal authority of local cities and municipalities and also drives global environmental change, highlighting the importance of scale (Sassen and Dotan, 2011; World Bank, 2010).

Effective urban climate governance is therefore constrained by the fact that the historical and socio-economic factors driving urban resource dependence and vulnerability are often operating at a scale that is well beyond the formal authority of urban authority structures (cf. Sassen and Dotan, 2011). Further complicating the distribution of adaptation and mitigation costs and benefits is the North-South dynamic of global climate politics. Until recently, global climate agreements have required emissions reductions only on the part of northern countries, those belonging to Annex I of the UNFCCC. However, as emerging economies such as China, India, South Africa and Brazil continue to grow, there is now an expectation that rapidly developing non-Annex I countries will make a commitment to future greenhouse gas reductions, and indeed many have made voluntary pledges following the 2009 Copenhagen COP.

Still, despite these complications and limitations, there is little doubt that cities will play a crucial role in this process. According to a report recently published by the McKinsey Global Institute, 40 percent of the world's 75 "most dynamic" cities are now in China (Dobbs and Remes, 2012: 63). ${ }^{6}$ In the words of the authors (2012: 63):

China's urbanization is thundering along at an extraordinary pace; it's happening at 100 times the scale of the world's first country to urbanize-Britain—and at 10 times the speed. Over the past decade alone, China's share of people living in large cities has increased from 36 percent to nearly 50 percent. In 2010, China's metropolitan regions accounted for 78 percent of its GDP. If current trends hold, the Middle 
Kingdom's urban population will expand from approximately 570 million to 925 million in 2025-an increase larger than the entire current population of the United States.

China of course is not alone in this regard. According to the 2011 World Urbanization Prospects, India's urban population is expected to grow by another 497 million by 2050,7 Nigeria's by 200 million, Indonesia's by 92 million and the United States by more than 100 million.

Underlying these transformations are complex processes that have gradually redefined the ways in which land, labor and related resources (e.g., water, fishing, mining rights) are being governed for the purposes of commercial and industrial development (Satterthwaite et al., 2007; Roy, 2009; 2010; 2011; Seto, 2011; Seto et al., 2011; 2012; Sassen and Dotan, 2011). One is a macro-economic shift away from primary production into manufacturing and services (Satterthwaite et al., 2010). A second is a process of global integration whereby urban and peri-urban areas have emerged as important sites of production, processing and exchange (Satterthwaite et al., 2010). A third has been the acquisition and conversion of forests, wetlands, and agricultural land for industrial, commercial and residential development (Roy, 2009; 2010; 2011; Seto et al., 2011).

In many instances, new patterns of land and resource governance have entailed the conversion of areas previously used for agricultural production, creating new forms of vulnerability to climate change (McGranahan et al., 2007; Munslow and O’Dempsey, 2011; McDonald et al., 2011; Adamo, 2010; Romero-Lankao and Dodman, 2011). First, the conversion of forests, water bodies and wetlands for commercial and industrial purposes has affected the ability of urban and surrounding ecosystems to absorb variations in rainfall and discharge, exacerbating vulnerability to flooding (Revi, 2008; Moench, 2010). Second, the loss of agricultural land has undermined local food systems, raising new concerns about urban food security (Satterthwaite et al., 2010; Roy, 2009; 2010; 2011; Seto et al., 2011). ${ }^{8}$ Third, and related, urbanization has displaced the livelihoods of populations dependent upon hitherto marginal urban and peri-urban spaces, such as wetlands and canals, exacerbating poverty and vulnerability to environmental change (Revi, 2008; Roy, 2009; 2010; 2011; Penz et al., 2011). Fourth, rapid urbanization often undermines the ability of local and national authorities to provide public services in housing, sanitation, water treatment and healthcare, exacerbating vulnerability to water and climate-borne disease (Revi, 2008; Satterthwaite et al., 2010; McDonald et al., 2011: 1). According to another modeling exercise carried out by McDonald et al. (2011), the number of people living with inadequate access to fresh water (defined as less than 1 liter per day) in cities is expected to increase from 150 million to 1 billion people by the year 2050 .

The urban climate challenge therefore presents a genuine policy paradox. On one hand, cities are major producers of wealth, productivity and 
ingenuity that allow us to understand and act upon the factors contributing to anthropogenic climate change (cf. Sassen and Dotan, 2011; Bulkeley and Broto, 2012). On the other, they are major emitters of greenhouse gases, highlighting the fact that the same forces that are driving an accumulation of wealth and prosperity in large urban centers are also often the factors that are creating new forms of poverty and vulnerability to global environmental change.

\section{UNDERSTANDING THE ROLE OF CITIES IN THE GLOBAL CLIMATE REGIME}

Recognizing the challenge of reducing emissions and vulnerability to global climate change highlights a number of conceptual and theoretical themes that have strong bearing on the study of environmental governance regimes. One concerns the challenge of incorporating mitigation and adaptation into urban policy and planning. Recent theoretical work on the ability of cities to mitigate and adapt to climate change has highlighted the importance of developing low-carbon strategies that can reduce the vulnerability of urban populations to climate change (Sassen and Dotan, 2011). The World Bank's report on Cities and Climate Change (2010), for instance, suggests that urban adaptation and mitigation can be reconciled by adopting an "integrated approach" that "considers mitigation, adaptation and urban development." Similarly, the IPCC's Fifth Assessment Report highlights "the importance of city and municipal governments acting now to incorporate climate change adaptation into their development plans and policies and infrastructure investments.”

This includes not only building that foundation of resilience (and its institutional, governance and financial underpinnings) but also mobilizing new resources, adjusting building and land-use regulations and continuously developing the local capacity to respond. ${ }^{9}$

However, the factors affecting urban engagement in climate policy processes are still poorly understood. Notwithstanding the instances in which cities have been able to foster local innovations, policy commitments to climate change are often low on the agenda of most urban planners and politicians, reflecting the challenge of prioritizing mitigation and adaptation over other more "pressing" urban needs, such as housing, transportation and waste disposal (Adamo, 2010; Satterthwaite et al., 2007; McDonald et al., 2011; Leichenko, 2011; Romero-Lankao and Dodman, 2011; Bulkeley and Broto, 2012).

A second and related theme concerns the factors affecting climate policy innovation in urban settings. Recent empirical work on the factors affecting urban climate governance has shown that cities can provide important 
"sites of experimentation," in which new plans, codes and infrastructural investments have been used to improve urban resilience to climate change (Tanner et al., 2009; Leichenko, 2011; Romero-Lankao and Dodman, 2011; Bulkeley and Broto, 2012). In their recent survey of 627 urban "climate change experiments" in 100 cities, Bulkeley and Broto (2012:1) found that cities provide important opportunities to invest in policy experiments that, because of possibilities for policy diffusion, can be used to reduce greenhouse gas emissions in other policy settings.

Framed in this way, cities can be usefully conceptualized as "complex adaptive systems," whose ability to decide land and resource use, the provision of infrastructure and services and the regulation of housing, transportation and industry is divided among multiple institutions and jurisdictions, highlighting the complex ways in which urban systems act and react to new patterns of environmental vulnerability (including ones revealed through climate science) (Bulkeley and Betsill, 2005; Betsill and Bulkeley, 2006; Moser and Satterthwaite, 2008; Tanner et al., 2009; Satterthwaite et al., 2010; Leichenko, 2011; Romero-Lankao and Dodman, 2011; Sassen and Dotan, 2011). Bulkeley and Broto (2012: 1), for instance, find that climate policy experiments "serve to create new forms of political space within the city, as public and private authority blur, and are primarily enacted through forms of technical intervention in infrastructure networks." Similarly, Sassen and Dotan (2011: 825) contend that cities can be conceptualized in terms of the "ruptures" they create within the Earth's biosphere. Whereas most of these ruptures are destructive (i.e., depleting resource flows and degrading resource sinks) they also "make visible the connectedness of cities and biosphere, and thereby open new ways to conceptualize urban-ecological flows." $" 10$

A third and related theme concerns the strategic ways in which cities are now using climate change norms and discourses to justify more comprehensive approaches to urban policy and planning (Bulkeley and Betsill, 2013; Aylett, this volume; Burch et al., this volume; Setzer et al., this volume). There is now a growing body of evidence to suggest that cities and transnational urban coalitions have used the language of the Kyoto Protocol and of climate change more generally to justify new forms of policy and investment at the urban scale (Bulkeley and Broto, 2012; Bulkeley and Betsill, 2013). However, the dissemination of climate policy norms is uneven (Acuto, 2013), reflecting large disparities in the size, capacity and leadership of urban governance institutions. Moreover, the geographical, institutional and discursive ties that connect cities and urban actors with global environmental regimes vary enormously, suggesting considerable room for empirical research.

Drawing upon Finnemore and Sikkink's distinction between "regulative norms, which order and constrain behavior and constitutive norms, which create new actors, interests, or categories of action" (Finnemore and Sikkink, 1998: 891), there is ample evidence to suggest that the UNFCCC, the 
Kyoto Protocol and-critically-the perceived failure of the Kyoto Protocol have created the conditions for new forms of regulative and constitutive norm formation. In recent years, cities like London and New York have adopted and expanded upon Kyoto targets in developing their own climate policy initiatives (cf. Acuto, 2013; Chapter 4, this volume). Similarly, transnational urban alliances, such as the Cities Climate Leadership Group (C40) and the International Council on Local Environmental Initiatives (ICLEI), have framed themselves explicitly in relation to the goals and perceived shortcomings of the UNFCCC.

However, theoretical insights about the factors affecting urban climate change norm formation remain poorly understood, reflecting the myriad ways in which cities and transnational urban networks may conceivably interact with global climate policy discourses and institutions. One obvious area of focus is the UNFCCC, whose funding mechanisms provide a number of channels (such as the Green Climate Fund, Joint Implementation and the Clean Development Mechanism) through which cities may implement new ways of reducing emissions and vulnerability to climate change. However, as noted earlier, the UNFCCC is but one source of authority, whose ability to achieve binding targets has been called into question. Another logical area of focus is the global aid regime. Here it is worth noting that bilateral and multilateral agencies like the UK Department for International Development, UNDP and the World Bank have become increasingly interested in cities and climate change (e.g., World Bank, 2010).

Beyond these official development channels are a number of informal, non-state actors and networks, whose impact on global climate governance dynamics is arguably less well understood. One is the wide range of transnational urban alliances, such as ICLEI and the C40, whose membership activities have entailed not only advocacy and awareness raising but also the dissemination of guidelines and information about "climate-smart" approaches to housing, transportation and registries for tracking emissions at the urban scale (Chapters 4 and 6, this volume). Similarly, corporations like Siemens and ARUP have become increasingly active in developing urban planning models for climate change adaptation and mitigation (cf. Chapter 5, this volume).

However, the role that corporations, transnational networks and multilateral governance institutions are having on urban climate policy remains poorly understood, highlighting the need for further empirical and theoretical work on the changing nature of global climate regimes. From a theoretical perspective, questions have been raised about the extent to which cities and transnational urban networks represent new forms of power within the international system (Bulkeley and Betsill, 2005; 2013; Curtis, 2011; Acuto, 2013). Empirically, questions have also been raised about the extent to which transnational urban networks can provide an alternative to the Kyoto Protocol's failed efforts to reduce global greenhouse gas emissions. 
A fourth and related theme concerns the role that cities and transnational urban networks are having on global environmental governance regimes. Recent empirical work on urban climate governance has documented the ways in which cities and municipal leaders have engaged in transnational urban networks, such as the Cities Climate Leadership Group (C40) and the International Council on Local Environmental Initiatives (ICLEI) (Betsill and Bulkeley, 2006; Toly, 2008; Acuto, 2013). Internationally, transnational municipal networks like the C40 Cities Climate Leadership Group (C40) and ICLEI have forged stronger commitments on the part of the international community (Acuto, 2013). Participation in transnational urban networks also appears to have facilitated the transmission of norms governing the need for urban climate action, including the diffusion of metrics used in measuring emissions, improving resource efficiency and reducing the urban carbon footprint (Acuto, 2013; Chapters 4-6, this volume).

For some, the appearance of cities in the international arena suggests an opening of a policy dialogue that has previously been the exclusive realm of climate scientists, government officials and nation-states (cf. Acuto, 2013). For others, questions have been raised about the extent to which networks like the $\mathrm{C} 40$ or the Clinton Foundation's Climate Initiative (CCI) are actually able to craft an alternative to the global climate regime. By virtue of their leadership in the C40 and the CCI, cities like London and New York have been able to position themselves as key players, forging new opportunities for proactive mayors like Michael Bloomberg and Ken Livingstone to showcase their efforts in the global fight against climate change. At the same time, cities like Lima, Addis Ababa and even Los Angeles were relegated to what was clearly a marginal status, suggesting a hierarchy of interest and involvement in the wider movement (Acuto, 2013).

One of the challenges in theorizing the role of cities in global environmental regimes is that they lack the formal standing that is often accorded to sovereign nation-states within international agreements, such as the UNFCCC. International regimes can be usefully defined as the "rules agreed to by states ... concerning their conduct in specific issue areas (trade, monetary exchange, navigation on the high seas or in the air, non proliferation ..., etc.) and often associated with international and non-governmental organizations linked to these regimes" (Viotti and Kaupi, 2010: 131). However, unlike states, cities have no formal authority to negotiate positions on UNFCCC commitments, suggesting an important dichotomy between the factors that are currently driving contemporary urbanization processes and the historical/territorial terms on which states have established sovereignty and legitimacy within the international system (Curtis, 2011). Like the international negotiations that gave them force, the UNFCCC and the Kyoto Protocol are products of an international system whose principal aim is to uphold the jurisdictional and territorial sovereignty of individual nationstates, highlighting the need to incorporate non-state actors and multi-scale processes into the analysis. 


\section{2}

Craig Johnson, Heike Schroeder, Noab Toly

Whether cities are influential through formal structures (e.g., municipalities, chambers of commerce, etc.) or informal networks (cf. Sassen, 2001), as sites or as actors (for this distinction, see Amen et al., eds., 2011 and Bouteligier, 2012) such discussions point to the need for more comparative, empirical analysis that captures the historical ways in which states and social forces have affected urban repositioning. Despite some enthusiasm about the implications of these changes for the potential for urban leadership on climate change, there remain uncertainties about the capabilities and competencies of cities, states and non-state actors to "manage" the complexities of urbanization and global environmental change. Both processes are reflective of a wider ideological transformation in which the legitimacy of state-led development has been challenged on the grounds that it produces systems of governance that undermine national economic performance and effective public policy, highlighting the need to theorize in greater detail the ways in which states and social actors respond to global economic forces.

A fifth theme concerns the scale at which we can usefully conceptualize the role of cities in global environmental governance regimes. Sassen and Dotan (2011) make an important distinction between what they call "multilevel" and "multi-scalar" dimensions of urban climate governance (cf. Sassen and Dotan, 2011). According to this distinction, "multilevel" implies a "relative position" in what Sassen and Dotan (2011: 832) have called a "hierarchically organized system." Scale, on the other hand, implies differences in interactions and relationships that often transcend formal organizations and institutions (Sassen and Dotan, 2011: 832). Understanding the political and administrative dimensions of city-state relations within a federal system, for instance, implies a multilevel analysis. Tracing the ecological impact of urban lifestyles on ambient and global atmospheric processes implies questions of scale.

When it comes to actually implementing policies (i.e., selecting beneficiaries, regulating actors and allocating costs), the multi-scalar dimensions of adaptation and mitigation become readily apparent. As the World Bank points out:

Adaptation will have impacts primarily on a local scale: actions are based on specific needs of the affected regions. Costs might be very high, especially in large-scale infrastructure such as flood protection works, roads, ports, and power generation facilities. The cost savings from adaptation efforts mainly accrue through reduced risk impacts (for example, insurance) often at an individual homeowner, business, or community level. (World Bank, 2010: 11)

Investment in adaptation is costly, but usually involves relatively marginal changes to urban social systems, significant co-benefits, and benefits that 
largely accrue to the communities in which the investment takes place. Mitigation, on the other hand

... is a global effort requiring broad changes of behavior and technological advancements. Mitigation strategies are usually expensive in the short term, because they are capital intensive (change in technology, urban transport, and collective infrastructure) and require fundamental changes to urban systems. Over time, the cost of mitigation is generally self-financed through cost savings (mainly in energy bills).

"Reconciling" the politics of adaptation and mitigation therefore entails an ability to reconcile the costs and benefits of acting to improve primarily local patterns of urban environmental vulnerability with the costs and benefits of acting to govern the global climate system.

A sixth and final theme concerns the normative terms on which urban climate governance may be conceptualized and evaluated for the purposes of empirical and policy analysis. In other words, what constitutes "successful" or sustainable urban climate governance?

By and large, the vast majority of policy writing about urban climate governance has been about vulnerability and resilience of cities to environmental hazards, as well as disaster risk reduction (cf. Leichenko, 2011). The UNISDR report (2012: 11) on "resilient cities," for instance, states that:

A resilient city is characterized by its capacity to withstand or absorb the impact of a hazard through resistance or adaptation, which enable it to maintain certain basic functions and structures during a crisis, and bounce back or recover from an event ...

Definitions of urban vulnerability often emphasize the exposure of populations, private assets (e.g., housing and property) and public services and infrastructure to a variety of climate stressors (Atkins, 2012; Romero-Lankao and Qin, 2011; Romero-Lankao and Dodman, 2011). The "Atkins Report" on "Future Proofing Cities" (Atkins, 2012), for instance, conceptualizes vulnerability in relation to levels of poverty and inequality, the strength of basic services (in transportation, communication, sanitation, drinking water, healthcare) and urban form. Romero-Lankao and Qin (2011: 143-4) further distinguish between what they call "vulnerability as impact" studies, in which a primary focus is placed on "exposure to climate hazards, sensitivity of urban infrastructures, populations or activities, and the resulting or potential impacts" and "inherent urban vulnerability" approaches, which explore "how and why particular cities or populations are more vulnerable-or more able to cope or adapt than others." A critical distinction concerns the ways in which and extent to which vulnerability is conceptualized as "an end point of a linear process" or a "dynamic process based on the 
decreasing ability of a city or its populations to cope with a set of environmental hazards and stresses" (Romero-Lankao and Qin, 2011: 145).

Focusing on process highlights important questions about the historical-structural forces (including ones affecting policy decisions) that exacerbate urban vulnerability to climate change. Political ecology approaches (e.g., Adger, 2006; Toly, 2011; Wisner et al., 2004), for instance, highlight the structural-historical patterns of trade and investment that induce unsustainable patterns of land-use and settlement, by creating large numbers of people whose livelihoods are dependent on economic activities that are by their very nature vulnerable to economic and ecological disruption. Whether people "choose" to live and work in unsafe urban areas is therefore a function of historical policy decisions (regulating land use, environmental protection, etc.) as well as the historical/structural forces affecting livelihoods, poverty, wage rates and migration (Adger, 2006; Wisner et al., 2004; Eakin and Luers, 2006; Satterthwaite et al., 2007; 2010).

Focusing on process also highlights the ways in which past struggles, decisions, changes and "ruptures" affect contemporary development pathways. From a resilience perspective, the development of roads, suburbs and public services, the consumption of food and energy and the production of goods, services and sectors all create potential rigidities that have strong bearing on the ability of urban systems to act and react to changing environmental conditions (cf. Sassen and Dotan, 2011; Kennedy, 2011). Changing the energy sources that are used to fuel large urban centers, for instance, implies one order of magnitude. Changing from extensive urban planning to higher-density living is another. Changing from an automobile-based system of private transportation to a public system of rail networks and linkages is another still.

Finally, conceptual questions can be raised about the appropriate range of indicators that may be used in measuring and evaluating urban greenhouse gas emissions. Recent discussions about the challenge of measuring urban $\mathrm{CO}_{2}$ emissions, for instance, have weighed the merits of defining emissions strictly on the basis of goods and services that are produced within a city's physical and institutional "limits" as opposed to measuring ones that are "embodied" in the goods and services that are consumed within the city but produced outside of its boundaries (World Bank, 2010: 10). Many indexes, such as the IEA figures cited earlier, use an aggregate indicator of total energy consumption or GHG emissions to classify and rank urban emissions. However, aggregate indicators provide at best a partial illustration of the extent to which cities are contributing to climate change, underplaying substantially the variations that exist in terms of density, connectivity and other aspects of resource efficiency. For this reason, alternative measurements use per capita readings to capture the relative contribution of urban centers to climate change (World Bank, 2010: 10).

From an analytical perspective, conceptual debates about the ambiguous nature of urban classification systems highlight the challenge of situating 
urban climate governance within a wider scale of economic and environmental interaction. From a policy perspective, it raises questions about the best and most appropriate means of establishing responsibility for reducing both greenhouse gas emissions and vulnerability to global climate change.

Which brings us back to politics and policy. The chapters in this volume cover a wide range of theoretical, geographical and political perspectives. The following section provides a roadmap for the rest of the volume.

\section{OUTLINE OF THE BOOK}

This book is organized into five parts. Part I sets the stage by exploring the theoretical dimensions of urban and global climate governance. Chapter 2 by Saskia Sassen explores the theoretical and political implications of understanding and addressing the challenge of climate change in an increasingly urban world. Sassen starts from the premise that "existing theories about environmental sustainability and global environmental governance centered on the inter-state system fail to incorporate cities in the most productive way." For Sassen, the political and intellectual challenge lies in re-conceptualizing the multiple ways in which cities can move away from "negative" articulations that produce "ruptures" in the Earth's biosphere to a more positive and sustainable condition. "The city," she argues, "has become a strategic space for the direct and brutal confrontation between forces that are enormously destructive to the environment and increasingly acute needs for environmental resources, from water and clean air." Chapter 3, by Katleen De Flander, builds upon the work of Sassen and others by theorizing the ways in which cities may "close the cycle" of urban resource flows while at the same time addressing processes of segregation and displacement that have become increasingly apparent in a context of globalization, urban land speculation and uneven spatial development. Building upon Sassen's concept of planetary ruptures, De Flander contends that efforts to understand the role of cities in global climate governance must entail a fundamental re-conceptualization of the ways in which we think about flows (of resources, energy and people), form, function and the production of urban space.

Part II of the book explores the mechanisms by which cities, transnational urban networks and multinational corporations are engaging with global governance processes and institutions. Chapter 4, by David Gordon and Michele Acuto, explores the role of cities, municipal leaders and transnational urban networks in shaping the international climate agenda. Documenting the formation and evolution of the C40, Gordon and Acuto cast a critical eye on the notion that transnational urban networks now constitute a substantial departure from the traditional multilateral framework. At the heart of their analysis is a critical exploration of the C40's capacity, authority and legitimacy in affecting global climate governance. Chapter 5, by Sofie Bouteligier, explores the role that multinational corporations are 
playing in the development of urban climate policy. By documenting the role of large MNCs, like Siemens and ARUP, Bouteligier examines the ways in which MNCs are affecting urban climate policies and outcomes, including the privatization of urban service delivery. She also explores the extent to which corporate engagement in urban climate policies is creating new forms of power and expertise within the global climate regime.

Part III next turns to the domestic level, comparing the ways in which interactions with national policy institutions have influenced governance processes and outcomes in different urban policy settings. In Chapter 6, Joana Setzer, Laura Valente de Macedo and Fernando Rei explore the ways in which transnational networks, including ICLEI and the C40, have influenced the legislation, adoption and implementation of climate change policies in the Brazilian city of São Paulo. Documenting the adoption of Law 14,933 ("Municipal Climate Law"), Setzer and colleagues examine the ways in which São Paulo's engagement in transnational networks affected the development of urban climate policy (including the transnational dissemination of information about energy efficiency and inventories for tracking urban emissions). They also document the ways in which São Paulo's interaction with transnational networks has affected its capacity to govern in other more ambitious forms of global climate governance. Chapter 7, by Sarah Burch and colleagues, explores the impact of national and provincial policy changes on urban climate governance in the Canadian province of British Columbia (BC). At the heart of their analysis is an enabling piece of legislation, the Climate Action Charter (CAC), which was enacted by the BC government in 2008 as a means of encouraging cities (as well as towns, regions and neighborhoods) to incorporate mitigation and more recently adaptation into local development initiatives. Presenting data from four $\mathrm{BC}$ municipalities, the authors explore the factors affecting urban climate governance, including the incentives provided by provincial and national agencies for integrating mitigation and adaptation into urban policy and planning. Chapter 8, by Emily Boyd, Aditya Ghosh and Max Boykoff, shifts our attention to Mumbai, an Indian city whose low elevation, large population and proximity to the coast make it particularly vulnerable to the impacts of climate change. Drawing upon key informant interviews and a content analysis of government policy documents and English-language newspapers, the authors explore the ways in which a series of devastating flood events in 2005 affected urban climate and disaster risk reduction policy in Mumbai. Central to their study is a critical analysis of the ways in which "unequal geographies" and international adaptation discourses affect the ability of municipal, regional and national governments to strengthen adaptation policy and planning at the urban scale. Finally, Chapter 9, by Alex Aylett, explores the challenges of mainstreaming climate change priorities across "the institutional silos" that characterize municipal politics and administration. Drawing upon data compiled by ICLEI and the Massachusetts Institute of Technology, Aylett examines the ways in which 
municipal leaders were able to put climate change onto the urban agenda in the American city of Portland, Oregon. Combining actor network theory and the new institutionalism, the chapter sheds light on the ways in which politicians and officials can build "coalitions of support" for effective urban climate governance.

Part IV offers a regional and comparative perspective on the politics of urban climate governance. Our logic in emphasizing the regional dimensions of the analysis in Chapters 10 and 11 is twofold. First, both chapters contextualize their analysis in relation to specific political histories, cultures and geographies that we can usefully associate with regional dimensions of social and environmental change. Second, both use a comparative logic of analysis. Chapter 10, by Patricia Romero-Lankao and colleagues, explores the factors affecting urban climate policy outcomes in three Latin American cities: Buenos Aires (Argentina), Mexico City (Mexico) and Santiago (Chile). Chapter 11, by Christopher Gore, situates a comparative analysis of Kampala (Uganda) and Dar es Salaam (Tanzania) in a broader context of African urban development. For Romero-Lankao and colleagues, Mexico City is understood as a "frontrunner" in the development of urban climate policy, against which the cases of Buenos Aires and Santiago may be usefully compared for the purposes of generalization. For Gore, the analysis centers upon the structure of government, highlighting specifically the extent to which urban climate initiatives are integrated within a supportive national policy context.

Finally, Part V of the volume highlights the central themes in the volume and identifies key questions for future empirical research.

\section{NOTES}

1. The authors thank Michele Betsill, Rosario Gómez and two anonymous reviewers for helpful comments on previous versions of this chapter. Any errors remain the responsibility of the authors.

2. Although the highest rates of urbanization can be found in Latin America, the vast majority of future urban growth is expected to occur in Asia and Africa (UN/DESA, 2012; cf. Montgomery, 2008; McDonald et al., 2011; Seto, 2011; Seto et al., 2011; 2012; Dobbs and Remes, 2012). According to the 2011 revision of the United Nations' World Urbanization Prospects, Africa's urban population is expected to increase from 414 million to over 1.2 billion by 2050; Asia's will increase from 1.9 billion to 3.3 billion. Data retrieved from http://esa.un.org/unpd/wup/index.htm; last accessed 23 January 2013.

3. Similarly, McGranahan and colleagues (2007) estimate that 600 million people (or 10 percent of the Earth's population) now live in areas that are within $100 \mathrm{~km}$ of the coast and at elevations less than 10 meters above sea level. Of these, 360 million people are in urban areas.

4. Whether this figure is an estimate of direct emissions and consumption as well as emissions that are "embodied" in the goods and services being produced and consumed by urban areas is unclear. More on this below.

5. The World Bank (2010: 29), for instance, cites a number of studies that have shown that higher-density urban areas are also prone to higher traffic congestion and traffic-related GHG emissions. 
6. According to the authors, "dynamic" is defined primarily in relation to demographic and GDP per capita growth projections. Cities in turn are defined as "integrated metropolitan areas, aggregating neighboring cities into a single urban center where appropriate" (Dobbs and Remes, 2012: 63).

7. Data retrieved from http://esa.un.org/unpd/wup/index.htm; last accessed 10 May 2012.

8. Whether urbanization processes are contributing to the loss of agricultural land is a matter of some debate (Satterthwaite et al., 2010). As Satterthwaite and colleagues have noted (2010: 2816), "the loss of agricultural land to the spatial expansion of urban areas is often exaggerated," reflecting the limitations of accurate data, agricultural land speculation and the impact of agricultural intensification and urban agriculture.

9. Retrieved from http://ipcc-wg2.gov/AR5/images/uploads/WGIIAR5-Chap8_ FGDall.pdf; last accessed 31 August 2014.

10. On this basis, they make their theoretical case for "delegating back" to the biosphere (Sassen and Dotan, 2011).

\section{BIBLIOGRAPHY}

Abu-Lughod, Janet. (2000) New York, Chicago, Los Angeles: America’s Global Cities. Minneapolis: University of Minnesota Press.

Acuto, Michele (2013) “The New Climate Leaders?” Review of International Studies 39: 835-57.

Adam, S. and H. Kriesi (2007) “The Network Approach.” In P. Sabatier (Ed.), Theories of the Policy Process. Boulder: Westview Press, 129-55.

Adamo, Susana B. (2010) "Environmental Migration and Cities in the Context of Global Environmental Change." Environmental Sustainability 2: 161-5.

Adger, W.N. (2006) "Vulnerability.” Global Environmental Change 16: 268-81.

Amen, Mark, Noah J. Toly, Patricia McCarney, and Klaus Segbers, eds. (2011) Cities and Global Governance: New Sites for International Relations. London: Ashgate.

Armitage, D., M. Marschke and R. Plummer (2008) “Adaptive Co-management and the Paradox of Learning." Global Environmental Change 18: 86-98.

Atkins PLC (2012) Future Proofing Cities: Risks and Opportunities for Inclusive Urban Growth in Developing Countries. Report published in collaboration with UKAid/DFID and the Development Planning Unit (DPU), University College London, last accessed 26 February 2013 at http://futureproofingcities.com/ executive_summary.html

Berkes, Fikret (2009) "Evolution of Co-management: Role of Knowledge Generation, Bridging Organizations and Social Learning." Journal of Environmental Management 90 (5): 1692-702.

Berkes, F. and Folke, C. (1998) "Linking Social and Ecological Systems for Resilience and Sustainability." In F. Berkes and C. Folke (Eds.), Linking Social and Ecological Systems. Cambridge: Cambridge University Press, 1-26.

Betsill, M. and H. Bulkeley (2004) "Transnational Networks and Global Environmental Governance: The Cities for Climate Protection Program.” International Studies Quarterly 48: 471-93.

Betsill, M. and H. Bulkeley (2006) "Cities and the Multilevel Governance of Global Climate Change." Global Governance 12: 141-59.

Bhagat, R. B. and Soumya Mohanty (2009) "Emerging Pattern of Urbanization and the Contribution of Migration in Urban Growth in India." Asian Population Studies 5 (1): 5-20.

Bhagwati, J. (2004) In Defense of Globalization. Oxford: Oxford University Press. 
Bhan, G. (2009) “'This Is No Longer the City I Once Knew': Eviction, the Urban Poor and the Right to the City in Millennial Delhi." Environment and Urbanization 21: 127-42.

Birkmann, Jorn, Matthias Garschagen, Frauke Kraas and Nguyen Quang (2010) "Adaptive Urban Governance: New Challenges for the Second Generation of Urban Adaptation Strategies to Climate Change." Sustainability Science 5: 185-206.

Bodin, Orjan and Beatrice I. Crona (2009) "The Role of Social Networks in Natural Resource Governance: What Relational Patterns Make a Difference?” Global Environmental Change 19: 366-74.

Bose, P. (2007) "Dreaming Of Diasporas: Urban Developments and Transnational Identities in Contemporary Kolkata." Topia 17: 111-30.

Bouteligier, Sofie (2012) Cities, Networks, and Global Environmental Governance. New York: Routledge.

Bulkeley, H. (2000) "Discourse Coalitions and the Australian Climate Change Policy Network." Environment and Planning C: Government and Policy 18: 727-48.

Bulkeley, H. (2010) "Cities and the Governing of Climate Change." Annual Review of Environment and Resources 35: 229-53.

Bulkeley, H. and M. Betsill (2005) "Rethinking Sustainable Cities: Multilevel Governance and the 'Urban' Politics of Climate Change." Environmental Politics 14 (1): 42-63.

Bulkeley, H. and M. Betsill (2013) "Revisiting the Urban Politics of Climate Change." Environmental Politics 22 (1): 136-54.

Bulkeley, H. and V. Broto (2012) "A Survey of Urban Climate Change Experiments in 100 Cities." Global Environmental Change 23 (1): 92-102.

Census of India (2011) "Rural Urban Distribution of Population (Provisional Population Tables)," Ministry of Home Affairs, Government of India, last accessed 7 May 2012 at http://censusindia.gov.in/2011-prov-results/paper2/data_files/ india/Rural_Urban_2011.pdf

Chaplin, Susan E. (2011) "Indian Cities, Sanitation and the State: The Politics of the Failure to Provide." Environment and Urbanization 23: 157-70.

Corbridge, S. and J. Harriss (2001) Reinventing India: Liberalization, Hindu Nationalism and Popular Democracy. Delhi: Oxford University Press.

Curtis, S. (2011) "Global Cities and the Transformation of the International System." Review of International Studies 37 (4): 1923-47.

De Sherbinin, A., L. K. VanWey, K. McSweeney, R. Aggarwal, A. Barbieri, S. Henry, L. M. Hunter, W. Twine and R. Walker (2008) "Rural Household Demographics, Livelihoods and the Environment." Global Environmental Change 18: 38-53.

Dobbs, R. and J. Remes (2012) "Introducing the Most Dynamic Cities of 2025." Foreign Policy The Cities Issue (Sept./Oct. 2012): 61-86.

Eakin, H. and A.L. Luers (2006) "Assessing Vulnerability of Socio-economic Systems." Annual Review of Environmental Resources 31: 365-94.

Finnemore, M. and K. Sikkink (1998) "International Norm Dynamics and Political Change." International Organization 52 (4): 887-917.

Folke, C. (2006) "Resilience: The Emergence of a Perspective for Social-Ecological Systems Analysis." Global Environmental Change 16: 253-67.

Folke, C., T. Hahn, P. Olsson and J. Norberg (2005) "Adaptive Governance of SocialEcological Systems.” Annual Review of Environmental Resources 30: 441-73.

Friedmann, J. (1986) “The World City Hypothesis.” Development and Change 17: 69-83.

Fuchs, Roland, Mary Conran and Elizabeth Louis (2011) "Climate Change and Asia's Coastal Urban Cities: Can They Meet the Challenge?" Environment and Urbanization Asia 2 (1): 13-28.

Fungfgeld, Hartmut (2010) "Institutional Challenges to Climate Risk Management in Cities." Environmental Sustainability 2: 156-60. 
Fussel, H-M. (2007) "Vulnerability: A Generally Applicable Conceptual Framework for Climate Change Research." Global Environmental Change 17: 155-67.

Hajer, M. (1995) The Politics of Environmental Discourse: Ecological Modernization and the Policy Process. Oxford: Clarendon Press.

Hartmann, B. (2010) "Rethinking Climate Refugees and Climate Conflict: Rhetoric, Reality and the Politics of Policy Discourse." Journal of International Development 22: 233-46.

Harvey, D. (2006) "Neo-Liberalism as Creative Destruction." Geografiska Annaler: Series B, Human Geography 88 (2): 145-58.

Hill, R.C. and J.W. Kim (2000) "Global Cities and Developmental States: New York, Tokyo and Seoul." Urban Studies 37 (12): 2167-95.

Holling, C.S. (2001) "Understanding the Complexity of Economic, Ecological, and Social Systems.” Ecosystems 4: 390-405.

IEA (International Energy Agency) (2012) “Urban Energy Policy Design," last accessed 21 January 2013 at http://www.iea.org/newsroomandevents/news/2012/ june/name,28079,en.html

IPCC (Intergovernmental Panel on Climate Change, WG2) (2014) "Chapter 8: Urban Areas," last accessed 5 August 2014 at http://ipcc-wg2.gov/AR5/images/ uploads/WGIIAR5-Chap8_FGDall.pdf

Johnson, C. (2012) "Governing Climate Displacement: The Ethics and Politics of Human Resettlement.” Environmental Politics 21 (2): 308-28.

Kennedy, C. (2011) The Evolution of Great World Cities: Urban Wealth and Economic Growth. Toronto: University of Toronto Press.

Kern, K. and H. Bulkeley (2009) "Cities, Europeanization and Multi-level Governance: Governing Climate Change through Transnational Municipal Networks.” Journal of Common Market Studies 47 (1): 309-32.

Kim, A.M. (2004) “A Market without the 'Right' Property Rights: Ho Chi Minh City, Vietnam's Newly-Emerged Private Real Estate Market.” Economics of Transition 12 (2): 275-305.

Kim, A. M. (2011) “Talking Back: The Role of Narrative in Vietnam's Recent Land Compensation Changes." Urban Studies 48 (3): 493-508.

Kingdon, J. (2003) Agendas, Alternatives and Public Policies. 2nd ed. Toronto: Longman Press.

Klinenberg, E. (2013) “Adaptation: How Can Cities Be 'Climate-Proofed?'” The New Yorker 7 January 2013, 32-7.

Kovats, Sari and Rais Akhtar (2008) "Climate, Climate Change and Human Health in Asian Cities." Environment and Urbanization 20 (2): 165-75.

Leaf, M. (2011) "Periurban Asia: A Commentary on 'Becoming Urban'," Pacific Affairs 84 (3): 525-34.

Leichenko, Robin (2011) "Climate Change and Urban Resilience." Current Opinion in Environmental Sustainability 3: 164-8.

McDonald, Robert I., Pamela Green, Deborah Balk, Balazs M. Fekete, Carmen Revenga, Megan Todd and Mark Montgomery (2011) "Urban Growth, Climate Change, and Freshwater Availability." PNAS, March 28, 2011. doi:10.1073/ pnas.1011615108.

McGranahan, G., D. Balk and B. Anderson (2007) "The Rising Tide: Assessing the Risks of Climate Change and Human Settlements in Low Elevation Coastal Zones." Environment and Urbanization 19 (1): 17-37.

Moench, M. (2010) "Responding to Climate and Other Change Processes in Complex Contexts: Challenges Facing Development of Adaptive Capacity in the Ganga Basin.” Technological Forecasting and Social Change 77: 975-86.

Montgomery, M. (2008) "The Urban Transformation of the Developing World." Science 319: 761-4.

Moser, C. and D. Satterthwaite (2008) "Towards Pro-Poor Adaptation to Climate Change in Urban Centres of Low- and Middle-Income Countries." Human 
Settlements Discussion Paper Series. London: International Institute for Environment and Development.

Moser, S. and A. L. Luers (2008) "Managing Climate Risks in California: The Need to Engage Resource Managers for Successful Adaptation to Change." Climatic Change 87 (Supplement 1): S309-S322.

Munslow, B. and T. O’Dempsey (2011) "Globalisation and Climate Change in Asia: The Urban Health Impact.” Third World Quarterly 31 (8): 1339-56.

Nair, K. Shadananan (2009) "An Assessment of the Impact of Climate Change on the Megacities of India and of the Current Policies and Strategies to Meet Associated Challenges." Fifth Urban Research Symposium, 1-10.

Nelson, D.R., W.N. Adger and K. Brown (2007) "Adaptation to Environmental Change: Contributions of a Resilience Framework.” Annual Review of Environmental Resources 32: 395-419.

Newell, P. (2011) "The Elephant in the Room: Capitalism and Global Environmental Change." Global Environmental Change 21: 4-6.

North, D. (1990) Institutions, Institutional Change and Economic Performance. Cambridge: Cambridge University Press.

O’Brien, K., L. Sygna, R. Leichenko, W.N. Adger, J. Barnett, T. Mitchell, L. Schipper, T. Tanner, C. Vogel and C. Mortreux (2008) "Disaster Risk Reduction, Climate Change Adaptation and Human Security.” GECHS Report 2008: 3, A Report commissioned for the Norwegian Ministry of Foreign Affairs, last accessed 12 May 2010 at http://www.crid.or.cr/digitalizacion/pdf/eng/doc17943/doc17943-a.pdf

Olsson, P., L.H. Gunderson, S.R. Carpenter, P. Ryan, L. Lebel, C. Folke and C.S. Holling (2006) "Shooting the Rapids: Navigating Transitions to Adaptive Governance of Social-Ecological Systems.” Ecology and Society 11 (1), last accessed 31 August 2014 at http://www.ecologyandsociety.org/vol11/iss1/art18/

Ostrom, Elinor (2010) "Polycentric Systems for Coping with Collective Action and Global Environmental Change." Global Environmental Change 20: 550-7.

Pahl-Wostl, C. (2009) "A Conceptual Framework for Analysing Adaptive Capacity and Multi-Level Learning Processes in Resource Governance Regimes." Global Environmental Change 19: 354-65.

Penz, P., J. Drydyk and P. Bose (2011) Displacement by Development: Ethics, Rights and Responsibilities. Cambridge: Cambridge University Press.

Perch-Nielson, S.L., M.B. Battig and D. Imboden (2008) "Exploring the Link between Climate Change and Migration." Climatic Change 91: 375-93.

Revi, Aromar (2008) "Climate Change Risk: An Adaptation and Mitigation Agenda for Indian Cities." Environment and Urbanization 20: 207-29.

Robinson, J. (2002 [2006]) "Global and World Cities: A View from off the Map." In N. Brenner and R. Kiel (Eds.), The Global Cities Reader. London and New York: Routledge, 217-23.

Rohland, K. (2012) "Locking Cities into Low-Carbon Growth." China Daily, 4 May 2012, last accessed 23 January 2013 at http://www.worldbank.org/en/ news/2012/05/04/locking-cities-into-low-carbon-growth

Romero-Lankao, P. and D. Dodman (2011) "Cities in Transition: Transforming Urban Centers from Hotbeds of GHG Emissions and Vulnerability to Seedbeds of Sustainability and Resilience." Current Opinion in Environmental Sustainability 3: 113-20.

Romero-Lankao, P. and Hua Qin (2011) “Conceptualizing Urban Vulnerability to Global Climate and Environmental Change." Current Opinion in Environmental Sustainability 3: 142-9.

Roy, Ananya (2009) "Why India Cannot Plan Its Cities: Informality, Insurgence and the Idiom of Urbanization." Planning Theory 8 (1): 76-87.

Roy, Ananya (2010) "Re-Forming the Megacity: Calcutta and the Rural-Urban Interface." In A. Sorensen and J. Okata (Eds.), Megacities: Urban Form, Governance and Sustainability. London: Springer, 93-109. 
Roy, Ananya (2011) "The Blockade of a World-Class City: Dialectical Images of Indian Urbanism.” In Ananya Roy and Aihwa Ong (Eds.), Worlding Cities: Asian Experiments and the Art of Being Global. Chichester: Blackwell, 259-79.

Sabatier, P. A. and C. M. Weilbe (2007) "The Advocacy Coalition Framework: Innovations and Clarifications," in P. Sabatier (Ed.), Theories of the Policy Process. Boulder: Westview Press, 189-222.

Sanchez-Rodriguez, Roberto (2009) "Learning to Adapt to Climate Change in Urban Areas: A Review of Recent Contributions." Environmental Sustainability 1: 201-6.

Sassen, S. (2001) The Global City. 2nd ed. Princeton: Princeton University Press.

Sassen, S. (2006) "Chicago's Deep Economic History: Its Specialized Advantage in the Global Network.” In R.P. Greene, M.J. Bouman and D. Grammenos (Eds.), Chicago's Geographies: Metropolis for the 21st Century. Washington, DC: American Association of Geographers, 75-86.

Sassen, S. and N. Dotan (2011) "Delegating, Not Returning, to the Biosphere: How to Use the Multi-scalar and Ecological Properties of Cities." Global Environmental Change 21: 823-34.

Satterthwaite, D., S. Huq, H. Reid, M. Pelling and P. Romero Lankao (2007) “Adapting to Climate Change in Urban Areas: The Possibilities and Constraints in Lowand Middle-Income Nations." IIED Human Settlements Discussion Paper, last accessed 23 March 2012 at http://pubs.iied.org/pdfs/10549IIED.pdf

Satterthwaite, D., G. McGranahan and C. Tacoli (2010) "Urbanization and Its Implications for Food and Farming." Philosophical Transactions of the Royal Society (Biological Sciences) 365: 2809-20.

Saunders, D. (2010) Arrival City: The Final Migration and Our Next World. Toronto: Knopf Canada.

Seto, K. (2011) "Exploring the Dynamics of Migration to Mega-Delta Cities in Asia and Africa: Contemporary Drivers and Future Scenarios." Global Environmental Change 21S: S94-S107.

Seto, K., M. Fragkias, B. Guneralp and M.K. Reilly (2011) "A Meta-Analysis of Global Urban Land Expansion.” PLoS One 6 (8): 1-9.

Seto, K., A. Reenberg, C. G. Boone, M. Fragkias, D. Haase, T. Langanke, P. Marcotullio, D. K. Munroe, B. Olah and D. Simon (2012) "Urban Land Teleconnections and Sustainability." PNAS 109 (20): 7687-92.

Shatkin, Gavin (2011) "Planning Privatopolis: Representation and Contestation in the Development of Urban Integrated Mega-Projects." In Ananya Roy and Aihwa Ong (Eds.), Worlding Cities: Asian Experiments and the Art of Being Global. London: Blackwell, 77-97.

Sikor, T. and C. Lund (2009) "Access and Property: A Question of Power and Authority," in T. Sikor and C. Lund (Eds.), The Politics of Possession: Property, Authority and Access to Natural Resources. Chichester: Wiley-Blackwell, 1-22.

Simon, D. (1995 [2006]) "The World City Hypothesis: Reflections from the Periphery.” In N. Brenner and R. Kiel (Eds.), The Global Cities Reader. London and New York: Routledge, 203-9.

Smit B. and J. Wandel (2006) "Adaptation, Adaptive Capacity and Vulnerability." Global Environmental Change 16: 282-92.

Stephens, Carolyn (2011) "Revisiting Urban Health and Social Inequalities: The Devil Is in the Detail and the Solution Is in All of Us." Environment and Urbanization 23 (1): 29-40.

Tanner, T., T. Mitchell, E. Polack and B. Guenther (2009) "Urban Governance for Adaptation: Assessing Climate Change Resilience in Ten Asian Cities.” IDS Working Paper 315. Brighton: Institute of Development Studies.

Taylor, Peter (2001) "Specification of the World City Network." Geographical Analysis 33 (2): 181-94. 
Taylor, Peter (2004) "The New Geography of Global Civil Society: NGOs in the World City Network." Globalizations 1 (2): 265-77.

Toly, Noah J. (2008) "Transnational Municipal Networks in Climate Politics: From Global Governance to Global Politics.” Globalizations 5 (3): 341-56.

Toly, Noah J. (2011) "Cities, the Environment, and Global Governance: A Political Ecological Perspective.” In Mark Amen, Noah J. Toly, Patricia L. McCarney and Klaus Segbers (Eds.), Cities and Global Governance: New Sites for International Relations. Burlington, VT: Ashgate, 137-50.

Toly, Noah J., Sofie Bouteligier, Graham Smith, and Ben Gibson (2012a) "New Maps, New Questions: Global Cities beyond the Advanced Producer and Financial Services Sector." Globalizations 9 (2): 289-306.

Toly, Noah J., Sofie Bouteligier, Graham Smith, and Ben Gibson (2012b) “American Cities, Global Networks: Mapping the Multiple Geographies of Globalization in the Americas." URBE: Revista Brasiliera de Gestao Urbana 4 (1): 73-86.

Tompkins, Emma L. and W. Neil Adger (2004) "Does Adaptive Management of Natural Resources Enhance Resilience to Climate Change?" Ecology and Society 9 (2): 2010.

True, J., B. Jones and F. Baumgartner (2007) "Punctuated Equilibrium Theory: Explaining Stability and Change in Public Policy Making.” In P. Sabatier (Ed.), Theories of the Policy Process. Boulder: Westview Press, 155-88.

Tschakert, P. and K. A. Dietrich (2010) "Anticipatory Learning for Climate Change Adaptation and Resilience." Ecology and Society 15 (2), last accessed 31 August 2014 at http://www.ecologyandsociety.org/vol15/iss2/art11/

UN/DESA (United Nations/Department of Economic and Social Affairs) (2012) World Urbanization Prospects: The 2011 Revision, last accessed 23 January 2013 at http://esa.un.org/unpd/wup/pdf/WUP2011_Highlights.pdf

UNISDR (UN International Office for Disaster Risk Reduction) (2012) Making Cities Resilient Report 2012, last accessed 26 February 2013 at www.unisdr.org

Van der Pluijm, R. (2007) City Diplomacy: The Expanding Role of Cities in International Politics, last accessed 23 January 2013 at http://www.uclg.org/sites/ default/files/20070400_cdsp_paper_pluijm.pdf

Viotti, P. and M. Kaupi (2010) International Relations Theory. 4th ed. Toronto: Longman.

Webster, D. (2011) “An Overdue Agenda: Systematizing East Asian Peri-urban Research.” Pacific Affairs 84 (4): 631-42.

Weible, C. M., P. A. Sabatier and K. McQueen (2009) "Themes and Variations: Taking Stock of the Advocacy Coalition Framework." Policy Studies Journal 37 (1): 121-40.

Wisner, B., P. Blaikie, T. Cannon and I. Davis (2004) At Risk: Natural Hazards, People's Vulnerability and Disasters. London and New York: Routledge.

World Bank (2010) Cities and Climate Change: An Urgent Agenda. Washington, DC: World Bank. 


\title{
2 Bringing Cities into the Global Climate Framework
}

\author{
Saskia Sassen
}

\section{INTRODUCTION}

Cities are de facto components of the global environmental governance regime. But they are not so de jure. That is to say that the incorporation of this practical role of cities into the global regime has already started at ground level, as is evident in the C40 network and the actual innovations in cities. Yet neither their weight in environmental damage production nor their specific capacities to reduce this damage have been factored directly into the formal regime. This tension between reality at ground level and high-level policymaking, mostly removed from those facts, is beginning to be unsustainable.

Inserting the city into existing formal inter-governmental frames can help overcome the narrow nationalisms of inter-state negotiated agreements. Cities share a specific position in this global governance system, partly because they share more with other cities across the world than they share with their national states and than national states share with each other. This is particularly so when we consider the challenges they face and the resources they need. One feature of cities that stands out and reveals the potential for global inter-city connections is that cities are critical, in ways that national governments are not, for emerging global networks of a broad range of actors (NGOs, formal urban governments, informal activists, global firms, and immigrants). These eventually begin to function as a political infrastructure for addressing some of our major environmental governance challenges from angles and with contents that differ from those of the inter-state system.

Finally, among many other aspects and of particular importance to this chapter, the city level makes possible the implementation and application of forms of scientific knowledge and technological capacities that are not practical at the overall national level. This is partly due to the fact that the city's multiple ecologies enable the mixing of diverse forms of knowledge and diverse technologies. Cities constitute a frontier space for new types of environmentally sustainable energy sources, construction processes, and infrastructures because implementation can happen at a practical level 
rather than depending on the making of new formal law, as it is mostly at the national level.

In enabling all the above, the city introduces a type of environmental governance option that takes a radically different approach from the common and preferred choice of an international carbon trading regime. The aim becomes addressing the carbon and nitrogen cycles in situ by implementing measures that reduce damage drastically, going well beyond the carbon-trading option of the international system. Further, and important, cities can bypass the constraints and obligations of inter-state protocols. Thus bringing cities into the international regime can generate a novel type of governance vector which could address what national governments do not address, or have difficulty addressing. From the perspective of cities, such a global, albeit partial, regime can contribute to develop new kinds of urban capacities that can cut across the geopolitics of national states. This can be enormously valuable in a world where inter-state geopolitics are increasingly contestatory and where international consensus is difficult to achieve.

\section{THE CITY LEVEL IN TODAY'S PLANETARY CATASTROPHE}

Environmental destruction has taken a distinctive turn over the last three decades: the biosphere can no longer re-balance our destructions in a way that was possible for centuries. One feature of the current period is the global scale-up whereby more and more regions of the world that have not contributed to environmental destruction are now experiencing the impact, notably the melt-down of glaciers in the Swiss Alps and of the Arctic permafrost. 1 Cities are among the key sources generating the scale-up of environmental destruction.

In what follows I develop a few elements for a conceptual framing that brings cities into a planetary environmental space (Sassen 2014: ch. 4; Sassen and Dotan 2011), and in that sense, de facto into a kind of geopolitics, although not that of the standard inter-state system. One mode of interpreting this is to posit that the city level de facto, although clearly not de jure, functions both at the diverse scales that constitute the city (for instance, household, neighborhood, city center) and at a planetary scale insofar as all cities share certain features (vast numbers of buildings, vast amounts of garbage, mass-transport, and so on). Herein lies a specific contribution of cities, one marked by facts at ground level that recur across the world and cannot be reduced to the "inter-state" view of the world. ${ }^{2}$

If we are to open up macro-level regimes to this sub-national scale, it becomes critical to recognize the specific and specialized difference of the local level. We can implement scientific discoveries and technological capacities in ways that would not be practical at a national level. The city has multiple ecologies that enable the mixing of diverse forms of knowledge 


\section{Saskia Sassen}

and diverse technologies. Thus, what might not be feasible in the business district, is feasible at the neighborhood level, and it is this level that tends to occupy most of a city's terrain. Another example is the multiplier effect in cities: if an experimental implementation works in one site that might serve as a demonstration case, it can, in principle, get promptly replicated across a city. This brings a scale-up effect in the reduction of the given environmental harm being addressed. In enabling such multiplier effects, the city introduces a type of environmental governance option that takes a radically different approach from the common and preferred choice of an international carbon-trading regime.

Introducing the city level into global governance regimes enables a kind of horizontal governance that can encompass at least some regimes able to work alongside traditional vertical forms of governance. This is not new: diverse urban initiatives have been an essential part of climate governance from the outset even if not a formal part of the global regime. But today we see a visible and explicit engagement by cities in this type of participation. Thus leading cities such as Stockholm, Copenhagen, Paris, New York, Tokyo, Vancouver, and many others, have become global players, with far more ambitious goals than their national governments. Increasingly city mayors are today active members of international networks (Toly 2008). They have developed comprehensive models to make cities carbon-free and climate-proof, thereby contributing to developing climate governance "from below."

Critical to this effort of inserting the city level into inter-state efforts is the necessity to address a range of often acute challenges that can be more easily, and mostly are, overlooked at the inter-state level. We can think of these as challenges for which cities are a first or urgent site of engagement: it is a global level constituted through the recurrence of many of these challenges in cities across the world. Many of today's major global governance challenges become tangible, urgent, and practical in cities. Urban leaders and urban residents have had to deal with many issues long before national governments and inter-state treaties addressed them, if at all. Among these challenges are some shared by many cities, such as racisms and extreme forms of inequality, and some not so widely shared, such as asymmetric war and extensive flooding or desertification.

Cities are sites where these challenges can be studied empirically and where policy design and implementation often is more feasible than at the national level, partly because it comes down to a kind of practical engagement, rather than, for instance, law-making as is often the case at the national level. Cities sooner or later have to face these conditions. They cannot pretend that they do not exist. National governments can avoid them, or, at the least, can endlessly postpone the moment of reckoning. In this practical need also lies the capacity of city leaderships to learn form each other, something not easily evident among national leaders across the world. 
The urgent need to bring cities into the global climate regime is further confirmed by the fact that the "urban hinterland," once primarily a confined geographic zone, is today a de facto global hinterland. The urban condition is directly and indirectly a planetary condition-its own kind of "internationalism." It is through cities and vast urban agglomerations that mankind is increasingly present in the planet and through which it mediates its relationship to the various stocks and flows of the environment. With the expansion of the global economy, a growing number of countries and firms have further added to our collective capacity to annex growing portions of the planet to support a limited number of industries, places, and people.

\section{THE CITY IN THE CURRENT CLIMATE GOVERNANCE FRAMEWORK}

Even though neither the Kyoto Protocol (KP) nor the United Nations Framework Convention on Climate Change (UNFCCC) (2012) include cities or local governments as key players in the global regime, they have begun to recognize cities as part of the larger effort. ${ }^{3}$ The reason is that cities themselves have established and built up financial and fiscal incentives, local knowledge and education, and other municipal frameworks for action. ${ }^{4}$ Some of these local initiatives go back to the 1980s and 1990s when major cities, notably Los Angeles and Tokyo, implemented clean air ordinances, not because their leaderships were particularly enlightened but because they had to for public health reasons.

The engagement of municipal-level governments in these efforts comes from their practical obligations and opportunities. Thus, and I find this very important, local governments have developed targets and regulations that often aim at far stronger and encompassing aims than those of national and sub-national state jurisdictional obligations. ${ }^{5}$ For instance, to address this neglect, the Local Government Climate Roadmap (a consortium of global municipal partnerships) has mobilized for recognition of the local government level in international climate negotiations. The global initiative "Cities for Climate Protection" developed by the International Council for Local Environmental Initiative's (ICLEI) Local Governments for Sustainability network has been active as far back as $1993 .{ }^{6}$ Local governments held Municipal Leadership Summits in 1993, 1995, 1997, and 2005, parallel to the official Conference of Parties (COP) meetings of national governments. The Local Government and Municipal Authority Constituency (LGMA) has built upon its role as one of the first NGO constituencies acting as an observer to the official international climate negotiations process (UNFCCC). ${ }^{7}$

These governance frameworks are a necessary part of the environmental struggle. But they are not enough, and cities make this need visible and urgent. The city has become a strategic space for the direct and brutal 


\section{Saskia Sassen}

confrontation between forces that are enormously destructive to the environment and increasingly acute needs for environmental resources, from water and clean air to mining products to build. ${ }^{8}$ It is likely that international and national standards will need to be implemented and enforced at the urban scale. ${ }^{9}$ There are limits to the urban scale, especially in the Global South where local governments have limited funds.

However, it is one of the scales at which many specific goals can be achieved. Local authorities are in a strong position to pursue the goals of sustainable development as direct or indirect providers of services, as regulators, leaders, and partners and as mobilizers of community resources. ${ }^{10}$ Each urban combination of elements is unique, as is its mode of insertion within local and regional ecosystems. From this specificity comes place-based knowledge that can be scaled-up and that can contribute to the understanding of global conditions. The case of ozone holes illustrates this scale-up. The damage is produced at the micro-level of cars, households, factories, and buildings, but its full impact becomes visible and measurable only over the poles, where there are no cars and buildings.

In short, city-related ecological conditions operate on a diversity of geographic scales. Importantly cities incorporate a range of scales on which a given ecological condition functions and, in that sense, cities make visible the fact itself of scaling. Further, cities make the multi-scalar properties of ecological systems present and recognizable to its residents. This urban capacity to make visible should be developed and strengthened as it will become increasingly critical for policy matters not only of cities but also at regional, national, and global levels.

\section{MAXIMIZING URBAN CAPACITIES IN THE ENVIRONMENTAL STRUGGLE}

A key starting point in the larger project (Sassen 2013; Sassen and Dotan 2011) on which this chapter is based has to do with recognizing the multiple articulations cities have with the biosphere. Today, these articulations are mostly negative-they damage the environment and produce ruptures in biospheric cycles that are meant to be continuous. The challenge is how to make these articulations positive. In contrast, today's more common policy approach is to focus on the damage and on what are basically minor mitigations of that damage; this is fine but not enough. Particular systemic properties of cities can enable a switch in the valence of those articulations, from negative to positive.

The substantive rationale for this project is that we need a better understanding of the role of cities because existing theories about environmental sustainability and global environmental governance centered on the inter-state system fail to incorporate cities in the most productive way. Cities are reduced to the local level and to a source of damage. Urbanists, on 
the other hand, have given us extensive examinations of how cities can be used at multiple levels to engage the environmental challenge. My effort goes in the opposite direction: to work with what is there at its most variable and complex. This also means going beyond the notion that the only way for cities to contribute to sustainability is mitigation and adaptation or to start from scratch. Mitigation and adaptation are not enough to address environmental damage. And most cities cannot start from scratch. Thus for most countries, Abu Dhabi's Masdar project of a fully self-sustained city is not a model because it is far too expensive and accommodates only a small population; it should be seen as a laboratory experiment that shows us what is possible, even if realistically it cannot be the solution for most of our existing cities. Thus it becomes urgent to recognize that one path into making cities part of the solution is to work from what is there but with the aim of changing the negative valence of current articulations with the biosphere.

The larger project has focused especially on the multi-scalar and ecological properties of cities; these mimic those of the biosphere thereby enabling a notion of bridging between these two parallel worlds. But once cities reach a certain size (i.e., very large cities), cities become "unbiological" consumers of the biosphere (Bettencourt et al. 2007; Bettencourt and West 2010; Environment and Urbanization 2007; Mol and Sonnenfeld 2011), and thus need to be conceived of as representing a diverse logic from that of the biosphere. In other words, the social, legal, and economic characteristics of cities need to be factored into this bridging with the biosphere. Scientific and technological types of knowledge are critical to this bridging, especially for amplifying the capacities of the biosphere so as to compensate for the "unbiological" consuming of the biosphere. But implementation of that scientific and technological knowledge will, in turn, require significant changes in the social, legal, and economic modus operandi of cities.

One assumption in the larger project is that the scale of the city can enable these transformations in more direct ways than can the scale of nation-states. This is partly because cities can avoid the nationalisms so present in the inter-state debates about environmental sustainability. The fact is that cities across the world are learning from each other and implementing a range of similar innovations. This points to an emergent de facto cross-border intercity geography for addressing environmental sustainability that can bypass much of the, often fruitless, debate around international carbon trading. Cities have implemented far more innovations than national governments, partly enabled by global urban networks for cross-border collaboration (Toly 2008). These types of interventions are beginning to reorient at least some of the articulations between cities and the biosphere. It is critical to avoid flattening the city into one singular scale and system, as is typical today and to develop and bring to the fore the multi-scalar and ecological properties of cities.

There are obstacles to this type of analysis and implementation project. One major obstacle to implementation is the absence of the urban level 
in most international agreements and documents aimed at protecting the environment. Another is the limitations in the urban-focused research on the environmental question: an enormous share of the attention devoted to urban sustainability in the literature has been on how people as consumers and household-level actors damage the environment. When measuring cities, inevitably individuals and households are by far the most numerous units of analysis. Yet, there clearly are shortcomings in this focus. In matters of policy, it leads to an emphasis on household recycling activities without addressing the fundamental issue of how an economic system prices modes of production that are not environmentally sound. An "urban" focus limited to individuals and households is problematic in that it can easily leave out global economic and ecological systems that are deeply involved, yet cannot be addressed at the level of households or many individual firms. For instance, those who insist that greenhouse gas emissions will have to be controlled at the local level are, in many ways, right. However, these emissions will also have to be addressed at the broader macro levels of our economic systems and, inevitably, the planetary level.

Some recent innovations suggest the possibility of planetary interventions through multiple local initiatives. One matter that I have researched is a range of discoveries in biological laboratories that would allow us to use biospheric capacities to do what we now do with chemicals made in factories (Sassen and Dotan 2011; Sassen, 2013). For instance, a newly developed "paint" mixed with bacteria that can live in concrete and deposit a kind of calcium helps seal the surfaces of buildings. This diminishes green gas emissions and purifies the air around the building. ${ }^{11}$ Our buildings would thus more closely model the self-sustaining homeostatic physical structures found in nature (Jonkers 2007). This is particularly significant in the current period because (a) buildings are the largest single source of green gas emissions and (b) it would create employment, mobilize citizens in their neighborhoods, and allow local governments to get involved by initial small subsidies, especially in modest neighborhoods. This simple technology may be used for all concrete buildings, whether they are located in modest neighborhoods or the business districts of global cities. It is just one example of how a global scale can be constituted through a vast number of local sites, all of which are using the same mix of scientific knowledge and technology.

There are many other such uses of the biosphere's capacity to address the environmental challenge in cities, although none as globally present as the challenge of greening buildings. Some of these were developed a decade ago. For instance, bioreactors (essentially, controlled ponds) that combine bacteria and algae can clean nitrate-contaminated water as gaseous nitrogen (N2) can be recycled into the atmosphere (Garcia et al. 2000).

These diverse questions can be analytically conceived of as questions of scale. Scaling is one way of handling what are now often seen as either/ or conditions: local versus global, markets versus nonmarket mechanisms, green versus brown environmentalism. I have found some of the analytic 
work on scaling conducted by ecologists helpful for conceptualizing the city in the context of environmental sustainability, particularly the question of bridging between the biosphere and the city. Of particular relevance is the notion that complex systems are multi-scalar systems, as opposed to multi-level systems, and that the complexity resides precisely in the relationships among scales.

We are still struggling to understand and situate how diverse types of environmental dynamics function in the context of cities. An insufficiently complex analysis of these dynamics could well mean that current environmental policy may be missing the best scale at which to use the city for a whole range of policy implementations. In contrast, there is a better understanding of what needs to be done when it comes to remedial policy and clean-up.

Research has raised a set of specific issues concerning ecological systems that point to possibly fruitful analytic strategies to understand cities and urbanization processes with regard to environmental conditions and policy. However, understanding the city as a broader system poses enormous difficulties precisely because of the multiple scales that constitute the city-as a system of distributed capabilities and as a political-economic and jurisdictional-administrative system. For instance, the individual household, firm, or government office can recycle waste but cannot address effectively the broader issue of excess consumption of scarce resources. An international agreement can call for global-level measures to reduce greenhouse emissions but depends on individual countries, individual cities, and individual households and firms to implement many of the necessary steps. A national government can mandate environmental standards, but the specifics of implementation may depend partly on the character of a country's systems of economic power and of wealth production.

A key analytic step is to decide which of the many scales of ecological, social, and economic processes is appropriate for addressing a specific environmental condition, whether negative or positive, and to design a specific action or response. Another analytic step is to factor in the temporal scales or frames of various urban conditions and dynamics; for instance, the cycles of the built environment are not the same as those of the economy, nor does the life of infrastructures correspond to the time frames of more and more investment instruments. The combination of these two analytic steps helps to deconstruct a given concrete urban situation and locate it in a broader grid of spatial, temporal, and administrative scales.

The connection between spatial and temporal scales evident in the biosphere may prove useful analytically to approach some of these questions in the case of cities. In the biosphere, it is clear that what may be negative in a small spatial scale or a short time frame can become positive in a larger scale or longer time frame. For a given set of environmental disturbances in a city, diverse spatiotemporal scales may produce (or make visible) different responses. Using an illustration from ecology, we can say that individual 


\section{Saskia Sassen}

forest plots may come and go, but the forest cover of a region can remain relatively constant overall.

This raises a question as to whether a city needs to be conceived as a multi-scalar system (rather than a collection of buildings, infrastructures, and population groups) in order to ensure a proper understanding of the character of the risk and how to address it. Conceivably what is experienced as negative and hence deserving of an all-out deployment of resources to solve it may turn out to be the equivalent of the forest plot, and in the long run have the effect of strengthening the overall forest (i.e., the city's overall capacity to deal with environmental damage). One research finding of ecologists in this domain is that movement across scales brings about change, which is the dominant process. It is not only a question of larger or smaller but rather that the phenomenon itself changes. Unstable systems come to be seen as stable, bottom-up control can turn into top-down control, and competition becomes less important. This mobile valence invites us to think of cities as containing solutions to types of environmental damage we now reduce to an "absolute" (i.e., absolute evil, absolutely destructive-with the city as a whole often seen as one such instance). What are the scales at which we can understand the city as contributing solutions to the environmental crisis?

An important issue raised by scaling in ecological research is the frequent confusion between levels and scales. What is sometimes described as a change of scales may merely be a change of level. A change of scale results in new interactions and relationships, often a different organization. Level, on the other hand, is a relative position in a hierarchically organized system. Thus, a change in levels entails a change in a quantity or size rather than the formation of a different entity. A level of organization is not a scale, even if it can have scale or be at a scale. Scale and level are two different dimensions.

Thus thinking of the city as multi-scalar entails recovering, for instance, that an urban feature such as density actually alters the nature of an event or condition-it is not more of the same. The individual occurrence is distinct from the aggregate outcome. It is not merely a sum of individual occurrences (i.e., a greater quantity of occurrences). It is a different event. The city contains both and, in that regard, can be understood as instigating a broad range of environmental damage that may involve very different scales and origins. $\mathrm{CO}_{2}$ emissions produced by the micro-scale of vehicles and coal burning by individual households can scale up and become massive air pollution covering the entire city with effects that transcend $\mathrm{CO}_{2}$ emission per se. Air- and waterborne microbes materialize as diseases at the scale of the household and the individual body. But they become epidemics that thrive on the multiplier effects of urban density and are capable of destabilizing the operations of firms whose machines have no intrinsic susceptibility to the disease.

A second way in which the city is multi-scalar is in the geography of the environmental damages it produces. Some of the damage is atmospheric and 
becomes planetary, therewith transcending the city. And some of it is internal to the built environment of the city; this might be the case with sewage or disease, whereas some of it, such as deforestation, is in distant locations around the globe.

A third way in which the city can be seen as multi-scalar is that its demand for resources can entail a geography of extraction and processing that spans the globe, although it does so in the form of a collection of confined individual sites distributed worldwide. This worldwide geography of extraction materializes in particular and specific forms (e.g., furniture, jewelry, machinery, and fuel) inside the city. The city is one moment-a strategic moment-in this global geography of extraction, and it differs from that geography itself.

A fourth way in which the city is multi-scalar is that it houses a variety of policy levels. It is one of the key sites where a very broad range of policies-supranational, national, regional, and local-materialize in specific procedures, regulations, penalties, forms of compliance, and types of violations. These specific outcomes differ from the actual policies-in terms of the design of these policies and the specifics of implementation at other scales of government.

\section{CONCLUSION}

Bringing the city level into larger governance regimes is not without its complications. Among the subjects examined in this chapter, let me emphasize two I consider strategic. One is the use of science and technology in ways that would mobilize urban capabilities to transform what are now negative articulations between cities and the biosphere into positive ones. This means making full use of the complexity of cities, notably their multi-scalar and ecological features. I do not think we are close to such a full use, but there is the beginning of a mobilizing in this direction. This should enable urban experts and scientists to connect on far more processes than they do now.

The second strategic element concerns the city as a social and power system-with laws, extreme inequalities, and vast concentrations of power. Implementing environmental measures that go beyond current modest mitigation and adaptation efforts will require engaging the legal systems and profit logics that underlie and enable many of the environmentally damaging aspects of our societies. Any advance toward environmental sustainability is necessarily implicated in these systems and logics. To this we need to add that the actual features of these systems vary across countries and across the North-South divide. Although in some domains concerned with the environmental question, such as national states, it might be possible to confine the analysis to scientific knowledge this is not the case when dealing with cities. 


\section{Saskia Sassen}

But it must be done. A focus on cities makes visible the limitations of existing climate governance framings. It would make every major city, regardless of country, a complex space for the implementation of processes that actually cut environmental damage rather than shifting it around as is the case with the carbon trading proposals. Using science and technology to reverse the negative articulations of cities with the biosphere would help make cities a strategic ground for active reductions of environmental damage. These types of efforts might well, and partly already do, bypass the intergovernmental debate on carbon trading and the protectionism of a country's "right" to pollute more than is allowed by the carbon trading regime.

Making "urban ground" a key component of a multi-sited global regime would operate on a practical rather than formal vector: the fact that cities tend to be ahead of their national governments in addressing environmental issues, and the fact that this is not the result of "good politics" but rather of practical and often urgent needs.

\section{NOTES}

1. I develop these issues in Chapter 4 of Expulsions.

2. I elaborate on this conceptual approach and its consequences in Sassen 2014, Chapter 4.

3. KP and UNFCCC lack specific references to local government or city-level actions to meet the Protocol commitments. (See also Arikan and Van Begin 2009.) Inclusion would bring with it both a bottom-up-information from local level-and a top-down understanding of how existing protocols and post-2012 agreements integrate cities. There are a few references to local-level involvement; for example, Article 10 in the KP recognizes that regional programs may be relevant to improve the quality of local emission factors. The much-anticipated Copenhagen UN Climate Conference (COP15) made little headway, even though Copenhagen is a model city on environmentally innovative initiatives.

4. This increasing recognition of a role for local governments and authorities is especially focused on reducing emissions from deforestation and forest degradation in developing countries (REDD) and the Nairobi work program (REDD Web Platform; UNFCCC) on adaptation within the new and emerging concepts of the international climate negotiations.

5. See for instance the Global Status Report on Local Renewable Energy Policies, Institute for Sustainable Energy Policies. Tokyo. Retrieved 13 October 2013 http://www.isep.or.jp/images/library/REN21_Local_Renewables_Policies_2011.pdf Date accessed can be listed as 8 December 2014.

6 . These were mostly result-based, quantified, and concrete local climate actions, launched long before the Convention and KP came into force. See, for instance, the ICLEI Climate Program at www.iclei.org/index. There is now a rapidly growing number of studies largely focused on greenhouse gas emissions (GHG) that show cities and metro regions can make a large difference in reducing global environmental damage.

7. The UNFCCC is focused on a successor to the climate protection agreement following 2012, also known as the post-Kyoto or post-2012 agreement.

8. This is a broad subject. For studies that engage a range of aspects, see Rees (1992), Sassen (2009), Satterthwaite et al. (2007), Girardet (2008), Mol and Sonnenfeld (2000; 2011), Beddoe et al. (2009), and Shonkoff et al. (2011). 
9. Some kinds of international agreements are crucial. Examples include agreements that set enforceable limits on each national society's consumption of scarce resources and their use of the rest of the world as a global sink for their wastes. Other agreements I find to be problematic, notably that concerning the market for carbon trading. The latter contain negative incentives. Firms need not change their practices insofar as they can pay others to take on their pollution. Overall there is a good chance of no absolute reduction in pollution.

10. For instance, instituting a sustainable consumption logic can be aided by zoning and subdivision regulations, building codes, planning for transport, water and waste, recreation and urban expansion, local revenue raising (environmental taxes, charges, levies) and by introducing environmental considerations when preparing budgets, purchasing contracting, and bidding (see Satterthwaite's and other researchers' work on the International Institute for Environment and Development (IIED) website (http://www.iiep.unesco.org/) for one of the most detailed and global data sets on these issues).

11. An experimental technology with a similar capacity to be deployed "globally at the local level" is the so-called carbon negative cement (see www.novacem. com/docs/novacem_press_release_6_aug_2009.pdf).

\section{BIBLIOGRAPHY}

Arikan, Y. and Van Begin, L., 2009. Local Climate Mitigation Action: From a Voluntary Initiative to a Global Mainstream Commitment. Boston: ICLEI.

Beddoe, Rachael, Costanza, Robert, Farley, Joshua, Garza, Eric, Kent, Jennifer, Kubiszewski, Ida, Martinez, Luz, McCowen, Tracy, Murphy, Kathleen, Myerse, Norman, Ogden, Zach, Stapleton, Kevin and Woodward, John, 2009. Overcoming Systemic Roadblocks to Sustainability: The Evolutionary Redesign of Worldviews, Institutions, and Technologies. PNAS 106 (8), 2483-2489.

Bettencourt, Luís M.A., Lobo, José, Helbing, Dirk, Kühnert, Christian and West, Geoffrey B., 2007. Growth, Innovation, Scaling, and the Pace of Life in Cities. PNAS 104, 7301-7306.

Bettencourt, L. and West, Geoffrey, 2010. A Unified Theory of Urban Living. Nature 467, 7318.

Environment and Urbanization, 2007. Special Issue: Reducing the Risk to Cities from Disasters and Climate Change, 19 (1), Sage Publications. Retrieved January 2011 from http://eau.sage-pub.com/content/vol19/issue1

Garcia, J., Mujeriego, R. and Hernández-Mariné, M., 2000. High Rate Algal Pond Operating Strategies for Urban Wastewater Nitrogen Removal. Journal of Applied Phycology 12, 331-339.

Girardet, H., 2008. Cities People Planet: Urban Development and Climate Change, 2nd ed. Amsterdam: John Wiley \& Sons.

Global Status Report on Local Renewable Energy Policies, Institute for Sustainable Energy Policies. Tokyo. Retrieved from http://www.isep.or.jp/images/library/ REN21_Local_Renewables_Policies_2011.pdf Date accessed can be listed as 8 December 2014.

Jonkers, H. M., 2007. Self Healing Concrete: A Biological Approach. Springer Series in Materials Science 100, 195-204.

Mol, A.P.J. and Sonnenfeld, D.A., 2000. Ecological Modernisation Around the World: Perspectives and Critical Debates. London and New York: Routledge.

Mol, A.P.J. and Sonnenfeld, D. A., 2011. Social Theory and the Environment in the New World (dis)Order. Global Environmental Change 21 (3), 771-775.

Rees, W.E., 1992. Ecological Footprints and Appropriated Carrying Capacity: What Urban Economics Leaves Out. Environment and Urbanization 4 (2), 121-130. 


\section{Saskia Sassen}

Sassen, S., 2005. The Ecology of Global Economic Power: Changing Investment Practices to Promote Environmental Sustainability. Journal of International Affairs 58 (2), 11-33.

Sassen, S., ed., 2009. Human Settlement and the Environment, in EOLSS Encyclopedia of the Environment, Vol. 14. Oxford: EOLSS and UNESCO.

Sassen, S., 2013. Land Grabs Today: Feeding the Disassembling of National Territory. Globalizations 10 (1), 25-46.

Sassen, S., 2014. Expulsions: Brutality and Complexity in the Global Economy. Cambridge: Harvard University Press.

Sassen, S. and Dotan, N., 2011. Delegating, Not Returning, to the Biosphere: How to Use the Multi-Scalar and Ecological Properties of Cities. Global Environmental Change 21 (3), 823-834.

Satterthwaite, D., Huq, S., Reid, H., Pelling, M., and Lankao, P. R., 2007. Adapting to Climate Change in Urban Areas: The Possibilities and Constraints in Low- and Middle-Income Nations. Human Settlements Discussion Paper Series. London: International Institute for Environment and Development. Retrieved 4 November 2014 from http://www.iied.org/pubs/pdfs/10549IIED.pdf.

Shonkoff, S. B., Morello-Frosch, R., Pastor, M. and Sadd J., 2011. The Climate Gap: Environmental Health and Equity Implications of Climate Change and Mitigation Policies in California-A Review of the Literature. Climatic Change 109 (1) Supplement, 485-503.

Toly, N.J., 2008. Transnational Municipal Networks in Climate Politics: From Global Governance to Global Politics. Globalizations 5 (3), 341-356.

United Nations Framework Convention on Climate Change. Retrieved 14 October 2012 from http://unfccc.int/2860.php 


\title{
3 Closed Cycles-Open City
}

\author{
Katleen De Flander
}

\section{INTRODUCTION: FIXING THE RUPTURES}

In a context where international and national actions seem to be moving too slowly to 'seriously' tackle climate change, cities often find themselves in a situation of 'necessity', one in which local realities simply demand that climate change be addressed. Looming natural disasters, acute air pollution, and water scarcity, among other challenges, are often exacerbated by growing populations and increasing inequality. These challenges prompt cities to take action, and even unexpected cities might sense the need to take a leadership role in urban climate action.

On the positive side, from engineering to medicine, actions stemming from practical necessity have proven much more innovative and effective compared to theoretically created solutions in places where the acuteness of the problem is more abstract (e.g. national and global political debates on climate change) but not physically present (Taleb, 2012). The fact that much of the key and emerging global climate risks are concentrated in urban areas (Revi et al., 2014), coupled with the possibility of extensive co-benefits, suggests that cities might play a pivotal role in the global climate regime. In practice, however, there is often still a huge gap between climate actions (e.g. as direct threat-response) and thinking through urban transformations in a systemic way. Such a systemic approach is crucial to leverage climate actions for an integrated urban strategy, which manages to tackle multiple environmental and social threats and stressors and align efforts towards a city's progressive transformation (Brugmann, 2009, p. 226).

"For the first time humankind is the major consumer in all the significant ecosystems. And urbanization has been a major instrument" (Sassen, 2009, p. 45). While the significance of the city as part of the solution is apparent, our current global ecological conditions are not the result of urban agglomeration and density in itself, but they are the results of the specific types of urban systems that we have developed to handle transport, waste disposal, building, heating and cooling, food provision, and the industrial processes by which we extract, grow, make, package, distribute, and dispose of the foods, services and materials that we use (Sassen, 2010). These systems 
concentrate in cities but extend far beyond their boundaries and form a variegated urban fabric that is now woven unevenly across vast stretches of the globe (Brenner, 2013). So far, instead of rethinking these systems, most current urban environmental strategies are stuck in trying to solve the problems within the same systems that created them. Instead, they could serve as a platform for rethinking these systems. Our transportation system is for instance for a large part based on the car and is a vast contributor to oil dependencies, climate change, health problems, air and water pollution, impervious soils, unliveable cities, and so on. Instead of rethinking the system and thinking in functions ('mobility') and not in goods ('I need a car'), dependencies on cars are now nurtured under the name of green cars, biofuel or electric mobility and car companies are bailed out in the name of 'saving jobs'. In addition, the proposed solutions are often so well packaged that they seem to be the right way to go. Their externalities are 'forgotten' or they are contributing to other non-related factors; a good example is the carbon-offsetting scheme. In Haughton's (1997, p. 190) words:

External impacts are the least talked about or understood aspects of the sustainable urban development debate at the moment, and yet arguably the very ability to use urban (and other political-administrative) boundaries to avoid accepting responsibility for external impacts helps fuel our current patterns of non-sustainable behaviour, as we transfer the costs of our consumption preferences to other people, other species, and other areas. We need to reform not just the city, but the way in which the city interacts with the rest of the global economy and environment.

Countering the epistemological focus on efficiency improvements and impact offsetting, this chapter explores the conceptual nature of urban systems transformations, placing urban resource flows at its basis. According to Sassen and Dotan (2011), cities have multiple articulations with the biosphere, which produce a number of negative externalities. First, cities produce ruptures in the biosphere's continuous flows. Second, their consumption of biospheric resources is 'unbiological' in the sense that they take more than the biosphere can replace. At the same time, the capabilities of cities can be used to redress the above negatives by activating biospheric capacities in urbanised settings (as well as multiple human-made technical and knowledge innovations and instruments). This framing suggests that taking up the urban climate challenge will require strategies that go beyond adaptation and mitigation to restoring the ruptures in the biosphere's continuous flows.

The following hypotheses guide this chapter:

- Cities produce ruptures in the biosphere's continuous flows, and their consumption of biospheric resources is 'unbiological' in the sense that they take more than the biosphere can replace (Sassen and Dotan, 2011). 
- Urban transformations entail the study of processes, not models. Models, which include replicable ready-made designed eco-cities and other technological 'fixes', exclude the citizens from the transition and are therefore likely to fail. Moreover, they greatly simplify the complexity of a city and lead to unexpected outcomes.

- To come to an effective transition of our extended urban systems (i.e. to tackle global climate change), a transition of urban resource flows (going back from 'open' to 'closed') will need to go hand in hand with a transition in urban space governance (going back from 'closed' to 'open'). In other words, a paradigm shift regarding resource flows will also demand an appropriate '(re-)production of urban space' (Lefebvre, 1991).

\section{CITIES ARE COMPLEX ADAPTIVE SYSTEMS}

Countering the negative externalities of cities entails a transition from linear to circular resource flows in urban areas. To explore what influences a city's ability to close its resource cycles (in other words to match resource production with consumption), this section starts with an abstraction of an urban area, outside of any economic or social system, with well-defined boundaries and with a specific supply and demand for the various resources (e.g. water, energy, food, nutrient, materials). Theoretically, in order to close a resource cycle within the edges of this system, we need to match the demand for this resource with the supply of this resource. At a certain point, demand and supply find equilibrium and the cycle closes (Figure 3.1).

\section{RESOURCE DEMAND}

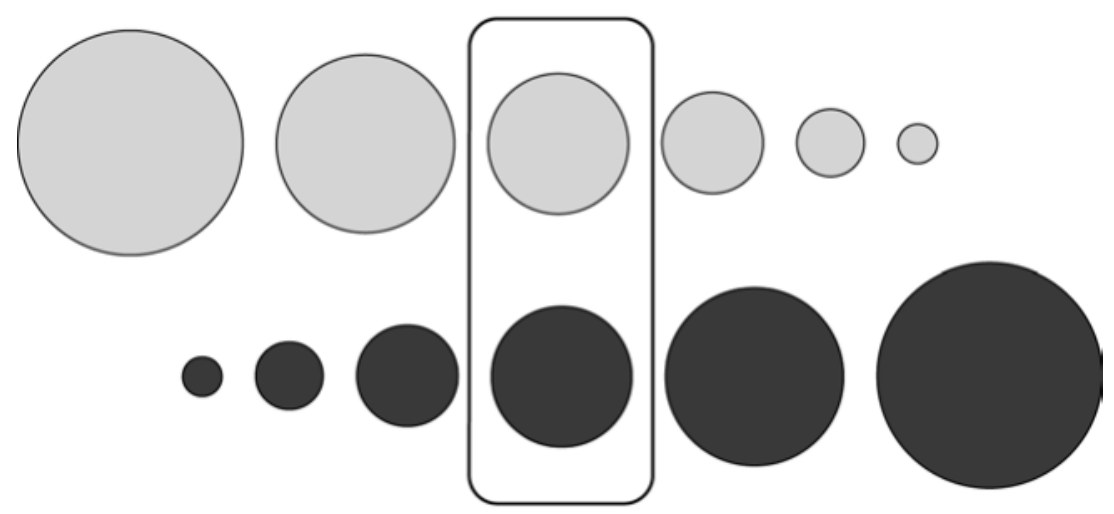

RESOURCE SUPPLY

Figure 3.1 Matching demand and supply. 


\section{Katleen De Flander}

This equilibrium for one resource within a specific urban area is influenced by four key parameters: resource production, resource consumption, scale of the (closed) resource cycle area, and population density. To illustrate this, picture a closed cycle (e.g. energy) as an area in the city within which there is equilibrium between the supply and the demand. Note that this is an abstract system and in physical space; this area does not match any social or administrative boundaries (Figure 3.2).

If at a certain moment in time the equilibrium is disturbed and the supply cannot cover the demand of the area anymore, there are several ways to react:

1. The area increases its resource production (supply) to be able to meet the demand.

2. The area reduces its demand by reducing resource consumption.

3. The area reduces its size to reduce the resource demand (of course this depends on the physical location of the resource production capacity) or increases its size to be able to produce more resources (Figure 3.3).

4. The area reduces its population density to reduce the resource demand (Figure 3.4).

5. Or a combination of some or all of the previous.

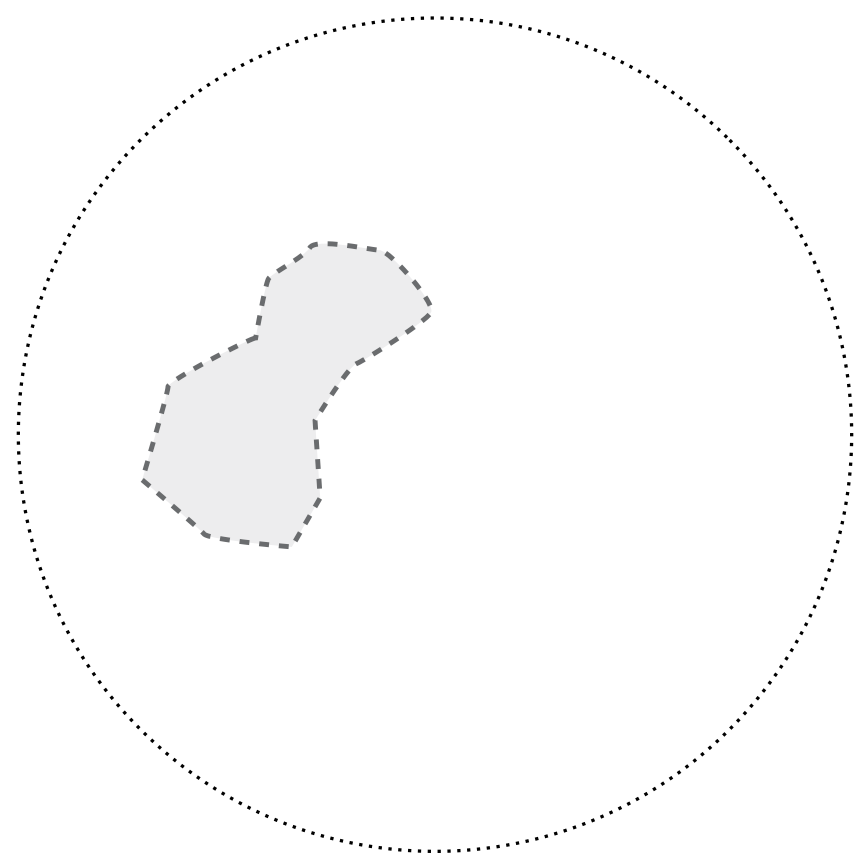

Figure 3.2 Closed energy cycle (grey area) in an abstract system. 

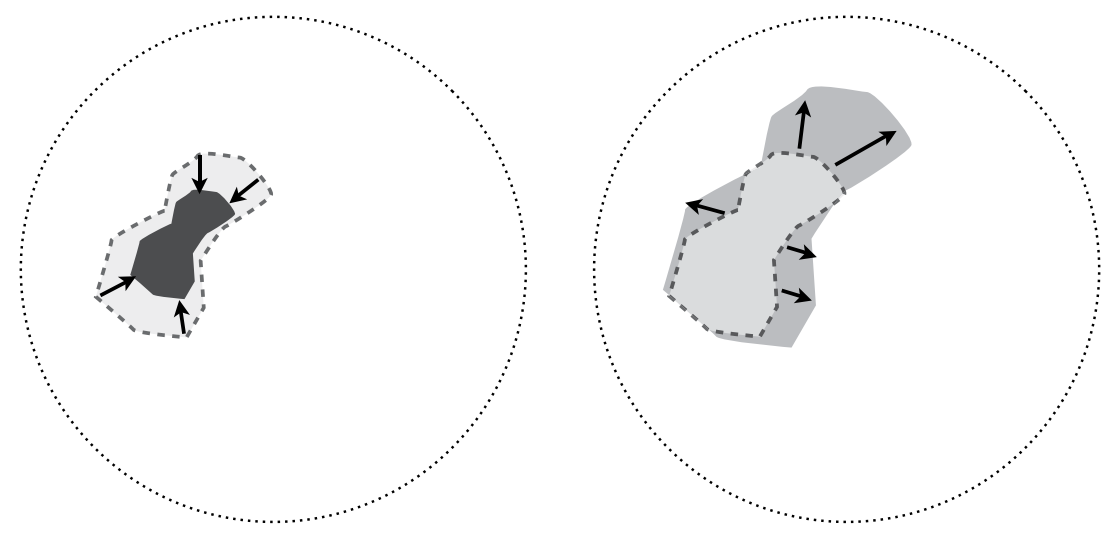

Figure 3.3 Reduce and increase size of closed cycle area in an abstract system.
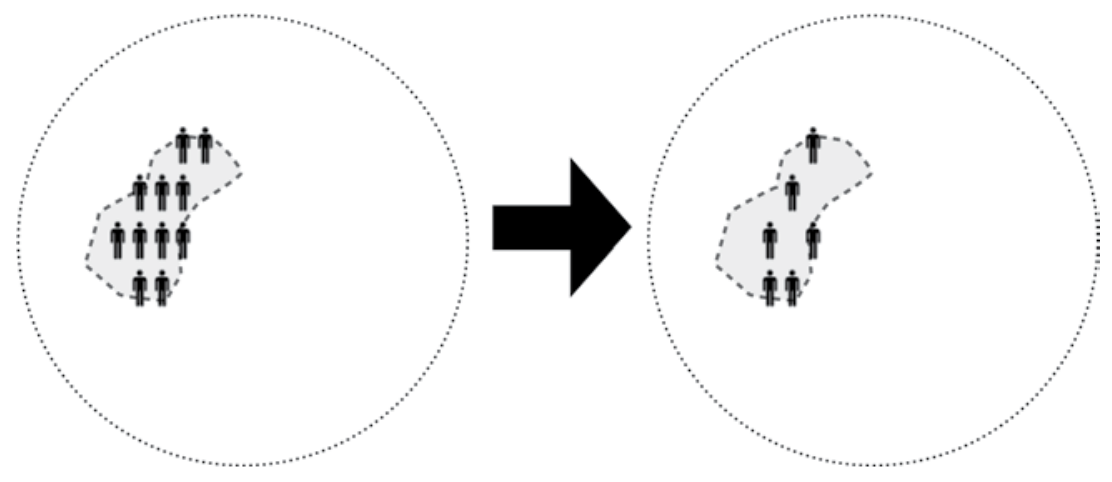

Figure 3.4 Reduce density in closed cycle area in an abstract system.

In the same way, when resource supply exceeds demand, several things can be manipulated to balance the production and demand of resources:

1. The area decreases its resource production (supply) or redirects overproduction to another area.

2. The area can allow for a higher consumption of resources.

3 . The area increases its size to enable a higher resource demand (Figure 3.5).

4. The area increases its population density (Figure 3.6).

5 . Or a combination of some or all of the previous.

A first important observation is that when one parameter changes, the others are all affected and play a role in finding a new balance. 


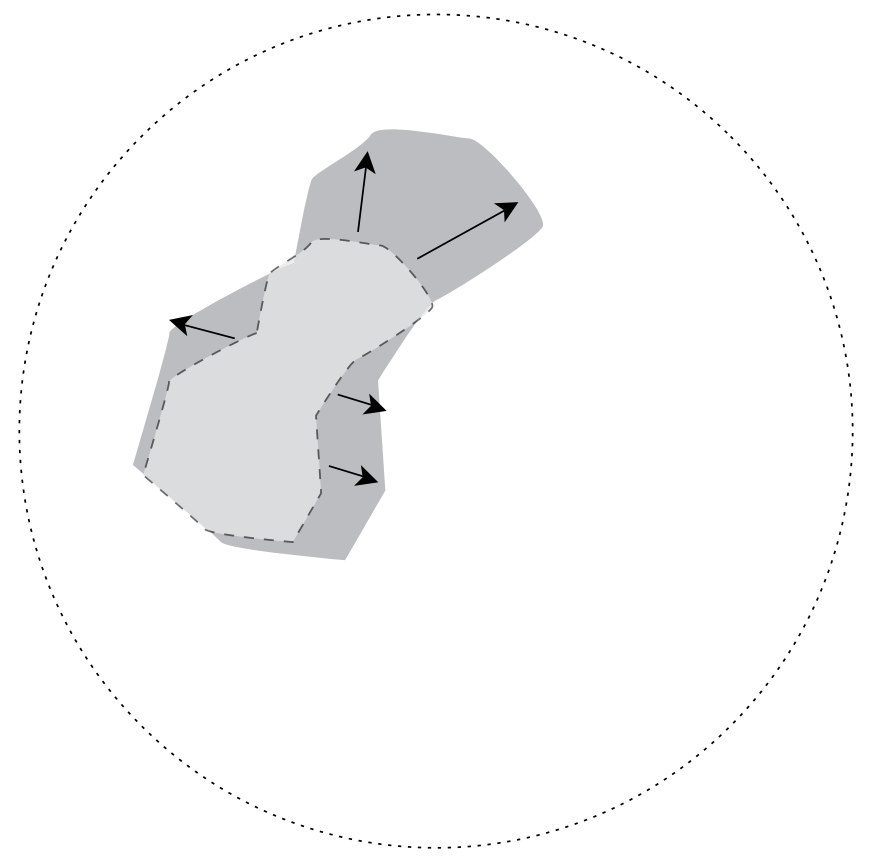

Figure 3.5 Increase size of closed cycle area in an abstract system.

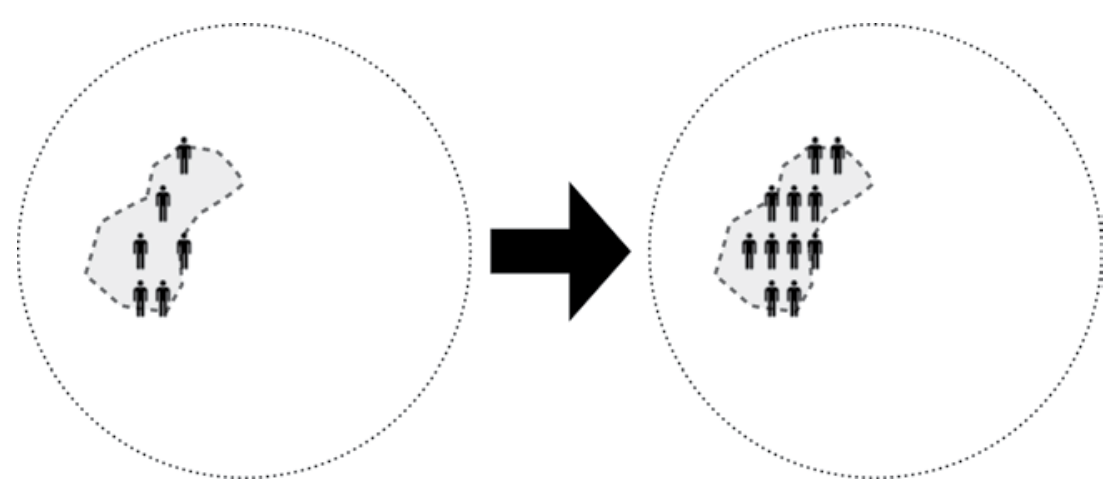

Figure 3.6 Increase density in closed cycle area in an abstract system.

An increase in resource production in a certain area allows for (a) a higher population density in that area; (b) an increased resource consumption in that area or (c) an expansion in size of the closed cycle area to take up more consumers (or a combination of these). A decrease in resource production, on the other hand, means that (a) consumption will need to be reduced; (b) the closed cycle area will need to shrink in size to reduce consumers; or (c) population density should decrease (or a combination of these). 
An increase in resource consumption in a certain area will demand (a) an increase in resource production in that area; (b) an expansion of the closed cycle area to be able to increase production; or (c) a decrease in population density to allow for a higher per capita consumption rate (or a combination of these). A decrease in resource consumption, on the other hand, could allow for (a) production to be reduced or partly exported; (b) the area to expand to take up more consumers; or (c) the population density of the area can increase (or a combination of these).

An increase in the scale of the closed cycle area mostly (a) increases the number of consumers, which often leads to a higher resource consumption; (b) increases the production capacity of the area (except in the case of resource deserts); and (c) changes the overall density of the area. A decrease in the scale of the closed area has the opposite effect.

An increase in population density in a certain area correlates with (a) an increased overall resource consumption; (b) a reduced availability of production space and therefore a reduced resource production capacity; (c) a need to expand the area to increase production capacity. A shrinking population density, on the other hand, opens opportunities for (a) an increased individual consumption; or (b) a reduced production rate or export potential of excessive production; or (c) an expansion of the area to take up more consumers.

Besides their interdependencies, each of the four parameters is in turn influenced by a number of variables, as follows.

Variables that influence the maximum production capacity of a certain area for a certain resource (e.g. energy) are current available technologies, (alterations in) the physical environment, possible innovations, and so on. The actual production of an area can, however, be very different from the maximum production capacity due to a number of reasons including regulations, private property, technology choices, financial limitations, the NIMBY (Not In My Backyard) phenomenon. Some physical places might not have any production capacity for a particular resource because of physical, natural or other restraints. These 'resource deserts' will have to become part of another cycle that can cover their demand (Figure 3.7).

Variables that influence resource consumption in an area include financial power of inhabitants, property prices, cultural and social influences, advertisement, accessibility, type of urban systems, and so on.

The scale of a closed cycle area can be influenced by variables such as specific urban fabric; technical, legal or natural restrictions; local actor initiatives; and others.

Population density is influenced by a number of variables, such as regulations, property/rental prices, location, transportation options, job opportunity, immigration, social structure, and can change drastically over time. A closed cycle area (dotted area in Figure 3.8) can have different densities inside (grey-scales in Figure 3.8), including lower density peri-urban areas or shrinking urban areas, which can boost the productivity of the closed cycle area while not adding much on the demand side. 

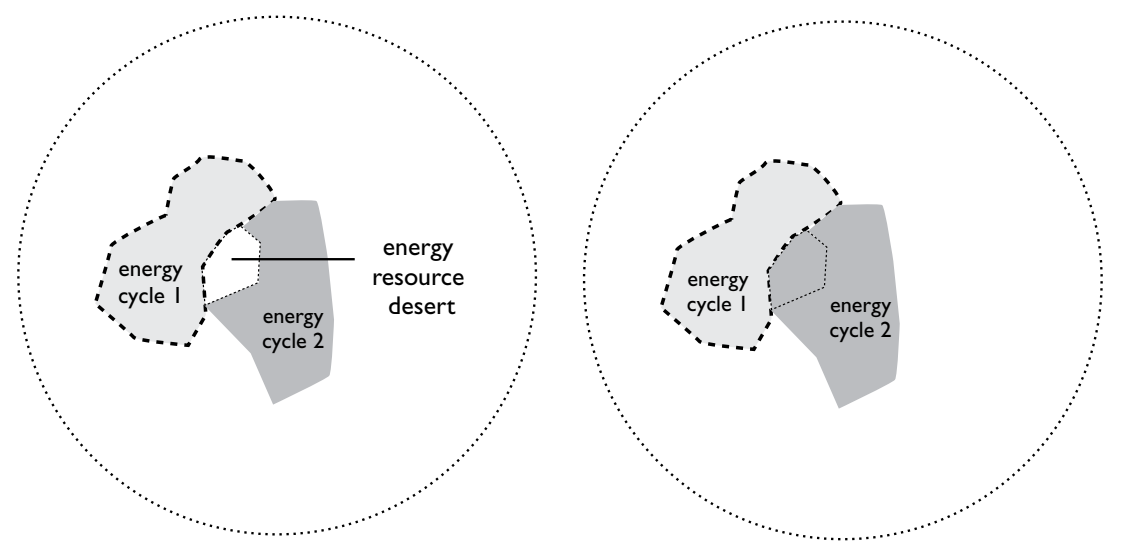

Figure 3.7 Resource deserts.
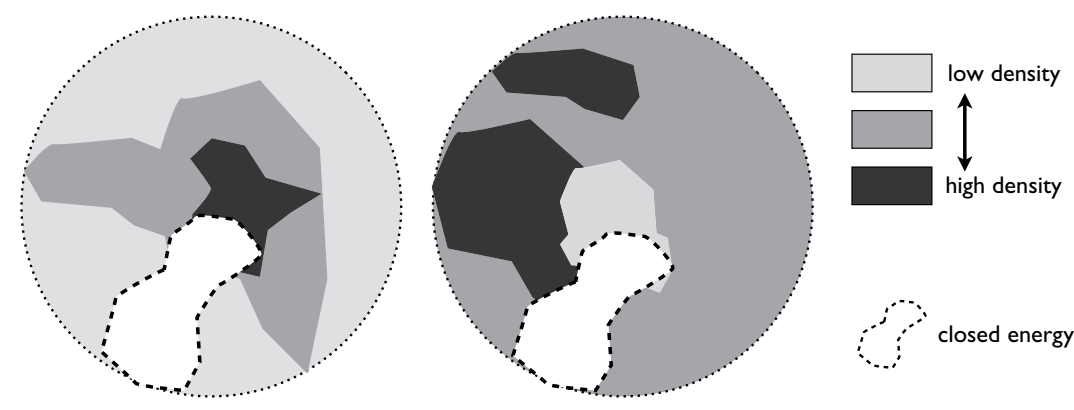

Figure 3.8 Different densities in closed cycle area in an abstract system.

The preceding suggests that the four parameters and their variables are in reality constantly changing and interacting in interdependent and unpredictable ways, creating non-linear feedback loops in a dynamic urban system.

Through the lens of complexity, we see that cities and communities are not linear cause-and-effect systems, but rather dynamic systems or 'complex adaptive systems', where the variables are constantly interacting and changing-for better or worse-in response to each other, creating non-linear feedback loops that either promote or deplete the life energy upon which their futures depend (Sanders, 2008). "This new, more complete, whole-systems approach is replacing the old reductionist paradigm, where scientists traditionally tried to understand and describe the dynamics of systems by studying and describing their component parts. Complexity science is moving us away from a linear, mechanistic view of the world, to one based on nonlinear dynamics, evolutionary development, and systems thinking" (Sanders, 2008, p. 276). 
This recognition of complexity proves crucial when dealing with urban resource flows. We need to understand that it is not one parameter that determines success or failure of closing resource cycles (e.g. low or high density) but rather the way they work together and the proportions in which they do. This means that there is no 'right' density or 'right' scale to close a resource cycle, nor does it make sense to define strict rules or prescribe specific urban forms. A well-known example is the rebound effect, whereby improving energy efficiency actually leads, through various feedback mechanisms on prices, to an increase in the demand for energy. This means that the current policy focus of most governments to improve energy efficiency as a means to reduce emissions may be more difficult than linear calculations suggests (Fanning, 2012). Similarly, Eidlin (2010) describes the danger of 'dense sprawl' as an unexpected result of tackling 'suburban sprawl' by rigid densification strategies. 'Dense sprawl' is the phenomenon where our disconnected cities become denser and denser without becoming more complex, resulting in even poorer urban conditions.

Therefore, urban models that only focus on one of the parameters and expect to have a linear cause-effect outcome when manipulating that parameter often fail. There are plenty of practical examples where 'Smart Growth' or 'Urban Intensification' implementations have failed, exactly because they didn't recognise the complexity of the city and only focussed on densification. They tried to reproduce vibrant quarters inspired by old city centres but didn't recognise that most of all, the urban form of older metropolitan areas is one of great variance, not great density (Eidlin, 2010).

\section{TRANSLATING COMPLEXITY IN THE CITY}

Adding to the complexity, there are also wider processes that influence the four parameters and make cities move to the left or right of the 'resource demand/resource supply' graph (Figure 3.1). Economic growth and an increasing GDP often lead to increased consumption and make cities move further to the left of the graph. This is the reason for the current attempts to decouple economic growth from resource consumption (UNEP, 2013). Also globalisation, and the underlying principles of neoliberalism, strongly influences a shift to the left as production is often outsourced to other parts of the world (decreasing local production) and consumption is placed as a central paradigm. The functional specialisations of cities or an aging (and shrinking) population are other examples of such wider influencing factors.

Also, taking more than one resource flow into account will lead unavoidably to a competition for production space within the urban fabric. Energy production will compete with food production, with spaces for water infiltration or with other urban functions such as a car park. A simple overlap of a solar potential map (already available in many cities) with a potential map for food production and a map of the existing car infrastructure would 
show immediately where trade-offs will need to be discussed. In addition, Rovers (2013) argues that when urban areas become resource producers, there is a necessity of seeing urban space in $3 \mathrm{D}$. He uses the example of a high-rise building, which takes the solar potential away from the buildings in its shade.

Approaching the city as a complex system suggests that existing methods to land-use planning have become out-dated and that there is a need to move to a system that doesn't describe size or form. Instead, it should define the processes around which form can be generated, processes that allow for maximum flexibility in local problem-solving. The idea of creating something whose size or form is not going to be known is alien to engineering and architectural practices. However, scale-free system design has been achieved before, for instance the Internet (Hélie, 2008).

One of the characteristics of a complex adaptive system is its unpredictability. This means that a high degree of uncertainty is a normal circumstance and the idea of prescribing a future (e.g. model approach to cities) or even the idea of roadmaps is too simplistic to serve as an adequate design. "Roads are linear. Roads lead to a certain destination. In a complex and uncertain world it is even dangerous to determine a final destination. Instead, notions like resilience provide guidance to actions but without a fixed point in the future" (in 't Veld, 2011, p. 82). Formulated differently, the structural uncertainties surrounding future development of cities necessitate more explorative, experimental, and reflexive approaches (Loorbach, 2010).

The preceding suggests that urban transformations can be usefully understood as a dynamic process in a complex system with constantly changing parameters (each influenced by its own variables), keeping in mind the uncertainty of the system, leaving space for multiple pathways and without expecting linear cause-and-effect outcomes (Figure 3.9). When we fail to acknowledge this when working on a transition of our urban systems, there is a realistic danger that the physical structures we end up with are not containing this complexity and therefore fail as urban structures. A "real city is complex and incomplete" (Sassen in: Guadalupe, 2013, p. 66) in which simplifications, too much technology or models lead to unexpected outcomes and "de-urbanise the city" (Sassen in: Guadalupe, 2013, p. 66).

In 'A City Is not a Tree', Alexander (1965) describes the difference between 'natural' cities, which have arisen more or less spontaneously over many years, and artificial cities, those cities and parts of cities which have been deliberately created by designers and planners. He argues that compared with ancient cities that have acquired the patina of life, there is some essential ingredient missing from artificial cities and calls them from a human point of view, entirely unsuccessful. Alexander (1965) then formulates two ways of thinking about how a large collection of many small systems goes to make up a large and complex system and calls them the 


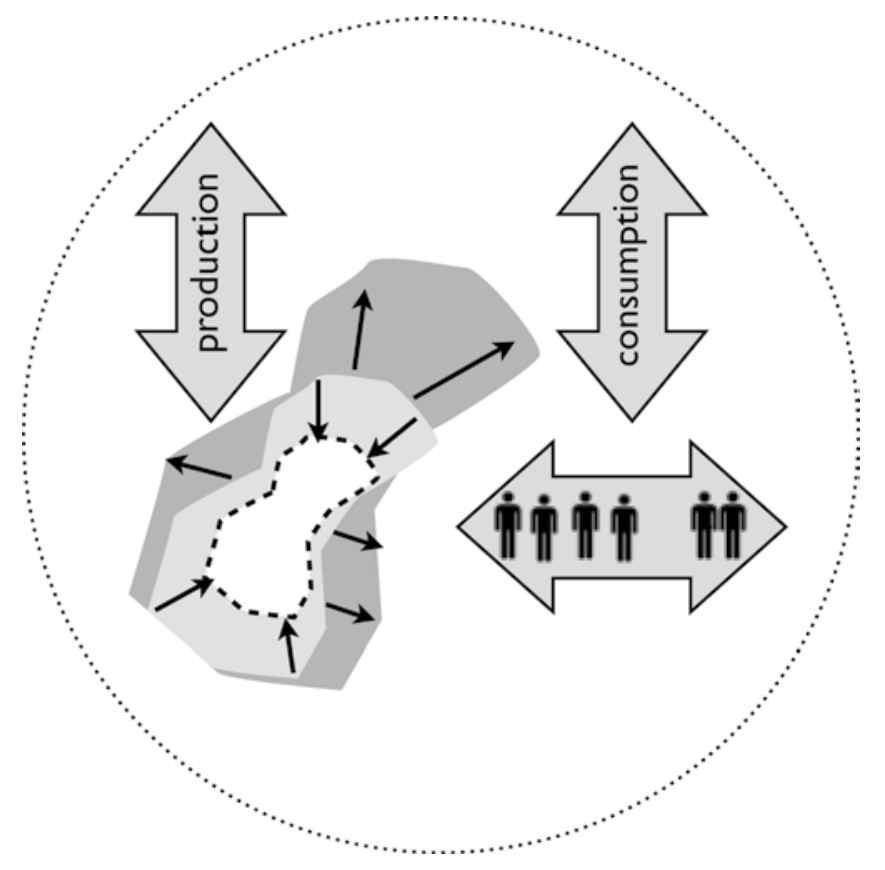

Figure 3.9 Dynamic interdependent parameters.

tree and the semi-lattice. More generally, they are both names for (abstract) structures of sets.

\section{$>$ TREE}

A tree is a structure in which no overlap occurs. The units of which an artificial city is made up are always organised to form a tree. Whenever we have a tree structure, it means that within this structure no piece of any unit is ever connected to other units, except through the medium of that unit as a whole (Figure 3.10).

\section{$>$ SEMI-LATTICE}

A semi-lattice is a structure in which overlap occurs. The idea of overlap, ambiguity, multiplicity of aspect and the semi-lattice are not less orderly than the rigid tree, but more so. They represent a thicker, tougher, more subtle and more complex view of structure (Figure 3.11). 

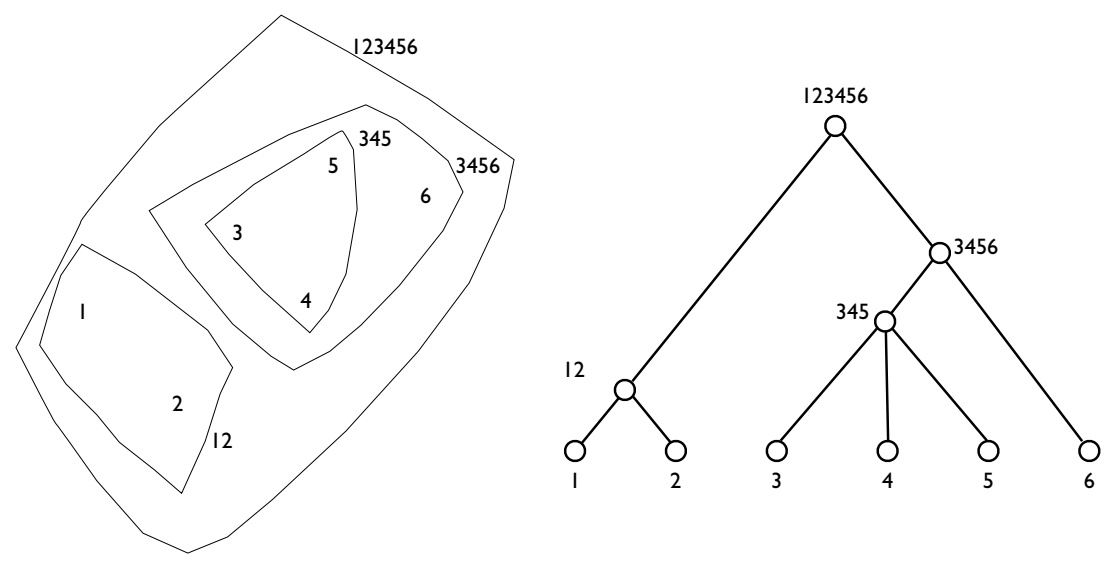

Figure 3.10 Tree structure.
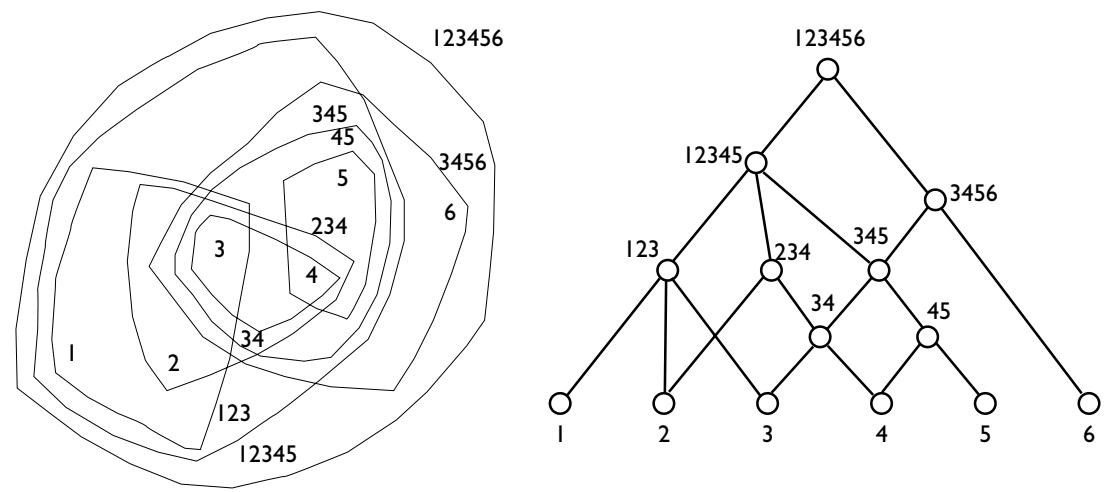

Figure 3.11 Semi-lattice structure.

Alexander (1965) argues that it is this lack of structural complexity, characteristic of trees, which is crippling our conceptions of the city. He illustrates this by analysing a number of modern 'designed' cities and describing them as 'tree' structures. Experiments suggest strongly that people have an underlying tendency, when faced by a complex organisation, to reorganise it mentally in terms of non-overlapping units. The complexity of the semi-lattice is replaced by the simpler and more easily grasped tree form (Figure 3.12).

Eco-cities are a good example to unfold the failings of a tree-type of structure. Eco-cities, mostly all-new developments with clearly defined borders and largely based on high-tech solutions, are one of the contemporary manifestations to tackle environmental problems in cities and change urban 

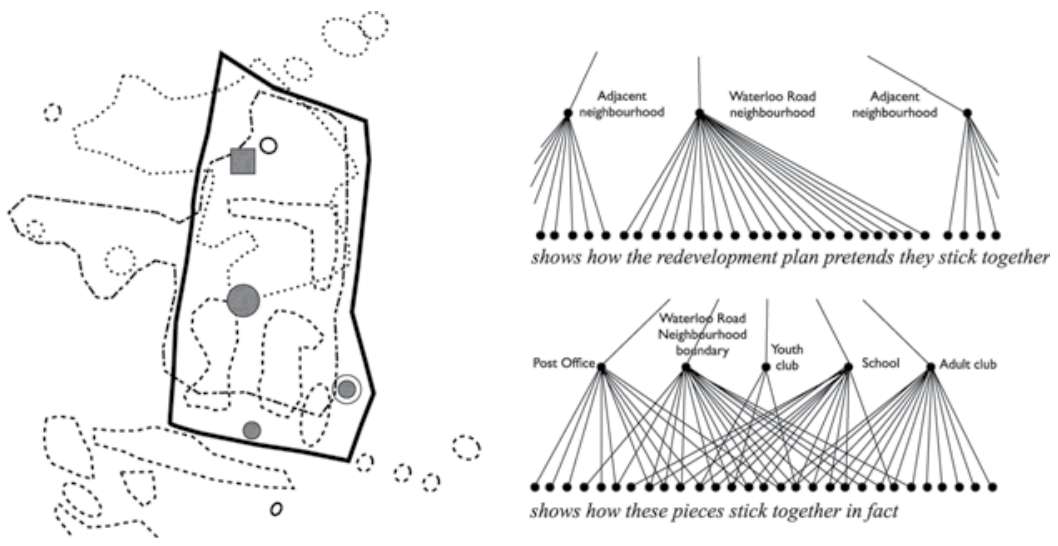

Figure 3.12 Social structure of a neighbourhood.

resource flows. Although in itself the idea of building 'sustainable' cities and creating incubators for innovations is a good thing, one could argue first that from a resources point of view, in many countries, it doesn't make sense to build cities from scratch. If we look at the demographics of Europe, for instance, it is clear that we have to make the systems change in our existing cities.

Second, the design of these eco-cities is often based on units or clusters and sub-units and even though mixed-use is intended, a tree-like translation still endures. The designers of Dongtan Eco-City, ${ }^{1}$ for instance, describe a model in which "village clusters form the basis of the city plan where the idea is that people live, work and shop in the same neighbourhood, reducing transport and creating a mixed-use street life typical of traditional city centres" (Steel, 2009, p. 287). This sounds nice but will people really live, work and shop in the same village cluster? It might be more complex than this. After analysing the Abercrombie plan for London, Alexander (1965) concludes that "the individual community in a greater city has no reality as a functioning unit. In London, as in any great city, almost no one manages to find work that suits him near his home. There are therefore many hundreds of thousands of worker-workplace systems, each consisting of individuals plus the factory they work in, which cut across the boundaries defined by Abercrombie's tree. The existence of these units, and their overlapping nature, indicates that the living systems of London form a semi-lattice. Only in the planner's mind has it become a tree". Similarly, in her discussion on urban neighbourhoods, (Jacobs, 1992, pp. 114-117) argues that we must first of all drop any ideal of neighbourhoods in the city as self-contained or introvert units. The often-used ideal unit of 7,000 persons is silly and even harmful for cities as there is a basic difference between city and town life. City people are 'mobile', they can and do pick and choose from the 
entire city (and beyond) for everything from a job, a dentist, recreation, or friends to shops, entertainment, or even in some cases their children's schools (Jacobs, 1992, p. 116).

A third aspect is that closed resource cycles are usually 'designed-in' to these eco-cities lacking consideration of the ways in which cities interact with their regional and global hinterlands. ARUP, ${ }^{1}$ for instance, planned Dongtan Eco-City (China) as a self-sufficient city, generating all its energy from renewable resources, growing all food and recycling all waste (incoming packaging will be stripped and recycled in consolidation centres at the borders) (Steel, 2009). However, questions can be asked about the ways in which the design principles will accommodate the complexity of urban life. Interestingly, the designers at ARUP have already raised concerns that populations living in Dongtan will ultimately be tempted to purchase cheaper food coming from outside the city (Steel, 2009, p. 289).

Fourth, here there is a danger that closed resource cycles will exacerbate differentiation and exclusion among different socioeconomic groups and communities. Eco-cities such as Masdar (United Arab Emirates) are already being criticised for being the gated communities of the 21st century (Hodson and Marvin, 2009, 2010). Hodson and Marvin (2010, pp. 310-311) argue that "this style of development is much more concerned with integration at the scale of development than with the wider transformation of the existing city or its incumbent infrastructure networks". As such, they continue, "we should see them (eco-cities) as the purest attempt to create neo-liberalised environmental security, not at the scale of the whole city or even the planet, but a more bounded divisible security in order to try to guarantee ecological security for elites". These critiques seem very similar to the one Marx had on the proposals for Utopian Cities, which he believed were necessarily doomed to failure because they attempted to create a perfect world, rather than change the existing one (Steel, 2009, p. 297). (Figures 3.13, 3.14, 3.15).

Finally, what seems to be missing in tree-like cities, including the readymade eco-cities, is the dimension of time. Ready-made cities short-cut the process phase of transition and ignore the transformative nature of cities. The power of a complex system lies in its ability to transform itself while remaining functional through this transformation. Idealised cities are simply too naïve with respect to the workings of the development process (Batty, 2008). This was the case during modernist planning, but we could say the same about the contemporary master-planned eco-cities. The notion that cities are managed by urban planners with master plans has always been a fiction (McGranahan, 2005). (Figure 3.16).

Alexander (1965) warns that tree-like city structures create lifeless cities. Similarly, Christiaanse (2007) raises the concern that "The City has become a tree, a patchwork of disjoined, sterile, and partially inaccessible sectors". With the emergence of the automobile as a private mass-transit technology, many cities have transformed from walkable to car cities (as cars often replaced rail service and pedestrianism). This allowed at the same 

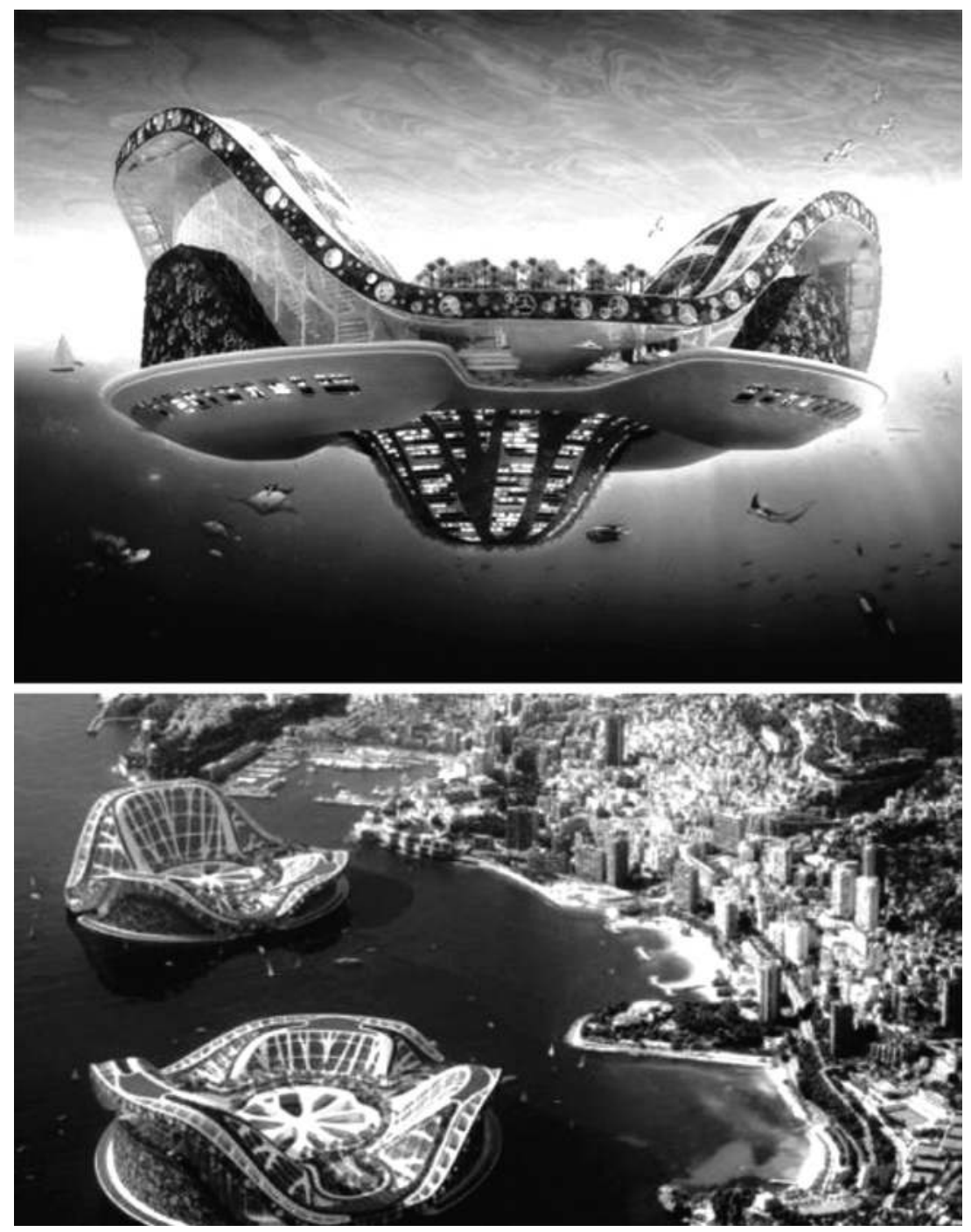

Figure 3.13 Lilypad Floating Ecopolis

time for a great acceleration of urban sprawl and functional separation. In addition, "a heightened demand for security has promoted restricted access to increasingly larger urban spaces, which are only open to certain people during certain times of the day or night. Circulation within the city increasingly means traveling along main transportation axis, and turning off only for the purpose of entering gated or enclosed sectors" (Christiaanse, 2007, p. 13). Because access to services and access to the city are closely linked with physical structures, this physical separation in the urban fabric has 


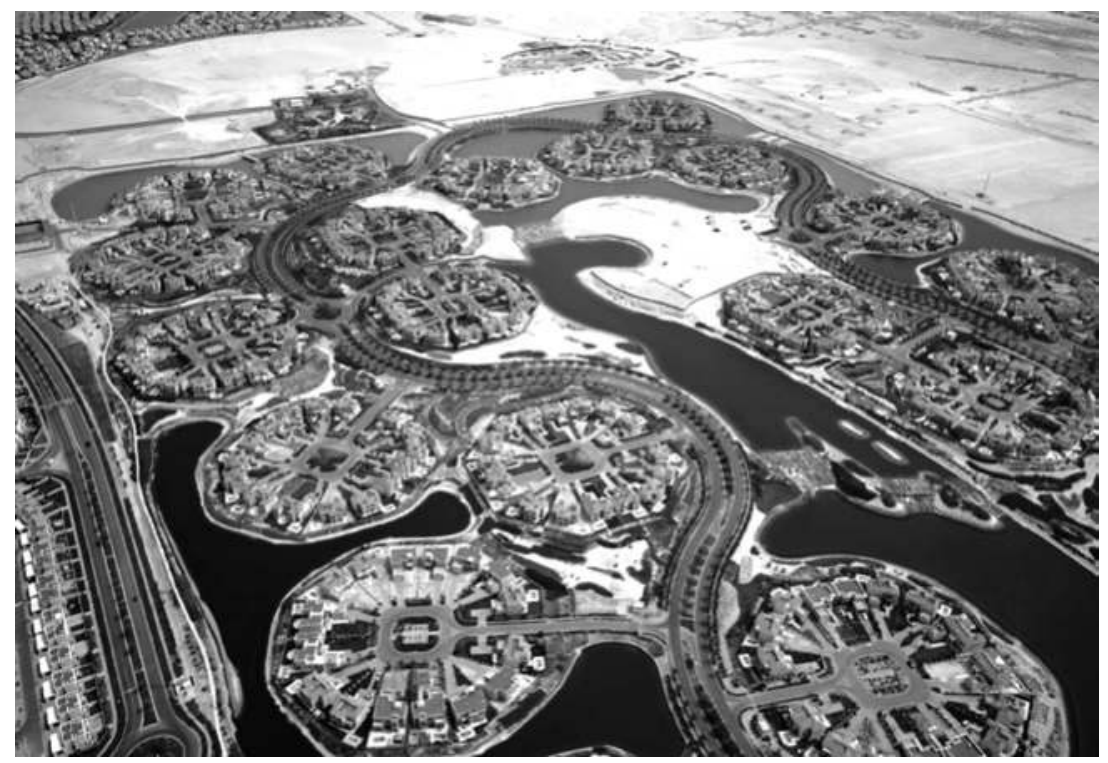

Figure 3.14 Masdar City.

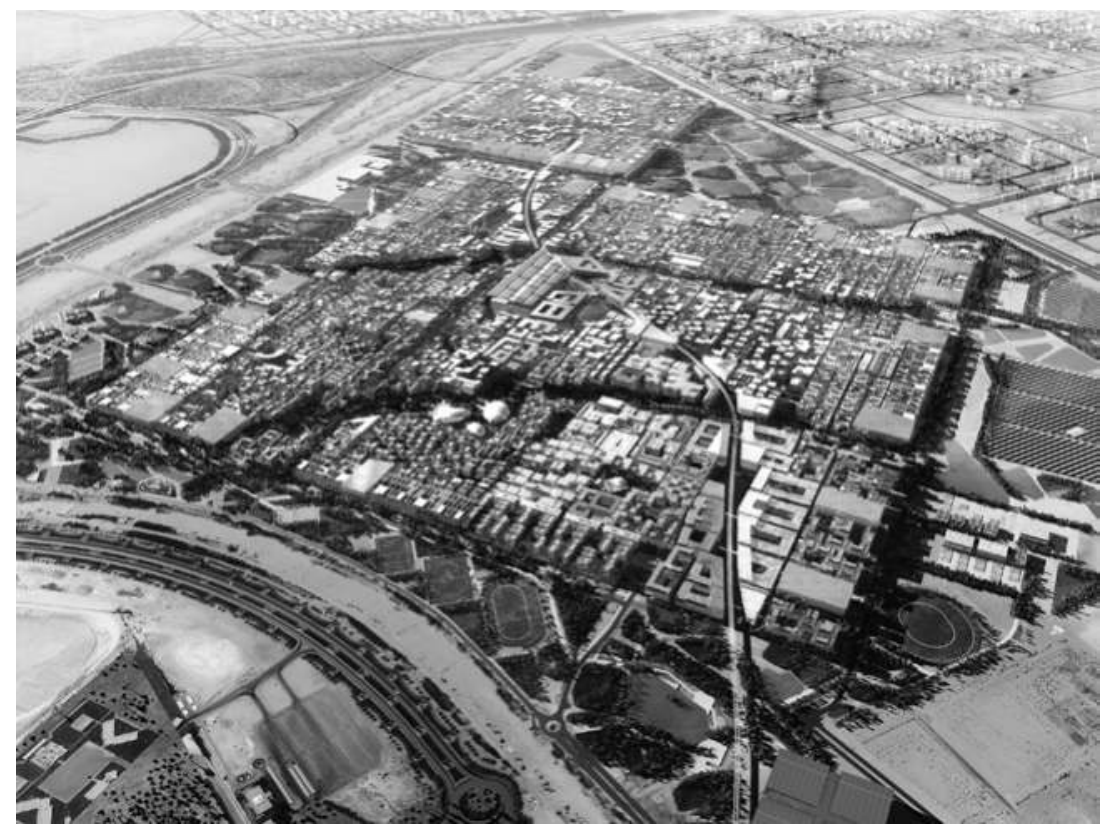

Figure 3.15 Masdar City. 


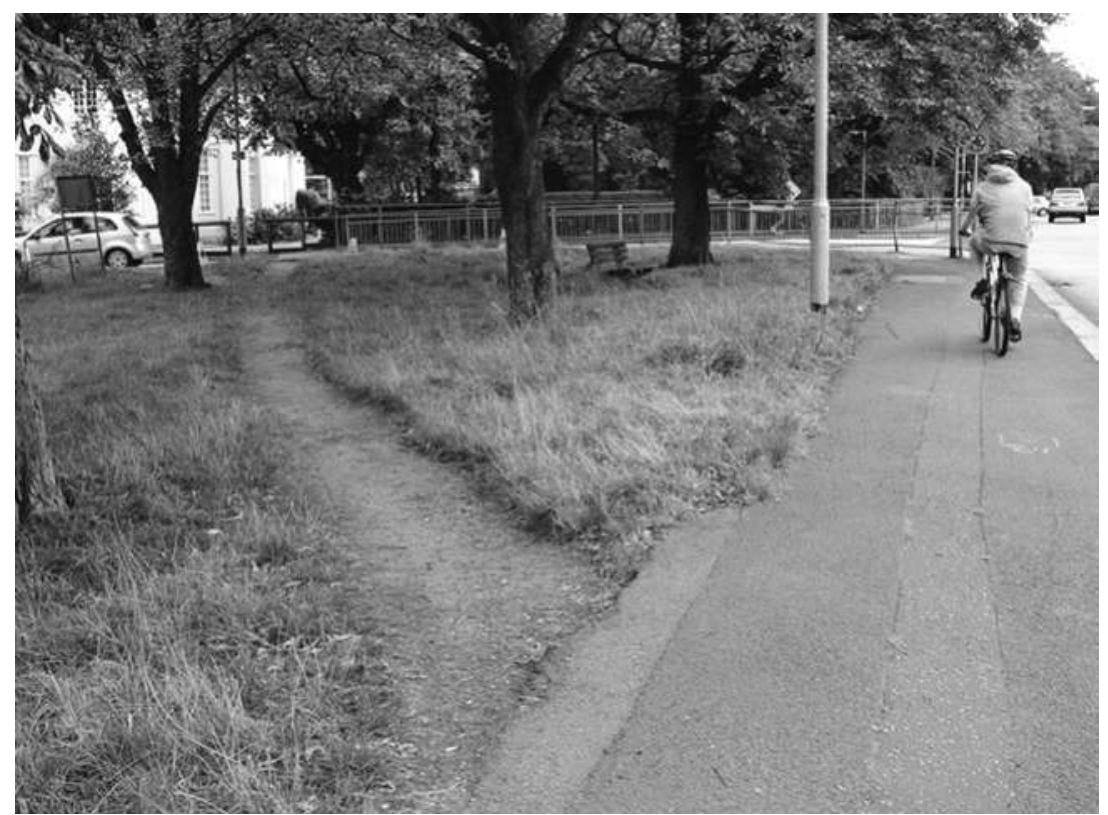

Figure 3.16 Short-cut path.

contributed to the segregation and differentiation of socioeconomic groups in urban areas. "Cities are no longer the spatial backdrop against which social inequalities may unfold, today the built environment itself is a means to determine inequality" (Esen, 2009, p. 20). At the same time, the role of public space as a place of social interaction has changed radically. People in the streets are almost exclusively of one kind: consumers (Christiaanse, 2007). We could say that cities have evolved from 'open' to 'closed', not just literally in the form of gated communities, campuses and shopping malls (that are divided by highways and other boundaries), but also in the form of social segregation and functional specialisation.

The leading consumption paradigm is one of the reasons behind this evolution. In many instances, marketing professionals have applied the logic of market segmentation to consumption patterns within the city (de Mello Franco, 2011). Factors such as social class, income and age, including sexual orientation, are often used to define the specialised character of new urban developments. The city becomes fragmented into specific marketing niches, which, in their intrinsic logic, group similar people and avoid the confrontation with different social values and models of behaviour while dissolving the common forms of coexistence (de Mello Franco, 2011, p. 186). 


\section{Katleen De Flander}

\section{CLOSING CYCLES-OPENING CITY}

I suggest that this transformation from 'open' to 'closed' cities went hand in hand with a transformation of the urban metabolism from 'circular' to 'linear'. In other words, resource flows evolved at the same time from 'closed' to 'open'2 (e.g. water, nutrients, food). It is particularly noteworthy that both transformations were facilitated by the availability of cheap energy and resources in a globalising world. This changed metabolism means that the urban populations have become completely disconnected from the externalities of urban consumption and thus from the biosphere's natural cycles. Many cities have lost their role in both primary and secondary resource production and live off their global hinterlands. This has in turn a considerable negative influence on urban resilience (e.g. resource provision), which is becoming increasingly important with global climate change.

\section{(Re-)production of Space}

Several urban environmental strategies are now advocating a return to a circular metabolism (e.g. WFC, 2014). However, many pay inadequate attention to the role of urban space. This chapter suggests that to come to an effective transition of our extended urban systems (i.e. to tackle global climate change), a transition of urban resource flows (going back from 'open' to 'closed') will need to go hand in hand with a transition in urban space governance (going back from 'closed' to 'open'). In other words, a paradigm shift regarding resource flows will also demand an appropriate '(re-)production of urban space' (Lefebvre, 1991).

Lefebvre (1991) criticised Soviet urban planners for failing to produce a socialist space, having just reproduced the modernist model of urban design and applied it onto that context. Could the same be said from current environmental strategies and eco-cities? Are they failing to produce an appropriate urban space to a new paradigm concerning urban resource flows? Are they fostering 'tree'-structures or 'closed' cities while they intend to tackle environmental problems?

The reason why both 'resource flows' and 'spatial' transitions should go hand in hand is the intrinsic link between the urban systems we have developed to handle transport, waste disposal, building, heating and cooling, food provision (Sassen, 2010) and the way we organise, use and move in urban space. Take, for instance, the fact that currently over $65-70 \%$ of public space in many cities is reserved exclusively for car infrastructure (Rueda, 2007). This exceptional spatial dominance of the car has a large impact on urban mobility and therefore on urban resource consumption (not only in terms of energy but also in terms of materials and embodied resources). Allocating urban space for automobile use precludes using urban space for other purposes, such as the production of resources, water treatment, and so on. Another example is the urban water system, which evolved from an 
integrated system on various city scales (water was supplied and treated on a local level, rainwater was collected and stored, drainage was part of the street and alley design and there was a close link to agriculture) to a centralised, invisible 'big pipes' system where several scales have been erased. The urbanites became completely disconnected from the biospheric water cycle because it has physically been reduced to the opening of a tap.

\section{(Re-)appropriation of Resources}

Urban contexts in need of solutions have produced alternative streams of action that could trace another path to act on climate change and urban resource flows. Although focusing mainly on urban space and infrastructure development, schemes such as participatory budgeting enjoy a certain acceptance on multiple levels of the political sphere. Could this scheme of participation also work on a broader level, integrating the biospheric water cycle in the urban political discussions? Water, for instance, is being re-appropriated by communities in poverty belts around many cities. In Medellin (Colombia), the 'right to water' features as a continuous conflict between the service provider and the inhabitants of some sectors of the city, who are re-claiming water as a natural resource rather than a commodity service provided by the state (Lopez, 2014). In this particular process, several ideas spark as people seem to finally understand where the water comes from, how to handle it and how to preserve and protect its sources. Contrary to megaprojects bringing entire watersheds into dams, small communal water reservoirs and micro-distribution systems seem to have found a way to re-appropriate water into the physical realm of the urbanites; often of course led by necessity. Could we similarly argue for the 'right to energy', allowing communities to engage in re-appropriation processes for understanding, managing and producing electricity?

\section{CONCLUSIONS}

This chapter places the urban climate challenge within a wider context of urban resource flows, exploring the idea that the current ruptures in the biosphere's cycles are caused by the urban systems we have created. This brings us to the task of restoring these ruptures, for which we will need to go beyond mitigation and adaptation strategies to urban system transformations centred on resources. I argued that changing urban systems should start from within the existing cities, trusting the transformative potential of the city and taking the citizens along in the process. Furthermore, an urban transition that is based on a paradigm change regarding urban resource flows (from 'open' to 'closed') will need to go hand in hand with an appropriate (re-)production of urban space (from 'closed' to 'open'). Failing to do 
so will lead to a further fostering of tree-like structures, which 'de-urbanise' the city.

Thus, finding a balance between the four interdependent parameters, this chapter started with (resource production, resource consumption, scale of the (closed) resource cycle area, and population density), should not be taken as a rigorous goal but as a guiding principle for a long-term transformation of a complex adaptive system (the city); one that leads towards different urban systems, a change in urban lifestyles and consumption behaviour and a recognition of a considerable urban productivity potential once the possibility of a re-production of urban space is taken seriously. Only an integrated urban strategy, which manages to tackle multiple environmental and social threats and stressors together in an ongoing and incomplete process, can support the complexity of a semi-lattice and will avoid tree-like structures.

The 'where' and 'how' these transformations can be initiated within cities opens a new research field that goes beyond most current urban environmental methodologies. Because models have proven not to work, we should turn to more experimental and reflexive approaches, which will demand transdisciplinarity at its process basis. The Closed Cycles-Open City cannot be designed, it has to be produced via an ongoing process of intraventions, triggering learning in real time how to optimise and reapply the learning. This is a very different process to planning. Intraventions, therefore, are attempts to transform the system from within, as opposed to interventions, which attempt to influence a system from outside (in ' $t$ Veld, 2011). Incremental demonstration through project-specific planning, and the learning that stakeholders derive from innovation at the project scale, provide us an important technique in urban strategy practice, because the focus is more on aligning interests and inventing new practices in pursuit of policy objectives. Lessons from successful project-scale interventions can then be used to determine how policy, regulatory and institutional contexts can be changed to support the scaling of new forms of development (Brugmann, 2009).

The introduction of the 'superblocks' in Barcelona, a new urban unit joining several existing urban blocks, is an example of re-thinking urban space together with re-organising resource flows starting in specific pressure points in the city. These units do not just change the local mobility system by blocking all pass-through car traffic, but they also push new learning: how to rethink the way people use and move in public space and become citizens again (and not just consumers), how to rethink resource flows and make these units more self-sufficient, how to re-activate urban space?

Another example to learn from is the ZEIS tool (Special Zones of Social Interest), which originally appeared since the 1980s in Recife, Brazil. ZEIS are demarcated areas in the territory of a city consisting of low-income housing settlements (arising spontaneously, existing, consolidated or proposed by the government), which are given the possibility of upgrading and land tenure regularisation. This tool eased the urbanisation process (led by 
the massive rural migration to cities), which would have been a catastrophe if those cities were following the conventional planning legislation, and activated participatory processes to improve urban space. Could such a tool be used for demarking areas in the city to start closing resource cycles, sparking local organisation and a re-appropriation of resources to the citizens while empowering public space?

We may find answers on 'how to close resource cycles' while studying cases of struggle for resources. The closing of a resource cycle is not a process that should be in the hands of a private service provider, neither by top-down city management structures, 'owning' the resources. The transgression of this status quo (service provider owning the resource, urban segregation, etc.) relies on further research focusing on local social movements and successful cases of resource appropriation, which could inform new organisational processes and dynamics to urban climate and resource governance.

\section{ACKNOWLEDGEMENTS}

With special thanks to Juan Pablo Ayala Cortés for the many inspiring discussions.

\section{NOTES}

1. The Dongtan Eco-City project has not been executed as planned by ARUP.

2. I do not want to claim that cities were $100 \%$ self-sufficient in the past but they had a much stronger connection with the natural resource cycles and had a much stronger component of primary and secondary resource production.

\section{BIBLIOGRAPHY}

Alexander, C. (1965) A City Is not a Tree. Architectural Forum 122 (1), 58-62 and (52), 58-62.

Batty, M. (2008) The Size, Scale ad Shape of Cities. Science 319, 769-771.

Brenner, N. (2013) Thesis on Urbanization. Public Culture 25, 85-114.

Brugmann, J. (2009) Welcome to the Urban Revolution: How Cities Are Changing the World. Toronto: Penguin Group (Canada).

Christiaanse, K. (2007) From Trees to Networks. Summary of keynote speach at the Second Holcim Forum "Urban_Trans_Formation”. Retrieved 9 September 2012 from http://www.holcimfoundation.org/T429/F07SPCHRISTIAANSE.htm.

de Mello Franco, F. (2011) Living on the Edge, in: Burdett, R. and Sudjic, D. (Eds.), Living in the Endless City. London: Phaidon Press, 182-187.

Eidlin, E. (2010) What Density Doesn't Tell Us About Sprawl. ACCESS: The Magazine of UCTC, 2-9.

Esen, O. (2009) Producing Inequalities by Producing Built Environment, in: Rieniets, T., Sigler, J. and Christiaanse, K. (Eds.), Open City: Designing Coexistence. Amsterdam: SUN, 175-186. 
Fanning, A. (2012) Economics, Growth and Energy in the Green Economy. Human Dimensions, 45-50.

Guadalupe, C. (2013) The Incomplete City Strikes Back. Interview with Saskia Sassen. DAMN'39 Magazine, 64-68.

Haughton, H. (1997) Developing Sustainable Urban Development Models. Cities $14,189-195$.

Hélie, M. (2008) Scale-Free Urban Systems. Emergent Urbanism-Rediscovering Urban Complexity. Retrieved 14 November 2012 from http://emergenturbanism. com/2008/04/28/scale-free-urban-systems.

Hodson, M. and Marvin, S. (2009) 'Urban Ecological Security': A New Urban Paradigm? International Journal of Urban and Regional Research 33, 193-215.

Hodson, M. and Marvin, S. (2010) Urbanism in the Anthropocene. Ecological Urbanism or Premium Ecological Enclaves? City 14, 299-313.

in 't Veld, R. (2011) Transgovernance-The Quest for Governance of Sustainable Development, Project Report: Science for Sustainable TRANSformations: Towards Effective GOVernance. Institute for Advanced Sustainability Studies (IASS), Potsdam.

Jacobs, J. (1992) The Death and Life of Great American Cities. New York: Vintage Books.

Lefebvre, H. (1991) The Production of Space. Oxford: Blackwell.

Loorbach, D. (2010) Transition Management for Sustainable Development: A Prescriptive, Complexity-Based Governance Framework. Governance 23, 161-183.

Lopez, M. (2014) Out of the Network, Out of the Game: Reclaiming Citizenship Through Access to Water in Medellín. Paper presented at the international conference "Putting Public in Public Services: Research, Action and Equity in the Global South." Cape Town, South Africa, 13-16 April.

McGranahan, G. (2005) Managing the Future City, in: Keiner, M., Koll-Schretzenmayr, M. and Schmid, W. (Eds.), Managing Urban Futures-Sustainability and Urban Growth in Developing Countries. Hampshire: Ashgate Publishing, xiii-xiv.

Revi, A., Satterthwaite, D. E., Aragón-Durand, F., Corfee-Morlot, J., Kiunsi, R.B.R., Pelling, M., Roberts, D.C. and Solecki, W. (2014) Urban Areas, in: Climate Change 2014: Impacts, Adaptation, and Vulnerability. Part A: Global and Sectoral Aspects. Contribution of Working Group II to the Fifth Assessment Report of the Intergovernmental Panel on Climate Change [Field, C.B., V.R. Barros, D. J. Dokken, K. J. Mach, M.D. Mastrandrea, T.E. Bilir, M. Chatterjee, K. L. Ebi, Y. O. Estrada, R. C. Genova, B. Girma, E. S. Kissel, A. N. Levy, S. MacCracken, P.R. Mastrandrea and L.L. White (eds.). Cambridge and New York: Cambridge University Press, 535-612.

Rovers, R. (2013) Urban and Building Dynamics: A 3D (Exergy) Approach Required, COST ELCAS Conference: Exergy, LCA and Sustainability. Nisyros, Greece, 7-9 July.

Rueda, S. (2007) Barcelona, a Compact and Complex Mediterranean City. A More Sustainable Vision for the Future. Barcelona City Council, Barcelona.

Sanders, I. (2008) Complex Systems Thinking and New Urbanism, in: Haas, T. (Ed.), New Urbanism and Beyond: Designing Cities for the Future. New York: Rizzoli, 275-279.

Sassen, S. (2009) Bridging the Ecologies of Cities and of Nature, The Fourth International Conference of the International Forum on Urbansim (IFoU). Amsterdam/ Delft, 26-28 November, 45-52.

Sassen, S. (2010) Cities Are the Center of Our Environmental Future. Surveys and Perspectives Integrating Environment and Society 2, 1-8.

Sassen, S. and Dotan, N. (2011) Delegating, not Returning, to the Biosphere: How to Use the Multi-scalar and Ecological Properties of Cities. Global Environmental Change 21, 823-834. 
Steel, C. (2009) Hungry City. How Food Shapes Our Lives. London: Vintage.

Taleb, N. (2012) Antifragile: Things That Gain from Disorder. New York: Random House.

United Nations Environment Programme (UNEP) (2013) City-Level Decoupling: Urban Resource Flows and the Governance of Infrastructure Transitions. A Report of the Working Group on Cities of the International Resource Panel. Swilling, M., Robinson, B., Marvin, S. and Hodson M. Nairobi.

World Future Council (2014) Regenerative Urban Development: A Roadmap to the City We Need. Hamburg.

Wilbanks, T.J. and Kates, R.W. (2010) Beyond Adapting to Climate Change: Embedding Adaptation in Responses to Multiple Threats and Stresses. Annals of the Association of American Geographers 100, 719-728. 
$\Longrightarrow$ Taylor \& Francis

Taylor \& Francis Group

http://taylorandfrancis.com 


\section{Part II}

\section{Going Global?}

The Changing Face of Urban Climate Governance 
$\Longrightarrow$ Taylor \& Francis

Taylor \& Francis Group

http://taylorandfrancis.com 


\title{
4 If Cities Are the Solution, What Are the Problems?
}

\author{
The Promise and Perils of \\ Urban Climate Leadership
}

\author{
David Gordon and Michele Acuto
}

\section{INTRODUCTION}

Global climate governance is at something of a crossroads. As states continue to toil away within the confines of the UN, engaging in negotiations towards a successor to the Kyoto Protocol, a constellation of governance 'experiments' (Hoffmann 2011; Bulkeley et al. 2014; Bulkeley \& Castan Broto 2012) has garnered the attention of practitioners and scholars alike. These novel governance initiatives both respond, and contribute, to the broader fragmentation of climate governance that has been observed in the literature (Biermann et al. 2009). The extent to which these experiments, as they co-evolve with the inter-state process, can generate progress or effective governance responses remains an open one. However, the general mood amongst practitioners and in the popular press is one of optimism and opportunity. This is especially apparent with respect to cities, such that our current epoch has been dubbed the "century of the city" (Pierce et al. 2009), and it has been suggested that "if only mayors ruled the world" a more effective, collective governance would be possible (Barber 2013: 3).

The promise of cities addressing international challenges echoes now broadly across a few global governance domains, and global environmental governance is where the 'urban age' (Burdett \& Sudjic 2008) has perhaps made the greatest impact. This is not, however, a top-down imposition nor a feat of popular culture: cities themselves, mostly through their highest officials (mayors in primis) have been progressively embracing that "sense of great responsibility" and "immense possibility" of cities as global actors in an urban century that former New York mayor Michael Bloomberg ascribed to all cities seeking to tackle climate change. ${ }^{1}$

This promise is multifaceted. Cities, after all, occupy interesting positions in the structural scaffolding of world politics. They are situated at the intersection of global pathways of people, ideas, and capital and while they certainly compete for the accumulation of these, they also operate with important degrees of autonomy from the constraints of sovereignty that both empower and enfeeble states (Bouteligier 2013). As global governors, cities thus offer interesting possibilities and potential. They face functional 
imperatives to respond to issues like climate change that manifest and are produced within city boundaries. They are empowered by the ability to meld global and local dimensions of climate governance (Betsill 2001; Aylett 2011). And they are able to slip the bonds of the collective action problem by creating, and participating in, novel forms of networked governance that span local, regional, and national borders.

We are now witnessing a proliferation of such networks of cities and local governments across a wide range of topical and geographical domains, from long-lived lobbying groups for peacebuilding and nonproliferation like Mayors for Peace, to national and regional associations like ALGA in Australia, or CITYNET and Eurocities in East Asia and Europe, respectively, to a suite of specific engagements on the variety of environmental challenges now confronting global governance. With respect to climate governance, however, the engagement of cities from the early 1990s and through the first decade of the 2000s was largely piecemeal and partial (Betsill \& Bulkeley 2013). The symbolic nature of city efforts at climate governance is most evident in the gap between rhetorical commitment and practical implementation, and the distance between publicly announced targets and actual governance performance. This 'first wave' of city-networks (Bulkeley 2010), which can be traced as far back as the 1980s, has been critical in raising the profile of cities in environmental governance, but has also had limited impact on the shape and direction of climate governance more in general.

In recent years a 'second wave' of cities have actively worked to reposition themselves in relation to the global climate regime in an attempt to establish themselves as autonomous climate governors capable of transforming nominal commitments into practical action with meaningful and timely aggregate effects (Betsill \& Bulkeley 2013). The archetypal illustration of this evolution is the C40 Climate Leadership Group, a global network of 67 cities created in 2005 . The C40 is explicitly oriented towards positioning cities as key actors in the global governance of climate change, and has in recent years undertaken an explicit agenda aimed at augmenting the governance capacity of the network so as to generate transformative change amongst its members and in the broader universe of cities. To the tune of "nations talk, cities act", a mantra repeatedly cited in the variety of summits and workshops organized by the C40, cities in this group have been pushing a slightly different, but potentially more profitable, model of city networking. The C40 has been explicit in its representativeness (of major 'global' cities capable of moving substantial public attention and financial support) and in its hybrid (i.e. public-private) operating principle, linking and even merging with private actors that are critical to its implementation capacity.

As this evolving body of city-led global action on international challenges has progressively developed, the scholarly literature in international relations and world politics, with the exception of some pioneers in environmental studies and some rare cases in IR (Bulkeley \& Betsill 2003; Bulkeley \& Schroeder 2012; Acuto 2013a, b; Bouteligier 2013), has conspicuously 
lagged behind in terms of recognizing the centrality of the 'urban age' (but see Brutsch 2013). The ways in which cities have done so have not yet been subject to systematic analytic attention in the literature; nor has the scholarship been able to develop a clear understanding of the ways that this phenomenon might impact the potential for cities (both inside and outside of formal governance networks) to effectively reduce carbon footprints and increase local resilience. This chapter, then, aims to provide some first-cut thoughts with respect to assessing both the promise embodied in this evolution of city, and city-network, efforts at global climate governance as well as the perils that might result from the effort to establish cities as legitimate and authoritative global climate governors.

With a focus on the $\mathrm{C} 40$ as an illustrative case, this chapter explores the internal and external dynamics that drive second-wave city-networks to increase their legitimacy, and specifies three distinct strategies-discursive, tactical, and organizational-adopted by the C40 to ground claims to authority and augment internal governance capacity. The chapter then assesses the implications and interactions of each of these approaches, and the ways in which they both enable the C40 and its member cities to adopt more fully the mantle of global climate governor and carry with them potentially negative effects such as collapsing innovation and experimentation, and potentially limiting the transformative capacity of cities. Cities are neither all promise nor all peril. As we argue in this chapter, the challenge moving forward, for scholars and practitioners alike, is to develop and apply appropriate tools to more systematically understand the ways in which these impacts operate, manifest, while not simply accepting, but rather critically assessing, the potential implications of the contemporary urbanization of global environmental governance.

\section{CITIES, CITY-NETWORKS AND CLIMATE GOVERNANCE}

Cities entered the global arena of climate governance in the early 1990s, and in some sense the ascendance of cities in this issue area has run hand-inhand with the evolution of inter-state efforts within the confines of the UN. As noted above, Bulkeley's distinction between first and second waves of city climate governance provides a useful starting point for discussion. The 'first wave' of city climate governance began in the early 1990s (Bulkeley 2010) and was oriented primarily towards symbolic engagement spurred on by the creation of the UNFCCC in 1992 and the formalization of efforts to develop a joint response to climate change. Cities engaged beyond their borders through participation in transnational city-networks, the primary exemplar of which is ICLEI's Cities for Climate Protection (CCP). ${ }^{2}$ Networks like ICLEI approached the task of collective participation in global climate governance by keeping city-commitments minimal and allowing considerable discretion to member cities. The result is that such networks 
are understood to have suffered from a stark division between small sets of pioneering cities engaged actively in local climate governance and large groups of cities who fail to translate nominal commitments into meaningful and ongoing practical action (Bulkeley \& Betsill 2003, Gore 2010; Bulkeley \& Kern 2009; Holgate 2007; Hakelberg 2014). They remain, in general, constrained by relatively limited entrepreneurial cores with looser networked connections with a wider populace of 'members' with varying but generally limited organizational commitment (Bouteligier 2013; Lee \& Van de Meene 2012).

Early scholarship on cities, city-networks, and climate governance focused to a large extent on understanding and theorizing those factors contributing to the decision of cities to put climate change on the local agenda (Kousky \& Schneider 2003; Bulkeley \& Betsill 2003; Betsill 2001), participate in city-networks (Zahran et al. 2008), and maintain ongoing commitment (Bulkeley \& Betsill 2003). Insights generated with respect to the impact of the 'network' focused on the ways in which it, as an independent actor, could utilize knowledge products, provision of resources, and epistemic resources to exert influence vis-à-vis member cities (Selin \& VanDeveer 2007; Andonova et al. 2009). This work was deeply linked to the formal structure of early city-networks like the CCP, which were configured as hub-and-spoke networks whereby the primary mode of interaction is between the city and the network-as-actor (Kahler 2009). Such networks comprised mostly mid-sized cities located in Western Europe, Australia, and North America who were leaders in local sustainability and joined such networks as a means of gaining legitimacy for actions already underway or undertaken, gaining access to additional/novel sources of financial aid or assistance, and enhancing authority claims of local policy champions (Bulkeley \& Betsill 2003; Betsill \& Bulkeley 2004). Little was implemented or networked with explicit focus on the so-called Global South (Parnell \& Robinson 2012; Bouteligier 2013). The networks to which cities belonged were mostly concerned with leveraging the legitimacy of pioneering cities to encourage other cities to join, and put climate change on the local agenda, and as such they pursued a broad/shallow strategy vis-à-vis city membership that focused on securing as many members as possible, with the hope that deeper engagement would follow over time.

Emerging in response to the rather novel phenomenon of city engagement in the traditionally state-bound realm of global governance, both early efforts by practitioners and scholars remained bound rather tightly within the status quo of deference to the state and the dominant frames of 'foreign policy' action (Hobbs 1994; Fry 1990). The role of city-networks like ICLEI/CCP was primarily understood in the manner of international institutions or regimes in the IR literature, whereby the network offered a means of influencing other actors through advocacy, symbolic engagement, or normative claims (Keck \& Sikkink 1998). 
This traditional understanding of city-networks as either purely city-based initiatives, creatures of wider institutions like the UN or the World Bank or 'paradiplomatic' actors (Hocking 1993) has had the tendency to place city-networks in a subjugated or secondary position. In this sense, networks like the $\mathrm{C} 40$ might be a rather blatant case of reaction to this somewhat dismissive approach, and might be able to prompt more in-depth engagement with the multiscalar complexity of the role of cities in global governance (Amen et al. 2011; Curtis 2011). To this extent, the C40 can be best understood as a constitutive element of the 'second wave' of city-climate governance (Bulkeley \& Schroeder 2012: 252-253) that emerged around 2005 and is characterized by engagement of a more economically and geographically diverse set of cities alongside a shift towards city-led or mayor-driven city-networks (Bulkeley 2010, Betsill \& Bulkeley 2013; Hodson \& Marvin 2010).

The C40 originated in 2005 as an initiative spearheaded by Greater London Authority (GLA) Mayor Ken Livingston and Deputy Mayor Nicky Gavron, who convened a two-day meeting of 18 major cities from each of the G20 member countries to run in parallel with the 2005 G20 Summit in Gleneagles, Scotland. The initial objective of the network was to facilitate communication between these cities on the local policies and practices already being deployed to address issues related to climate change and sustainability, as a means of establishing the legitimacy of city engagement in climate governance and gaining voice within the state-centric UN process (Acuto 2013a). Initially dubbed in contradiction to states as the ' $\mathrm{C} 20$ ' initiative, the network quickly expanded. Membership was increased to 49 cities (on in invitation-only basis) by 2007, and as of writing now sits at 67. In order to augment the operational capacity of the network, a formal relationship was forged in 2006 between the (now-renamed) C40 and the Clinton Climate Initiative. ${ }^{3}$ The network has held regular summits in 2007 (New York), 2009 (Seoul), 2011 (Sao Paolo), and Johannesburg (2014) with a variety of member city-hosted and issue-specific workshops in between, ${ }^{4}$ and is led by a rotating Chair (who is the mayor of a member city) of which there have been four to date. ${ }^{5}$ Governance of the network has, since 2008, been overseen by a Steering Committee comprising 10 member cities that, until recently, met on an ad hoc basis and operated without formal rules or procedures. In December 2012 the C40 Steering Committee adopted specific terms of reference that commit them to meeting on a regular basis (four times/year), specific procedures regarding agenda-setting and decision-making, and a clear process for the regular transition/rotation of Steering Committee members. The C40, in 2013, updated the governance structure of the network with the creation of a Board of Directors comprising the C40 Chair, city-representatives, and appointees from major funding providers and partner organizations. ${ }^{6}$

City-networks such as the C40 represent an interesting and potentially important transition in transnational city-networking. The C40, in addition 
to a membership structure that undercuts inter-state coordination impasses (major U.S., Chinese, Brazilian, Indian, Russian, South African, and Indonesian cities are all members) attempts to leverage the structural asymmetries of global urbanism by bringing together cities that are, for the most part, the 'spikes' in the global distribution of economic activity, innovation, and productivity. C40 member cities reside atop the global city hierarchy, accounting for 42 of the top 78 cities in the most recent Globalization and World Cities ranking (GaWC 2012) and 44 of the top 66 spots in a similar ranking exercise carried out by A.T. Kearney and Foreign Policy (A.T. Kearney 2012). The C40 brings together cities that account for $8 \%$ of global population, generate nearly $20 \%$ of global GDP, and produce over $10 \%$ of annual global GHG emissions (ARUP 2011: 13; see also World Bank 2010: 18). Given these figures, there is a case to be made that meaningful change driven by actions at the city level will invariably have to pass through this sub-set of urban centers around the world.

While the early years of the C40 in some sense mirror the first-wave network orientation towards encouraging and enabling cities to put climate change on the local agenda, the network has undergone a significant transformation since early 2010. Prior to this the C40 hedged between making claims for city inclusion in inter-state and national efforts and initiatives, and financial/jurisidictional support to do so more effectively (essentially fitting into the standard city-state dynamic whereby the former pleads "can I have some more, sir" to the latter). Following 2009, and the failure of the COP15 negotiations to craft a successor agreement to the Kyoto Protocol, the $\mathrm{C} 40$ shifted emphasis towards producing meaningful local/global effects through individual and collective action by member cities. This was also coupled with greater investment by private actors and the success of C40-like urban campaigning.

Furthermore, the C40 differs from earlier city-networks across a number of levels. First, it has been operating on the basis of closed and unlimited, rather than open and unlimited, membership. As Bouteligier (2013) notes, this has for long equated to an unspecified typology of 'members' mostly centered around 'global' or 'mega' cities progressively co-opted in the network by its core secretariat. This has allowed the $\mathrm{C} 40$ to maintain an attractive albeit exclusive membership that, only in 2011, was rendered explicit to the general public by developing an 'organizational strategy' to overcome the almost informal nature of the network as initially set by Livingstone. Presented at the November 2010 Hong Kong workshop, this strategy was the first step in Bloomberg's C40 chairmanship, who took over from Toronto's David Miller (2006-2010) just a month before that. This is what has informally become known as the 'Hong Kong Strategy' which was devised to strengthen the Group's "organizational capacity and its ability to work with other organizations" as well as ensure a more integrated support by the C40 secretariat, and make "the C40 a more visible and effective leader in urban sustainability." ${ }^{7}$ 
Fundamentally, the Strategy pushes in the direction of consolidation of membership categories, but does not specify criteria for membership accession or possibilities for enlargement. The exclusive membership of the C40, reserved to internationally recognizable 'mega' and 'innovator' cities (besides the global cities of the steering committee) is a highly attractive element of the Group's institutional organization for many cities aspiring to become 'leaders' on a global stage.

This structure has been mobilized by C40 following a 'two-track' process (Acuto 2013b) based on direct political advocacy, mostly in the shape of city diplomacy, alongside more technical implementation of the C40's effort to curb climate change via on-the-ground pilots and expertise sharing on matters like waste management and energy retrofit. Via its technical track, C40 aims to move beyond the symbolism of demonstration effects and actions to reduce emissions from city government operations to produce meaningful, city-wide and cross-city effects. While the jury might still be out on the effectiveness of this technical exchange, the C40's own reporting via two editions (2011 and 2014) of the group's Climate Action in Megacities, in collaboration with engineering consultancy ARUP, seems to have already attested some solid evidence. C40 is in this sense organized so as to encourage and emphasize peer-to-peer interaction and information-sharing, while still mobilizing a very effective PR machinery capable of attracting substantial attention from the international sphere of climate governance. As such, C40 attempts to engage in both autonomous climate governance as well as advocacy vis-à-vis state and inter-state actors, as we highlight below more extensively. ${ }^{8}$

These joint ARUP-C40 reports of 2011 and 2014 (colloquially referred to as CAM 1.0 and 2.0) testify not only the capacity by the group to promote and pool action in cities; they also illustrate the emphasis placed by the $\mathrm{C} 40$ on tracking and measuring and serve to signal both the refinement of network action and the importance of the network. This (growing, as we note below) focus on data and pooled capacity is also a measure of the group's capacity to link and capitalize its 'hybrid' connection with the private sector-another critical dimension of the 'second wave' of city-networks. The C40 has been successful in attracting large investments (potential and actual) of capital by linking with major international funders such as the World Bank Institute and Siemens as well as hybridizing the network with corporate support from organizations such as Bloomberg Philanthropies and the Clinton Climate Initiative.

In sum, then, the C40 has explicitly expressed its objective: to be the "world's leading, and most indispensable, climate change organization." In pursuit of this objective, the C40 has oriented itself towards gaining recognition as a key actor from other governance actors, and securing resources to assist cities in producing governance effects independent of or in parallel with the inter-state process. Addressing this challenge requires the $\mathrm{C} 40$ to find ways of (a) demonstrating its capacity to produce autonomous effects, and (b) legitimating its claims to authority as a global governor. However, 


\section{David Gordon and Michele Acuto}

as the subsequent section aims to address, grounding the claim that cities are authoritative and appropriate agents of global climate governance presents something of a challenge, especially given the hybrid positioning of cities in world politics, situated as they are with one foot firmly planted in the Westphalian world of state sovereignty (and jurisdictional subordination) while the other searches for stable footing in the ephemeral and emergent world of transnational governance (Sassen 2006, Ruggie 1993, 2004).

\section{STRATEGIES OF LEGITIMATION: DISCURSIVE, TACTICAL, ORGANIZATIONAL}

In order to develop a recognized and effective positioning across the intricate edifice of global environmental governance the $\mathrm{C} 40$ has, especially since its expansion into a fully fledged network, deployed a multifaceted practice of legitimation. We would argue that this has been underwritten by three key strategies to sustain claims to authority and augment the governance capacity of the network:

- Discursive strategy aimed at repositioning cities as 'leaders' and as central points through which both the causes and solutions to climate change must pass;

- Tactical strategy aimed at supplementing the authority gaps that cities must confront by forging partnerships with a variety of actors in order to leverage their epistemic and financial sources of authority;

- Organizational strategy focused on reconfiguring the 'network' so as to increase coercive capacity and ability to close the rhetoric/action gap and drive peer-to-peer flows of information, practices, and policies.

Each of these, in isolation, offers the $\mathrm{C} 40$ a means of responding to the legitimation and governance imperatives in ways that will be reviewed below. The manner in which they interact, and their likely consequences at local, network, and global scales, will be discussed in the section that follows.

\section{Discursive Strategy}

The first element of C40 efforts to legitimate claims with respect to the authority of cities as global climate governors operates through explicit discursive strategy. This, in actuality, has been a central component of the C40 approach since its origins in 2005 wherein the C40 sought to establish cities as both major sources of GHG emissions as well as key actors in the global response (C40 2005).

These two components were central components of the bulk of C40 public statements during the early years of the network. At the second C40 Summit, held in New York in May 2007, the public communiqué issued 
by the network took note that "[c]ities account for $75 \%$ of global carbon emissions," and as such, "the fight against climate change will therefore be won or lost in cities" (C40 2007). This, or some variation of this statement, is included in virtually all public statements or speeches made by C40 representatives (ARUP 2011, 2014; C40 2009, 2011, 2014) and is best understood as a means of positioning the network as essential to any meaningful global the response to climate change. ${ }^{10}$

This discursive strategy was supplemented in 2009 by adoption of a second discursive track organized around the notion that "cities act while nations talk." This strategy, adopted in the lead-up to the 2009 COP15 negotiations in Copenhagen, Denmark, aimed to establish a disjuncture between the governance capacities of these two types of actors and took two central forms. Discursive statements aimed to establish cities as pragmatic and apolitical actors, as opposed to the politicism and partisanship of state actors involved in inter-state climate politics. Organized around the functional imperative of city-level governance and the need to provide basic services (a common meme delivered at C40 meetings by U.S. city representatives is the notion that "there is no Republican or Democratic way to pick up the garbage") and the proximity of city leaders to voting publics. ${ }^{11}$ In addition, network discourse further aimed to define cities as governors on the basis of their practical capacity for innovation and experimentation, and highlighted the fact that they empowered by formal powers and levers of jurisdictional authority. Lastly, this discursive strategy draws out the notion that the $\mathrm{C} 40$ has the capacity to combine coordinated action and aggregate impact with responsiveness to local context and specificity.

This discursive emphasis on the 'action' orientation of cities-they have an inescapable imperative to act, a legal-operational capacity to act, and a history of practical action-has, especially in the aftermath of COP15 and the failed attempt to pass domestic climate legislation in the U.S., had a major implication. The network must find ways to substantiate such claims, to 'prove' in other words that cities do in fact 'act' in ways that distinguish them from other levels of governance. The primary response has been, as noted above, the joint C40-ARUP effort to document and communicate the extent and nature of climate governance actions undertaken by member cities. The first report, issued in 2011, made much out of the claim that "over 4000 actions" were undertaken by C40 cities between 2005 and 2010. The second report, recently released in February 2014, was utilized to underscore that not only are cities acting, but by documenting an increase in actions by member cities, helped to underscore the notion that cities are stepping into the governance void and taking on the mantle of leadership.

\section{Tactical Strategy}

The second dimension of the effort to legitimate C40 claims with respect to legitimacy and authority as a global climate governor takes the form of 
governance relationships, which, to paraphrase Avant et al. (2010: 22-24) involve efforts by non-state actors to supplement, augment, or enhance governance capacity by drawing on the authority of other governance actors. Cities, whether in the C40 or not, are both enabled and constrained by their institutional position within sovereign states. On the positive side of the equation, cities are largely unbound by the constraints of state sovereignty, enabling them (for the most part) to interact and engage across borders outside of geopolitical or ideological considerations. Cities also possess substantial opportunities to link climate governance to other, pressing issues on the local agenda. However, while subject to variation from state to state, cities for the most part occupy subordinate or weak positions vis-àvis upper levels of government. This means that they generally lack both formal jurisdictional authority (although many nonetheless possess meaningful jurisdictional competencies) as well as fiscal autonomy. The latter is centrally important in that it constrains not only the practical capacity of city governments to engage in local governance initiatives, but also renders cities subject to the imperatives of urban development (as a major source of city revenue) and can manifest in limited bureaucratic capacity in the city government.

Recognizing these limitations, the $\mathrm{C} 40$ has consistently included as part of its public positioning demands for increased provision of revenues and resources from upper levels of government (C40 2005, C40 2009). In addition, however, the $\mathrm{C} 40$ has pursued a tactical strategy of operational partnerships with a variety of non-state actors in an attempt to augment the governance capacity of both the network and its member cities. This approach, which Roman (2010) characterizes as "governing from the middle," has been present since the C40 partnered up with the Clinton Climate Initiative in 2006. This partnership, organized around the premise that cities could use their collective purchasing power to both drive down the costs of, and create markets and demand for, novel technologies, ultimately failed to bear fruit as a function of the limitations of the CCI model in combination with the jurisdictional barriers to explicit coordination of city purchasing. However, the C40 since 2010 effectively reconfigured this approach and engaged a variety of non-nation state organizations in a variety of partnership agreements aimed more explicitly at (a) addressing epistemic limitations related to a lack of local knowledge, awareness, or technical capacity, (b) providing access to financial resources, (c) providing measurement and accountability tools to enhance leadership claims advanced to local, national, and international audiences, and (d) providing financial resources directly to the network.

The rationale for these various partnership agreements is in many cases to bring to the network different outside organizations that can enhance the capacity of the $\mathrm{C} 40$ to both bring about, demonstrate, and communicate meaningful governance effects. For example, the C40 announced in 
2011 a strategic partnership with the World Bank. The relationship was touted as offering C40 cities the potential for a direct access window to World Bank funds without having to rely on access through traditional country access points, a not unappealing possibility for city officials and politicians. For cities to qualify for World Bank funds, however, a higher degree of standardized measurement, accounting, and reporting of citywide emissions would be necessary, so as to allow for both funding triage and performance evaluation. This imperative was addressed by the C40 through a partnership with the World Resources Institute and ICLEI to develop a standardized approach to calculation, measurement, and tracking of local GHG emissions. In the future, this tool can provide a mechanism for funding partners like the World Bank to evaluate and grant funding requests. This relationship is interlinked with partnership agreements between the C40 and the Carbon Disclosure Project (CDP) and ARUP, both of which offer the C40 a means of identifying, packaging, and communicating the extent of member city governance, as well as the effects generated locally. A partnership between the C40 and Siemens, which manifested amongst other things in the creation of the City Climate Leadership Awards, offers an additional means of increasing the international visibility and political benefits of climate governance for local politicians in C40 cities. ${ }^{12}$ Lastly, recent partnerships between the C40 and Bloomberg Philanthropies, Realdania, and CIFF offer the C40 stable, predictable sources of funding to allow for the organizational restructuring that forms the third leg of the legitimation strategy discussed in the section to follow.

\section{TEXT BOX A: LIST OF MAJOR STRATEGIC PARTNERSHIPS ENGAGED BY THE C40 2006-PRESENT*:}

- Clinton Climate Initiative (CCI) (2006)

- ARUP (2010)

- World Bank (2011)

- World Resources Institute (WRI) (2011)

- ICLEI (2011)

- Carbon Disclosure Project (CDP) (2011)

- Bloomberg Philanthropies (2011)

- Siemens (2013)

- Children's Investment Fund Foundation (CIFF) (2013)

- Realdania (2013)

*Years in which partnerships were forged are given in parentheses. 


\section{Organizational Strategy}

The third and final leg of the C40 approach to legitimating claims to autonomous governance authority is of a more recent vintage than the other two, and involves the explicit and conscious effort to strengthen the organizational capacity of the network (Kahler 2009). Emerging alongside the ascendance of New York Mayor Michael Bloomberg to the position of C40 Chair in early 2010, this approach can be best understood as both a response to the limitations of the earlier organizational and operational approaches adopted by the C40 in partnership with the CCI as well as an effort to increase the capacity of the network to generate not collective action but rather collective effects. As recently as 2010, the C40 as a network-actor was extremely limited. The C40 had always, since inception, had a Secretariat, but this was limited to a staff of two embedded within the GLA City Hall. Since 2010 the C40 has gone from a network with no core to one in which there now exists considerable financial, epistemic, and logistical capacity. The C40 now has a staff of more than 40 , with plans to continue expanding in the near-term future.

Organizationally, the C40 has staff sections dedicated to Initiatives, Regions \& Events, Operations, Communications, and Research, Measurement \& Planning. Located across a variety of regions, and embedded in a number of different $\mathrm{C} 40$ cities, the organizational expansion has increased the capacity of the C40 to proactively engage member cities and offer meaningful resources, connections, and services. The staff expansion has both accompanied and enabled the increased specialization of topical or issue-oriented network initiatives, as C40 staff have been assigned to managing, coordinating, and servicing sub-networks related to Adaptation \& Water, Energy, Finance \& Economic Development, Transportation, Solid Waste, Measurement \& Planning, and Sustainable Communities. ${ }^{13}$ The C40 has undertaken this expansion with an eye to increasing the capacity of the network to drive member cities from nominal commitment to practical local action, and to generate meaningful collective governance effects. As such, the organizational expansion and reconfiguration has also included the creation of a dedicated intranet for member cities, increased capacity to facilitate city-city interactions (closed-door workshops, webinars, and site visits, for example), and an internal strategic review of jurisdictional affinities between member cities.

The organizational restructuring and strengthening has also taken place in terms of the governance mechanisms and structures within the C40. In 2011, the network updated and augmented membership standards and formalized internal governance rules and practices with respect to steering committee meetings, voting rules, and decision-making. The C40 then created a Board of Directors in 2013 to give funding partners oversight and influence with respect to network operations. In all of this, the C40 has undertaken to provide the network with a degree of autonomy and independence from 
member cities, on which it had, prior to 2011 , heavily relied. Through transparency provisions and codification of decision-rules and governance procedures the network has attempted to undertake organizational strengthening without losing the trust, legitimacy of its member cities.

\section{IMPACTS AND IMPLICATIONS: LEGITIMATION VERSUS HOMOGENIZATION}

Each of the three legitimation strategies discussed above is being pursued by the C40 as a means of grounding authority claims on the basis of augmenting, and communicating, the governance capacity of the network. While separated out analytically in the preceding section, these three strategies are in practice deeply interconnected. Adopting a discursive strategy of city leadership has offered the $\mathrm{C} 40$ a means of underpinning the claim that cities are essential to effective global climate governance. This discursive strategy has contributed to the widespread uptake of the idea that cities are 'natural' climate governors, and constitutes a source of normative pressure on member cities to conform to this role. Furthermore, the implication of a discursive strategy premised on the leadership and 'action' orientation of cities is that it creates the need to demonstrate and validate such claims. This constitutes a knock-on effect in the sense that the network must both augment the capacity to encourage or enable cities to in fact 'act' while developing the tools and resources required to identify, account for, and communicate that action to broader publics and partners with vested interests. Yet, while the goal of network reconfiguration has been to demonstrate and drive the 'network effect' on member cities and in terms of aggregate effects, the C40 to date is mostly constituted by pooled financial capacity and symbolism. Whether these can be translated into pooled agency on the ground and pooled scaling up beyond pilots remains an open question. It also draws attention to the potential impacts of the ongoing popularization (the ' $\mathrm{CNN}$ effect' some would say) of the C40, which put it under the spotlights, raising substantial expectations in terms of network performance and impact.

Given these high expectations, augmenting authority/legitimacy gaps through tactical use of partnerships can be effective as a means of gaining access to expertise, financial resources, and logistical capacity. It also may create demands on the kinds of action taken by cities, the expectations on member cities, and the accountability of cities (to one another or other non-nation state organizations or to local populations). It may also, by focusing on "governing from the middle" constrain or limit the substance of local climate governance in C40 cities (focusing on those issue areas that are most amenable to a public-private approach, or emphasizing modes of authority that rely on financial incentives, subsidization, or information-based change rather than use of command/control authority). In this vein, it should be noted that the $\mathrm{C} 40$ already exhibits considerable 
convergence around neoliberal governance ideas and practices in the network (market-logics, measurement, and disclosure) related to/resulting from the hybridization of the network with market actors.

Reconfiguring the network organization to increase staffing and financial capacity offers a means of better networking the network (actively linking cities together or facilitating joint action or information sharing-both positive and negative experiences-from which they can learn). It also provides the C40 with a degree of internal stability and predictability. However, it runs the risk of alienating member cities: large degree of control over the process was asserted by Bloomberg, updated membership standards were implemented with limited input from member cities, and the creation of a new Board of Directors presents a clear possibility that decision-making authority will shift from the Chair to the Board, over which Bloomberg now presides. The shift of the new Chair to the Global South is a good sign, but there is still substantial imbalance (not least in numbers and geographical spread) towards the Global North and a sustained New York-London dominance of the network. Bouteligier (2013) makes just this point in noting the internal power asymmetries that operate within the C40 between those cities that possess opportunities to exert influence and those that do not. In light of the catalytic expectations with respect to the ability of the C40 to drive governance in non-member cities, this raises further questions related to exclusion and homogenization. If the primary benefit of city-scale climate governance is the capacity to experiment, innovate, and implement novel approaches that are fitted to the specific demands and needs of local settings, the homogenization of climate governance across the network poses a serious danger.

Lastly, the imperative to generate and demonstrate the collective governance capacity of the C40 may ultimately backfire and lead to the fracturing of the network. Network governance, after all, is premised on voluntary participation and adherence by cities to expectations or network standards. Networks of all sorts must constantly negotiate the balance between network coherence and member-oriented flexibility, and the C40 is no exception in this regard (Thompson 2003).

\section{CONCLUSIONS}

The C40 has in some sense begun to acquire the recognition and legitimacy that it seeks. The presence of UNFCCC Secretary Figueres at the C40 Summit held in Johannesburg in February 2014, the appointment of Bloomberg as Special Representative to the Secretary General for Cities and Climate Change, the shift in the UNFCCC process to make some room for cities in the process and bring them in as means of illustrating the extent to which governance 'action' is actually being undertaken by cities, and the inclusion of the C40 in innovative climate governance proposals all indicate the extent to which cities, and the C40, are being taken seriously as global climate governors. 
However, cities as global climate governors face considerable hurdles if they are to contribute to meaningful global climate governance while continuing to respond to the practicalities and particularities of local conditions and context. In this chapter we have attempted to explore the ways in which cities are attempting to fulfill or actuate that promise, through a set of active discursive, tactical, and organizational strategies aimed at repositioning cities as key governance actors. We have also, however, tried to temper the breathless enthusiasm that sometimes accompanies claims of city-driven global governance.

Collective governance as undertaken by cities is facing a difficult challenge as it must balance between what Temenos \& McCann (2012: 1390) refer to as bespoke and prêt a porter solutions to problems that are both common and distinct. The C40 must thread a difficult needle between generating effective global governance while maintaining the flexibility essential to effective network governance. In some sense this brings both the analytic and practical discussions back to the challenge identified by scholars such as John Ruggie and Saskia Sassen, whereby the difficulty is to find the language, concepts, and perspectives to understand and assess the implications of an ongoing transition away from the state-centric world of yesteryear into a novel phase of global politics that is as yet inchoate and only partially discernible. The promise of cities lies in the possibility that they can bring into existence a mode of global governance characterized by a disconnection of the modernist bonds that exist between territory, authority, and rights. The peril, however, is twofold. On one hand, cities may be co-opted back into the status quo system of state-centric governance and attempt to either reproduce inter-state relations or be swallowed up by them. On the other, the structural imperative to legitimate claims to governance authority has the potential to crush the innovative, locally adaptive nature of city-network governance thus robbing them of their capacity for innovation and experimentation. Both represent important challenges for practical governance and opportunities for academic inquiry, and indeed the nexus between the two is where much important work is left to be done.

\section{NOTES}

1. For Mayor Michael Bloomberg's opening speech, C40 São Paulo Summit, 1 June 2011. Available at http://c40.org/blog_posts/video-c40-cities-summitopening-speeches-2011. Last accessed 28 October 2014.

2. See Keiner \& Kim 2007 for a sense of the broader landscape of city-networks.

3. The CCI Cities Initiative was created in 2006 for the explicit purpose of partnering with the C40. The CCI was, at this time, looking for avenues through which to engage in the global governance of climate change, and cities were deemed to offer a potent means of doing so (confidential interviews with C40 officials).

4. These include workshops on Transportation \& Congestion (London 2007); Airports (Los Angeles 2008); Adaptation (Tokyo 2008); Carbon Finance (Basel 2009, 2011); Waste (London 2010); Urban Efficiency (Berlin 2010); 
Delta Cities (Rotterdam 2010); Low-Carbon Cities (Hong Kong 2010); and Sustainable Development (Melbourne 2012).

5. GLA Mayor Livingstone: 2005-2008; Toronto Mayor David Miller: 2008-2010; New York Mayor Michael Bloomberg: 2010-2013; Rio Mayor Eduardo Paes: 2014-present.

6. Former Mayor of New York, and C40 Chair, Michael Bloomberg is now the President of the Board of Directors, which also has former C40 Executive Director Jay Carson. Other Board members are Shirley Rodrigues (CIFF), Jesper Nygard (Realdania), Matthew Pencharz (GLA), Aisa Tobing (Jakarta), and Bruce Lindsey (Clinton Foundation). Rit Aggarwala, special advisor to Mayor Bloomberg during his tenure as C40 Chair (and previously head of the Office of Long-Term Planning and Sustainability in New York, responsible for developing PlaNYC), has been retained as consultant. Source: http://www. prnewswire.com/news-releases/c40-announces-new-milestones-in-leadershipand-funding-236187111.html. Last accessed 28 October 2014.

7. The Strategy was sketched at the Hong Kong Summit (5-6 November 2010) and first illustrated publicly by Bloomberg in the address to the fourth biannual summit in São Paulo (31 May-2 June 2011).

8. C40 of course does both and increasingly seems to be looking for pathways to have a voice at COP22 in Paris, 2015.

9. Bloomberg's opening speech, C40 São Paulo Summit, 1 June 2011.

10. The exact percentage of emissions for which cities are responsible shifts across time in C40 statements, but remains within the range of 70 to $80 \%$. For a dissenting view on emissions generation or responsibility in cities see Dodman $\&$ Satterthwaite (2009).

11. The quote is originally attributed to New York City Mayor La Guardia, and was echoed by Bloomberg in his opening speech at the 2011 São Paulo Summit.

12. http://cityclimateleadershipawards.com/

13. There are currently 13 issue-specific sub-networks operational inside the C40 across these seven broad categories. These include, for example, networks on Bus Rapid Transit, Electric Vehicles, and Green Growth. For a full listing see: http://www.c40.org/networks

\section{BIBLIOGRAPHY}

Acuto, M. 2013a. The New Climate Leaders? Review of International Studies 39(4): $835-857$.

- 2013b. Global Cities, Governance, and Diplomacy: The Urban Link. London: Routledge.

Amen, M., N. J. Toly, P.L. McCarney, and K. Segbers, eds. 2011. Cities and Global Governance: New Sites for International Relations. Burlington, VT: Ashgate.

Andonova, L., M. Betsill, and H. Bulkeley. 2009. Transnational Climate Governance. Global Environmental Politics 9(2): 52-73.

ARUP. 2011. Climate Action in Megacities: C40 Cities Baseline and Opportunities. Available at: http://www.arup.com/Publications/Climate_Action_in_Megacities. aspx. Last accessed 28 October 2014.

. 2014. Climate Action in Megacities: C40 Cities Baseline and Opportunities Volume 2.0. Available at: http://issuu.com/c40cities/docs/c40_climate_action_in_ megacities. Last accessed 28 October 2014.

A.T. Kearney. 2012. 2012 Global Cities Index. Available at: http://www.atkearney. $\mathrm{com} / \mathrm{gbpc} / \mathrm{global}$-cities-index/full-report/-/asset_publisher/yAl1OgZpc1DO/ content/2012-global-cities-index/10192. Last accessed 28 October 2014. 
Avant, D., M. Finnemore, and S. Sell. 2010. Who Governs the Globe? Cambridge: Cambridge University Press.

Aylett, A. 2011. The Urban Governance of Climate Change: A Comparative Socio-Institutional Analysis of Transformative Urban Responses to Climate Change in Durban (South Africa) and Portland (OR, USA). Unpublished PhD Dissertation, University of British Columbia.

Barber, B. 2013. If Mayors Ruled the World: Dysfunctional Nations, Rising Cities. New Haven: Yale University Press.

Bernstein, S. 2001. The Compromise of Liberal Environmentalism. New York: Columbia University Press.

Betsill, M. 2001. Mitigating Climate Change in U.S. Cities: Opportunities and Obstacles. Local Environment 6: 393-406.

Betsill, M. and H. Bulkeley. 2004. Transnational Networks and Global Environmental Governance: The Cities for Climate Protection Program. International Studies Quarterly 48: 471-493.

. 2013. Revisiting the Urban Politics of Climate Change. Environmental Politics 22(1): 136-154.

Biermann, F., P. Pattberg, H. Van Asselt, and F. Zelli. 2009. The Fragmentation of Global Governance Architectures: A Framework for Analysis. Global Environmental Politics 9(4): 9-40.

Bloomberg, M. 2010. Keynote Address at C40 Climate Leadership Hong Kong Workshop, November 5 2010. Available at: http://on.nyc.gov/1jjRLFR. Last accessed 18 November 2013.

Bouteligier, S. 2013. Cities, Networks, and Global Environmental Governance. London: Routledge.

Brutsch, C.M. 2013. From Sovereign Prerogatives to Metropolitan Rule? The Anarchical Society in the Urban Age. International Studies Perspective 14: 307-324.

Bulkeley, H. 2010. Cities and the Governing of Climate Change. Annual Review of Environment and Resources 35: 229-253.

Bulkeley, H., L. Andonova, M. Betsill, D. Compagnon, T. Hale, M. Hoffmann, P. Newell, M. Paterson, C. Roger, and S. VanDeveer. 2014. Transnational Climate Change Governance. Cambridge: Cambridge University Press.

Bulkeley, H. and M. Betsill. 2003. Cities and Climate Change: Urban Sustainability and Global Environmental Governance. New York: Routledge.

Bulkeley, H. and V. Castan Broto. 2012. Government by Experiment? Global Cities and the Governing of Climate Change. Transactions of the Institute of British Geographers 38(3): 361-375.

Bulkeley, H. and K. Kern. 2009. Cities, Europeanization and Multi-level Governance: Governing Climate Change through Transnational Municipal Networks. Journal of Common Market Studies 47(2): 309-332.

Bulkeley, H. and H. Schroeder. 2012. Global Cities and the Politics of Climate Change. In Peter Dauvergne (Ed.), Handbook of Global Environmental Politics, 2nd ed. Northampton, MA: Edward Elgar, 249-260.

Burdett, R. and D. Sudjic. 2008. The Endless City. London: Phaidon.

C40. 2005. Communique from Large World Cities: London C40 Summit. On file with the author.

- 2007. C40 New York City Summit Joint Communique. On file with the author.

—. 2009. C40 Large Cities Climate Summit: Seoul Declaration. On file with the author.

- 2011a. CDP Cities 2011: Global Report on C40 Cities. Available at: https:// www.cdproject.net/en-US/Results/Pages/cities-Reports.aspx. Last accessed 28 October 2014. 
2011b. Opening remarks by C40 Chair Michael Bloomberg at C40 Cities Climate Leadership Group Summit 2011. São Paulo, Brazil. Available at: http:// bit.ly/1bBh1mK. Last accessed 19 November 2013.

- 2012a. Carbon Disclosure Project (CDP). 2009. Carbon Disclosure Project: Cities Pilot Project 2008. Available at: https:/www.cdproject.net/en-US/Results/ Pages/cities-Reports.aspx. Last accessed 28 October 2014.

- 2012b. Measurement for Management: CDP Cities 2012 Global Report Including Special Report on C40 Cities. Available at: https://www.cdproject.net/ en-US/Results/Pages/cities-Reports.aspx. Last accessed 28 October 2014.

- 2013. CDP Cities 2013: Summary Report on 110 Global Cities. Available at: https://www.cdproject.net/en-US/Results/Pages/cities-Reports.aspx. Last accessed 28 October 2014.

Curtis, S., 2011. Global Cities and the Transformation of the International System. Review of International Studies 37(4): 1923-1947.

Derudder, B., P. Taylor, P. Ni, A. De Vos, M. Hoyler, H. Hanssens, D. Bassens, J. Huang, F. Witlox, W. Shen, and X. Yang. 2010. Pathways of Change: Shifting Connectivities in the World City Network, 2000-08. Urban Studies 47(9): 1861-1877.

Dobbs, R., S. Smit, J. Remes, J. Manyika, C. Roxburgh, and A. Restrepo. 2011. Urban World: Mapping the Economic Power of Cities. McKinsey Global Institute Research Report. Available at: http://www.mckinsey.com/Insights/MGI/ Research/Urbanization/Urban_world. Last accessed 28 October 2014.

Dodman, D., and D. Satterthwaite. 2009. Climate Change: Are Cities Really to Blame? Urban World 1(2): 12-13.

Fry, E. 1990. State and Local Governments in the International Arena. Annals of the American Academy of Political and Social Science 509(1): 118-127.

Globalization and World Cities (GaWC). 2012. The World According to GaWC 2008. Available at: http://www.lboro.ac.uk/gawc/world2012t.html. Last accessed 28 October 2014.

Gordon, D. 2013. Between Local Innovation and Global Impact: Cities, Networks, and the Governance of Climate Change. Canadian Foreign Policy Journal 19(3): 288-307.

Gore, C. 2010. The Limits and Opportunities of Networks: Municipalities and Canadian Climate Change Policy. Review of Policy Research 27(1): 27-46.

Grewal, D.S. 2008. Network Power: The Social Dynamics of Globalization. New Haven, CT: Yale University Press.

Hafner-Burton, E. M., M. Kahler, and A.H. Montgomery. 2009. Network Analysis for International Relations. International Organization 63: 559-592.

Hakelberg, L. 2014. Governance by Diffusion: Transnational Municipal Networks and the Spread of Local Climate Strategies in Europe. Global Environmental Politics 14(1): 107-129.

Hobbs, E. 1994. City Hall Goes Abroad: The Foreign Policy of Local Politics. Ann Harbor: University of Michigan Press.

Hocking, B. 1993. Localizing Foreign Policy: Non-Central Governments and Multilayered Diplomacy. New York: St. Martin's Press.

Hodson, M. and S. Marvin. 2010. World Cities and Climate Change: Producing Urban Ecological Security. Milton Keynes: Open University Press.

Hoffmann, M. J. 2011. Climate Governance at the Crossroads: Experimenting with a Global Response. Oxford, UK: Oxford University Press.

Holgate, C. 2007. Factors and Actors in Climate Change Mitigation: A Tale of Two South African Cities. Local Environment 12: 471-484.

Kahler, M., ed. 2009. Networked Politics: Agency, Power, and Governance. New York: Columbia University Press. 
Keck, Margaret and Kathryn Sikkink. 1998. Activists beyond Borders: Advocacy Networks in International Politics. Ithaca: Cornell University Press.

Keiner, M. and A. Kim. 2007. Transnational City Networks for Sustainability. European Planning Studies 15: 1369-1395.

Kousky, C. and S.H. Schneider. 2003. Global Climate Policy: Will Cities Lead the Way? Climate Policy 14(5): 1-14.

Lee, T. 2013. Global Cities and Transnational Climate Change Networks. Global Environmental Politics 13(1): 108-127.

Lee, T. and S. van de Meene. 2012. Who Teaches and Who Learns? Policy Learning through the C40 Cities Climate Network. Policy Sciences 45(3): 199-220.

Lindseth, G. 2004. The Cities for Climate Protection Campaign (CCPC) and the Framing of Local Climate Policy. Local Environment 9(4): 325-336.

Parnell, S. and J. Robinson 2012. (Re)theorizing Cities from the Global South: Looking beyond Neoliberalism. Urban Geography 33(4): 593-617.

Pierce, N., C. W. Johnson, and F. M. Peters. 2009. Century of the City: No Time to Lose. New York: Rockefeller Foundation.

Roman, M. 2010. Governing from the Middle: The C40 Cities Leadership Group. Corporate Governance 10(1): 73-84.

Ruggie, J. G. 1993. Territoriality and Beyond: Problematizing Modernity in International Relations. International Organization 47(1): 139-174.

- 2004. Reconstituting the Public Domain: Issues, Actors, and Practices. European Journal of International Relations 10(4): 499-531.

Sassen, S. 2001. The Global City: New York, London, Tokyo, 2nd ed. Princeton, Oxford: Princeton University Press.

- 2006. Territory, Authority, Rights: From Medieval to Global Assemblages. New York: Princeton University Press.

Selin, H. and S.D. VanDeveer. 2007. Political Science and Prediction: What's Next for U.S. Climate Change Policy? Review of Policy Research 24(1): 1-27.

Temenos, C. and E. McCann. 2012. The Local Politics of Policy Mobility: Learning, Persuasion, and the Production of a Municipal Sustainability Fix. Environment and Planning A 44(6): 1389-1406.

- 2013. Geographies of Policy Mobilities. Geography Compass 7(5): 344-357.

Thompson, G. 2003. Between Hierarchies and Markets: The Logic and Limits of Network Forms of Organization. Oxford: Oxford University Press.

Toly, N.J. 2008. Transnational Municipal Networks in Climate Politics: From Global Governance to Global Politics. Globalizations 5(3): 341-356.

World Bank. 2010. Cities and Climate Change: An Urgent Agenda. Washington, DC: World Bank.

Zahran, S., S.D. Brody, A. Vedlitz, H. Grover, and C. Miller. 2008. Vulnerability and Capacity: Explaining Local Commitment to Climate-Change Policy. Environment and Planning C: Government and Policy 26: 544-562. 


\title{
5 Multinational Companies and Urban Climate Governance
}

\author{
Market Making or Successful \\ Policy Innovation?
}

Sofie Bouteligier

\section{INTRODUCTION}

The conception of the 21st century as the "urban millennium" ${ }^{1}$ drew the attention of both scholars and policy-makers to the importance of cities. Apart from the recognition of their economic importance-both nationally and globally - as centers of production and consumption, the idea that they need to be part of the solution to multiple global challenges made cities' roles in global governance become widely studied and discussed. ${ }^{2}$ The unprecedented speed and size of urbanization in Africa and Asia and the already high urbanization rates in the Americas and Europe make the urban question-once again - unavoidable. Despite the many challenges faced by new and old cities, the very fact that more than half of the world's population now consists of urbanites pushes towards seeing cities as key places for ensuring a livable and sustainable future. Moreover, some even conceptualize them as laboratories or testing grounds for advancing innovative policies and governance arrangements, especially when they can stimulate changes at larger scales. ${ }^{3}$

Also in the realm of climate governance, growing attention has been paid to the role of cities in sharing the burdens and solutions for mitigating and adapting to climate change. As seven out of ten people will live in urban areas by $2050^{4}$ and as cities have a huge ecological footprint and generate environmental effects far beyond their own territories, ${ }^{5}$ transformations and transitions in and of cities indeed matter when thinking about pathways to a climate proof and more sustainable future. Many current urban environmental challenges are linked to or framed by climate change. In terms of mitigation, cities are thought to generate a significant amount of the global greenhouse gas (GHG) emissions. And although there is debate about cities' exact share, ${ }^{6}$ they are considered to be places where ambitious reduction targets should and could be achieved. ${ }^{7}$ In terms of adaptation, many cities around the world are already confronted with consequences of climate change (e.g. sea level rise in the case of coastal cities, urban heat island effect, and extreme weather events $)^{8}$ and are therefore conceptualized as laboratories for developing innovative responses. ${ }^{9}$ Urban climate 
governance has become an umbrella for addressing a wide range of environmental issues. Now framed in a different way, conventional urban environmental challenges like transport and mobility, waste management, water and food security are addressed from a climate perspective. Besides air quality and health, decreasing $\mathrm{CO}_{2}$ emissions is now part of addressing transport and mobility challenges; waste is no longer approached as a cost to be dealt with, but is part of policies on renewable energy; water security policies now do not only focus on water quality and infrastructure but also on projections on changing water availability and presence (drought, flooding, extreme weather events, sea level rise, and so on) and food security is now linked to self-sufficiency and policies on greening urban space to decrease the urban heat island effect. Therefore, this chapter also refers to a broad set of examples that can all be put under this umbrella of urban climate governance.

High expectations have been formulated regarding the role that cities can play in tackling climate change. "Cities can change the world", "Cities can be the solution to climate change", "Local actions can have immediate impact and can add up to create global effects", ${ }^{10}$ these are just a few of the ambitious claims that cities themselves-through city networks like the C40 Cities Climate Leadership Group-have been articulating in the past years. As climate challenges threaten the quality of urban life, cities are keen to tackle these problems. Further, there is an ongoing competition between cities to be the most eco-friendly, sustainable, livable, and climate proof city. The variety of existing rankings shows that (the perception of) a city's environmental performance can be as important for city branding as its economic or cultural performance. Where nation-states do not bid against each other for the most ambitious mitigation targets or adaptation measures, many cities do. A quick look at urban climate actions shows how many cities are in a race towards becoming the first climate neutral city in the world. ${ }^{11}$ Yet, in order to live up to the high expectations cities are creating for themselves about their role in tackling climate change, cities are in need of assistance and advice of others. As they often lack the necessary knowledge and capacity, they make an appeal to multinational companies (MNCs)-like environmental consultancy, engineering, or urban planning firms, and energy service companies—for their expertise and experience with climate action in other cities. ${ }^{12}$ The results of the interactions between cities and MNCs in the realm of urban climate governance range from MNCs advising on and assessing cities' climate policies (e.g. ARUP in Ho Chi Minh City $^{13}$ and Melbourne ${ }^{14}$ ), to harmonizing urban transport (e.g. Siemens in London ${ }^{15}$ ), and developing applications that encourage behavioral change and a reduction of citizens' carbon footprint (e.g. Cisco in Amsterdam ${ }^{16}$ ). As such, these MNCs diffuse particular environmental solutions and shape the future of multiple cities. These MNCs gain environmental authority from their expertise and the perception that they have the capacity to formulate appropriate solutions. ${ }^{17}$ By framing what such solutions should look 


\section{Sofie Bouteligier}

like and stimulating the replication of so-called best practices in multiple urban settings, they have the potential to mold our global urban future. At a time when information and knowledge have become substantial resources that have a central place in contemporary competitive dynamics and set in motion transformative dynamics, companies that have the provision of knowledge at the core of their activities are gaining relative importance. ${ }^{18}$ Due to these companies' global action radius, they can shape urban environmental futures worldwide. This chapter provides a critical reflection of the interactions between cities and MNCs in the realm of climate governance and on the role of these interactions in the long-term mitigation and adaptation efforts of cities.

The text is structured as follows: the first section sets the scope by briefly introducing the link between MNCs and urban climate governance. The following section then reflects critically on the ways in which MNCs can contribute to sustainable urban futures and the ways in which their approach fails to do so. A final section concludes on how the interactions between cities and MNCs make us conceptualize processes and dynamics in urban climate governance differently. Further, it lists possible questions to address in future research.

\section{MNCS AND URBAN CLIMATE GOVERNANCE}

Siemens has set up a Centre for Urban Sustainability, ${ }^{19}$ AECOM created the Global Cities Institute, ${ }^{20}$ IKEA's investment arm Landprop is developing a new neighborhood in London, ${ }^{21}$ and IBM has set up a Smarter Cities Challenge. ${ }^{22}$ The press releases announcing and illuminating these initiatives all talk about today's great urban challenges and about how MNCs can play a crucial role in creating more sustainable and livable cities. Whilst cooperation between city governments in transnational municipal networks ${ }^{23}$ and cities' strategic importance for MNCs' office networks ${ }^{24}$ have received wide scholarly attention, the interactions between cities and MNCs, and the resulting projects are understudied. Nevertheless, these interactions raise many interesting issues and push us to conceptualize urban climate governance processes and dynamics differently and develop critical reflections. First, they show how cities are continuously (re)created and (re)developed by multiple actors that find each other in coalitions of social interests. ${ }^{25}$ Cities are not only shaped by their governments and by the citizens that inhabit them and the companies and organizations they are home to. In addition, 'external' actors (e.g. visitors, higher-level governments, etc.) are shaping cities and this is more and more true for MNCs that are involved in cities' environmental policies and as such shape the actions and agendas of cities. Second, as private actors have a role in shaping the urban future, there is a need for more research on the agency and authority of private actors in (global) governance. ${ }^{26}$ Questions are asked about the rationale behind 
MNCs' activities in cities. MNCs favor solutions that are based in neoliberal environmentalism ${ }^{27}$ and ignore non-market-based solutions. This pushes urban climate governance in the direction of entrepreneurialism, which does not necessarily benefit the environment, as will be highlighted later on in this chapter. Third, it exemplifies new forms of expertise and how this expertise is mobile and generates new power constellations. ${ }^{28} \mathrm{MNCs}$, like ARUP and Siemens, produce and distribute solutions for environmental problems and as such they are gaining power and are seen as the new experts that will guide cities in the right direction. As they operate in multiple cities worldwide they are-at present-molding our urban future on a global scale. Fourth, they broaden the transfer and diffusion literature, ${ }^{29}$ paying attention to both mobility ${ }^{30}$ and friction, i.e. "the awkward, unequal, unstable, and creative qualities of interaction across difference." ${ }^{31}$ Although it is often thought that successful approaches can be replicated anywhere-and thus are mobile-replication might fail, simply because a particular approach is not necessarily suited for every city. The design of eco-cities by MNCs, for example, can be a source of inspiration for other governments all over the world or can fail due to local circumstances. Both are true for ARUP's design of Dongtan Eco-City, as it inspired the UK government in terms of design, but was thwarted in its implementation. ${ }^{32}$ Finally, they illustrate the space of replication and competition in which today's cities 'travel' ${ }^{33}$-i.e. have their successes replicated elsewhere-and in which cities themselves are (pro)actively constructing climate and sustainability practices and discourses. ${ }^{34}$ Ever more cities are competing with each other for attracting capital, also in the environmental domain. This competition for green capital is stimulated by the multiple sustainability awards and city indexes that have boomed in the last decade. Receiving an award, or being high up in a list, is now something to compete for, but also allows cities to showcase their successes to others and influence the further development and implementation of climate governance.

As indicated above, the interactions between cities and MNCs in the realm of climate governance provide both opportunities and new challenges. Yet, the essential question that needs to be answered is the following: are interactions between MNCs and major cities in the realm of urban climate governance leading to a more sustainable urban future? The remainder of this chapter contains a reflection on this question. This reflection is the result of the multiple interactions between MNCs and major cities I came across during my research on cities, networks, and global environmental governance. ${ }^{35}$ As this question is rather normative, it is not often dealt with in the existing literature. And although the question is indeed tricky to answer-as it is hard to know exactly what the future consequences will be of current urban climate governance initiatives-it is definitely one that needs to be asked. With a future that will be ever more urbanized, it will be key to think critically about what kind of solutions are needed in order to make that future more sustainable and livable. 


\section{IS THIS THE WAY TO A MORE SUSTAINABLE URBAN FUTURE?}

"Sustainability thus relates not only to questions of environmental crisis or the nexus between economy and ecology. It concerns the human condition from the local to the global, including both the nature of urban settlements and the forms that community-life take. It concerns the basic question of how we are to live." 36

Cities are increasingly seen as having great potential to function as sustainability laboratories ${ }^{37}$ and are therefore remade as "real and symbolic nodes", ${ }^{38}$ showcases, and "national exemplars" 39 that inform policies in other urban contexts and at other governmental levels. ${ }^{40}$ Through the retrofitting of a municipal building, the creation of a zero emissions neighborhood or the redevelopment of the waterfront in the historic center, cities portray themselves as the next 'sustainability hub' and show what is possible to achieve. Siemens's report "Green Cities. Sustainable Solutions for Buildings, Traffic, and Energy" ${ }^{41}$ gives an overview of projects that reflects the current way of dealing with urban climate and sustainability challenges. LED-lightening for skyscrapers; energy control systems that manage illumination, heating, and air conditioning according to need; electronic smart meters that help you save energy; information systems that reduce congestion; electric car infrastructure; virtual power plants that network multiple small power stations to form a large, smart power grid, and so on. Often these projects and solutions are applied on a small scale and they deal with one aspect of a much broader and more complex climate and sustainability challenge. The results tend to be very visible or noticeable in the short-term: less energy and water is used in a particular building; people know better where traffic jams will occur and start choosing alternative routes or alternative transport modes; information on carbon performance is displayed; and so on. Yet, the overall environmental footprint of cities taking such initiatives is not shrinking, nor is the footprint of their residents, to the contrary. Those cities often called exemplars have amongst the biggest environmental footprints. Furthermore, "the more the language of sustainability is used, the more it seems to be directed at rationalizing unsustainable development." ${ }^{42}$ It is commonly assumed that techno-fixes will make our cities more sustainable and are deceived by gloomy presentations of vibrant sustainable cities. Yet, reality is that many so-called sustainable cities have exported pollution and emissions to other places, either in their hinterland or abroad. So-called sustainable cities are now often centers of consumption, whereas the production processes needed to sustain that consumption and the pollution and emissions related to these production processes are taking place elsewhere. Or as James puts it: "The hardware supporting urban lifestyles is being manufactured under Dickensian conditions in places like Shenzhen, China, and Dhaka, Bangladesh. This occurs while 'post-industrial' cities are dressed in the cosmetic glamour of urban renewal." 43 
As I have argued elsewhere, ${ }^{44}$ urban projects and technological solutions can be usefully conceptualized as a means of advancing urban climate policies. Indeed, from a transition management and policy diffusion perspective, the projects resulting from the interactions between MNCs and city governments can have broader relevance as they have the potential to contribute to broader societal transitions. If we follow this line of thinking, it is not useful to analyze the merits of individual projects, but it is essential to look at the bigger picture of which these projects form a part. Sustainability transitions ideally consist of long-term, mid-term, and short-term horizons, suggesting changes in culture, structures, and practices. ${ }^{45}$ Thus, when embedded in comprehensive policies, the above-mentioned short-term, small-scale projects can be part of broader sustainability transitions. They are important sources of inspiration for other cities and even governments at other levels, as they are often used as laboratories to experiment with new technologies and approaches. They can also generate support for a broader policy within one city. In other words, the enthusiasm that follows from a techno-fix like an application that shows in real-time the energy and water usage of a building is logical, as this app can raise awareness about energy and water use, can help save energy and water, and can create support for making ever more buildings energy and water efficient. There are even examples that show that successful initiatives in particular cities influence developments at higher levels of government. ${ }^{46}$ However, such projects are often limited to privileged neighborhoods in cities, thus only being available for the 'happy few'. This could lead to the creation of ecological enclaves instead of finding solutions for cities as a whole. Having urban climate and sustainability (pilot) projects being replicated throughout the city or in other cities, having them scaled-up at higher levels, and embedding these projects in broader environmental policies for the cities as a whole seem ways to let these projects contribute to broader societal transitions ${ }^{47}$ Yet, something fundamental seems to be missing to see these projects being the way forward to climate proof cities and a more sustainable urban future, even if-or better, especially when-the bigger picture comes into play. It is not necessarily their size and scope that is the problem, but more their underlying rationale. What these and similar projects and solutions share is that they are rooted in a new urban entrepreneurialism, favoring neoliberal environmentalism, and assuming that technological solutions will fix all our environmental challenges. Cities want to attract investments and funding and right now that means that they are looking for green capital, as this allows them to adapt buildings and infrastructure, put themselves on the map as the next sustainability hub, and do this with the lowest possible own investment. In order to do this, they have to cooperate with actors that favor market-based solutions and neoliberal environmentalism. This means that everything is evaluated in terms of a cost-benefit analysis and that a growth-oriented interpretation of sustainability and the private sector way of doing things are put central. ${ }^{48}$ This entails the development of "potentially replicable" 


\section{Sofie Bouteligier}

global products and a "strongly technocratic and productionist oriented" approach. ${ }^{49}$ And thus market making-not policy innovation that serves climate proof and sustainable urban futures-seems to be the ultimate goal. Entrepreneurial governance is characterized by a pro-growth alliance of business leaders and politicians and "constructs nature only to promote its destruction." ${ }^{50}$ It is therefore this particular approach that leads to the question: to what extent are interactions between cities and MNCs in the realm of climate governance contributing to a climate proof and sustainable urban future? These projects often seem innovative and appropriate, as they showcase technological advancements that make it possible to use less energy and water, use resources and materials in a more efficient way, and brand your city as the next sustainability hub. However, they do not question or challenge our way of living, nor do they fundamentally change production processes and consumption patterns. In other words, they are treating the symptoms, but they are not dealing with the cause of the disease. Even if a city's whole car fleet would run on renewable energy, the congestion problem has not been solved, nor the increasing demand for energy. Even if technologies to make buildings most energy and water efficient are in place, the architectural design can be inappropriate for the climate by ignoring the needs of the local environment (e.g. glass buildings in the desert). Even if a new climate neutral neighborhood is built, this does not equal a solution for the insulation of the already existing buildings. And if such a climate neutral neighborhood is still dominated by cars (e.g. in the form of space to park cars), you will have climate neutral houses without stimulating their inhabitants to also adapt their lifestyle. If we take a look at the bigger picture, such an approach seems to be characteristic for our times. We all want a better environment, but not at the expense of our current lifestyle and a better environment seems to be reached by consuming more green products and by having the latest green application on our mobile devices. That these products unnecessarily replace older products that could still be of use and that the newest devices perhaps consume more energy instead of less is not something we seem to care-or at least not want to think-about, as it makes us uncomfortable. Challenging our current global urban lifestyles, production processes, and consumption patterns is 'not done', as it is like opening Pandora's box: a chain of questions without answers emerges. By addressing one problem, five new ones seem to pop up. "The more we recognize that we face contradictory pressures, the more we give ourselves an excuse for not responding decisively or comprehensively." 51 So, instead of dealing with these questions, we happily continue to green wash global urban lifestyles, happy to claim that cities provide energy efficiency opportunities because of density, while at the same time silencing that migration from the rural to the urban mostly implies enlarging ecological footprints due to increased wealth and changing diets. The Chinese government's policy to push many more to move from rural areas to (old and new) cities is not prompted by energy efficiency or sustainable mobility concerns, but by the need to boost 
the Chinese economy. As more Chinese will live in cities, their welfare will increase, as will their consumption. As such, this will enable to shift the Chinese economy from an export economy to an economy that is much more focused on the internal market in China.

In a time in which economic growth is the key concern, it is not easy to bring the message that our current production processes and consumption patterns are unsustainable. It is not easy to say that when we really want to address the climate and sustainability challenges we face, it will not be enough to make all our devices energy efficient, to run all our cars on electricity, or to be constantly online to be aware of our carbon footprint. Constructing buildings that are completely disconnected from the local climate and environment is unsustainable, even if the most energy efficient illumination, heating, and cooling systems are used. ${ }^{52}$ Buying high-performance devices is of no use and is not helping us to consume less resources and materials, if they need to be replaced by new ones after one year, because they are out of date. An installation that recovers energy from waste is not helping us to produce less waste, as it will need the waste streams to provide enough 'green energy'. I list here only a couple of examples to illustrate that what is today often portrayed as a (more) climate friendly or sustainable solution often originates from a market making logic and not from thinking that should lead us to a climate proof and more sustainable future. Indeed, James's message "the world is in crisis and yet the argument here is that we need to slow down and go back to basics" ${ }^{33}$ is not the message we want to hear. And therefore we continue to believe that successful urban climate governance can be achieved with simple techno-fixes.

\section{IS THERE ANOTHER WAY?}

Today, global urban lifestyles put a huge pressure on the environment and ecosystems all over the world. Overconsumption of manufactured products, a diet in which animal products have a major share, and a quickly expanding built environment significantly influence resource and materials scarcity, emissions, and biodiversity losses. Although in the past years the opportunity to make cities an essential part of the solution has emerged, this opportunity is not fully used. So-called transformative solutions are not going beyond easy techno-fixes, short-term, small-scale, visible and noticeable effects. And this will remain the situation in the future, unless cities and urbanites start questioning current global urban lifestyles. They will have to question production processes and consumption patterns. If we really want to move towards a climate proof and more sustainable urban future, we will have to rethink the design, organization, and use of urban space, planning and (re)development in a fundamental way.

Urban (re)development should not start from the question: how do we put ourselves on the map as the next sustainability hub? It should start from the 
question: how to organize the city in such a way that a climate friendly and sustainable lifestyle becomes the easiest, most logical, and cheapest choice for each citizen? Cities should not focus on small changes here and there, but they should fundamentally rethink the very basics. Seriously questioning how we live, eat, work, move around, organize our social lives, ... will be key for thinking about how to move to a more sustainable urban future. How cities are organized today-in terms of infrastructure, planning, and the link between the urban areas and the surrounding rural areas and green space-is not stimulating a sustainable lifestyle, to the contrary. In many cities there is, for example, still a lack of adequate and safe cycle paths, the distances between office, school, and homes are too big, and non-sustainable products are promoted and overconsumption is stimulated. If it is easy to get locally grown fresh food, if it is logical to cycle to school and work, if it is cheap and doable to share houses and create a sharing economy, if the green-blue infrastructure is not only surrounding the city, but is actually part of the city, urbanites will be living in an environment in which they are not only making sustainable choices individually, but in which this is done by all actors that make use of and constitute the city. Only if sustainable choices become the next 'normal', global urban lifestyles will shift to lifestyles that sustain a climate proof and more sustainable urban future.

In order to make this fundamental change in global urban lifestyles possible, action will have to be undertaken at three levels. In the first instance, the very basic infrastructure to make possible sustainable ways of living needs to be provided. Bicycle paths connected with public transport modes, advanced waste management systems, renewable energy technology, low energy and low emissions distribution systems, and advanced water provision and sanitation are just a few examples. Second, cities need to be organized differently. Current centralized energy systems, for example, limit the potential of renewable energy systems and put citizens in the sole role of individual consumers. Decentralized energy systems at the community level can provide a more efficient use of renewable energy, giving citizens the dual role of collective producers and consumers. This opens more potential for awareness raising and behavioral change regarding energy use and energy efficiency. ${ }^{54}$ Third, enabling a different way of citizen interaction can enable more sustainable urban lifestyles. Removing barriers to develop collaborative consumption could contribute significantly to reduce energy and resource use and consequently to lowering emissions. "Resource efficiency in production and technological innovations are inadequate for considerably reducing the current use of natural resources. Both social innovations and a complementary and equally valued strategy of sustainable consumption are required: goods must be used longer, and services that support collaborative consumption (CC) patterns must be extended. 'Using rather than owning' strategies, such as product sharing, have the potential to conserve resources", 55 reduce the amount of materials used, stimulate reuse and prevent generating waste. 


\section{CONCLUSION}

The current interactions between cities and MNCs in the realm of urban climate governance and the more sustainable urban future we envisage push us to conceptualize urban climate governance processes and dynamics differently. First, as cities are continuously (re)created and (re)developed by multiple actors that find each other in coalitions of social interests, this means that coalitions of social interests can also emerge around the aim to create climate proof and more sustainable urban lifestyles. Second, privatization of cities and the linked preference for solutions that are based in neoliberal environmentalism triggers us to redefine welfare and development. Instead of GDP, alternative measures of progress could become central. Sustainable urban (re)development should be part of such alternative measures. Although alternatives measures of progress (like Gross National Happiness in Bhutan) and urban sustainability assessments are existing, ${ }^{56}$ they have not yet gained ground. Third, as MNCs produce and distribute solutions for environmental problems, they are gaining power and are seen as the new experts that will guide cities in the right direction. But, not only MNCs have this mobile expertise that informs urban (re)development all over the world, citizens and civil society equally have the possibility to have this. Environmental activists and citizens that are transforming their communities towards climate proof and more sustainable communities are connected with each other through virtual communication and well-established worldwide networks. As such, they inspire one another, build a global movement and contribute to the continuous changes in urbanites' behavior. Transition movements and towns-which "support community-led responses to climate change and shrinking supplies of cheap energy, building resilience and happiness" ${ }^{57}$-are just one example of how this is occurring already today. Fourth, in terms of transfer and diffusion it remains important to have both mobility and friction on the radar. No matter which actors are involved and what solutions are developed, the message remains that not one size fits all and that successful alternatives to today's unsustainable urban (re)development do not necessarily work anywhere in the world. Finally, when establishing more sustainable global urban lifestyles, both cooperation and competition between cities will remain to exist and cities will remain key to constructing practices and discourses.

This chapter ends with three research agendas that will be key to make the interactions between MNCs and cities more valuable for urban climate governance and to find ways to come to a more sustainable urban future:

1. Identify alternative roles for MNCs-as one of the actors that is contributing to urban climate governance and sustainable urban (re)development-that go beyond market making.

2. Develop ways to move from projects that aim at short-term, noticeable results towards encompassing long-term policies for the city as a whole that still can be advocated by mayors. 


\section{Sofie Bouteligier}

3. Suggest ways in which to organize the city that a sustainable lifestyle becomes the easiest, most logical, and cheapest choice for each citizen.

Working towards a climate proof and more sustainable urban future will work best if we have innovative MNCs with their worldwide scope of action on board as they can provide a wealth of knowledge, services, and products. Yet, their rationale will have to change. Initiatives are already ongoing to involve companies in experiments with alternative business models. The future will have to show whether such models help us to advance sustainable solutions. Further, it will be necessary to find ways in which mayors-whose scope is short-term-can advocate long-term, encompassing policies without the fear that this will automatically damage the possibility to become re-elected. This also means finding ways to better communicate about long-term, encompassing goals and about the ways that lead to achieving these goals. And finally, it will be necessary to have all citizens involved. Sustainable cities should not be made for the happy few only. They should inspire all people to organize their lives differently. They should enable citizens to unfold more sustainable lifestyles together with others. They should provide an environment that makes the sustainable choice the logical choice, removing all barriers that hamper such a choice. Only then, a climate proof and more sustainable urban future has a chance to succeed.

\section{NOTES}

1. UNFPA, State of the World Population 2007.

2. Amen, Toly, McCarney, and Segbers, Cities and Global Governance. Curtis, The Power of Cities in International Relations.

3. Bulkeley, "Boundary Work"; Bulkeley, "Urban Sustainability"; Hodson and Marvin, "Understanding the Role of the National Exemplar"; Sánchez and Moura, "Ciudades-modelo"; Stead, de Jong, and Reinholde, "West-East Policy Transfer"; Stone, "Transfer Agents and Global Networks".

4. UN-Habitat, State of the World's Cities 2010/2011.

5. Wackernagel, Kitzes, Moran, Goldfinger, and Thomas, "The Ecological Footprint of Cities and Regions"; Wall and van de Knaap, "Sustainability within a World City Network".

6. Dodman, "Blaming Cities for Climate Change"; Satterthwaite, "Cities' Contribution to Global Warming".

7. ARUP, Climate Action in Megacities; OECD, Cities and Climate Change; Rosenzweig, Solecki, Hammer, and Mehrotra, Climate Change and Cities.

8. Aerts, Major, Bowman, Dircke, and Marfai, Connecting Delta Cities; Bulkeley, "Cities and the Governing of Climate Change"; Corburn, "Cities, Climate Change and Urban Heat Island Mitigation"; Dircke, Aerts, and Molenaar, Connecting Delta Cities. OECD, Cities and Climate Change.

9. Aerts, Major, Bowman, Dircke, and Marfai, Connecting Delta Cities; ARUP, Climate Action in Megacities; Dircke, Aerts, and Molenaar, Connecting Delta Cities; Hodson and Marvin, "Understanding the Role of the National Exemplar"; Hodson and Marvin, "Can Cities Shape Socio-Technical Transitions"; Mees and Driessen, "Adaptation to Climate Change in Urban Areas"; OECD, Cities and Climate Change. 
10. http://c40.org/ending-climate-change-begins-in-the-city. Last accessed November 4, 2014.

11. ARUP, Climate Action in Megacities; ARUP, Climate Action in Megacities Version 2.0.

12. Hodson and Marvin, "Can Cities Shape Socio-Technical Transitions"; Hogan, Bunnell, Pow, Permanasari, and Morshidi, “Asian Urbanisms"; McCann, "Expertise, Truth, and Urban Policy Mobilities".

13. http://www.arup.com/News/2010_05_May/12_May_2010_Ho_Chi_Minh_ C40_workshop.aspx. Last accessed November 4, 2014.

14. http://www.arup.com/Projects/Zero_Net_Emissions.aspx. Last accessed November 4, 2014.

15. http://www.siemens.com/sustainability/pool/umweltportfolio/siemens_envi ronmental_portfolio.pdf (p. 7). Last accessed November 4, 2014.

16. http://www.cisco.com/web/strategy/docs/scc/smart_work_center_solution_ overview_us_0725.pdf (p. 12). Last accessed November 4, 2014.

17. Bouteligier, "Exploring the Agency".

18. Mol, Environmental Reform.

19. http://www.siemens.com/entry/cc/en/urbanization.htm. Last accessed November 4, 2014.

20. http://globalcities.aecom.com/. Last accessed November 4, 2014.

21. http://strandeast.com/. Last accessed November 4, 2014.

22. http://smartercitieschallenge.org/about.html. Last accessed November 4, 2014.

23. Betsill and Bulkeley, "Transnational Networks"; Keiner and Kim, "Transnational City Networks"; Kern and Bulkeley, "Cities, Europeanization and Multi-Level Governance"; Toly, "Transnational Municipal Networks".

24. Acuto, "Global Cities"; Castells, The Information Age; Friedmann, "The World City Hypothesis"; Sassen, The Global City; Taylor, World City Network.

25. Bunnell and Maringanti, "Practising Urban and Regional Research"; Hodson and Marvin, "Can Cities Shape Socio-Technical Transitions".

26. Avant, Finnemore, and Sell, "Who Governs the Globe?" Biermann et al., Earth System Governance.

27. Hodson and Marvin, "Urbanism in the Anthropocene".

28. McCann, "Expertise, Truth, and Urban Policy Mobilities".

29. Dolowitz and Marsh, "Who Learns from Whom?"; Hoyt, "Importing Ideas"; Stone, "Transfer Agents"; Wolman and Page, "Policy Transfer".

30. Urry, Sociology beyond Society.

31. Tsing, Friction, 4.

32. Chang and Sheppard, "China's Eco-Cities".

33. Bunnell and Maringanti, "Practising Urban and Regional Research"; Hogan, Bunnell, Pow, Permanasari, and Morshidi, "Asian Urbanisms"; McCann, "Expertise, Truth, and Urban Policy Mobilities".

34. Chang and Sheppard, "China's Eco-Cities", 59.

35. Bouteligier, Cities, Networks, and Global Environmental Governance.

36. James, Urban Sustainability in Theory and Practice.

37. Corfee-Morlot, Kamal-Chaoui, Donovan, Cochran, Robert, and Teasdale, Cities, Climate Change and Multilevel Governance.

38. Bunnell and Das, "Urban Pulse".

39. Hodson and Marvin, "Understanding the Role of the National Exemplar".

40. Bulkeley, Hodson, and Marvin, "Emerging Strategies"; Corfee-Morlot, Kamal-Chaoui, Donovan, Cochran, Robert, and Teasdale, Cities, Climate Change and Multilevel Governance.

41. http://www.siemens.com/innovation/pool/en/publikationen/pof-toi-2011-edoppel.pdf. Last accessed November 4, 2014.

42. James, Urban Sustainability in Theory and Practice, chapter 1. 


\section{Sofie Bouteligier}

43. James, Urban Sustainability in Theory and Practice, chapter 2.

44. Bouteligier, "Urban Sustainability Pilot Projects".

45. Loorbach, "Transition Management".

46. Bouteligier, "Urban Sustainability Pilot Projects". Hodson and Marvin, "Understanding the Role of the National Exemplar".

47. Bouteligier, "Urban Sustainability Pilot Projects".

48. Falkner, Business Power; Porter, "Private Authority".

49. Hodson and Marvin, "Urbanism in the Anthropocene".

50. Prytherch, "Selling the Eco-Entrepreneurial City", 787.

51. James, Urban Sustainability in Theory and Practice, chapter 1.

52. Vandevyvere, "How to Cut across the Catchall?"

53. James, Urban Sustainability in Theory and Practice, chapter 2.

54. Catney et al., "Community Knowledge Networks".

55. Leismann, Schmitt, Rohn, and Baedeker, "Collaborative Consumption", 184.

56. James, Urban Sustainability in Theory and Practice.

57. www.transitionnetwork.org. Last accessed November 4, 2014.

\section{BIBLIOGRAPHY}

Acuto, Michele. "Global Cities: Gorillas in Our Midst.” Alternatives. Global, Local, Political 35 (2010): 425-448.

Aerts, Jeroen, David C. Major, Malcolm J. Bowman, Piet Dircke, and Muh Aris Marfai. Connecting Delta Cities: Coastal Cities, Flood Risk Management and Adaptation to Climate Change. Amsterdam: VU University Press, 2009.

Amen, Mark M., Noah J. Toly, Patricia McCarney, and Klaus Segbers (eds.). Cities and Global Governance. New Sites for International Relations. Surrey, Burlington: Ashgate, 2011.

ARUP. 2011. Climate Action in Megacities: C40 Cities Baseline and Opportunities. London: ARUP.

ARUP. 2014. Climate Action in Megacities: C40 Cities Baseline and Opportunities. Version 2.0. London: ARUP.

Avant, Deborah D., Martha Finnemore, and Susan K. Sell. "Who Governs the Globe?" In Who Governs the Globe?, edited by Deborah D. Avant, Martha Finnemore, and Susan K. Sell, 1-31. Cambridge: Cambridge University Press, 2010.

Betsill, Michele M., and Harriet Bulkeley. "Transnational Networks and Global Environmental Governance: The Cities for Climate Protection Program.” International Studies Quarterly 48 (2004): 471-493.

Biermann, Frank, Michele M. Betsill, Joyeeta Gupta, Norichika Kanie, Louis Lebel, Diana Liverman, Heike Schroeder, Bernd Siebenhüner, Ken Conca, Leila da Costa Ferreira, Bharat Desai, Simon Tay, and Ruben Zondervan. Earth System Governance: People, Places and the Planet. Science and Implementation Plan of the Earth System Governance Project. Bonn: IHDP, 2009.

Bouteligier, Sofie. "Exploring the Agency of Global Environmental Consultancy Firms in Earth System Governance." International Environmental Agreements: Politics, Law and Economics 11 (2011): 43-61.

Bouteligier, Sofie. Cities, Networks, and Global Environmental Governance. Spaces of Innovation, Places of Leadership. New York: Routledge, 2012.

Bouteligier, Sofie. 2014. "Urban Sustainability Pilot Projects: Fit or Misfit between Challenge and Solution?" In Scale-Sensitive Governance of the Environment, edited by Frans Padt, Paul Opdam, Nico Polman, and Katrien Vermeer, 188-202. Oxford, West Sussex, Hoboken: Wiley-Blackwell, 2014.

Bulkeley, Harriet. "Boundary Work: Knowledge, Policy, and the Urban Environment." Environment and Planning C: Government and Policy 24 (2006): 633-643. 
Bulkeley, Harriet. "Urban Sustainability: Learning from Best Practice?" Environment and Planning A 38 (2006): 1029-1044.

Bulkeley, Harriet. "Cities and the Governing of Climate Change." Annual Review of Environment and Resources 35 (2010): 229-253.

Bulkeley, Harriet, Mike Hodson, and Simon Marvin. "Emerging Strategies of Urban Reproduction and the Pursuit of Low Carbon Cities." In The Future of Sustainable Cities. Critical Reflections, edited by John Flint and Mike Raco, 113-129. Chicago: Polity Press, 2012.

Bunnell, Tim, and Diganta Das. "Urban Pulse-a Geography of Serial Seduction. Urban Policy Transfer from Kuala Lumpur to Hyderabad.” Urban Geography 31 (2010): 277-284.

Bunnell, Tim, and Anant Maringanti. "Practising Urban and Regional Research beyond Metrocentricity." International Journal of Urban and Regional Research 34 (2010): 415-420.

Castells, Manuel. "Urban Sustainability in the Information Age." City 4 (2000): 118-122.

Catrey, Philip, Andrew Dobson, Sarah Marie Hall, Sarah Hards, Sherilyn MacGregor, Zoe Robinson, Mark Ormerad, and Simon Ross. "Community Knowledge Networks: An Action-Orientated Approach to Energy Research." Local Environment: The International Journal of Justice and Sustainability 18 (2013): 506-520.

Chang, I-Chun Catherine, and Eric Sheppard. "China's Eco-Cities as Variegated Urban Sustainability: Dongtan Eco-City and Chongming Eco-Island." Journal of Urban Technology 20 (2013): 57-75.

Corburn, Jason. "Cities, Climate Change and Urban Heat Island Mitigation: Localising Global Environmental Science.” Urban Studies 46 (2009): 413-427.

Corfee-Morlot, Jan, Lamia Kamal-Chaoui, Michael G. Donovan, Ian Cochran, Alexis Robert, and Pierre-Jonathan Teasdale. Cities, Climate Change and Multilevel Governance. OECD Environmental Working Papers $N^{\circ} 14$. Paris: OECD, 2009.

Curtis, Simon (ed.). The Power of Cities in International Relations. New York, London: Routledge, 2014.

Dircke, Piet, Jeroen Aerts, and Arnoud Molenaar. Connecting Delta Cities. Sharing Knowledge and Working on Adaptation to Climate Change. Rotterdam: City of Rotterdam, 2010.

Dodman, David. "Blaming Cities for Climate Change. An Analysis of Urban Greenhouse Gas Emissions Inventories.” Environment and Urbanization 21 (2009): 185-201.

Dolowitz, David, and David Marsh. "Who Learns from Whom: A Review of the Policy Transfer Literature." Political Studies 44 (1996): 343-357.

Falkner, Robert. Business Power and Conflict in International Environmental Politics. Basingstoke, New York: Palgrave MacMillan, 2008.

Friedmann, John. "The World City Hypothesis." Development and Change 17 (1986): 69-83.

Hodson, Mike, and Simon Marvin. "Understanding the Role of the National Exemplar in Constructing 'Strategic Glurbanization'." International Journal of Urban and Regional Research 31 (2007): 303-325.

Hodson, Mike, and Simon Marvin. "Can Cities Shape Socio-Technical Transitions and How Would We Know If They Were?" Research Policy 39 (2010): 477-485.

Hodson, Mike, and Simon Marvin. "Urbanism in the Anthropocene: Ecological Urbanism or Premium Ecological Enclaves?" City 14 (2010): 298-313.

Hogan, Trevor, Tim Bunnell, Choon-Piew Pow, Eka Permanasari, and Sirat Morshidi. "Asian Urbanisms and the Privatization of Cities." Cities 29 (2012): 59-63.

Hoyt, Lorlene. "Importing Ideas: The Transnational Transfer of Urban Revitalization Policy." International Journal of Public Administration 29 (2006): 221-243.

James, Paul. Urban Sustainability in Theory and Practice: Circles of Sustainability. New York, London: Routledge, 2014. 
Keiner, Marco, and Arley Kim. "Transnational City Networks for Sustainability." European Planning Studies 15 (2007): 1369-1395.

Kern, Kristine, and Harriet Bulkeley. "Cities, Europeanization and Multi-Level Governance: Governing Climate Change through Transnational Municipal Networks." Journal of Common Market Studies 47 (2009): 309-332.

Leismann, Kristin, Martina Schmitt, Holger Rohn, and Carolin Baedeker. "Collaborative Consumption: Towards a Resource-Saving Consumption Culture." Resources 2 (2013): 184-203.

Loorbach, Derk. "Transition Management for Sustainable Development: A Prescriptive, Complexity-Based Governance Framework." Governance: An International Journal of Policy, Administration, and Institutions 23 (2010): 161-183.

McCann, Eugene. "Expertise, Truth, and Urban Policy Mobilities: Global Circuits of Knowledge in the Development of Vancouver, Canada's 'Four Pillar' Drugs Strategy." Environment and Planning A 40 (2008): 885-904.

Mees, Heleen-Lydeke P., and Peter P.J. Driessen. "Adaptation to Climate Change in Urban Areas: Climate-Greening London, Rotterdam, and Toronto." Climate Law 2 (2011): 251-280.

Mol, Arthur P. J. Environmental Reform in the Information Age. The Contours of Informational Governance. New York: Cambridge University Press, 2008.

OECD. Cities and Climate Change. Paris: OECD, 2010.

Porter, Tony. "Private Authority, Technical Authority, and the Globalization of Accounting Standards." Business and Politics 7 (2005): 1-30.

Prytherch, David L. "Selling the Eco-Entrepreneurial City: Natural Wonders and Urban Stratagems in Tucson, Arizona." Urban Geography 23 (2002): 771-793.

Rosenzweig, Cynthia, William D. Solecki, Stephen A. Hammer, and Shagun Mehrotra (eds.). Climate Change and Cities. First Assessment Report of the Urban Climate Change Research Network. Cambridge: Cambridge University Press, 2011.

Sánchez, Fernanda, and Rosa Moura. "Ciudades-Modelo: Estrategias Convergentes Para su Difusión Internacional.” Revista Eure 31 (2005): 21-34.

Sassen, Saskia. The Global City: New York, London, Tokyo. 2nd ed. Princeton, Oxford: Princeton University Press, 2001.

Satterthwaite, David. "Cities' Contribution to Global Warming: Notes on the Allocation of Emissions." Environment and Urbanization 20 (2008): 539-549.

Stead, Dominic, Martin de Jong, and Iveta Reinholde. "West-East Policy Transfer: The Case of Urban Transport Policy." In Crossing Borders. International Exchange and Planning Practices, edited by Patsy Healey and Robert Upton, 173-190. London, New York: Routledge, 2009.

Stone, Diane. "Transfer Agents and Global Networks in the 'Transnationalization' of Policy." Journal of European Public Policy 11 (2004): 545-566.

Taylor, Peter J. World City Network. A Global Urban Analysis. London: Routledge, 2004.

Toly, Noah J. "Transnational Municipal Networks for Climate Stabilization: From Global Governance to Global Politics.” Globalizations 5 (2008): 341-356.

Tsing, Anna Lowenhaupt. Friction. An Ethnography of Global Connection. Princeton, Oxford: Princeton University Press, 2005.

UNFPA. State of the World Population 2007. Unleashing the Potential of Urban Growth. New York: United Nations Population Fund, 2007.

UN-Habitat. State of the World's Cities 2010/2011. Bridging the Urban Divide. London, Washington, DC: Earthscan, 2010.

Urry, John. Sociology beyond Society. London: Routledge, 2000.

Vandevyvere, Han. "How to Cut across the Catchall? A Philosophical-Cultural Framework for Assessing Sustainability." International Journal of Innovation and Sustainable Development 5 (2011): 403-424. 
Wackernagel, Mathis, Justin Kitzes, Dan Moran, Steven Goldfinger, and Mary Thomas. "The Ecological Footprint of Cities and Regions: Comparing Resource Availability with Resource Demand.” Environment and Urbanization 18 (2006): 103-112.

Wall, Ronald, and Bert van de Knaap. "Sustainability within a World City Network." GaWC Research Bulletin 205 (2006). http://www.lboro.ac.uk/gawc/rb/ rb205.html. Last accessed November 4, 2014.

Wolman, Harold, and Ed Page. "Policy Transfer among Local Governments: An Information-Theory Approach." An International Journal of Policy, Administration, and Institutions 15 (2002): 477-501. 
$\Longrightarrow$ Taylor \& Francis

Taylor \& Francis Group

http://taylorandfrancis.com 


\section{Part III}

\section{Domestic Policy Responses}

Integrating Mitigation and

Adaptation into Urban

Climate Governance 
$\Longrightarrow$ Taylor \& Francis

Taylor \& Francis Group

http://taylorandfrancis.com 


\title{
6 Combining Local and Transnational Action in the Adoption and Implementation of Climate Policies in the City of São Paulo
}

\author{
Joana Setzer, Laura Valente de Macedo \\ and Fernando Rei
}

\section{INTRODUCTION}

It is increasingly recognised that the governance of climate change occurs simultaneously at multiple levels. Responses to the problem of climate change are now formulated through intergovernmental (i.e. the United Nations Framework Convention on Climate Change-UNFCCC), as well as by transnational processes. Transnational climate governance occurs when cities, companies, non-governmental organisations (NGOs), and other sub- and non-state actors coordinate across borders to govern climate change. Attempts to map transnational climate governance have identified that between 60 and 75 transnational climate 'institutions', 'initiatives' or 'experiments' (Bulkeley et al., 2012; Hale \& Roger, 2014; Hoffmann, 2011) have been introduced since the 1990s.

Cities, and networks of cities, acting transnationally to address climate change receive particular attention in the literature on transnational climate governance. The proliferation of voluntary subnational action during the past decade reveals the multiple levels-local, regional, national, transnational and global-involved in climate governance (Andonova \& Mitchell, 2010). However, the ways in which transnational and local levels of governance interact have not yet been fully understood. Are transnational and local modes of governance interacting in ways that challenge, complement, stimulate, or simply have no effect on each other? Another limitation of this literature concerns the implementation of climate policies and legislation. Beyond the mere political commitment of joining transnational networks or adopting climate programmes, are these initiatives actually being implemented?

This chapter contributes to the literature with an analysis of the interactions between transnational and local initiatives in the adoption and implementation of climate policies and legislation in the city of São Paulo. Local action involves the legislation (i.e. municipal laws and decrees) and policies 
put in place by the city to inventory and reduce GHG emissions, as well as to promote adaptation measures. Transnational action in this case involves the city establishing decentralised international cooperation initiatives, participating in UNFCCC conferences and transnational climate networks, notably ICLEI Local Governments for Sustainability (ICLEI) and C40 Cities Climate Leadership Group (C40). The assessment of legal and policy documents and transnational activity was complemented by interviews with nine key representatives from the local government and both these networks. All the interviewees were directly involved in the adoption and implementation of the municipal climate policy. This chapter also contributes to the literature with an analysis of how a city in the Global South is addressing climate change and becoming part of the complex fabric of global climate governance.

The chapter first reviews the literature around transnational climate governance, and within it the literature on cities and climate change. It then goes on to outline São Paulo's municipal climate change policy. The next section considers the factors that drove the adoption of Law 14,933 ("Municipal Climate Law") in 2009, notably São Paulo's transnational action and the establishment of leadership vis-à-vis the federal government. The subsequent section considers different mitigation and adaptation measures in place, as well as some of the challenges of implementing a local climate policy in São Paulo. The analysis confirms that transnational activity was paramount in introducing the topic of climate change into the municipal agenda (Back, 2012; Setzer, 2009). However, transnational activity lost importance at the implementation stage of the municipal climate change policy. While transnational climate governance offers a fascinating laboratory in which to study larger shifts in the nature of global governance (Hale \& Roger, 2014), the longevity of such initiatives remains uncertain.

\section{THE TRANSNATIONAL CLIMATE GOVERNANCE LITERATURE}

The transnational aspect of climate change governance has been the object of increasing academic attention. Studies on the international participation of sub- and non-state actors are found in the realms of international relations (Abbott, 2013; Andonova et al., 2009; Bäckstrand, 2008; Falkner et al., 2010; Hoffmann, 2011; Lidskog \& Elander, 2010), international law (Abbott, 2012; Abbott, 2013; Heyvaert, 2013) and other social sciences such as sociology and geography (Bulkeley, 2005; Giddens, 2009). Thanks to this multidisciplinary approach, the literature covers diverse understandings of transnational climate governance.

Alongside private actors, scholarship of transnational climate governance has paid particular attention to the participation of subnational governments in transnational climate governance. Scholars examine the emergence 
of cities, regions, and networks of cities and regions acting transnationally to address climate change. A recent survey of urban climate experiments in 100 cities shows that most interventions to reduce emissions and/or vulnerabilities in cities started after 2005, and that they are not confined to any regions in the world, occurring in both richer and poorer cities (Broto \& Bulkeley, 2013).

Broadly speaking, studies highlight the local responses to climate change. They assess how different cities are mitigating and adapting to climate change by changing transportation systems and promoting climate-friendly economies (Bulkeley et al., 2011). There has been particular interest in exploring the governance functions and activities in which cities and networks of cities engage (Acuto, 2013; Bulkeley et al., 2012), as well as the policy learning and bilateral cooperation they promote (Betsill \& Bulkeley, 2006). There has also been consideration of subnational governments' subsequent effects on intergovernmental governance (Toly, 2008). While case studies initially focused on examples of subnational governments from developed countries, some recent works have raised attention to cities in the Global South (Fisher, 2012; Romero-Lankao, 2007; Setzer \& Biderman, 2013).

However, less attention has been given to the potential result from different initiatives. Only a small number of studies have gone beyond the political commitments undertaken (e.g. membership in ICLEI) onto analysing cities' actual implementation of subnational climate action (Krause, 2012; Wang, 2013). Furthermore, there is an incipient understanding of the interaction between the local and transnational levels. Andonova and Mitchell (2010) make a start, proposing that transnational networks help localise global issues, globalise local issues, and organise collective action across political levels. Abbott (2013) suggests that transnational climate governance enables institutions and networks to penetrate national governments at multiple levels. An examination of the urban context promotes a deeper understanding of how the local and transnational levels interact in climate change governance. This chapter proceeds with such an examination through an analysis of the adoption and implementation of climate initiatives in place in the city of São Paulo.

\section{THE CASE OF THE CITY OF SÃO PAULO}

The city of São Paulo is located in the southeast of Brazil. It is the capital of São Paulo state and the largest urban conglomeration in South America, with a population of about 11.5 million inhabitants in a territory of 590 square miles. The capital is the centre of a metropolitan region comprising 39 municipalities, with almost 20 million inhabitants. In the past decades the city's economic profile has witnessed a deep transformation, from a strongly industrialised base economy towards service- and technology-oriented activities. The city of São Paulo is the largest municipal economy of Brazil, 
with a GDP of approximately USD 200 billion, $11.5 \%$ of the national economy (IBGE, 2011). The scale of the figures above is comparable with whole countries. For example, the city's GDP is equivalent to that of Bolivia, and its population is equivalent to Annex I countries (those with GHG emissions reductions targets within the UNFCCC) such as Portugal, Belgium and Denmark.

In São Paulo's first GHG inventory in 2003, emissions in the city were estimated at 15 million tons of carbon equivalent $\left(\mathrm{CO}_{2} \mathrm{e}\right)$ per year (UFRJ, 2005). Of these emissions, $76.12 \%$ were generated by the energy sector, and $23.48 \%$ by solid waste management. Road transport accounted for $88.78 \%$ of the energy sector emissions, or $68.6 \%$ of the total municipal $\mathrm{CO}_{2}$ emissions. The inventory presented road transport, particularly passenger vehicles running on gasoline, as the major factor responsible for GHG emissions in the municipality. Solid waste management came second, followed by public and freight transport. Action on transportation and waste management, therefore, presented major opportunities for the public administration to reduce GHG emissions.

Acting upon the city's first GHG inventory, São Paulo became the first city in Brazil-and one of the major cities in the world-to address climate change. The city's actions involved the adoption of municipal regulation and implementation of local policies to reduce GHG emissions. The city also engaged in transnational networks promoting climate change adaptation and mitigation strategies among subnational governments. This policy agenda was led by the city's Environment Secretariat, which is responsible for planning, coordinating and regulating environmental protection at the municipal level.

On the regulatory front, São Paulo passed a number of municipal laws and decrees which directly or indirectly address climate change. The enactment of such regulations is based on the municipality's constitutional competency to address environmental protection. In fact, the 1988 Federal Constitution establishes a shared jurisdiction between the national government, subnational states, the Federal District and municipalities, to protect the environment and fight pollution in any form (article 23, VI). Consequently, the national and state governments share responsibility with the Federal District for ruling on environmental protection and pollution control (article 24, VI). Municipalities are responsible for ruling on local issues and complementing federal and state legislation when applicable (article 30, I and II).

The bulk of São Paulo's municipal climate change legislation was passed between 2005 and 2012. For instance, Decree 45,959 established the Municipal Committee on Climate Change and Sustainable Eco-Economy in 2005. In 2007, Law 14,266 created the city's bikeway system, Law 14,459 (regulated by Decree 49,148/2008) required the installation of solar heating systems in new buildings of a certain scale, and Law 92,205 established the city's green procurement policy. In 2009, the Municipal Climate Law was 
approved unanimously by the City Council, Law 14,971 regulated freight activities, and Decree 50,977 established controls over the use of native timber products and by-products. In 2011, Decree 52,260 established the Vehicular Pollution Control Plan, integrating climate change concerns into the traffic planning process. In 2012, Decree 53,223 required that the taxi fleet include cleaner fuel and motor technologies such as electric, ethanol and flex fuel vehicles, and Decree 53,323 established the Municipal Solid Waste Integrated Management Plan.

The 2009 Municipal Climate Law stands as the most important act in this regulatory framework. It asserts that mitigation of, and adaptation to, climate change in the city will contribute towards Brazil's compliance with the UNFCCC objectives. Furthermore, the Law establishes principles and measures to be adopted by several sectors in the economy engaged in climate mitigation and adaptation. The Municipal Climate Law also establishes an ambitious mandatory reduction target for the municipality. Article 5 of the Law targets a $30 \%$ reduction by 2012 of aggregate municipal GHG emissions in $\mathrm{CO}_{2} \mathrm{e}$, relative to the 2003 baseline values reported in the municipal inventory published in 2005.

According to preliminary estimates, the $30 \%$ reduction target was not reached. In 2011, the municipality commissioned a second GHG emissions inventory, expanding the scope of the first inventory to include emissions from the energy and waste sectors (solid and effluent) until 2011, using the Intergovernmental Panel on Climate Change (IPCC)'s 2006 revised methodology. A preliminary version was presented in November 2012 and its results were discussed in technical workshops held in March 2013. The final version of the inventory was published in March 2014, along with a summary for policy makers, indicating a disappointing increase in GHG emissions (Instituto Ekos Brasil and Geoklock Consultoria e Engenharia Ambiental, 2013). An assessment of the reasons why the city failed to achieve the targets specified by the Law is beyond the scope of this study. Yet, it is possible to explore aspects of the adoption and implementation of São Paulo's municipal climate policy by examining both the transnational and local processes involved therein.

\section{ADOPTING THE MUNICIPAL CLIMATE POLICY}

Several studies within the multilevel governance literature find that there is a relationship between adopting a subnational climate agenda and participation in transnational networks (Andonova \& Mitchell, 2010; Betsill \& Bulkeley, 2004, 2006; Broto \& Bulkeley, 2013; Gore, 2010). Drawing upon these studies, we examine the impact of São Paulo's international agenda on the development of its climate change policies and legislation. The case study suggests that the municipality's engagement in transnational networks of local governments addressing climate change played an important role in 
driving the development and adoption of a climate policy. Moreover, assuming a leadership role in climate policy development further propelled the city into transnational grounds.

\section{Transnational Activity}

Transnational activity was paramount in introducing the topic of climate change into São Paulo's municipal agenda (Back, 2012; Setzer, 2009). Represented by the Environmental Secretariat, the city has been a member of ICLEI since 1994. ICLEI is a global association of cities and local governments dedicated to sustainable development; it was founded in 1990 and is present in 86 countries (ICLEI, 2014b). Since 2005 the city has been a member of ICLEI's Regional Executive Committee, the regional representation of Global Association members in each ICLEI region. Between 2005 and 2012 the city was also a member of ICLEI's Global Executive Committee, which represents members of the Association at a global level.

The first measures specifically addressing climate change in São Paulo resulted from the city's participation in ICLEI's international campaign, Cities for Climate Protection (CCP). In 2003, São Paulo signed a technical cooperation agreement with ICLEI and committed to the campaign's five milestones. The first milestone requires the city to undertake a GHG emissions inventory for a baseline year. The second calls for the establishment of targets for GHG emissions reduction or avoidance for a given year. The third milestone requires the development of a Local Action Plan based on the GHG inventory findings. The fourth concerns the implementation of the Action Plan, usually targeting quick wins such as improving public transport and energy efficiency of public buildings, retrofitting water pumping and public lighting systems, using renewable energy, and capturing methane from landfills to generate electricity for local communities. The fifth milestone consists of monitoring the implementation of the Action Plan.

It was in accordance with the CCP's first milestone that the city undertook its GHG emissions inventory, published in 2005. The inventory identified the city's main GHG emission sources and provided guidance for the action plan to reduce emissions, as well as for the development of projects qualified to receive carbon credits within the Clean Development Mechanism (CDM). In addition to ICLEI's milestones, the city committed to coordinate the activities of different departments and municipal bodies, and chairmanship of the Climate Committee was given to the Urban Development Secretariat, with executive support from the Environment Secretariat.

City representatives participated in several other activities promoted by ICLEI, including attending Conferences of the Parties (COPs) within the UNFCCC as ICLEI delegates. At COP-10 in 2004, São Paulo actively participated in an international seminar and technical workshop on cities and climate change, organised by ICLEI. Earlier that year, the Environment Secretariat of São Paulo held a climate conference on sustainable transport 
within the CCP, highlighting the city's activities towards reducing its GHG emissions (ICLEI, 2005). The CCP programme was mentioned in the Brazil's Communications to the UNFCCC (Brasil, 2004, 2010), acknowledging the role of cities and of this particular programme in the national efforts to address climate change.

In 2005, the city increased its participation in global climate governance. São Paulo was part of the group of cities that gathered in London to launch the C40 (by then still C20). C40 is a network of the world's megacities to promote action to reduce GHG emissions. In 2006 the C40 forged a partnership with former U.S. president Bill Clinton's Climate Initiative to reduce carbon emissions and increase energy efficiency in large cities across the world $(C 40,2014)$. The city's representatives also attended and actively participated in the IV Mayors Summit, a parallel event to COP-11 led by ICLEI. At the Summit, former U.S. president Bill Clinton delivered a speech to the plenary in which he highlighted the importance of local government leadership in addressing climate change (IISD, 2005). One of the spin-off results of the Summit was the creation of the Mayor's Council on Climate Change and a Declaration in which over 120 mayors committed to adopting GHG reduction or avoidance targets within their municipalities.

In 2006, a joint effort between several local government networks resulted in the Local Government Climate Roadmap, led by ICLEI and funded by the European Community. The initiative further strengthened and enhanced local governments' action in international climate negotiations (ICLEI, 2014a). São Paulo participated in activities within this project, as well as side events in the climate conferences in Bali (COP-13, 2007), Poznan (COP-14, 2008) and Copenhagen (COP-15, 2009).

In 2007, São Paulo's Mayor Gilberto Kassab participated in a conference organized by the C40 in New York. At this conference, Mayor Kassab joined the Executive Board of the network and publicly committed to enact a law to address climate change (Biderman, 2011). The next step was to draft the bill of law. The City of São Paulo assigned the task to the Centre for Sustainability Studies at Fundação Getúlio Vargas, in partnership with ICLEI and with support from the United Nations Programme on Environment. The experts involved included Professor Jose Goldemberg from the University of São Paulo, Fabio Feldmann, former congressman and former secretary for the environment of the state of São Paulo, Stela Goldenstein, a senior advisor for the municipal government, and researchers from the National Reference Centre on Biomass. The Municipal Climate Law also benefited from research by a group of technical experts in the state environmental agency, CETESB, which since 1995 had been working in the state Climate Change Program, established by Fabio Feldmann during his term as secretary. While discussing the bill, ICLEI pushed forward the establishment of GHG emissions reduction targets.

During COP-15 in Copenhagen in 2009, São Paulo participated in several side events and activities for local governments, most of which were led 
by ICLEI. São Paulo's former mayor, and then São Paulo State Governor José Serra, participated in the Copenhagen Climate Summit for Mayors, held in partnership by the city of Copenhagen, C40 and ICLEI. The Summit of Mayors was an emblematic event, especially in the face of the poor results of international negotiations during COP-15.

São Paulo's Participation in ICLEI and C40 encouraged the city to undertake commitments including the development of a GHG inventory and a climate action plan, setting reduction targets and a monitoring procedure. By adhering to these commitments, even if rhetorically, the city's administration was motivated to take action (Back, 2012). The partnership between the city and ICLEI was particularly important. The methodology developed by the CCP campaign was used in the city's GHG inventory, and ICLEI was deeply involved in drafting the Municipal Climate Law, pushing forward the inclusion of reduction targets into the bill (Biderman, 2011). The city's participation in the $\mathrm{C} 40$ further contributed towards the mayor's decision to take on a leadership role in addressing climate change.

\section{Leadership vis-à-vis the Federal Government}

While transnational networks played a relevant role in the adoption of the Climate Law, this is certainly not the only-or even the most important-factor driving the city's climate change agenda. Several studies suggest that national government reluctance to undertake real action contributes to the growing municipal leadership in adopting policies to address climate change. Examples of this phenomenon were described by Rabe $(2007,2010)$ in the context of the United States, and in general by Andonova et al. (2009), Abbott (2012), Engel (2006), Falkner (2010) and Ostrom (2010). In other cases, however, the lack of national government engagement in the climate change agenda led to a lack of interest by their respective subnational governments (Amundsen et al., 2010).

São Paulo's municipal climate action is connected to the federal government's lack of action in establishing a national climate change policy. While the city discussed its climate policy, the national government delayed the adoption of a national climate change policy. For instance, despite being required (by Decree 6,263, of 21 November 2007) to develop a National Climate Change Plan by April 2008, the national government only presented such a plan in December 2008. The National Climate Change Policy was presented to Congress and passed following COP-15 (Law 12,187, of 29 December 2009) after São Paulo's municipal climate policy had been approved. São Paulo's municipal climate action is also connected to the federal government's decision not to commit to mandatory reduction targets. Similarly to other non-Annex 1 countries, the Brazilian national government is reluctant to establish GHG emissions reduction targets. When Brazil finally established reduction targets (between $36.1 \%$ and $38.9 \%$ by 2020 , 
based on 2005 emissions), these were voluntary, whereas the target determined by the municipal law in São Paulo was mandatory.

São Paulo's leadership established a national example in taking action to address climate change. There is evidence that the subnational-level policies in both São Paulo city and state have influenced other Brazilian cities and states, and even encouraged the federal government to adopt climate policies (Lucon \& Goldemberg, 2010; Romeiro \& Parente, 2011). The National Association of Municipal Environmental Departments (ANAMMA), which gathers heads of municipal environmental secretariats and departments, called on Brazilian cities to follow São Paulo's example and adopt climate legislation. Proactive action in São Paulo also contributed to a change in the Brazilian government's position, both in international climate negotiations and domestically (Rei et al., 2013).

Finally, the city's leadership in adopting ambitious climate legislation helped promote the city internationally. The adoption of the municipal climate policy supported São Paulo's participation in the C40's International Executive Board-at the time the only Latin American city to do so. With the passing of the Municipal Climate Law, São Paulo gained visibility within the C40. Therefore the city's climate agenda provided international recognition to São Paulo, repositioning it ahead of the national government in relation to the global climate debate.

To conclude, São Paulo's climate agenda was used to demonstrate its leadership vis-à-vis the federal government. The city used an international climate agenda to position itself ahead of the national government. Besides undertaking its own GHG emissions inventories, the municipal government established an ambitious and mandatory reduction target, which passed in the City Council by unanimous vote. Engaging in climate change action and participating in the international debate, the city of São Paulo also found a way to reposition itself in relation to the global climate regime. In fact, São Paulo's initiative made clear that a city from a developing country-even if comparable to Annex I countries—can commit to fighting climate change.

\section{IMPLEMENTING THE MUNICIPAL CLIMATE CHANGE POLICY}

As seen in the previous section, the city of São Paulo adopted climate legislation and a mandatory GHG emissions reduction target. However, five years after the enactment of the Municipal Climate Law, the city is failing to keep up with its commitments. There are some policies in place promoting mitigation and adaptation measures, but many had already been established prior to the enactment of the Climate Law. A transnational interface is observable in some of these policies, particularly in the case of the city's landfill gas recovery facilities and in promoting energy efficiency in the city. 


\section{Joana Setzer et al.}

Yet, the climate-oriented measures implemented so far have not promoted sufficient reductions.

\section{São Paulo’s Mitigation and Adaptation Measures}

The city of São Paulo has been trying to match policies that reduce GHG emissions, control local pollution and generate revenue (Puppim de Oliveira, 2009). The most successful example is the capture and flare of methane gas from landfill sites. The city has two of the world's largest biogas power plants in its landfills. This first methane-to-energy project began operating in 2004 to collect and process biogas from the Bandeirantes landfill and generate electricity at an on-site power plant. The project was developed as a public-private partnership between the city of São Paulo and Grupo Biogás. It was the first landfill gas-to-energy project implemented in Brazil to obtain certified emissions reductions under the CDM. In the first auction, held in September 2007, the transaction totalled about USD 16 million. The other two auctions held in September 2008 and in June 2012 resulted in approximately USD 17.5 million and USD 2.3 million, respectively (BMF-BOVESPA, 2012). The initiative therefore created a triple win situation: GHG emissions reduction, cheap clean energy generation and financial gain from selling carbon credits.

This municipal policy has a clear transnational component. The landfill gas recovery project was replicated in other South American cities (Brasil, 2013) and São Paulo shared its technical knowledge with other cities through transnational networks. ICLEI published a special "Case Study Series” about São Paulo's experience (ICLEI, 2009), the C40 included the case of São Paulo's gas recovery project it in its reports (C40, 2011), and the city shared its technical knowledge with other C40 cities, including Mexico City and Lagos. The project is also part of the United Nations Sustainable Development Knowledge Platform (UN, 2014), and is cited as a benchmark in World Bank $(2011,2012)$ and OECD (2010) publications dedicated to the study of cities and climate change.

C40, in partnership with the Clinton Foundation, has also been involved in initiatives to develop urban transportation systems and energy efficiency technologies in São Paulo. The projects address route optimisation, operational planning, cleaner fuel options, rapid transit systems, and pave the way for replication in other cities around the world (C40-CCI, 2014). As a result of a Memorandum of Understanding entered with the Clinton Foundation, the city substituted 30,512 incandescent lamps for LEDs in traffic lights, out of a total of 142,846 operational units, reducing energy consumption by over $70 \%$. Once all the units are refitted a further economy of 1.5 million $\mathrm{KWh}$ per month in energy consumption is expected. Other energy efficiency projects are in place to substitute old lighting systems with LEDs in tunnels, schools, hospitals and other municipal buildings. 
Policies in the transport sector resulted in further reductions in GHG emissions in the city. Preliminary data from the Second Municipal GHG Inventory estimates that transport-related measures implemented between 2003 and 2011 resulted in reductions of $6.3 \%$ in local air pollutants, as well as a $\mathrm{CO}_{2}$ e emissions reduction of $6.7 \%$-equivalent to avoiding 7.835 tons of $\mathrm{CO}_{2} \mathrm{e} /$ month. These measures began in 2005 and included fossil fuel substitution, improvements in public transport and urban mobility, as well as air quality control. The Ecofrotas programme, for instance, expanded the bus fleet using vehicles moved by cleaner fuels: 1,200 new buses using biodiesel, 60 buses using ethanol and 319 buses using sugar cane diesel. Furthermore, the city invested in retrofitting and recovering the tram system of 190 vehicles, 92 of which are new, and reopened an old tram factory in the city. Hybrid, biofuel, electrical and hydrogen buses are expected to be introduced into the public transport system in the near future. Implementing bus corridors became a top priority for the new administration, which after eight months surpassed its goal of $150 \mathrm{~km}$ (93 miles).

Another municipal climate policy which improved mobility and air quality in São Paulo was the Inspection and Maintenance Programme for motor vehicles. The Programme started in 2008 and was expanded in 2009 to include all vehicles manufactured since 2003 which run on diesel; as of 2010, the inspection became mandatory for the whole city fleet. However, since the change in administration in 2013, contention over the contract with the inspection company has compromised the whole programme. The contract was cancelled in January 2014 and a new tender will have to be launched, following different terms of reference.

Adaptation measures were also included in the Municipal Climate Law. As part of the strategy to reduce climate vulnerability in São Paulo, the city is expanding linear parks through tree planting, revitalizing 100 existing parks, and establishing a 1,320,000ha park in partnership with the private sector. Other initiatives required by the municipal housing plan establish the urbanisation of shanty towns (favelas), removal of houses in risk areas and restructuring slums (PMSP, 2012a). With regard to the public health impacts of climate, the municipality is addressing the proliferation of tropical diseases, particularly leptospirosis and dengue (PMSP, 2012b). Adaptation policies in the city have received less attention from transnational networks and international organisations.

\section{Challenges}

Measures implemented by the city addressing waste, transport, energy efficiency and public health indicate that there are prospects for São Paulo to reduce its urban carbon footprint. However, the target established by the Municipal Climate Law is still far from being achieved. The modest scale and impact of the policies in place reflect the challenges of implementing 


\section{Joana Setzer et al.}

the Municipal Climate Law and cutting emissions in the city. Five specific challenges connected to the implementation of local climate policies are considered here.

The first challenge concerns the implementation of legislation broadly. Although rigorous and thorough, the Municipal Climate Law is not being enforced. Similarly, implementation of the law requiring solar heating systems in new buildings has been limited to a few municipal schools in the city. There are many reasons why environmental regulation often fails to be enforced. Considering the context of developing countries, McAllister (2009) argues that the proximate cause involves the limited capacity of regulatory agencies in terms of staff, technical expertise, financial resources and political will. Environmental regulation also fails to be implemented because of a mismatch between interests opposing and favouring it. Moreover, laws are often symbolic, passed to satisfy some political interest, but not to be implemented.

However, even a law which is not completely enforced has its merits. For one, the relevance of city initiatives and networks is not completely dependent on the amount of GHG reduced. Rather, "the ultimate goal of climate action is redirection of the economy and society onto a low-carbon pathway" (Hoffmann, 2011, p. 107). Furthermore, once there is a law, its content can be enforced. Brazilian public prosecutors have become significant actors in the enforcement of environmental laws and regulations. Under the 1988 Constitution, public prosecutors are entitled to defend environmental interests and call for the enforcement of existing legislation which is not being implemented.

The second challenge to achieving the reduction target is that emissions from the transport sector continue to increase steadily. In 2012, the city had a fleet of approximately 8.6 million licensed vehicles, corresponding to $17.3 \%$ of the national fleet. Between 2001 and 2012, car ownership increased by $76 \%$ in the city, leading to over 3.7 million more cars (Rodrigues, 2013). With a new emerging middle class, the car market has been flourishing. Brazil is already the fourth-largest car market in the world behind China, the U.S. and Japan, and it is likely that new policies established by the federal government in 2012, promoting tax abatements for the car industry and its production chain, will only worsen this scenario.

The third challenge in implementing the municipal climate policy consists of integrating the climate policy into other municipal policies, such as the Master Plan, the main urban regulation that is revised every 10 years. While the city's 2014 Master Plan addresses many issues directly and indirectly connected to climate change, the synergies are not explicit. The 2014 Plan considers a number of social motivations, without relating them to climate mitigation and adaptation policies. To increase mitigation and adaptation efforts, these need to be crosscutting, encompassing all related activities.

The fourth challenge is coordinating the implementation of the municipal climate policy with regional and national policies. Coordination between subnational and national action is prescribed by the national Climate Change 
Law, which establishes implementation through sectoral plans, including transport and energy, directly affecting subnational policies. Gradually, there have been some attempts to coordinate São Paulo's municipal climate policy with the implementation of state climate policies. For example, technical staff from both the city and state share information and data, and communication was facilitated after the state government established the GHG emissions public registry system. In addition, the state government enacted its state climate change law (Law 13,798, of 9 November 2009), which promotes decentralisation of climate policy-making from the regional to the local level. Nevertheless, in Brazil there are many cases of conflict or at least weak coordination between cities, states and the federal government, leading to insufficient or inefficient implementation efforts of climate policies (Puppim de Oliveira, 2009).

Lastly, maintaining and improving transnational action also constitutes a challenge when implementing local climate policies. The Municipal Climate Law contemplates the use of international cooperation mechanisms to provide the city with access to funds for mitigation and adaptation. The city's Climate Action Plan further calls for international interface in the implementation mechanisms for the municipal policy (São Paulo, 2011). The document requires the municipality to identify opportunities to work with national and international institutions. However, since the adoption of the Climate Law, and especially after the new administration took office in 2013, participation in transnational networks and transnational forums has decreased. Moreover, the city's previous engagement in these forums has not been enough to spur lasting agreements and programmes with other cities in the networks. By limiting its transnational participation, the city is restraining itself from playing a role in global climate governance.

\section{CONCLUSION}

This chapter has explored São Paulo's climate policy through an examination of the interactions between transnational and local initiatives that took place during the adoption and implementation of the Municipal Climate Law. Transnational interaction was paramount in promoting the debate about climate change at the local level; for example, requiring the establishment of a local GHG inventory. Transnational interaction also contributed to the adoption of the Municipal Climate Law, which established an ambitious legal framework for reducing emissions. As a result, the city established a precedent for other subnational governments in Brazil to follow. In addition, being a city of a non-Annex I country, São Paulo positioned itself at the forefront of international climate change policy-making.

However, the reduction target is still far from being achieved. The transnational action which helped the city to establish a legal framework and strengthen its international standing has been less relevant in the 


\section{Joana Setzer et al.}

implementation of the Climate Law. Five specific challenges connected to the implementation of local climate policies were considered: enforcing legislation; controlling emissions from the transport sector; integrating the climate policy into other municipal policies; coordinating the implementation of the municipal climate policy with regional and national policies; and maintaining and improving transnational action.

Structural factors further contribute to the discrepancy between the adoption and implementation of São Paulo's Climate Law. For instance, in Brazil a change in government can dramatically alter policy implementation. In the case of São Paulo's climate action, the Municipal Climate Law was adopted within a government that prioritised this agenda, but the new coalition in power opted to focus on improving transport in the city, without explicitly linking it to climate concerns. It could also be that the contribution given by transnational networks to the adoption of São Paulo's Climate Law furthered a Northern agenda which the city could not implement. Yet, such a discrepancy is not exclusive to the city of São Paulo, nor to cities in developing countries. Similarly, many local authorities in rich countries are not making substantial progress in implementing local climate policies (Allman et al., 2004; Bulkeley \& Kern, 2006; Wheeler, 2008).

Despite these challenges, the case suggests that urban climate change policies in São Paulo might well be irreversible. The city took the first step in redirecting its development towards a low-carbon pathway, and fostered a wide debate throughout the country. In addition, because São Paulo's climate policy was established through a municipal law, its terms can be enforced through legal action at any time. Given the potential for local governments to complement global and national-level policies, our findings suggest that reducing the discrepancy between adoption and implementation of local climate policies will become all the more critical. Along these lines, the multilevel governance literature could further explore the impact of interactions between the local and the transnational levels over actual implementation of climate polices and regulation. More generally, future research should give more attention to effectiveness-rather than mere existence-of subnational climate action.

\section{BIBLIOGRAPHY}

Abbott, Kenneth. (2012). The transnational regime complex for climate change. Environment and Planning C: Government and Policy, 30(4), 571-590.

Abbott, Kenneth W. (2013). Strengthening the transnational regime complex for climate change. Transnational Environmental Law, FirstView, 1-32.

Acuto, Michele. (2013). The new climate leaders? Review of International Studies, FirstView, 1-23.

Allman, Lee, Fleming, Paul, \& Wallace, Andrew. (2004). The progress of English and Welsh local authorities in addressing climate change. Local Environment, 9(3), 271-283. 
Amundsen, H., Berglund, F., \& Westskog, H. (2010). Overcoming barriers to climate change adaptation: a question of multilevel governance? Environment and Planning C: Government and Policy, 28(2), 276-289.

Andonova, Liliana B., Betsill, Michele M., \& Bulkeley, Harriet. (2009). Transnational climate governance. Global Environmental Politics, 9(2), 52-73.

Andonova, Liliana B., \& Mitchell, Ronald B. (2010). The rescaling of global environmental politics. Annual Review of Environment and Resources, 35(1), 255-282.

Back, Adalberto Gregório. (2012). Agenda climática do município de São Paulo: contribuição de redes transnacionais de governos locais. Teoria \& Pesquisa: Revista de Ciência Política, 21(2), 97-107.

Bäckstrand, Karin. (2008). Accountability of networked climate governance: the rise of transnational climate partnerships. Global Environmental Politics, 8(3), 74-102.

Betsill, Michele M. (2006). The multilevel governance of global climate change (pp. 1-6). MEA Bulletin: Published by the International Institute for Sustainable Development (IISD) in cooperation with the United Nations Environment Programme's Division for Environmental Law and Conventions (UNEP DELC).

Betsill, Michele M., \& Bulkeley, Harriet. (2004). Transnational networks and global environmental governance: the Cities for Climate Protection program. International Studies Quarterly, 48(2), 471-493.

Betsill, Michele M., \& Bulkeley, Harriet. (2006). Cities and the multilevel governance of global climate change. Global Governance, 12(2), 141-159.

Biderman, Rachel. (2011). Limites e alcances da participação pública na implementação de políticas subnacionais em mudanças climáticas no municipio de São Paulo. (PhD dissertation), Fundação Getulio Vargas, São Paulo.

BMF-BOVESPA. (2012). BM\&FBOVESPA anuncia resultado do leilão de créditos de carbono realizado nesta terça-feira, 12/06. Retrieved 28 October 2014 from http://www.bmfbovespa.com.br/pt-br/noticias/2012/BMFBOVESPA-anunciaresultado-do-leilao-de-creditos-de-carbono-2012-06-12.aspx?tipoNoticia=1\&id ioma $=\mathrm{pt}-\mathrm{br}$

Brasil. (2004). Comunicação Nacional do Brasil à Convenção-Quadro das Nações Unidas sobre Mudança do Clima.

Brasil. (2010). Segunda Comunicação Nacional do Brasil à Convenção-Quadro das Nações Unidas sobre Mudança do Clima.

Brasil. (2013). Produção brasileira de biogás será modelo para o Uruguai. Portal Brasil. Retrieved 28 October 2014 from http://www.brasil.gov.br/ciencia-e-tec nologia/2013/08/producao-brasileira-de-biogas-sera-modelo-para-o-uruguai

Broto, Vanesa Castan, \& Bulkeley, Harriet. (2013). A survey of urban climate change experiments in 100 cities. Global Environmental Change, 23, 92-102.

Bulkeley, Harriet. (2005). Reconfiguring environmental governance: towards a politics of scales and networks. Political Geography, 24(8), 875-902.

Bulkeley, Harriet, Andonova, Liliana B., Bäckstrand, Karin, Betsill, Michele M., Compagnon, Daniel, Duffy, Rosaleen, Kolk, Ans, Hoffmann, Matthew, Levy, David, Newell, Peter, Milledge, Tori, Paterson, Matthew, Pattberg, Philipp, \& Van Deveer, Stacy D. (2012). Governing climate change transnationally: assessing the evidence from a database of sixty initiatives. Environment and Planning C: Government and Policy, 30(4), 591-612.

Bulkeley, Harriet, Broto, Vanesa Castan, Hodson, Mike, \& Marvin, Simon (Eds.). (2011). Cities and low carbon transitions. London and New York: Routledge.

Bulkeley, Harriet, \& Kern, Kristine. (2006). Local government and the governing of climate change in Germany and the UK. Urban Studies, 43(12), 2237-2259.

C40-CCI. (2014). C40-CCI Cities. Retrieved 28 October 2014 from http://www.clin tonfoundation.org/our-work/clinton-climate-initiative/programs/c40-cci-cities 


\section{Joana Setzer et al.}

C40. (2011). Climate action in megacities: C40 cities baseline and opportunities. New York: C40 and ARUP.

C40. (2014). About C40. Retrieved 3 September 2014 from http://www.c40.org/ about

Engel, Kirsten. (2006). State and local climate change initiatives: what is motivating state and local governments to address a global problem and what does this say about federalism and environmental law? Urban Lawyer, 38(3), 1015-1030.

Falkner, Robert, Stephan, Hannes, \& Vogler, John. (2010). International climate policy after Copenhagen: towards a 'building blocks' approach. Global Policy, $1(3), 252-262$.

Fisher, Susannah. (2012). Policy storylines in Indian climate politics: opening new political spaces? Environment and Planning C: Government and Policy, 30(1), 109-127.

Giddens, Anthony. (2009). The politics of climate change. Cambridge: Polity Press.

Gore, Christopher D. (2010). The limits and opportunities of networks: municipalities and Canadian climate change policy. Review of Policy Research, 27(1), 27-46.

Hale, Thomas, \& Roger, Charles. (2014). Orchestration and transnational climate governance. Review of International Organizations, 9(1), 59-82.

Heyvaert, Veerle. (2013). What's in a name? The covenant of mayors as transnational environmental regulation. Review of European, Comparative and International Environmental Law, 22(1), 78-90.

Hoffmann, Matthew J. (2011). Climate governance at the crossroads: experimenting with a global response after Kyoto. Oxford: Oxford University Press.

IBGE. (2011). Posição ocupada pelos 100 maiores municípios, em relação ao Produto Interno Bruto a preços correntes e participações percentuais relativa e acumulada (Vol. 2011).

ICLEI. (2005). Boletim Conexão Clima No. 4. In ICLEI (Ed.). Climate Connection Report, p. 14. Retrieved 28 October 2014 from http://archive.iclei.org/fileadmin/ user_upload/documents/LACS/Portugues/Noticias_e_Eventos/Conexao_Clima/ Conexao_Publicacoes/Conex_o_Clima_4_A.pdf

ICLEI. (2009). Turning pollution into profit: the Bandeirantes Landfill Gas to Energy Project. ICLEI Case Studies. São Paulo.

ICLEI. (2014a). Local Government Climate Roadmap. Retrieved 28 October 2014 from http://www.iclei.org/climate-roadmap/home.html

ICLEI. (2014b). Who is ICLEI? Retrieved 3 September 2014 from http://www.iclei. org/iclei-global/who-is-iclei.html

IISD. (2005). Eleventh session of the Conference of the Parties to the Climate Change Convention and first meeting of the Parties to the Kyoto Protocol, Palais de Congrès, Montréal, Canada, 28 November-9 December 2005. Retrieved 28 October 2014 from http://www.iisd.ca/climate/cop11/

Instituto Ekos Brasil and Geoklock Consultoria e Engenharia Ambiental (2013). Inventário de emissões e remoções antrópicas de gases de efeito estufa do município de São Paulo de 2003 a 2009 com atualização para 2010 e 2011 nos setores de energia e resíduos. São Paulo, ANTP. 148pp. Retrieved 28 October 2014 from http://www.prefeitura.sp.gov.br/cidade/secretarias/meio_ambiente/ menu/index.php?p=167735

Krause, Rachel M. (2012). An assessment of the impact that participation in local climate networks has on cities' implementation of climate, energy, and transportation policies. Review of Policy Research, 29(5), 585-604.

Lidskog, Rolf, \& Elander, Ingemar. (2010). Addressing climate change democratically. Multi-level governance, transnational networks and governmental structures. Sustainable Development, 18(1), 32-41. 
Lucon, Oswaldo, \& Goldemberg, Jose. (2010). São Paulo, the "other" Brazil: different pathways on climate change for state and federal governments. Journal of Environment and Development, 19(3), 335-357.

McAllister, Lesley K. (2009). Regional climate regulation: from state competition to state collaboration. San Diego Journal of Climate and Energy Law, 81(1), 81-102.

OECD. (2010). Cities and climate change. Paris: OECD.

Ostrom, Elinor. (2010). Polycentric systems for coping with collective action and global environmental change. Global Environmental Change, 20(4), 550-557.

PMSP. (2012a). Ata da 10a Reunião do Grupo de Trabalho Sustentabilidade e Uso do Solo-14/03/2012. Retrieved 28 October 2014 from http://www.prefei tura.sp.gov.br/cidade/secretarias/upload/chamadas/ata_da_10_reuniao_do_gt__ uso_do_solo_-_14-03-2012_1331922980.pdf

PMSP. (2012b). Ata da 31 ${ }^{a}$ Reunião do Comitê Municipal de Mudanças Climáticas e Ecoeconomia de São Paulo-22/11/2012. Retrieved 28 October 2014 from http://www.prefeitura.sp.gov.br/cidade/secretarias/upload/chamadas/ata_31_reu niao_comite_1355854241.pdf

Puppim de Oliveira, Jose Antonio. (2009). The implementation of climate change related policies at the subnational level: an analysis of three countries. Habitat International, 33(3), 253-259.

Rabe, Barry G. (2007). Beyond Kyoto: climate change policy in multilevel governance systems. Governance, 20(3), 423-444.

Rabe, Barry G. (Ed.). (2010). Greenhouse governance: addressing climate change in America. Washington, DC: Brookings Institution.

Rei, Fernando, Cunha, Kamyla Borges da, \& Setzer, Joana. (2013). Paradiplomacia ambiental: a participação brasileira no regime internacional das mudanças climáticas. Revista de Direito Ambiental, 71, 265-287.

Rodrigues, Juciano Martins (2013). Crescimento da frota de automóveis e motocicletas nas metrópoles brasileiras (2001-2012). Rio de Janeiro: Observatório das Metrópoles, Instituto Nacional de Ciência e Tecnologia (INCT), p. 17. Retrieved 28 October 2014 from http://www.observatoriodasmetropoles.net/download/ auto_motos2013.pdf

Romeiro, Viviane, \& Parente, Virginia. (2011). Climate change regulation in Brazil and the role of subnational governments. In Ronaldo Seroa da Motta, Jorge Hargrave, Gustavo Luedemann, \& Maria Bernadete Sarmiento Gutierrez (Eds.), Climate change in Brazil: economic, social and regulatory aspects (pp. 45-57). Brasília: Institute for Applied Economic Research-IPEA.

Romero-Lankao, Patricia. (2007). How do local governments in Mexico City manage global warming? Local Environment, 12(5), 519-535.

São Paulo. (2011). Guidelines for the Action Plan of the city of São Paulo for mitigation and adaptation to climate change. The Municipal Committee on Climate Change and Eco-economy and the Working Groups for Transportation, Energy, Construction, Land Use, Solid Waste and Health. São Paulo.

Setzer, Joana. (2009). Subnational and transnational climate change governance: evidence from the state and city of São Paulo, Brazil. Paper presented at the 5th World Bank Urban Research Symposium. Cities and Climate Change-Responding to an Urgent Agenda, Marseille. Retrieved 28 October 2014 from www.siteresources. worldbank.org/INTURBANDEVELOPMENT/336387-1256566800920/Setzer.pdf

Setzer, Joana, \& Biderman, Rachel. (2013). Increasing participation in climate policy implementation: a case for engaging SMEs from the transport sector in the city of São Paulo. [Special issue "Novel Multi-sector Networks and Entrepreneurship in Urban Climate Governance”. Schroeder, H., Burch, S., \& Rayner, S. (guest eds.)]. Environment and Planning C: Government and Policy, 31(5), 806-821. 


\section{Joana Setzer et al.}

Toly, Noah J. (2008). Transnational municipal networks in climate politics: from global governance to global politics. Globalizations, 5(3), 341-356.

UFRJ. (2005). Inventario de emissões de gases de efeito estufa do município de São Paulo. São Paulo: Prefeitura Municipal de São Paulo and Secretaria do Verde e do Meio Ambiente Retrieved 28 October 2014 from http://ww2.prefeitura.sp.gov. br//arquivos/secretarias/meio_ambiente/Sintesedoinventario.pdf

United Nations. (2014). The Bandeirantes Landfill Gas to Energy Project. Retrieved 28 October 2014 from http://sustainabledevelopment.un.org/index.php?page= view\&type $=1006 \&$ menu=1348\&nr=2180

Wang, Rui. (2013). adopting local climate policies: what have California cities done and why? Urban Affairs Review, 49(4), 593-613.

Wheeler, Stephen M. (2008). State and municipal climate change plans: the first generation. Journal of the American Planning Association, 74(4), 481-496.

World Bank. (2011). Guide to climate change adaptation in cities. Washington, DC: World Bank.

World Bank. (2012). Climate change, disaster risk, and the urban poor: cities building resilience for a changing world. In Judy L. Baker (Ed.), Urban development series. Washington, DC: World Bank, Anex 7, 235-267. 


\title{
7 Urban Climate Governance through a Sustainability Lens
}

Exploring the Integration of Adaptation and Mitigation in Four British Columbian Cities ${ }^{1}$

\author{
Sarah Burch, Alison Shaw, Freya \\ Kristensen, Jobn Robinson and \\ Ann Dale
}

\section{INTRODUCTION}

The landscape of climate change governance is shifting; global negotiations have produced modest successes, but have largely failed to trigger a rapid or ambitious transition towards low carbon development pathways. New actors and scales of governance are thus entering the fray: non-state actors, including the private sector (Burch et al. 2013), civil society, and transnational networks (Betsill and Bulkeley 2004) are increasingly influential, and experiments in climate governance are taking place at the urban scale (Bulkeley and Castan Broto 2013).

At all scales, climate change presents complex and uncertain challenges that drastically reduce the likelihood that the goals of sustainability will be achieved (Cohen et al. 1998, Robinson 2004, Adger et al. 2005). As such, arguments have arisen to suggest that unless climate change policies are embedded in social, economic, technological and environmental decisions, which comprise underlying socioeconomic trajectories and development paths, it will be prohibitively expensive and disruptive to achieve our climate goals (Nakicenovic and Swart 2000, Morita et al. 2000, Robinson et al. 2001, Swart et al. 2003). Indeed, the IPCC's Fourth Assessment Report (2007) argued for a strong linkage between mitigation, adaptation and sustainable development (Klein et al. 2007, Sathaye et al. 2007) and more recently the IPCC's Special Report on extreme weather events makes direct connections between the risk and extent of climate impacts, such as extreme weather, and socioeconomic conditions, stating that "the interactions among climate change mitigation, adaptation, and disaster risk management may have a major influence on resilient and sustainable pathways" (IPCC 2012: 16).

The common notion that adaptation is inherently local, while mitigation is entirely a global issue, has also come under critical scrutiny. While the 


\section{Sarab Burch et al.}

emission of greenhouse gases may be effectively governed at the global level, specific mitigation projects are implemented locally, having implications for urban sustainability priorities. At the same time, adaptation in cities may result in tradeoffs for mitigation by increasing greenhouse gas emissions, and may also best be supported by transfer of funds and technology via supra-national mechanisms. The aspects of adaptation that are deeply local, however, such as climatic and geographic differences, governance systems, public infrastructure and the importance of traditional knowledge (Laukkonen et al. 2009: citing: Huq et al. 2006, Satterthwaite et al. 2007), are true of mitigation as well. While a tonne of carbon dioxide reduced anywhere on the planet has the same effect on the climatic system, the design and implementation of mitigation is a deeply local endeavor, contingent on local values, capacities and governance. Furthermore, mitigation, when embedded with adaptation into broader sustainability initiatives, can yield a suite of co-benefits, ensuring deeper integration with existing planning processes and operations, perhaps enabling a transition towards more sustainable pathways in the process (Burch et al. 2014). For instance, many energy efficiency strategies contribute to both mitigation and adaptation, which may prove this artificial separation spurious in the long run.

The urban scale is the level at which decisions about energy and transportation infrastructure, service and provision decisions, forest and biodiversity protection, agro-fuels cultivation, storm-water infrastructure and natural hazard and flood risk systems play out. All of these policies, some of which are political priorities, are deeply influenced by climate goals and strategies, while also having broader implications for community sustainability. Indeed, long-term planning in these realms may have been considered in some communities prior to the advent of the climate change or sustainability discourse. Explicit efforts to integrate these various policy realms, however, may offer opportunities to embed climate mitigation and adaptation goals into existing mandates and budgets within municipal organizational structures (Bizikova et al. 2008). For instance, the City of Vancouver is in the preliminary stages of linking urban biodiversity, storm-water management and climate mitigation and adaptation, achieving synergistic and reinforcing adaptation policies that identify and build upon co-benefits of climate action. Cities face hurdles, however, due to diverse combinations of technology lock-in, policy and institutional rigidities and lack of support and agency among the broader community (Burch 2010a, Kollmuss and Agyeman 2002, Lorenzoni et al. 2007, Unruh 2000). 'Best practice' approaches for the integration of climate change goals and policies into broader sustainability priorities are being identified globally, but little empirical evidence exists on the ways that integration of climate change and sustainability may offer benefits capable of leveraging existing (or required) political, social, technological community capacity to build overall resilience (Smit et al. 2001, Adger et al. 2004, Adger et al. 2005, Yohe et al. 2007). (For one exception, focusing on the City of Vancouver, see Robinson 2013). 
Thus, a reconceptualization of the nature of urban climate governance is justified: not only are both adaptation and mitigation squarely within the domain of governance mechanisms at this scale, but weaving the two response options together and considering holistic sustainability outcomes may require the inclusion of new actors, processes and tools.

Urban sustainability requires rapid and significant responses to the threat of natural and anthropogenic change, climate and otherwise. Little empirical evidence exists, however, that points to the types of and extent to which net positive effects, or co-benefits, can be attained with a broader sustainability framing. By analyzing data gathered in four case study cities ${ }^{2}$ in the Canadian province of British Columbia, as part of the "Meeting the Climate Change Challenge $\left(\mathrm{MC}^{3}\right)$ " project, for the purposes of this chapter we ask the following three questions: (1) what, if any, are the benefits of embedding climate mitigation and adaptation action into a sustainability framework at the urban scale; (2) how is this initiated in practice; and (3) in what ways is this shaped by partnerships and interactions between both state and non-state actors at multiple scales (see www.mc-3.ca)? The first question pertains to the issue of framing, the second addresses drivers and the third pertains to governance. Ultimately, these features are explored for their potential for more broad-scale transformative changes in underlying development paths.

The section that follows explores the common dichotomy between adaptation and mitigation, and provides theoretical underpinnings for uncovering the common roots of adaptation and mitigation in the underlying development path. Section 3 describes the goals of the $\mathrm{MC}^{3}$ project and the overall context in the Province of British Columbia (B.C.). Section 4 briefly describes the comparative case study methods used to investigate the relationships between sustainability, adaptation and mitigation in four case study communities in the $\mathrm{MC}^{3}$ project. Section 5 outlines and discusses key findings from the case studies. Section 6 provides concluding lessons and future research on the implications of a sustainability framing for the conceptualization of adaptation and mitigation in the context of urban climate governance.

\section{INTEGRATING ADAPTATION, MITIGATION AND SUSTAINABILITY}

It has been common in the climate change literature to emphasize the differences between adaptation and mitigation (Klein et al. 2007), a distinction embedded in the very structure of the Intergovernmental Panel on Climate Change (IPCC). This dichotomy initially arose out of the perception that mitigation would be implemented rapidly enough to address the climate change problem, while adaptation proponents were 'defeatist' or 'fatalistic' (Biesbroek et al. 2009). Framing climate change as an environmental rather 


\section{Sarab Burch et al.}

than human issue perpetuates this distinction, leading to different ways of producing knowledge about mitigation and adaptation: largely economic and technologically oriented in the case of mitigation, compared with the more ecologically and socially oriented expertise brought to bear on adaptation. Spatial, temporal and stakeholder differences between the two (Biesbroek et al. 2009) may also be over-emphasized. The beneficial effects of mitigation, for instance, are often depicted as being external to the region implementing the strategies (Wilbanks et al. 2007). However, this is only the case if potential co-benefits associated with mitigation remain unexplored, and the social, political and economic interconnections between regions and nations are ignored. These perceived differences have become enshrined in complex institutional architectures, trickling down even to the local level, and maintaining significant path dependencies through the separation of adaptation and mitigation approaches in practice.

Both mitigation and adaptation are more likely to be undertaken if compelling co-benefits can be demonstrated (Markandya and Halsnaes 2002, Dang et al. 2003). For instance, reforestation in watersheds that initially aimed to decrease flood risk (Dang et al. 2003) may also lead to carbon sequestration, decreased death and illness due to air pollution and enhanced ecosystem integrity (Beg et al. 2002, Cifuentes et al. 2001). The importance of co-benefit approaches is that they may simultaneously decrease vulnerability to climate change impacts, enhance ecological integrity and biodiversity, sink carbon, and contribute to healthier, more livable communities (Naumann et al. 2011). A zero-sum relationship between development and climate change is less likely to occur if synergies are explored and tradeoffs are avoided, and these are more clearly revealed through an integrated approach to community planning.

Illustrating and capitalizing upon these co-benefits is important in urban contexts more broadly speaking. It opens up the 'space' for framing climate change in a way that resonates with local political priorities, ensuring traction with the public and potentially more effective collaboration on a diverse and inter-disciplinary set of issues. This is compatible with the suggestion to frame climate change as a development problem rather than an environment problem (Metz et al. 2002). Reframing the linkage between adaptation and mitigation moves beyond a discourse that simply reveals inter-connections between the two, to a framing that instead encourages an examination of how both arise out of deeper development trajectories and to promote innovative designs for new ones (see Burch et al. 2014).

Responding to climate change represents a significant opportunity, if addressed through the lens of sustainability: mitigation and adaptation may simultaneously contribute to increased efficiency of resource use, decreased human pressure on local and regional ecological systems and improved human health and well-being (Munasinghe and Swart 2005). While planners and development practitioners once viewed climate change as only one of many stressors and competing priorities (alongside poverty, health and 
sanitation, for instance), the fundamental way in which climate change is shaping (and being shaped by) development is leading to an increasing recognition that a broader sustainability-oriented perspective on adaptation and mitigation is required (Biesbroek et al. 2009, Robinson et al. 2006).

As such, development paths, characterized by inertia or path dependency, with varied capacities and constraints on agency occurring at each scale and governed at multiple levels, are viewed as the unit of analysis for broad systems change towards sustainability. An alternative development pathway arises from a constellation of social and ecological systems, networks amongst actors and diverse technologies (Burch et al. 2014). It determines the costs of emissions reductions and adaptation over the short and long run and raises the challenge of ensuring that actions taken to address climate change do not obstruct local and regional sustainable development (Beg et al. 2002). The concept of response capacity has emerged to help with this calculus and is defined as a pool of resources that is rooted in the underlying development path, which gives rise to and supports both adaptive and mitigative responses to climate change (Burch and Robinson 2007, Burch 2010a).

The lack of progress on climate change policy at the international level does not appear to be due to a lack of technological options nor even prohibitive costs (Munasinghe and Swart 2005), and evidence suggests that this is true in the context of cities as well (Burch 2010a, Burch 2010b). Mitigation can become more attractive if integrated with broader socioeconomic strategies (Munasinghe and Swart 2005), overcoming a suite of financial, cultural and institutional barriers (Burch 2010b). Incentives to do so are lacking, however, while organizational design and institutional rules often prohibit this type of cross-departmental collaboration. The urban scale becomes an interesting test-bed to investigate the co-benefits of embedding climate change into broader sustainability goals. Thus, it is of interest to explore whether and how this embeddedness is occurring in cities in the Province of B.C., already an identified leader on climate mitigation. We explore the different approaches to climate innovation and the potential for net benefits if integrated within broader sustainability goals.

\section{CLIMATE CHANGE AND SUSTAINABILITY INNOVATION IN BRITISH COLUMBIA, CANADA}

Within B.C., cities are responding to a series of unique policy instruments implemented by the B.C. government, including a revenue-neutral carbon tax implemented in 2008, incentives for carbon-neutral government operations, and a requirement for legislated climate change targets and planning to be included in official community plans. Ambitious provincial targets of reducing province-wide emissions to $33 \%$ below 2007 levels by 2020 have been a key element of these instruments. The resultant widespread 


\section{Sarab Burch et al.}

local-scale climate innovation has provided a unique opportunity to investigate types of policy, institutional, technical and social innovations that communities employ to respond to such policy and targets, and the types of inertia being addressed in order to implement effective plans and projects.

The Meeting the Climate Change Challenge $\left(\mathrm{MC}^{3}\right)$ (2011-2012) project explored the dynamics of community-level best practice responses to climate change in B.C., including key obstacles and opportunities faced, the drivers of innovation and the potential for these community actions to lead to transformative change (see www.mc-3.ca). Ultimately, the goal of this work is to directly support community responses to climate change and build momentum behind actions that hold significant potential to reach ambitious provincial and local mitigation targets. The project addresses four research questions through comparative case study analysis research in communities and regional districts in B.C.:

1. In what ways are communities responding to legislative and policy changes for climate change mitigation adopted by B.C.?

2. What are the drivers of innovative community action on climate change in B.C., and what obstacles and opportunities exist?

3. What potential do these activities have to lead to transformative change, or a fundamental shift in the underlying development path?

4. How best might knowledge mobilization be supported both within the community of best practice cases as well as between leaders and those who have yet to respond to climate change?

Drivers of transformative change and 'best practices' on climate action at the community scale that were investigated included: (i) culture and leadership, (ii) institutional and technical change, (iii) systems of governance and integrated decision-making, (iv) the role of partnerships and intermediaries, (v) types and styles of knowledge mobilization and social learning.

The $\mathrm{MC}^{3}$ project included multiple methodological components: collection and analysis of greenhouse gas inventory data for local governments across the province; an assessment of the state of local climate change responses, resources and policies; and detailed case study field work in 11 case study communities. A mixed-methods and contextual, comparative case study approach (Yin 2003, Stake 2006, Stake 1995) was used. Case selection followed a replication (rather than a sampling) logic; cases selected are expected to have both similar and contrasting results from one another based on the theoretical framework, differences in size, location and composition (Yin 2003).

Two primary criteria structured the initial selection of case studies and subsequently informed the interview template (see below).

1. Leadership on adaptation, mitigation, integrated adaptation/mitigation approaches and sustainability. We chose examples of particularly 
innovative action that has either transformed emissions pathways and/ or vulnerability or holds significant promise to do so in the future.

2. Evidence of multi-stakeholder involvement and social learning on climate change. The scale of the cases were not limited to municipal governments, thus opening up the possibility of studying compelling action in neighbourhoods, regions and other scales. We chose cases where action at one scale has been taken up by, or is of direct relevance to, other scales.

To enhance the relevance of findings from these cases to a variety of communities across the province, secondary case selection criteria were chosen to identify best practices from diverse communities and a range of approaches. Secondary criteria included: (1) a mix of small, medium and large communities; (2) a mix of rural and urban; (3) communities with a long history of climate change action and emerging leaders; (4) a mix of resource-based and diversified economies; (5) a mix of government-led and grass-roots approaches; (6) generalizability or relevance to other communities; and (7) evidence of social mobilization as a component of action. These criteria alone demonstrate the ways that climate change and sustainability planning emerge from and integrate with a wide range of questions already considered in the community planning process.

Nine B.C. communities and two projects at the regional and neighbourhood scale were selected as case studies (see www.mc-3.ca for greater detail). Each of these cases met the two primary criteria and represented a diverse sample with regard to the seven secondary criteria (see Figure 7.1). Cases were chosen in close collaboration with an array of research, civil society and government actors involved in climate change actions at the community scale in B.C. The 11 case studies were chosen for their notable, but varying, efforts to address climate change. Given the provincial policy focus, noted above, the $\mathrm{MC}^{3}$ project emphasized leadership on mitigation in its case selection criteria. For the purposes of this chapter, however, the analysis is limited to data gathered in four urban cases: Surrey, Vancouver, the City of North Vancouver and Victoria.

A project of this size demands checks and balances in order to ensure the relative comparability of cases and robustness of analysis and findings. A comparative case-study approach was used both in the data collection and in the analytical aspects of the project. Outlined below is the five-step approach undertaken to do this.

1. Document review and collection: the substantive local knowledge of the research team was to used to identify key technical and policy documents and initiatives relevant to climate change and sustainability for each of the case study communities.

2. A comparative interview template and interview-training workshop: a common interview template was used to ensure interviewees were 


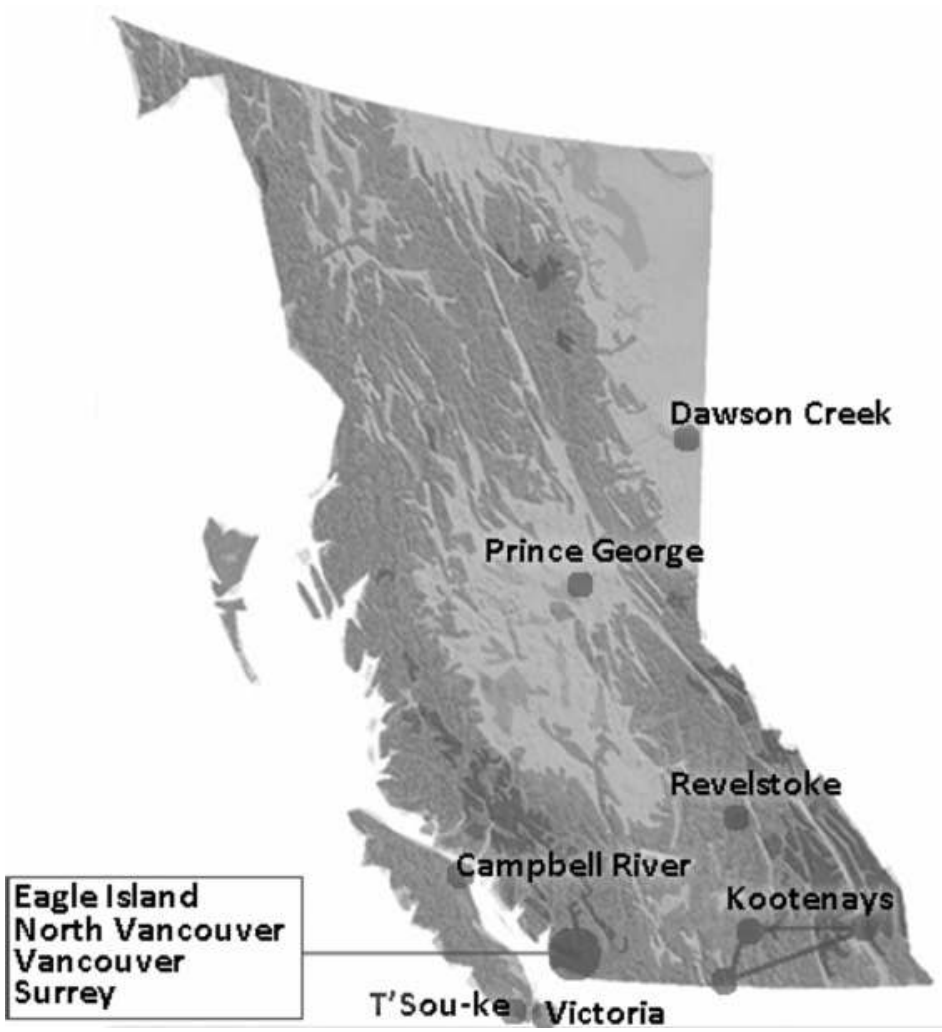

Figure 7.1 Diverse case study selection in 11 communities across the Province of British Columbia.

asked the same research questions while also using common interviewing techniques (developed through the workshop). Semi-structured interviews were conducted with 5-12 key actors (individuals directly involved in the design and implementation of the initiatives, as well as decision-makers and practitioners integrally involved in the community's climate change responses) from each case. Snowball sampling (cf. Heckathorn 1997) helped identify other critical stakeholders. The interviewees ranged from Mayors, Chief Administrative Officers, City Managers, city staff (e.g. planning, engineering, sustainability and climate coordinating staff) and elected officials to community leaders and intermediary partners. Interviewers filled out the template after each interview, as established in the interview-training workshop. Interviews were analyzed using a coding structure informed by the key research questions. This common interview approach facilitated the relative comparability of the 88 interviews both within and across case communities. 
3. A comparative protocol for each case: a case study protocol was developed and case leads were asked to provide relevant information in the form of a systematized protocol. Each of the case protocols had consistent format and comparable content across the cases, becoming a significant reservoir for critical, detailed information. Information ranged from contextual information about the community, its policies, documented actions, initiatives, and so on (taken from the document review) to relevant analysis from the interviews about key indicators and drivers of climate action; perceived responsibility and capacity of government and other actors; the influence of intermediaries and the capacity for transforming the way decisions are made in practice. The protocol provided a way to systematize information while also incorporating the case leads' individual analyses and could be referred back to for clarity in the meta-analysis.

4. A synopsis protocol from each case: each of the case study leads was then asked to fill out an abbreviated version of the comparative protocol which outlined the key analytical findings of each case, again in a systematized format, relating to the overall research questions. This concise three- to five-page synopsis provided a comparable overview of each of the cases.

5. Master comparative worksheet: For the purposes of this chapter, analysis of the data was limited to questions relating to the drivers of climate action in communities, interactions between mitigation and adaptation and synergies and/or tradeoffs in the integration of sustainability, adaptation and mitigation. Using MS Excel software, a master comparative worksheet was developed for each of the relevant questions. Both the detailed and abbreviated protocols were coded from each case to identify most relevant responses, facilitating optimal comparison.

Mendeley collaborative software was used throughout the process, providing a secure and common site for all research team members to organize and access relevant case documents. This data is available to be mined for numerous other questions that may arise. A separate, secure University-based site was used to store the raw interview data.

\section{FINDINGS: LINKING ADAPTATION AND MITIGATION, AND THE INFLUENCE OF A SUSTAINABILITY FRAMING}

In many communities, either mitigation or adaptation remains the dominant or primary focus of climate change responses, rather than an integration of the two. In part this is because provincial policy has focused on legislating mitigation, while adaptation has only recently begun to build momentum. To varying extents, communities that are mainly pursuing one of these 


\section{Sarah Burch et al.}

strategies are also considering the synergies or tradeoffs with adaptation, as well as the implications of the mitigation activities for other development priorities. The four urban cases presented here, however, have undertaken climate actions under the banner of a broader, systems-oriented sustainability mandate. In these communities, climate change is often integrated into existing policies and master plans, such as the official community plans (OCP), embedding it into other social, economic and environmental policies. Two broad approaches to the conceptualization of adaptation and mitigation linkages in urban spaces have been identified. These are:

1. Primarily (a) mitigation or (b) adaptation focus, with varying levels of integration (or consideration of synergies/tradeoffs)

2. A systems-level sustainability approach.

Rather than being distinct categories, these approaches represent positions along a spectrum of responses (see Figure 7.2). Integration of adaptation with mitigation, for instance, can range from simply simultaneously considering greenhouse gas reduction and protection against impacts in climate change policy and planning documents to embedding these concerns within the entire range of municipal functions. The emphasis of the $\mathrm{MC}^{3}$ project was on examining the climate change responses that were sparked, in part, by provincial leadership on mitigation. As such, leadership on adaptation became a secondary focus in case study selection. Empirical work in the communities revealed that an integrated sustainability approach was prevalent amongst many of the 'leading' communities-hence the emerging focus on a sustainability framing. The four cases presented here fall on the right side of this spectrum, while other cases considered by the $\mathrm{MC}^{3}$ project

- Response to impacts OR causes

- Adaptation / Mitigation
- Responses to both
Responses to

development

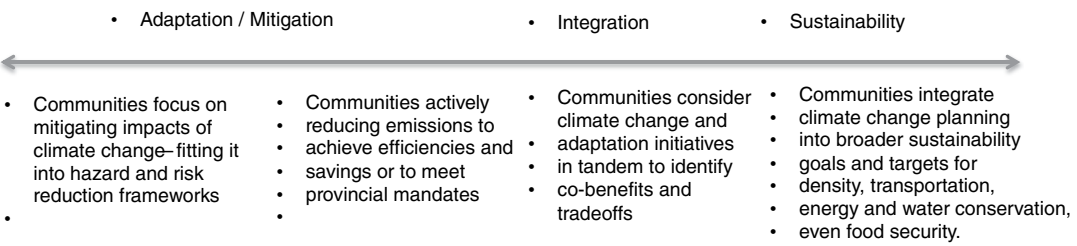

Figure 7.2 Different responses and levels of integration in community climate change planning.

Note: It is clear that community responses to climate change can begin at any point along the axis. Yet, for the purposes here, the left side of the arrow represents a business as usual, or siloed planning approach, whereas moving right along the axis represents increasingly greater integration of mitigation and adaptation with a sustainability framing embedding climate change in overarching development goals. 
(which range from rural towns to multi-region collaborations) occupy a range of positions (see Shaw et al. 2014).

The difference between positions along this continuum is crucial for three reasons. First, completely different actions may be suggested when a sustainability approach is taken, when compared to narrowly focusing on climate change adaptation and/or mitigation. Examples include greater integration with initiatives that address social equity, biodiversity conservation and public health. Second, if a development path framing is employed to understand the deeply interwoven trajectories that give rise to emissions and vulnerability, a sustainability approach may be more likely to address these fundamental drivers (via patterns of development, urban form, socio-technical innovation, culture and so forth). Finally, each approach faces different challenges with respect to governance; for example, a climate-centric approach may require the participation of a narrower set of stakeholders. Both approaches, however, suggest the need for more fluid, issue-oriented arrangements characteristic of multi-level governance (Betsill and Bulkeley 2006).

Table 7.1 below identifies the key drivers of climate change responses and innovations (or outcomes of that response). The analysis focuses, in particular, on the integration of mitigation and adaptation and embeddedness of climate action within other existing policies, plans and initiatives, characterized as a sustainability approach.

\section{Key Findings and Implications for Urban Climate Governance}

All communities credited the provincial government's 2008 Climate Action Charter (CAC) for either legitimizing or incentivizing climate mitigation efforts occurring within their communities. This may be an artifact of the case study selection that emphasized climate change leadership (as there are many communities that are signatory to the Charter but have not achieved carbon neutrality, and others still which have not signed the Charter). This credit may also result from complementary provincial legislation including:

- The 2005 Integrated Community Sustainability Planning (ICSP) Initiative, which combines efforts for addressing climate change and community sustainability planning

- The 2008 Bill 27, the Green Communities Act, that provides local governments with the incentive and tools to reduce emissions, conserve energy and work towards creating more compact, sustainable communities, including by enshrining climate targets in the legislative framework of the official community plan (OCP) across the province.

All four of the communities presented here used the lens of sustainability to frame and develop mitigation and adaptation policies and plans. This framing employs a more systems-oriented approach to climate responses, in 


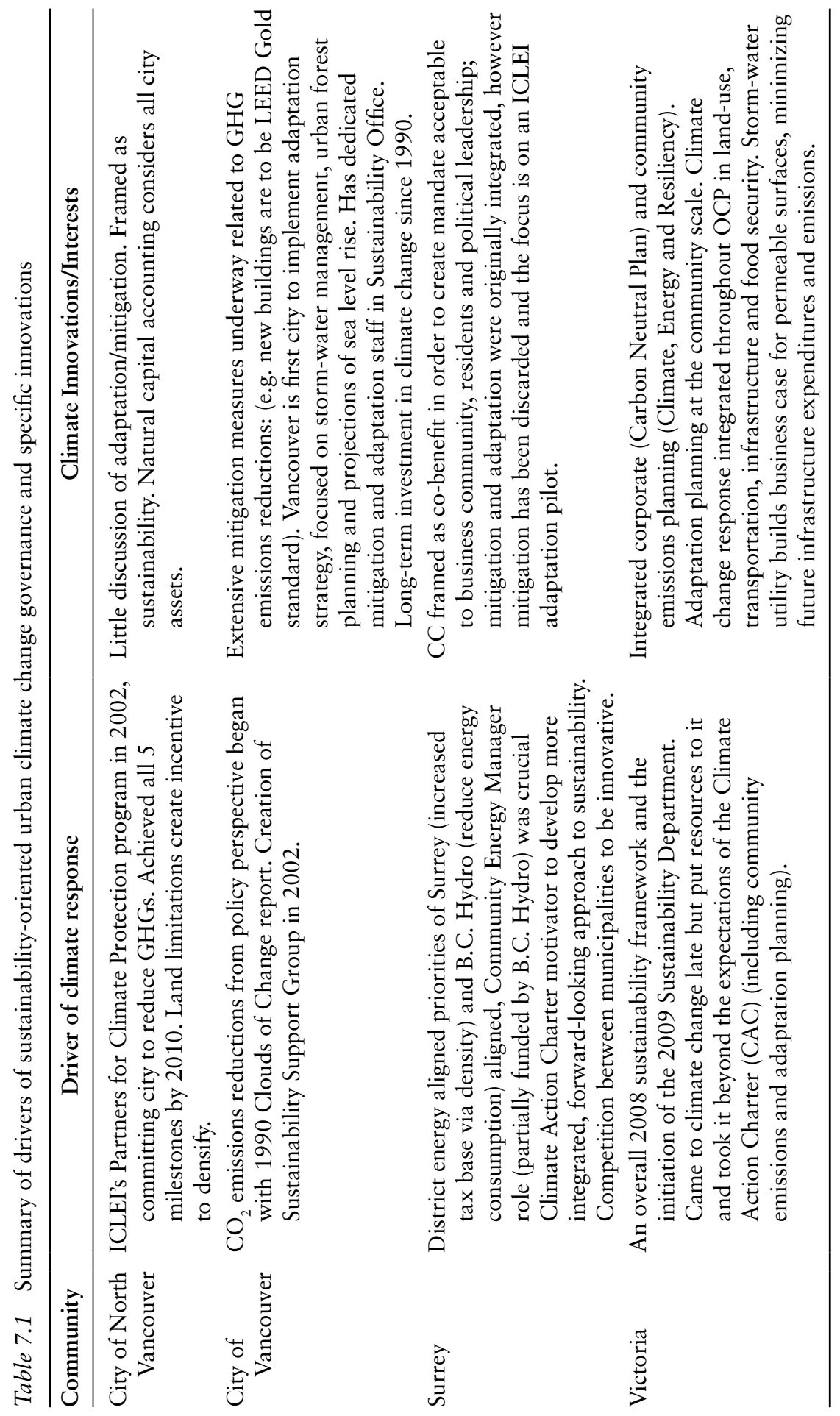


most cases recognizing that mitigation and adaptation dovetail with existing policies such as land-use, transportation, infrastructure, water and flood management and even food security planning. Communities clearly employ different sustainability framings to support climate mitigation and adaptation actions and the unique partnerships and inter-governmental arrangements required to design and implement these actions.

The question remains, however: how does a sustainability framework add value for communities leading on climate innovation in the province? Regardless of provincially supported sustainable community planning initiatives and/or selection bias, in practice, a sustainability approach is being developed and applied in some cities. As discussed above, the theoretical literature suggests that sustainability offers opportunities for integrating climate change mitigation and adaptation into existing policies, plans and priorities (for a synthesis of this theory see Burch et al. 2014). What is clear from our findings is that, in practice, there may be advantages to a sustainability-oriented approach.

In communities where sustainability has not yet become a long-term project, or where there tends to be more of a conservative, economic culture, such as in the City of Surrey, the term 'sustainability' helps to convey a sense of independence, resilience and self-sufficiency. In these communities, 'climate change' can be problematic because of its perceived roots in an environmental ethos. In the case of the City of Surrey, however, climate change efforts are dwarfed by an emphasis on economic growth. Instead, an economic strategy emphasizes density to increase the municipal tax base and build energy resilience via a district energy system indirectly addressing climate mitigation, without climate action being the primary goal. In this example, the district energy system is promoted as a way to achieve energy and economic security, garnering support from the business community, residents and political leadership.

Other leading urban centres framed climate action as an explicit aspect of sustainability planning, with key targets and indicators being adopted by the city that take into account not only environmental aspects but social and economic aspects as well. In the cities of North Vancouver (CNV), Vancouver and Victoria, climate action is integrated as part of overall sustainability goals. Each of these communities has a long history of doing sustainability work. Vancouver's 1990 Clouds of Change Report through to the 2002 initiation of the Sustainability Support Group has led to the development of the ambitious 2010 Greenest City Action Plan, whereby the City meets provincial 2020 targets and also builds resilience with regard to emergent issues such as sea level rise. Victoria's 2008 Sustainability Framework led to the 2009 initiation of the Sustainability Department, which developed the 2011 Climate Action Program, performing corporate and community emissions planning, with the integration of mitigation and adaptation in the official community plan (OCP). The City of North Vancouver's 2008 100 -year sustainability plan that is embedded across departments ranging from planning, to engineering to finance, is a planning initiative that shaped 


\section{Sarah Burch et al.}

the overall vision for decision-making in the community. In this vision there is a clear awareness of the importance of sustainability, with key targets and indicators being adopted by the city that take into account not only environmental aspects but social and economic aspects, as well as a natural capital accounting framework.

In these three cases, sustainability measures began long before provincial mandates came into effect, thereby providing the a priori infrastructure for climate action to be integrated. Interestingly, all three cases initiated adaptation planning processes shortly after taking action on mitigation. While they remain separate endeavours, the goal in each city is to ensure cross-fertilization of plans, identifying and capturing the co-benefits of adaptation and mitigation actions. In the CNV case, integrated planning and decision-making for sustainability has been a critical driver of climate action, embedding mitigation (and more recently, adaptation) into development decisions. A demonstration of this is in the use of an incentive, the density bonus, provided to developers to achieve its densification and energy efficiency goals. The bonus is given if a developer connects a new building to the district energy system and provides space in the basement for a mini-plant; the developer in exchange is approved to build additional units in order to make up for possible economic losses. This incentive has resulted in a $100 \%$ uptake by developers and has signaled a new way of doing business.

In Victoria's Sustainability Department, the Climate Action Charter motivated the Department to 'safeguard' funds from provincial incentive programs in order to undertake the Climate Action Program. This program came after the City had already undertaken considerable public and partner engagement to approve a sustainability policy framework. The timing of the corporate and 'bottom-up' community climate action plans, in turn, aligned with Victoria's OCP revision process, firmly embedding mitigation and adaptation action into the existing sustainability orientation, particularly in land-use, transportation, infrastructure planning and food security sections throughout the legislated 30-year plan. In 2013, the Sustainability Department was dismantled with the goal of trimming the city's budget while embedding sustainability planning in all municipal operations and activities.

In Vancouver, the City's Sustainability Support Group was formed in 2002 and has been a key trigger of climate change policy in the city and has led to planning in new areas related to climate change, including adaptation. Policies such as changing the building code to ensure all new development meets LEED Gold Standard, including electric vehicle plug-ins in multi-occupant buildings and changing land-use bylaws to allow for in-fill creates development efficiencies and creates an enabling environment for reduced emissions. The development of bike lanes and bike corridors has been a signature of Vancouver, creating alternative transportation options. In addition, Vancouver's 2011 Climate Change Adaptation Strategy was 
the first in B.C., focusing on physical infrastructure, integrated storm-water management, urban forest and sea level rise planning and related implications. A recent study of Vancouver's experience suggests that the sustainability framing of climate change policy and programs allowed for more substantial and integrated policy development (Robinson, 2013).

\section{DRIVERS, BENEFITS AND TRADEOFFS ASSOCIATED WITH A SUSTAINABILITY FRAME}

A common theme emerged in cities employing an integrated sustainability lens: a sustainability-oriented approach could fulfill multiple objectives in a community and provide the flexibility required to achieve climate action without explicitly applying the adaptation or mitigation label. Climate champions and leaders who focused on these arguments highlight the need for a deeper appreciation of the local politics associated with climate change, identifying contextual priorities, awareness levels and perceptions of the risks held by each constituency. By broadening the framing, the potential of realizing co-benefits became real. Of course caution must be taken in regard to the nebulous nature of a sustainability framing to avoid obfuscation and underlying aims that may in fact directly contradict emissions reductions, adaptation and overall sustainability goals.

The $\mathrm{MC}^{3}$ cases illustrate that the integration of climate action into broader sustainability goals may optimize efforts to reach climate targets. Fundamental design and planning requirements to incorporate these changes into by-law development, stringent building and development codes and integrated transportation planning contributed to further integrated decision-making. The province's integrated community sustainability plan (ICSP) process, for instance, initiated from the 2005 Gas Tax Agreement (GTA), enshrines climate change in the legal framework of the official community plan (OCP) locking in temporal commitments for climate change over 20- to 30-year time horizons. The extent to which this policy integration is transforming the ways day-to-day decisions are made on climate change and sustainability requires further research.

One key finding from all four cities is that integrating climate change planning in a broader sustainability framework increases the breadth of actors/stakeholders enrolled in planning (e.g. transportation, energy, water, etc.), and it is expected that with implementation, more actors will also be engaged in the process of operationalizing climate action in practice. In some cases a sustainability approach has allowed cities to build support for mitigation activities that would have been rejected by more conservative stakeholders. Indeed, many municipal governments are already taking action to reduce GHG emissions indirectly through efforts to sustain other environmental and quality-of-life values. When climate change priorities are integrated into existing policy and legal frameworks, such as transportation 


\section{Sarah Burch et al.}

plans or official community development plans, such as in the City of North Vancouver, they also become more embedded into operational and planning structures. Despite these benefits, other communities may employ a sustainability frame while giving more force and effect to policies that support other priorities (for instance, economic growth or expanded transportation infrastructure in support of single occupancy vehicles), which may ultimately be incompatible with deep and lasting emissions reductions.

There are of course communities whose political priorities may not have this deep municipal and public commitment to climate change and sustainability planning. Particularly in rural communities, climate change planning may be at odds with community identity and lifestyles, and some may believe that the concept of sustainability is a primarily urban concept emphasizing, for example, densification, public transit and green technology. In a more urban context, however, the City of Surrey used the concept of economic sustainability to promote district energy in new developments, although many of the City's sustainability policies and tools lack the regulatory force to transform development proposals or transportation decisions in the long run.

Ultimately, many communities across the province of B.C. have begun to take action on climate change largely as a result of the provincial legislation that came into force in 2008. While mitigation dominates, some communities are also taking steps to adapt to climate change, and this appears to be especially prevalent in communities where climate-related risks are clear. An integrated sustainability approach is characteristic of many of the identified leading communities and holds out the promise for actions that address the underlying drivers of emissions.

\section{CONCLUSIONS AND FUTURE RESEARCH}

Cities are increasingly innovative and influential contexts in which integrated responses to climate change are being governed. These integrated responses, however, require the crafting of a different set of policies than might be suggested by pursuing either adaptation or mitigation in isolation from one another. Attention must also be paid to the deeper underlying drivers of emissions and vulnerability, which has implications for how we conceptualize urban climate governance processes. Alternative development pathways determine the costs of, and potential for, both emissions reductions and adaptation, and in turn we face a challenge in ensuring that actions taken to address climate change do not obstruct local and regional development (Beg et al. 2002). Recent scholarship suggests that this obstruction is less likely to occur if synergies are explored and tradeoffs are avoided. Illustrating and capitalizing upon these co-benefits, however, is also important in local contexts more broadly speaking. A sustainability approach opens up the possibility of framing climate change in a way that resonates with local political priorities, ensuring traction with the public and potentially more effective collaboration on a diverse and inter-disciplinary set of issues. 
Many communities in British Columbia have demonstrated leadership on climate change. In this exploratory research, four urban $\mathrm{MC}^{3}$ case communities were presented that have employed a sustainability frame. These cases illustrate that a sustainability approach may provide a deeper level of integration with existing policies, plans and priorities. Such a framing has expanded the suite of actions deemed desirable, built alliances with new and influential stakeholders, and offered opportunities to reveal synergies and tradeoffs between multiple priorities. This identifies opportunities for co-benefits that firmly embed mitigation and adaptation activities into local priorities and operational practices. In practice, the cases also suggest that pre-existing context matters in determining which approach will be most desirable; reinforcing the understanding that local priorities play a role in determining whether a sustainability focus is appropriate.

Many of the cases illustrate the importance of deep and ongoing public and partner engagement, as well as adaptable multi-level governance arrangements. A critical finding is that a sustainability approach enlists a diverse breadth of departments and staff, more so than mitigation and adaptation planning alone. During implementation, it is expected that this diversity operationalize climate action across more parts of the organization, helping to embed it into the organizational framework in a robust manner, which in turn becomes more immune to electoral cycles. Ongoing longitudinal research in these communities will establish if plans transform into action, whether that action, if it is undertaken, ultimately achieves the targets that have been set, and to what extent this enrollment of diverse departments and actors contributes to embedding climate action in broader development plans, changing the way decisions are made in practice.

\section{NOTES}

1. This chapter is an adapted version of a paper first published in the journal Global Environmental Change: Shaw, A, Burch, S, Kristensen, F, Robinson, J and Dale, A. 2014. Accelerating the sustainability transition: Exploring synergies between adaptation and mitigation in British Columbian communities. Global Environmental Change 25: 41-51.

2. These 4 cases are part of a larger study that examined 11 case study communities, some of which were rural towns, multi-regional collaboratives, or neighbourhood initiatives. The cases selected for this chapter were largest cities of the sample, with populations ranging from 48,000-603,000.

\section{BIBLIOGRAPHY}

Adger, W N, Brooks, N, Kelly, M, Bentham, S and Eriksen, S. 2004. New indicators of vulnerability and adaptive capacity. Technical Report 7. Tyndall Centre for Climate Change Resource.

Adger, W N, Hughes, T P, Folke, C, Carpenter, S R and Rockström, J. 2005. Social-ecological resilience to coastal disasters. Science 309: 1036. 


\section{Sarah Burch et al.}

Beg, N, Morlot, J C, Davidson, O, Afrane-Okesse, Y, Tyani, L, Denton, F, Sokona, Y, Thomas, J P, La Rovere, E L B, Parikh, J K, Parikh, K and Atiq Rahman, A. 2002. Linkages between climate change and sustainable development. Climate Policy 2: 129.

Betsill, M and Bulkeley, H. 2004. Transnational networks and global environmental governance: The Cities for Climate Protection program. International Studies Quarterly 48: 471-93.

Betsill, $\mathrm{M}$ and Bulkeley, H. 2006. Cities and the multilevel governance of global climate change. Global Governance 12: 141-59.

Biesbroek, GR, Swart, R and van der Knaap, W G M. 2009. The mitigation-adaptation dichotomy and the role of spatial planning. Habitat International 33: 230-7.

Bizikova, L, Neale, T and Burton, I. 2008. Canadian communities' guidebook for adaptation to climate change: Including an approach to generate mitigation co-benefits in the context of sustainable development. Vancouver: Environment Canada and University of British Columbia.

Bulkeley, H and Castan Broto, V. 2013. Government by experiment? Global cities and the governing of climate change. Transactions of the Institute of British Geographers 38: 361-75.

Burch, S. 2010a. In pursuit of resilient, low-carbon communities: An examination of barriers to action in three Canadian cities. Energy Policy 38: 7575-85.

Burch, S. 2010b. Transforming barriers into enablers of action on climate change: Insights from three case studies in British Columbia, Canada. Global Environmental Change 20: 287-97.

Burch, S and Robinson, J. 2007. A framework for explaining the links between capacity and action in response to global climate change. Climate Policy 7: 304-16.

Burch, S, Schroeder, H, Rayner, S and Wilson, J. 2013. Novel multi-sector networks and entrepreneurship in metro Vancouver: A study of small business as an emerging non-state actor on climate change mitigation. Environment and Planning $\mathrm{C}$ 31: 822-40.

Burch, S, Shaw, A, Dale, A and Robinson, J. 2014. Triggering transformative change: A development path approach to climate change response in communities. Climate Policy 14(4): 467-87.

Cifuentes, L, Borja-Aburto, V H, Gouveia, N, Thurston, G and Davis, D L. 2001. Hidden health benefits of greenhouse gas mitigation. Science 293: 1257-9.

Cohen, S, Demeritt, D, Robinson, J and Rothman, D. 1998. Climate change and sustainable development: Towards dialogue. Global Environmental Change 8: 341-71.

Dang, H H, Michaelowa, A and Tuan, D D. 2003. Synergy of adaptation and mitigation strategies in the context of sustainable development: The case of Vietnam. Climate Policy 3S1: S81-S96.

Heckathorn, D D. 1997. Respondent-driven sampling: A new approach to the study of hidden populations. Social Problems 44: 174-99.

Huq, S, Reid, H and Murray, L A. 2006. Climate change and development links. The Gatekeeper Series. London: International Institute for Environment and Development.

IPCC. 2012. Special report: Managing the risks of extreme events and disasters to advance climate change adaptation. New York, NY: Cambridge University Press.

Klein, R J T, Huq, S, Denton, F, Downing, T E, Richels, R G, Robinson, J B and Toth, F L. 2007. Inter-relationships between adaptation and mitigation, in M L Parry, O F Canziani, J P Palutikof, P J van der Linden and C E Hanson, eds: Climate change 2007: Impacts, adaptation and vulnerability. Contribution of Working Group II to the Fourth Assessment Report of the Intergovernmental Panel on Climate Change. Cambridge: Cambridge University Press, 745-77. 
Kollmuss, A and Agyeman, M. 2002. Mind the gap: Why do people act environmentally, and what are the barriers to pro-environmental behaviour? Environmental Education Research 3: 239-60.

Laukkonen, J, Blanco, P K, Lenhart, J, Keiner, M, Cavric, B and Kinuthia-Njenga, C. 2009. Combining climate change adaptation and mitigation measures at the local level. Habitat International 33: 287-92.

Lorenzoni, I, Nicholson-Cole, S and Whitmarsh, L. 2007. Barriers perceived to engaging with climate change among the UK public and their policy implications. Global Environment Change 17: 445-59.

Markandya, A and Halsnaes, K. 2002. Climate change and sustainable development: Prospects for developing countries. London: Earthscan Publications.

Metz, B, Berk, M, Elzen, M D, Vries, B D and Vuuren, D V. 2002. Towards an equitable climate change regime: Compatibility with Article 2 of the Climate Change Convention and the link with sustainable development. Climate Policy 2: 211-30.

Morita, T, Nakicenovic, N and Robinson, J. 2000. Overview of mitigation scenarios for global climate stabilization based on new IPCC emission scenarios (sres). Environmental Economics and Policy Studies 3: 65-88.

Munasinghe, M and Swart, R. 2005. Primer on climate change and sustainable development: Facts, policy analysis and applications. Cambridge: Cambridge University Press.

Nakicenovic, N and Swart, R. 2000. Special report on emissions scenarios. Report of the Intergovernmental Panel on Climate Change. London: Cambridge University Press.

Naumann, S, Anzaldua, G, Gerdes, H, Frelih-Larsen, A, Davis, M, Berry, P, Burch, S and Sanders, M. 2011. Assessment of the potential of ecosystem-based approaches to climate change adaptation and mitigation in Europe. Final Report to the European Commission, DG Environment, Contract no. 070307/2010/580412/ser/b2. European Commission, DG Environment.

Robinson, J. 2004. Squaring the circle? Some thoughts on the idea of sustainable development. Ecological Economics 48(4): 369-84.

Robinson, J, Bradley, M, Busby, P, Connor, D, Murray, A, Sampson, B and Soper, W. 2006. Climate change and sustainable development: Realizing the opportunity. Ambio 35: 2-8.

Robinson, J, Morita, T, Adegbulugbe, A, Alcamo, J, Herbert, D, Lebre La Rovere, E, Nakicenovic, N, Pitcher, H, Raskin, P, Riahi, K, Sankovski, A, Sokolov, V, de Vries, B and Dadi, Z. 2001. Greenhouse gas emissions: Mitigation scenarios and implications, in B Metz, O Davidson, R Swart and J Pan, eds: Climate change 2001: Mitigation. Cambridge: Cambridge University Press, 115-66.

Robinson, S. 2013. Implications of governance in regards urban sustainability: A case study of Vancouver and its 'Greenest City Action Plan'. Environment and Development. London: King's College.

Sathaye, J, Najam, A, Cocklin, C, Heller, T, Lecocq, F and Robinson, J. 2007. Sustainable development and mitigation, in B Metz, O Davidson, P Bosch, R Dave and L Meye, eds: Climate change 2007: Mitigation. Contribution of Working Group III to the Fourth Assessment Report of the Intergovernmental Panel on Climate Change. Cambridge: Cambridge University Press, 691-743.

Satterthwaite, D, Huq, S, Pelling, M, Reid, H and Romero Lankao, P. 2007. Adapting to climate change in urban areas: The possibilities and constraints in lowand middle-income nations. London: International Institute for Environment and Development.

Shaw, A, Burch, S, Kristensen, F, Robinson, J and Dale, A. 2014. Accelerating the sustainability transition: Exploring synergies between adaptation and mitigation in British Columbian communities. Global Environmental Change 25: 41-51. 


\section{Sarah Burch et al.}

Smit, B, Pilifosova, O, Burton, I, Challenger, B, Huq, S, Klein, R and Yohe, G. 2001. Adaptation to climate change in the context of sustainable development and equity, in J McCarthy, O Canziani, N Leary, D Dokken and K White, eds: Climate change 2001: Impacts, adaptation and vulnerability. Cambridge: Cambridge University Press, 877-912.

Stake, R. 1995. The art of case research. Thousand Oaks, CA: Sage.

Stake, R. 2006. Multiple case study analysis. New York, NY: Guilford Press.

Swart, R, Robinson, J and Cohen, S. 2003. Climate change and sustainable development: Expanding the options. Climate Policy, Special Issue on Climate Change and Sustainable Development 3: S19-S40.

Unruh, G C. 2000. Understanding carbon lock-in. Energy Policy 28: 817-30.

Wilbanks, T J, Leiby, P, Perlack, R, Ensminger, T J and Wright, S B. 2007. Toward an integrated analysis of mitigation and adaptation: Some preliminary findings. Mitigation and Adaptation Strategies for Global Change 12: 713-25.

Yin, R K. 2003. Case study research: Design and methods. Thousand Oaks, CA: Sage.

Yohe, G W, Lasco, R D, Ahmad, Q K, Arnell, N W, Cohen, S J, Hope, C and Janetos, A C. 2007. Perspectives on climate change and sustainability, in M L Parry, O F Canziani, J P Palutikof, P J van der Linden and C E Hanson, eds: Climate change 2007: Impacts, adaptation and vulnerability. Contribution of Working Group II to the Fourth Assessment Report of the Intergovernmental Panel on Climate Change. Cambridge: Cambridge University Press, 811-41. 


\title{
8 Climate Change Adaptation in Mumbai, India
}

\author{
Emily Boyd, Aditya Ghosh and \\ Maxwell T. Boykoff
}

\section{INTRODUCTION}

Bombay's fate is solidly, inextricably, linked to India's fate, much as the city would like to pretend otherwise.

-(Mehta, Maximum City, 2004)

This chapter connects the more formal and emergent climate adaptation governance regime operating at multiple scales to everyday urban spaces, in the case of reoccurring flood events in Mumbai (Bombay), India. As the author Suketu Mehta describes in the quote above, the collective climate future of Mumbai links to that of the larger story arc of India. The chapter examines how this relationship scales up to the international community and extends to other cities and contexts in relation to climate adaptation governance.

This chapter seeks to explore the idea that in the urban context, unequal geographies, rooted in historical socio-political and environmental contextscoupled with international political representations of climate change-may ultimately exacerbate the challenge of adaptation to climate change and illuminate ongoing considerations of consequences from the new carbon economy.

Adaptation to climate change refers to the adjustments in natural or human systems in response to actual or expected climate stimuli or their effects, which moderate harm or exploit beneficial opportunities (IPCC, 2001). Adaptation is specific to sectors and countries, and demands a response from local managers (Dang et al., 2003). Adaptation can differ in purpose, across time and space and according to actors. It is distinct from mitigation in several ways, in particular in terms of the sectors, the scale at which policies are targeted, and the time scales at which they occur (Tol, 2007). While mitigation policy is devised at the national and international level, adaptation strategies are often developed at the local level where the effects of climate change are felt through events such as floods, storms and drought. The dependency of livelihoods sensitive to climate-related extreme 
events has focused international attention on adaptation at the local level (Tanner et al., 2009: 5).

Adaptation can occur before or after a disaster and is shaped by legal, financial, socio-cultural and technological instruments and include activities that are autonomous or planned. For example, the United Kingdom is one of the first countries in the world to be guided by a legal framework in the form of the Climate Change Bill 2008, which requires a national-level risk assessment to be conducted every five years. Institutions matter to adaptation in that they can act as a barrier or a bridge to action. Where formal institutions are weak, social capital and networks act as important mechanisms to buffer local vulnerability and enhance adaptive capacity (Adger et al., 2009).

Adaptation is increasingly a multi-scale environmental governance challenge (Tschakert, 2012)-where sensitivities to climate change in institutions and their ability to respond are based on ability to connect across scales of decision-making. The discourse on adaptation has gained salience with the urgency and magnitude of climate change impacts now recognised generally. Climate change is unequivocal and the severity of the problem across rural and urban spaces has intensified. The politics of adaptation has largely focused on the provision of 'development assistance' to compensate least developed countries. Adaptation is now being discussed in terms of global justice, ethics and compensation for damage incurred by climate change to developing countries.

In this chapter, we analyse vulnerabilities and discourses in Mumbai and the intersections between adaptation and development through the lens of the surprise event of the flood events that played out in Mumbai on 26 July 2005 (26/7 floods). We evaluate how interactions between municipal institutions and other levels of management shaped the 2005 flood responses and subsequent actions that played out in the city. Findings suggest that responses are forthcoming, but depend on budgets, local developmental constraints and priorities, scientific understandings of climate change and international responses.

This study aims to link lessons from the 2005 floods to broader understandings of environmental governance in multi-scale adaptation discourse. We argue that what discourses and actions that are developing out of Mumbai are signs of what's to come; moreover, these harbingers can inform and enhance ongoing as well as future adaptation governance, In this chapter we apply an historical/analogue approach to understanding the events of 2005. We draw on in-depth interviews conducted with key informants in Mumbai in October 2008, January 2009 and April 2014. The interviews consist of 12 qualitative interviews, with journalists, representatives of the municipal corporation of Mumbai, private organisations, nongovernmental organisations, architects and scientists. Qualitative interviews are helpful ways to understand the different agent's perspectives (Kvale, 1996). The interview data has been triangulated with published literature, reports, policy 
documents and newspaper articles from the four main broadsheets in India, The Times of India, Hinudstan Times, the Indian Express and The Hindu. Key words 'climate change', 'global warming' and 'urban floods' were sought on the Factiva database.

Mumbai, located on the west coast of India, is constructed on a set of seven islands that are reclaimed. It is the modern financial hub of South Asia. Mumbai makes for an illuminating case-study area for three primary reasons:

1. India is now the second fastest-growing global economy after China, yet it is a 'developing country' (non-Annex I) in terms of ongoing international climate policy negotiations.

2. Mumbai city proper is considered the most populous city in the world with about 13.6 million people, and is the fifth most populous by metropolitan area (19.2 million).

3. Mumbai is also considered one of the more densely populated large cities in the world with two thirds of its population living in 5 percent of the city.

These factors make it a particularly fascinating space for analyses of urban adaptation to climate change. It also experiences competing nature-society pressures (such as the conflicts between human settlements and leopard protection in Sanjay Gandhi National Park).

\section{CLIMATE CHANGE ADAPTATION IN CITIES}

Cities are hubs of economic activity, growth and development, especially in the Global South where-because of changes in the patterns of economy-large-scale migrations are occurring in urban spaces. It is estimated that 50 percent of the world's populations live in cities and that is likely to grow (McGranahan et al., 2007). Now more of the world's population lives in urban areas than in rural areas. This trend is expected to continue, and nearly two thirds of the world's population will inhabit cities by 2030 . With this growth associated consumption patterns are changing-including of food and energy. According to the Stern Review (2007) the predominant source of anthropogenic carbon dioxide emissions from cities contributes as much as 78 percent of global emissions. Mega cities that are occupied by 10 million people or more, for example, Shanghai, Rio de Janeiro and Mumbai, are essential centres of transformation regionally and nationally (de Sherbinin et al., 2007).

Cities are identified as complex and adaptive systems (Benton-Short and Short, 2008) managed by networks of governance structures from local to global (Swyngedouw, 1997). Cities concentrate large populations, and are pockets of uneven development geographies (Harvey, 1996). Cities are 
spaces of nature-power relations and stage for the politics of natural disasters (Swyngedouw, 1997; Pelling, 1999; Klein, 2007). Cities are also actors central to formulating sustainable transitions to low carbon economies and climate change mitigation (Bulkeley and Betsill, 2004) and cities are increasingly spaces where climate experiments are carried out (Castán-Broto and Bulkeley, 2012).

In cities in the Global South there are potentially distinct embedded questions of competency, legality, histories, culture and capacity of local governments to address a multi-layered environmental problem such as climate change. Nonetheless, cities have taken an increasingly visible role in several global and local initiatives such as the 1992 Cities for Climate Protection (CCP) formed through initiative by the International Council for Local Environmental Initiatives (ICLEI); 2005 U.S. Mayors Climate Protection Agreement-from Seattle Mayor Greg Nickels to 850 cities by July 2008 (representing over 80 million), 2006 C40 network of global cities through the Clinton Climate Initiative and the 2007 World Mayors and Local Governments Climate Protection Agreement, put forward at the Bali COP-13.

Cities are particularly vulnerable to natural disasters attributed to extreme weather events such as storms and flooding (Huq et al., 2007). These events are likely to become more pervasive threats due to human-induced climate change and sea level rise (Adger et al., 2005). While cities such as Mumbai are much more vulnerable to climatic changes and disasters in the short range compared to corresponding rural areas, they can also provide better level of protection, both socio-economically and physically, to those who live precariously in fragile ecosystems and are dependent more on natural resources.

Recent works on disaster management in cities strongly urge understanding how to better coordinate the relative strengths and contributions of climate change adaptation and disaster risk reduction to the everyday, on-the-ground challenge of responding to climate change in cities (Solecki et al., 2011). With increasing pressure on the infrastructure with rapid and unplanned growth, these mega cities have, albeit inadvertently, added incremental structural attributes that compromise their resilience against disaster events and increase their vulnerabilities to climatic shifts-both sudden and slow onset ones. According to Climate Change Vulnerability Index 2014, an annual rating by UK-based global risk analyst Mapplecroft, Mumbai is now the second most vulnerable city to climate change after Dhaka. According to the CCVI's sub-national calculations, of the 50 cities studied, 5 present an 'extreme risk'-Dhaka in Bangladesh; Mumbai and Kolkata in India; Manila in the Philippines and Thailand's Bangkok. ${ }^{1}$

\section{CLIMATE CHANGE ADAPTATION IN MUMBAI}

Among the 20 cities projected to be the most vulnerable to coastal flooding in 2050 Mumbai is second only to Guangzou, China (Hallegatte et al., 
2013). It has the sixth largest 'at-risk' assets among all major port cities and by 2070 , an estimated 11.4 million people and assets worth $\$ 1.3$ trillion would be at peril in Mumbai due to climatic extremes, so predicts the OECD study carried out by the University of Southampton. Some of the cities with the most 'at-risk' assets now-Tokyo, New Orleans, Amsterdam, Rotterdam, and Nagoya-will, over the next 50 years, be surpassed by Kolkata, Shanghai, Mumbai, Tianjin, Bangkok, Ningbo, and Ho Chi Minh City, booming Asian coastal metropolitan areas where trillions of dollars in economic assets will be vulnerable (Stutz, 2012).

The Mumbai Metropolitan Region (MMR) is now spread over 4,355 sq km and consists of eight Municipal Corporations-Greater Mumbai, Thane, Kalyan-Dombivali, Navi Mumbai, Ulhasnagar, Bhiwandi-Nizamapur, Vasai-Virar and Mira-Bhayandar; and nine Municipal Councils viz. Ambarnath, Kulgaon-Badalapur, Matheran, Karjat, Panvel, Khopoli, Pen, Uran, and Alibaug, along with more than 1,000 villages in Thane and Raigad Districts. According to the provisional population data from the Census of India 2011, the total population of MMR is about 24 million, more than Iran, Australia, Romania and many other countries. It is now among the top 10 most-populated urban clusters in the world.

The city uses a mix of transport options, and residents of Mumbai travel fairly long distances every day with the average trip length of $22.2 \mathrm{~km}$ for train, $4.7 \mathrm{~km}$ in bus, $14.2 \mathrm{~km}$ in cars and $5.8 \mathrm{~km}$ in a taxi, the population of 23 million generating about 21 million trips a day. Recently, municipal administrators in Mumbai established an assessment to help frame policies to cope with the current gaps in data available about the quality of the environment in the Mumbai Metropolitan Region. In August 2013, The Energy Research Institute (TERI) was given the task of environment assessment. The ongoing project, titled 'Environmental Status Report of Mumbai Metropolitan Region', will provide information on the region's vital resources-air, water, land use and its changing patterns, and biodiversity-and will be used as guides for Mumbai Metropolitan Region Development Authority's (MMRDA's) infrastructure and development plan, which is prepared every 20 years.

The federal government has also directed all the states to commission a state report of an action plan on climate change. The report is led by TERI in collaboration with the Met office, Hadley Centre, UK, and aims to develop an adaptation strategy for Maharashtra. The report will offer suggestions to alleviate the threat of climate change to the economy, to society and to people's lives. The strategy focuses primarily on water resources, agriculture, coastal areas and livelihoods. However, the stress is on generating high-quality climate-change information at a regional level for impact assessments, to inform adaptation options and for mitigation planning. The plan is to provide a range of possible future projections for the region at $25 \mathrm{~km}$ spatial grid, a first for the region. According to its preliminary finding, all four projections used suggest a warmer, wetter monsoon season and 
sea level will rise by $4 \mathrm{~cm}$ over next 100 years (Lukose 2014). These changes are characterised by more frequent days of extremely high temperatures and intense rainfall events, with the duration of these extreme days lasting longer into the month of August. Moreover, the report has predicted that an increase in rainfall which, combined with the sea level rise, will escalate risks of flooding, and would lead to reduction in availability of fresh water due to saltwater intrusion as well as contamination of water supply through pollutants from submerged waste dumps.

In Mumbai's case, the 2005 floods can prove to be an agent to rethink development strategies in the time of changing climate. While the city seems to be taking up assessments to chart an alternative development pathway, it is still unclear how adaptation must be situated in the urbanisation and urban planning of Mumbai other than by instruments such as insurance (Hallegatte, 2012). Processes to develop a nuanced socio-economic, political and cultural adaptation policy that 2005 floods in the city established as necessary need further research along with understanding its intersections with urbanisation and development processes.

\section{The 2005 Floods in Mumbai}

On 26 July (26/7), 2005, the city of Mumbai experienced severe flooding up to a $100 \mathrm{sq} \mathrm{km}$ area, resulting in the death of over 1,000 people and significant damage to property and displacement of hundreds of thousands of the most vulnerable people living in the low-lying areas of the city. In the space of 24 hours the city received 37.2 inches of rainfall-a once-in-100-year event, catching the city residents 'unaware'. Revi (2005) recalls that the majority of the city services were shut down for almost five days. The most affected area of the city was the densely populated area of the northwest, inhabited by a mixture of social groups. These areas include Kurla, Kalina, Jari-Mari, Bandra East, Saki Naka, Govandi, Chembur, Kandivli, Malad and Bandra West. There is a well-organised system of river flood forecasting in India, under the auspices of the Central Water Commission, including active engagement of the Flood Meteorological Offices of the India Meteorological Department. However, the floods that occurred in 2005 were not a result of 'flooding' as defined by these institutions (i.e. water spilling over river banks). The main cause was 'inundation', which was brought about by the accumulation of heavy local rainfall and 'draining congestion'; the drainage process was unable to match the rate of rainfall coupled with the high tide (Kelkar, 2005).

In Mumbai there are many different agencies, including the Slum Rehabilitation Authority-SRA, MHADA (Maharashtra Housing Area Development Authority), MMRDA (Mumbai Metropolitan Region Development Authority), that have responsibility for flood mitigation and management. The MMRDA is the regional planning agency with special powers to execute infrastructure work in the city and MSRDC (Maharashtra State Road Development Corporation). There are also various authorities, such as the 
chief minister and the Secretary of Relief and Rehabilitation who play a role in flood mitigation and management.

The Mumbai Disaster Management Plan (MDMP) is a comprehensive document that lists the different crises (e.g. flooding, cyclones) that can affect Mumbai and the areas likely to be impacted. It contains a strategy to avert disasters (infrastructure development, communication and public information systems and land use policies and planning) and plans to address crises. It also contains sub-plans for city wards. There is a Mumbai Disaster Management Committee (DMC), headed by the Additional Chief Secretary and heads of other departments. Their role is to ensure functioning departmental coordination between state departments, make decisions; as well as to provide information to the government. The implementation of disaster preparedness and response is the responsibility of the municipality of Mumbai, the Municipal Commissioner is chairman of the DMC. In the case of emergency the Assistant Municipal Commissioner of the ward assumes overall responsibility for his/her area (CCC, 2005).

None of these authorities was prepared for the 2005 floods. NGOs and civil society joined forces to launch the Concerned Citizen's Commission only three weeks after the event on 4 August 2005 (CCC 2005). The Commission's report provides compelling anecdotal evidence that local humanitarian organisations, families and individual slum dwellers largely acted collectively in response to the crisis, while the official response was far less effective despite the existence of city disaster risk management plans. The report identifies the lack of planning in the housing sector, which is challenged with meeting needs of an ever-swelling population. Moreover, physical characteristics, such as assessment of elevation and drainage, have largely been neglected in Mumbai. Litigation, disputes and irregularities such as land use conversion indicate compulsions and concomitant vulnerabilities of people-especially among Mumbai's slum-dweller communities. According to the CCC (2005) following the floods a rehabilitation package of Rs 230 crores was allocated by the state, of which no funding was earmarked for slum pockets of Mumbai. According to the commission 'the government's contention being that a rehabilitation package for slum dwellers would be an acknowledgement of their illegality' (p. 10).

The deluge also saw a lack of police presence in most of the flood-affected areas and their role in providing support and emergency relief was absent. As was the fire brigade and the coast guard. Information was also lacking in terms of early warning. Some point to the failures in the Indian Meteorology Department (IMD) to provide adequate warning. This is despite scientists raising their concerns 15 years ago in a published report called the Brimstowad Report, where they cautioned the impacts of inadequate drainage and risks of an extreme flood event in Mumbai. Combined with historical articles on the city's reclamation schemes, the Brimstowad Report was identified in the post-disaster response as evidence that the authorities had failed to take action on tackling the city's drainage problems (CCC, 2005). 
Interviews with government and civil society stakeholders in Mumbai reveal that there remain information, knowledge and organisational gaps between official and informal organisations regarding flood preparedness strategies. There are weak institutional incentives (at a larger scale) that interact with decision-makers and organisations in Mumbai. For example, city officials look towards international adaptation funds to take things further despite the precariousness of the adaptation funds and the realities that India will not be entitled to these funds. In the words of the Assistant Municipal Commissioner five years after the deluge 'the municipality of Mumbai would hesitate to take action on climate change adaptation until the international community has taken steps to deliver climate funds to support India's adaptation efforts' (R.A. Rajeev, Interview, 12 January 2009). The Municipal Additional Commissioner suggested that it was not an Indian responsibility to tackle adaptation actions, but an international responsibility to provide resources, noting 'we are the victims of climate change' (ibid., 2009). Moreover, the many government departments and sectoral institutions in the city of Mumbai offer little protection of the city's most vulnerable (Chatterje, 2010).

Since 2009, the municipality has introduced the placement of rain gauges throughout the city and new satellite technology is planned that will help to monitor rainfall. A new project is underway, funded by the Municipal Corporation of Mumbai, which aims to address the problems posed by waste and sewage clogging Mumbai's waterways, as well as recent efforts to map the city by aerial photography. Local government funds have also been provided to support interdisciplinary scientific research at the Indian Institute of Technology Bombay into the impacts on the slum-dweller communities. The city has also been putting in place coastal defences to protect the city from breaches from the sea. The official in charge of BMC's flood control has also now changed roles to be the principal secretary of the Environment Department of the government of Maharashtra and who is the key officer on the climate change impact assessment study that the state of Maharashtra commissioned following the 2005 floods. The state government currently supports a partnership between TERI and the United Kingdom Met office-in developing a climate action plan-to understand and prepare a strategy that would help meet the additional challenges posed by climate change such as changes in the rainfall pattern (Rajeev, Interview, March 29, 2014). In part, these actions reflect the effects of the 2005 floods on a wide range of the city's population.

\section{ANALYSIS}

In this chapter we examine the more formal and emergent climate adaptation governance regime operating at multiple scales in relation to everyday urban realities of the 26/7 flood events in Mumbai. In this section, we now 
turn to analyse how this relationship scales up to the international community and extends to other cities and contexts in relation to climate adaptation governance.

The experience of the Mumbai 2005 floods is revealing in terms of the magnitude of challenges facing a 'megalopolis' of its scale. We identify two important scalar relationships in Mumbai, between the city-international and the city-local, which plays an important role in how climate change action is played out.

Between the city and international, on the one hand, authorities are reluctant to take action on adaptation as the scientific predictions of risks of more frequent and intense monsoon rainfall and floods are perceived to be far in the future. Officials do not want to bear the costs of these future events now. The Municipal Corporation of Mumbai points out that it learned from the 26/7 floods that it needs assistance, among others from the private sector, to support city-level change to prepare for climate change and that it welcomes external input to develop risk and resilience mechanisms for the city. As demonstrated by the Municipal Additional Commissioner who suggested that it was not an Indian responsibility to tackle adaptation actions, but an international responsibility to provide resources.

The international adaptation funds are thought of as a way to 'compensate' current populations, governments and cities for the future climate risks caused by the wealthy nations in the past. The issue of sea-level rise lies in the future and there are possibilities of constructing large-scale infrastructure such as sea walls. Other options could be to move the old city to the suburbs of the city (Hunt and Watkiss, 2007). At a policy level, while the government does not have internal funds earmarked for adaptation, it claims to have been in the process of assessing needs based on submissions from its state governments. While mainstreaming adaptation at the global level often creates the risk of overseas development assistance for the Millennium Development Goals being rebranded as climate funds, at the national level in India it leads potentially to a similar risk of development funds being diverted to adaptation in the absence of new and additional funds for specific policy intervention to bolster adaptation systems and services.

It appears to be that there is growing recognition in India among decision-makers of the links between global climate change and local-level adaptation actions. For instance, the government of India, more in hindsight, has declared the Mahatma Gandhi National Rural Employment Guarantee Act (MNREGA) as an adaptation instrument, highlighting the scheme's adaptation co-benefits (Anon., 2010). The policy document on MNREGA claims that it "integrates responses to climate change and adaptation measures into strategies for poverty reduction to ensure sustainable development. Works such as drought proofing, plantations, flood control, land development significantly contribute to provision of local environmental services. These environmental services could contribute to both, mitigation as well as adaptation to climate change, by reducing vulnerability to 
climate variability and climate change as well as enhancing food and water security for the poorest of the rural population."

The dynamic between the city and local include challenges of adaptation solutions, which are often absent or inadequate. For example, to shift the old city of Mumbai to the suburbs or to rely on remittances from abroad (De Sherbinin et al., 2007) are not realistic or necessarily desired adaptation options. Revi (2008) suggests that the political economy of Mumbai is its problem, noting that it is important for the city's leaders-both politicians and private elite-to take an interest in the challenges posed by climate risk and the necessary urban transformations required beyond real estate planning. In particular, tensions exist around the 9 million slum dwellers in Mumbai who continue to be overlooked as stakeholders in climate change adaptation policy and planning. It is this most vulnerable group that is most at risk from flood risk hazards. Many do not have official entitlements and this group of people remains marginal to climate adaptation discussions. It is common that local communities that are vulnerable to climate change are sidelined in such discussions (Paavola and Adger, 2002).

Chatterje (2010) finds from conducting household surveys among slum dwellers in Mumbai that flood mitigation strategies in urban societies and in slum settlements will have to be more inclusive of marginal groups, be sensitive to the limitations and scope of old and new social structures, and will have to incorporate innovative networks of support to tackle global climate change. This, while being true in the spirit of historic responsibility, does not absolve the local administration, polity or the central government of their collective responsibility towards ensuring good development and governance. The failure to ensure holistic, inclusive development exacerbates climate-induced changes and scale of damage in the short as well as long term. In this regard, mainstreaming adaptation in the overall development strategy and plan for the most vulnerable seem crucial.

While Mumbai provides a perfect case study and a window to understand future challenges in wake of climate change, we must, we feel, ask about the role of the national media in focusing the loss and damage concerned, apart from the poor and vulnerable, on the rich and famous also. News stories on loss of valuables because of inundation of some of the bank vaults and lockers, expensive paintings, volume of insurance claims dominated the media and elicited policy responses much faster than a flood, for example, in the hinterlands of Bihar (an Indian state in the eastern parts) or Tamil Nadu (another Indian state in the southern part of the country).

On the other hand, the Mumbai floods established that the rich were perhaps equally vulnerable to the poor towards the impacts of extreme weather events. This also mainstreamed the adaptation discourse to some extent and more so, the climate change debate in the public domain much more strongly than it otherwise was covered in the lay press. The Mumbai floods also raised questions about the notion of vulnerability as we understand it. It was argued after the floods in Mumbai that the poor, by nature, 
were more resilient than the wealthy, even though this perspective might be also interpreted as 'insensitive'.

The cause of inundation needs to be clearly understood. All identified causes-choking of Mithi River, overuse of plastic bags, failure to implement segregation of domestic waste, narrow storm-water drains, programmatic failures in disaster management and the failure to disseminate weather forecasting - are not climate-induced crisis but long-pending administrative lacuna. It is also important to understand whether large-scale in-migration that Mumbai witnesses makes the city more vulnerable as an urban sprawl, while the poor who migrate often find themselves less vulnerable. A season of crop damage leads to a year-long strife but a city flood leads to loss of income for a month or so. So while the poor feel safer in a city, the same influx throws serious challenges to the city infrastructure. A case in point would be widespread floods in the Konkan coastal areas of Maharashtra (areas like Raigarh) in 2005 that preceded the Mumbai floods. Despite widespread devastation it had little impact in policy and administrative reforms.

Natural disasters in a country like India lead to cascading effects, particularly in the socio-cultural and economic landscapes of regions that may not have been affected by the disaster. Also disaster management in India has so far failed to address the structural causes behind the scale of loss. The 2013 floods in Uttarakhand in northern India and coastal Orissa in eastern India were two significant cases here. While the former highlights how unplanned urbanisation in a disaster-prone, fragile ecosystem escalated the quantum of damages from an extreme weather event, the latter highlights the need of integrating disaster management into long-term development policy as despite arresting the number of deaths by efficient forecast, communication and evacuation, the losses remain higher than the previous cyclone in the same region 10 years ago that had resulted in far greater number of casualties.

\section{DISCUSSION AND CONCLUSIONS}

In this chapter we set out to explore the idea that unequal geographies, rooted in historical socio-political and environmental urban contexts-coupled with international political representations of climate change-may ultimately exacerbate the challenge of adaptation actions. Along the lines of Scheffer et al. (2003) we find that there was inertia in responding to dangerous weather-related events in Mumbai. First, our analysis points to the weak credibility of authorities and pressing development and competing agenda issues. De Sherbinin et al. (2007) identify a fragmented political authority at central, provincial and municipal level, and absence of coordinated actions in environmental policy. In addition they observe that building conditions and low incomes are barriers to improvement and that future multiple shocks are likely to occur between the growing population and sea 
level rise. The inability to address poverty and deliver services to the middle class have alienated these two largest segments of Mumbai residents from participating in and being sensitive to environmental services that would help the administration. This is also coupled with lack of awareness among stakeholders. The best example perhaps of lack of citizen participation is in segregation of waste. Despite repeated attempts to do so, it has been a major failure in ensuring better environmental services for the city.

Second, following the 26/7 floods a shift has occurred in opinion among some of the elite, decision-makers and organisations that govern Mumbai, perhaps indicating a change in perception about the risks of climate change. A climate action plan for Mumbai has been announced, financed by the state of Maharastra Rs 97.99 lakh to examine projected climate change impacts on hydrology and water resources, agriculture, coastal areas, marine ecosystems and livelihoods, including impacts on migration in Mumbai (Ghoge, Hindustan Times, 1 April, 2010). The draft of the report, which was submitted in April 2014 to the environment department of the state government, is now being finalised by the TERI and UK Met Department. This shift is manifest through actions such as the commission hearings following the Mumbai floods. A number of actions have emerged as outlined earlier; still the media attention to the issues has been short-lived moving on quickly to more newsworthy issues. This indicates that there are other competing issues that capture the attention of the public. In this example, we suggest that delay in regulating for new climate problems such as frequency of extreme weather events or sea level rise is related to the linkages understood, the uncertainty of the climate problem and the allocation of resources-or lack of them-from the global community. Along with absence of quality science research, another major issue is reticence of the scientific community in India to comment on or interpret climate change issues. There might be various reasons to it including political sanctions not being given to certain scientific findings. It also underlines a pronounced two-culture debate, between science and society in India. The association is very weak and both media as well as the scientific community can be blamed for this. Given that the global community is unable to commit adequate resources to adaptation actions potentially risks sending a message to the Global South that climate change is a low priority. India is also in an unusual position in that it is not eligible for adaptation funds. Nevertheless, the recent investments by the state for a climate change action plan for Mumbai indicates national commitment to taking adaptation seriously. The development of an action plan will require consideration of the importance of local power structures (in particular local social capital and the engagement of local non-state actor groups) and the existing capacity to respond to climate change that was illustrated in the flood events in 2005.

Third, our analysis shows that those climate change-related extreme events have influences on cultural interpretations of disaster risk, vulnerability and 
adaptation in urban India. This has been evident through distinct internal/external discourses: a la Robert Putnam-two levels of discourses; the international and domestic community. So far, we are finding that representations and reports surrounding more recent Mumbai flood events have cohered with universal policy stances that lack textured acknowledgements of differential risk and vulnerability. For example, Chatterje (2010) suggests that in the slums of Mumbai capacity to respond and recover from floods varies depending on socio-cultural divisions and economic and political constraints. We hypothesise that these dominant framings-in combination with other dynamic and complex factors (such as the interplay between municipal governance structures and community agency)-have actually distracted on multiple scales from important adaptation initiatives that build adaptive capacity thus far. So while purportedly just discourses on 'burden sharing' of emissions reductions is prevalent, people on the ground vulnerable to urban flood events continue to suffer from consequent priorities for action.

Through a political economic lens, we attribute these trends to the further entrenchment of market environmentalism and the maintenance of associated (unequal) social and material conditions. Therefore, not all climate adaptation should be considered equal, and that contemporary treatment of climate adaptation strategies can in fact prove counterproductive to stated aims, when more carefully considering cultural factors. An example may be the perspective that relocation of peoples from flood-prone areas is an appropriate universal adaptation strategy. Such measures fail to take into account differentiated roles that individual, group and community agents may play in upholding potential social, political, economic, cultural and ecological resilience of the cityscape. One of the main reasons behind resistance to relocation is past experience of rehabilitation, which has, time and again, failed to consider cultural factors and offer complete economic rehabilitation. The risk of maladaptation is also high in such a dynamic and complex socio-economic cultural milieu. The political constraints have failed to appreciate the microcosm that Mumbai is while in its cultural fabric, the apathy towards political participation as well as cooperation has been deeply entrenched. The voter turnout in civic polls is a miniscule $40-50 \%$ in Mumbai, which goes up a little higher to about $55-60 \%$ in state elections. ${ }^{2}$

Our analysis has important implications for adaptation in cities, and vulnerability to climate change. The main response pattern reflects that climate change governance is at present still an elite issue. The governing institutions and mass media are conduits for information and action on climate change and for adaptation options to climate change. In other words, social change to collectively prepare for climate change impacts and responses is influenced by these positions of responsibility and power: 'Bombay's fate is solidly, inextricably, linked to India's fate, much as the city would like to pretend otherwise' (Mehta, 2004: 131). This highlights the cross-scale 


\section{Emily Boyd, Aditya Ghosh, Maxwell Boykoff}

nature of adaptation. The city of Mumbai has a relationship to the state and to the federal level. The federal level has only recently taken on board climate change in the creation of the first national action plan, which has a limited focus on urban adaptation to climate change. While local knowledge of rainfall plays an important role, more worrying is the development of areas of the city, overpopulation and the risks that displacement of slum dwellers face.

How does this analysis inform the wider debates on adaptation, cities and vulnerability? Through this work, we hope to enable further analyses as to how expert-led scientific forecasts on future extreme events influence discourses and planning, primarily at the city level, and movements to access emergent 'adaptation funds' and breakdown North-South impasses.

This work also seeks to illuminate ongoing considerations of consequences from the new carbon economy, especially how particular discursive tropes have contributed to consequent priorities for climate governance. Mass media representations of climate change actors, action, predicaments and progress remain key influences that shape discourses and bounding considerations for possible climate risk and resilient adaptation actions. To the extent that researchers fail to examine 'how' these representations and symbols are negotiated through relations of dominance, subordination, inequalities of access and resources, we organise our own irresponsibility in effectively constricting the "scope of politics" (Rosati, 2007: 996) or the spectrum of possibilities for future climate mitigation and/or adaptation action.

Translations and interpretations through the spaces of cultural politics are not viewed as reified markers, but rather windows into the processes that contribute dynamically to the formation and maintenance of identity as well as the cumulative characteristics of society (Maleuvre, 2004). Thus, we seek to make sense of these activities, and situate questions within unfolding activities in the (new) carbon economy and ongoing climate risk and adaptation strategy. This might be a first step towards the re-configuration (or re-organisation) of discourses that can open up new possibilities for climate change governance (Swyngedouw, 2007).

\section{ACKNOWLEDGEMENTS}

Thanks are extended to Leverhulme Trust, James Martin Fellowship and the Environmental Change Institute at Oxford University for the finance and institutional support during which this work was initiated.

\section{NOTES}

1. Climate Change and Risk Atlas 2014. http://maplecroft.com/portfolio/ new-analysis/2013/10/30/31-global-economic-output-forecast-face-high-or- 
extreme-climate-change-risks-2025-maplecroft-risk-atlas/. Last accessed 30 April 2014.

2. Information sources: India Today, 1 May 2009. http://www.indianexpress.com/ news/45-pc-turnout-in-peaceful-bmc-polls/22330/0. Last accessed 15 March 2014. Express News Service, 14 October 2009. http://www.indianexpress.com/ news/city-does-it-again-only-45.98-vote/528899/0. Last accessed 16 March 2014.

\section{BIBLIOGRAPHY}

Adger, W. N., S. Dessai, M. Goulden, M. Hulme, I. Lorenzoni, D. R. Nelson, L. O. Naess, J. Wolf, A. Wreford (2009) 'Are There Social Limits to Adaptation to Climate Change?', Climatic Change 93: 335-354.

Adger W.N., T.P. Hughes, C. Folke, S. Carpenter, J. Rockström (2005) 'Socialecological Resilience to Coastal Disasters', Science 309 (5373): 1036-1039.

Anon., (2010) Mahatma Gandhi National Rural Employment Guarantee Scheme, Report to the People 2006-2010, Ministry of Rural Development, Government of India.

Benton-Short, L., J.R. Short (2008) Cities and Nature. London: Routledge.

Bulkeley, H., M. Betsill (2004) Cities and Climate Change. Abington: Taylor \& Francis.

Castán Broto, V., H. Bulkeley (2012) 'A Survey of Urban Climate Change Experiments in 100 Cities', Global Environmental Change 23 (1): 92-102.

CCC (Concerned Citizen's Commission) (2005) Mumbai Marooned: An Enquiry into the Mumbai Floods. Mumbai: Conservation Action Trust.

Chatterje, M. (2010) 'Slum Dwellers Response to Flooding Events in the Megacities of India', Mitigation and Adaptation Strategies to Global Environmental Change 15: 337-353.

Dang, H.H., A. Michaelowa, D. D. Tuan (2003) 'Synergy of Adaptation and Mitigation Strategies in the Context of Sustainable Development: The Case of Vietnam', Climate Policy Supplement 1: S81-S96.

de Sherbinin, A., A. Schiller, A. Pulsipher (2007) 'The Vulnerability of Global Cities to Climate Hazards', Environment and Urbanization 19 (39): 39-64.

Ghoge, K. (2010) 'Climate Change Action Plan for Mumbai in Two Years', Hindustan Times, 1 April. http://www.hindustantimes.com/india-news/mumbai/ climate-change-action-plan-for-mumbai-in-two-years/article1-525623.aspx. Last accessed 10 April 2014.

Hallegatte, S. (2012) 'Coastal Cities, Climate Change Vulnerability, and Adaptation, Copenhagen and Mumbai Examples', An OECD project led by Jan Corfee-Morlot. http://www.oecd.org/env/cc/44104953.pdf. Last accessed 20 April 2014.

Hallegatte, S., C. Green, R. J. Nicholls, J. Corfee-Morlot (2013) 'Future Flood Losses in Major Coastal Cities', Nature Climate Change 3: 802-806. doi:10.1038/ nclimate 1979.

Harvey, D. (1996) Justice, Nature and the Geography of Difference. London: Wiley-Blackwell.

Hunt, A, P. Watkiss (2007) Literature Review on Climate Change Impacts on Urban City Centres: Initial Findings. Paris: Organization for Economic Co-operation and Development, 1-53.

Huq, S., S. Kovats, H. Reid, D. Satterthwaite (2007) 'Editorial: Reducing Risks to Cities from Disasters and Climate Change', Environment and Urbanisation 19 (1): 3-15. 


\section{Emily Boyd, Aditya Ghosh, Maxwell Boykoff}

IPCC (2001) Climate Change 2001: Impacts, Adaptation and Vulnerability. Cambridge: Cambridge University Press.

Kelkar, R. R. (2005) 'Understanding the Extreme Weather Events'. IWRS Newsletter, November. https://rrkelkar.files.wordpress.com/2007/08/kelkar-understandingextreme-weather-events.pdf. Last accessed 4 November 2014.

Klein, N. (2007) The Shock Doctrine: The Rise of Disaster Capitalism. New York: Metropolitan Books.

Kvale, S. (1996) Interviews: An Introduction to Qualitative Research Interviewing. London: Sage Publications.

Lukose, A. (2014) 'Mean Sea Level along Mumbai to Rise by $4 \mathrm{~cm}$ in 100 Yrs: Study', The Indian Express, April 17. http://indianexpress.com/article/cities/ mumbai/mean-sea-level-along-mumbai-to-rise-by-4-cm-in-100-yrs-study/. Last accessed 20 April 2014.

Maleuvre, D. (2004) 'Beyond Culture', Journal of Human Values 10 (2): 131-141.

McGranahan, G., D. Balk, B. Anderson (2007) 'The Rising Tide: Assessing the Risks of Climate Change and Human Settlements in Low-elevation Coastal Zones', Environment and Urbanisation 19 (1): 17-37.Paavola, J., W.N. Adger (2002) 'Justice and Adaptation to Climate Change', Tyndall Centre Working Paper 23. Norwich: Tyndall Centre for Climate Change Research.

Mehta, S. (2004) Maximum City: Bombay Lost and Found. India: Penguin Books Ltd.

Pelling, M. (1999) 'The Political Ecology of Flood Hazard in Urban Guyana', Geoforum 30: 249-261.

Prime Minster's Council on Climate Change (2008) National Action Plan on Climate Change. New Delhi: Government of India.

Rajeev, R. A. (2009) Interview, 12 January; (2014) Interview, 29 March.

Revi, Aromar. (2005) 'Lessons from the Deluge: Priorities for Multi-Hazard Risk Mitigation', Economic and Political Weekly 40 (36): 3911-3916.

Revi, Aromar. (2008) 'Climate Change Risk: A Mitigation and Adaptation Agenda for Indian Cities', Environment and Urbanization 20 (1): 207-229

Rosati, C. (2007) 'Media Geographies: Uncovering the Spatial Politics of Images', Geography Compass 1 (5): 995-1014.

Scheffer, M., F. Westley, W. Brock (2003) 'Slow Response of Societies to New Problems: Causes and Costs', Ecosystems 6: 493-502.

Solecki, W., R. Leichenko, K. O'Brien (2011) 'Climate Change Adaptation Strategies and Disaster Risk Reduction in Cities: Connections, Contentions, and Synergies', Current Opinion in Environmental Sustainability 3 (3): 135-141.

Stern, N. (2007) The Economics of Climate Change: The Stern Review. Cambridge: Cambridge University Press, 673.

Stutz, B. (2012) 'Too Big to Flood? Megacities Face Future of Major Storm Risk'. Yale Environment, The Guardian, 17 December. http:/www.theguardian.com/ environment/2012/dec/17/megacities-future-major-storm-risk. Last accessed 17 March 2014.

Swyngedouw, E. (1997) 'Power, Nature, and the City. The Conquest of Water and the Political Ecology of Urbanization in Guayaquil, Ecuador: 1880-1990', Environment and Planning A 29: 311-332.

Swyngedouw, E. (2007) 'Impossible Sustainability and the Post-political Condition' in R. J. Krueger, D. Gibbs (eds.), The Sustainable Development Paradox: Urban Political Economy in the United States and Europe, 13-40. New York: Guildford Press.

Tanner T, T. Mitchell, E. Polack, B. Guenther (2009) 'Urban Governance for Adaptation: Assessing Climate Change Resilience in Ten Asian Cities', IDS Bulletin No. 13. 
Tol, R. (2007) 'The Double Trade-off between Adaptation and Mitigation for Sea Level Rise: An Application of FUND,' Mitigation and Adaptation Strategies for Global Change 12: 741-753.

Tschakert, P. (2012) 'From Impacts to Embodied Experiences: Tracing Political Ecology in Climate Change Research', Geografisk Tidsskrift-Danish Journal of Geography 112 (2): 144-158. 


\title{
9 Relational Agency and the Local Governance of Climate Change
}

\author{
International Trends and \\ an American Exemplar
}

\author{
Alexander Aylett
}

\section{INTRODUCTION}

Since the first urban climate initiatives began in the early 1990s, urban responses to the climate challenge have progressively shed their narrow environmental framings. A technocratic focus on measuring and reducing emissions is being challenged by a more holistic conception of climate planning and action that embraces increasingly complex engagements with other issues like economic development, equity, spatial development, health, and quality of life. ${ }^{1}$

As a result, this chapter argues, a new form of agency is emerging to drive urban responses to climate change forward. A top-down vision of climate action focused on the regulatory powers of isolated local government agencies is being replaced by one that is horizontal, relational, and collaborative. This is in response to the fact that no one agency or organization can take the cross-cutting action that holistic responses to climate change require. Rather, climate-relevant policies and programs are driven forward by coalitions of multiple different actors. This collaborative and networked approach to urban climate governance capitalizes on the synergies between objectives across different subject areas (emissions reductions and health, for example) and also between different groups of actors that cut across scales and bridge the governmental, civil-society, and private sectors. This approach transforms relationships both inside and outside of local governments, by linking together traditionally siloized municipal agencies and also forging partnerships with civil-society and business actors.

This chapter delves into the realities of orchestrating that type of networked and collaborative response to climate change. It focuses on the internal dynamics of mainstreaming engagement with climate change across the institutional silos that characterize municipal bureaucracies. The empirical material for this exploration comes from an in-depth case study of Portland, OR (a North American leader in urban responses to climate change). To put this case study into a broader context, the discussion also draws from the results of the MIT-ICLEI Urban Climate Change Governance Survey 
(UCGS). The UCGS is the first large-scale international survey to gather information on the relationships of governance that shape urban responses to climate change. Analytical concepts drawn from institutionalism, new institutionalism, and actor network theory will help structure the discussion of this material and provide the foundation for a broader discussion of how we theorize climate governance at the urban scale.

My goal is to balance empirical and critical richness in a way that satisfies readers interested in the particularities of Portland's journey to being a climate leader, as well as those more focused on expanding how we theorize the urban as a sphere for action on climate change.

\section{BROADENING HORIZONS}

Local governments have progressively been moving towards more holistic engagements with climate change. This is a profound shift that is taking us from rational technocratic and state-dominated processes to broad-based networked undertakings that attempt to structure effective partnerships across silos, sectors, and scales. Conceptions of climate agency are moving away from hierarchical and legalistic conceptions of action to ones that are increasingly relational and emergent. Conceptions of the issue of climate change itself are expanding beyond narrow framing centered around the environment and energy to ones that are increasingly woven into, even subsumed by, other issues of concern.

This shift responds to a series of technical, institutional, and political realities. At its most basic, networked approaches to climate governance reflect the fact that only a small percentage of urban emissions (roughly 1 to $10 \%$ ) are under the direct control of municipal governments. ${ }^{2}$ Taking action beyond the scope of the assets directly owned by local governments requires a coordinated use of the different policy tools that local governments have at their disposal. ${ }^{3}$

Discussions of "mainstreaming" engagement with climate change across multiple municipal departments are rooted in a recognition of the fact that to act at this level necessarily means going beyond what can be accomplished by any one government agency acting in isolation. It also implies creating and maintaining effective partnerships with private and civil-society actors able to act as partners in designing and implementing emissions reduction programs in areas outside of municipal control.

From a political point of view, this more holistic approach to climate planning also has the added benefit of building a broader base of support by directly supporting efforts to meet other pressing social and economic development goals. While maximizing outcomes by effectively coordinating the use of limited resources, attention to synergies therefore also helps effectively position mitigation programs within the complex political economy of competing local priorities. 


\section{Alexander Aylett}

Certain aspects of this continuing transformation are increasingly well understood. There are growing literatures on synergies between climate change and other local development priorities, the multi-scalar nature of urban responses to climate change, and the role of non-governmental (particularly civil-society actors) in responses to climate change. The importance of political champions and strong leadership has also received an increasing amount of attention.

Less well understood is what this transition means for the internal dynamics within and across municipal agencies. This is problematic. Both climate change and the agencies or individuals responsible for climate change planning are recent arrivals on the municipal policy making scene. They are often marginal, underfunded, and poorly staffed. From this position of relative weakness, increasingly holistic and integrated responses to climate change require them to negotiate coalitions of support that span multiple municipal agencies each with their own pre-existing mandates and core responsibilities. Understanding the internal functioning of municipal institutions is essential if we are going to talk meaningfully about local responses to climate change. This chapter aims to help get that conversation started.

Bureaucracies are perceived to be highly resistant to change. Superficially it is easy to blame the challenges faced by climate policies on the path-dependency of reactionary institutions. But that does not tell the whole story. Despite their apparent intransigence, organizations clearly do change. As other institutionalist and new institutionalist work has shown, the key question is not "why are institutions resistant to change?" But rather "how do complex organizations adapt to changing circumstances, and why are certain new courses of action accepted while other are not?" (see March \& Olsen 1989, Schoenberger 1997).

In earlier work, I have focused on the organizational cultures and path-dependency of municipal bureaucracies, as well as the role of power elites in steering processes of change so as to protect established assets and divisions of power (Aylett 2011a, b, c).

Building on that work, this chapter will take a closer look at the strategies used by change-makers in the municipal bureaucracy to bring about change despite their often marginal positions.

\section{ACTOR NETWORK THEORY AND BUREAUCRATIC PATH-DEPENDENCY AND CHANGE}

The literature around local responses to climate change is rich with discussions of the synergies and co-benefits of climate policies (Betsill 2001, Gibbs et al. 2002, Wilbanks 2003, Swart et al. 2003, Pielke 2005, Van Asselt et al. 2005). Specific renewable energy strategies can simultaneously reduce emissions, increase access to electricity among marginalized communities, and increase the resilience of the local energy system. These synergies have 
important technical advantages; they allow multiple real-world objectives to be realized simultaneously and efficiently. But they also have important political advantages; they allow for multiple political imperatives to be met by a single policy.

By changing the value narrative(s) that surround a given policy, attention to synergies changes the way a given policy moves through the complex political economy of municipal decision making and the multiple (sometimes conflicting) priorities of local governments. Latour's work on Actor Network Theory (ANT), and the concept of "translation" specifically, shows how this process functions and how it can be used intentionally to facilitate changing long-established practices and (eventually) the priorities that undergird them.

ANT proposes a relational theory of agency deeply at odds with the hierarchical and exclusive vision of power embodied in hierarchical institutions. Rather than sovereign actors imposing their will from above, ANT envisions the capacity for action as the result of working with, or through, various other actants. Agency, in short, is acquired and relational, rather than inherent and individually possessed.

If actants end up working together, it is not because of any inherent alignment of their goals, or the ability of one to dictate terms to another. Rather, through processes of translation, their different interests become aligned and they have come to see collaboration with other parties on a given project or policy as the most effective route towards achieving their own objectives.

As Latour points out, interests are not the same thing as goals; rather "interests are what lie in between actors and their goals" (1987, 108). As a result, very different goals ("access to affordable energy for all!" or "reduced carbon emissions!") can be achieved by advancing the very same interests. "Translation" in this context is used to denote the process through which this alignment of interests is created (Latour 1987, 108-121).

Latour outlines five specific translation strategies that those wishing to advance a specific issue or technology (people Latour refers to as "contenders") can use to gain the support of other parties. I would like to touch briefly on three that are particularly relevant to the history of municipal climate action in Portland.

The first and most basic of Latour's approaches to translation involves identifying ways in which your goals can be met by simultaneously catering to others' interests. "The easiest means to enroll people," he points out, "... is to let oneself be enrolled by them!" $(1987,110)$. Even when effective, however, this strategy has limited reach. Used alone it requires that the contender's goals be completely subsumed within the priorities of other actors, and gives them no say in strategic decisions.

To more directly transform interests and goals so that they align with the contenders' interest, Latour describes a process he refers to as "displacing goals" (ibid., 114). In this scenario, the contender transforms the existing interests of a more powerful agency by convincing them that conditions 
have changed and that-if they wish to reach their stated goals-they must pursue new interests. Latour gives the example of how atomic physicists approached the Pentagon and convincingly redefined the Second World War, not as a conventional armed conflict which they had to win, but as a race to create and control atomic weapons. The physicists' research, and funding for it, thus became central to the Pentagon's goal of winning the war.

Finally, Latour's last approach to translation is "becoming indispensable" (ibid., 119). What becomes indispensable, in Latour's analysis, is not the efforts and activity of the contender themselves, but rather the necessity of pursuing the course of action which they advocate. This is, in other words, the description of a state where the contender's goals have become integrated into the operations of other agencies to the point that they have become a necessary part of doing business. In this new arrangement "[n]o negotiation, no displacement would be necessary since the others would do the moving, the begging, the compromising and the negotiation. They are the ones who would go out of their way" (ibid., 120).

As will become clear below, these critical concepts are productive tools for isolating the techniques used by contenders in Portland to mainstream climate change across the municipality as a whole. The account that follows begins with an overview of the historical foundations of Portland's climate change work. It then moves into a detailed account of the work of the city's Office of Sustainable Development (OSD) during the first eight years of its existence. Throughout I will overlay key findings from the UCGS to highlight how the Portland experience relates to broader international trends in the urban governance of climate change.

\section{PORTLAND AND THE URBAN CLIMATE GOVERNANCE SURVEY}

Portland is a leader in urban climate policy. In 1993 it became the first city in the United States (and among the first in the world) to enact a climate change strategy. Since then it has maintained its position by setting and meeting challenging emissions reduction targets, and nurturing cutting-edge initiatives in areas like renewable energy, green building, and (most recently) neighborhood-scale sustainability planning. Now an international icon of green urbanism, it has come a long way since the 1950s when it was, as one local historian pithily described it, "a strikingly dull and derivative city, only a restaurant or two above a logging town" (Johnson 2008, 16).

This chapter takes a critical look at that transition. Concrete achievements, like reducing emissions to 6\% below 1990 levels (BPS 2012), are what grab headlines. But far more interesting are the conditions that made this type of successes possible. Behind the scenes, two years of extensive interviews and policy analysis ${ }^{4}$ show that significant systemic transformations have been taking place within Portland's municipal structures. Portland has 
managed to take climate change planning from being a marginal exercise conducted at the fringes to one that is central to the municipality's approach to operations and planning as a whole.

Results from the Urban Climate Change Governance Survey (UCGS) show that a similar transition ${ }^{5}$ is taking place in many other cities. Conducted in collaboration with ICLEI-Local Governments for Sustainability, the UCGS surveyed 736 ICLEI member cities across all five continents. Of these $350(47.5 \%)$ responded to the survey. While cities report that initially their climate change plans were confined narrowly to plans specifically focused on climate change, we now see an increasing integration of climate change as a variable in sectoral and long-range planning across local government operations. The survey shows a $79 \%$ increase in the number of cities reporting that climate change is being integrated into sectoral plans, and a $55 \%$ increase in integration into long-range planning.

In Portland's case this process took nearly two decades, in other cities within the UCGS it appears to have happened more quickly. But in all cases those responsible for climate change planning had to negotiate the complex internal dynamics of hierarchical and siloized bureaucracies. Exploring the processes that made this transition possible are what we will turn to next.

\section{PORTLAND: FROM LOGGING TOWN TO GREEN MECCA}

Portland's engagement with climate change dates back to the early 1990s, when it became one of the first cities in the world to commit to specific, citywide reductions in greenhouse gas emissions, and was part of the initial cohort of cities that helped to found ICLEI. ${ }^{6}$ The municipality conducted its first community-wide GHG emissions inventory in $1990,{ }^{7}$ and passed its first "Global Warming Reduction Strategy" ${ }^{8}$ three years later (Portland 1993).

But the foundations for the city's approach to climate change were laid decades earlier in an interesting confluence of environmental, energy, financial, and legislative factors that all positioned the city to be one of the first cities to later pursue municipal climate policies. The year 1979 was a critical one in the history of Portland's approach to energy and environmental issues. In that one year the municipality passed its first energy policy, founded its Energy Office, and adopted its first urban growth boundary. Enacted in response to a prolonged energy crisis that was affecting the region, and prior state-level legislation, these interventions laid the foundation for its later work on climate change (see Rutland \& Aylett 2008 for a more detailed account of these events).

By 1998, Energy Office head Susan Anderson had developed a variety of program ideas that did not fit into the narrow focus on energy efficiency that had guided the Office's work since the late 1970s. Working with the support of key commissioners on Portland's City Council, Anderson won 


\section{Alexander Aylett}

support first for Green Building Initiative that kicked off in 1999, and then in 2000 into the creation of the Office of Sustainable Development, which she went on to direct.

OSD was created through the merger of the city's solid waste and recycling program with the Energy Office, the Green Building Initiative, and an existing advisory Sustainable Portland Commission. As well as a solid institutional home, this arrangement gave Anderson and her team a small but reliable source of funding derived from the fees and revenue associated with the waste and recycling functions they now supervised (OSD 2002). ${ }^{9}$

\section{OSD First Years: Translation, Bridging, and Decentralization}

How to facilitate broad-based and creative engagement with climate change across the municipality as a whole became OSD's overarching goal. Echoing Latour's vision of becoming "indispensable" Anderson explained her ultimate objective: "Over time you want this just to be taken for granted as part of the way the world is. Something so normal that you don't even need to think about it" (Interview, 29 October 2008). By 2008, OSD had already come some way in making that goal a reality. But the challenge for the office when it began was how a marginal office with two staff and a small budget could have that kind of impact.

The initial approach was simple: "We worked with everybody" (ibid). Putting into place the most basic of Latour's strategies of translation, Anderson met with the heads of all the municipal bureaus early on. From these meetings she identified ways that OSD could help them with their own mandates while beginning to integrate climate change and sustainability considerations:

One of the first things that I learnt [was that] we were nothing unless someone wanted us. So the first thing that I did when I had the job there was that I went around to each Bureau Head and got an hour or a half hour of their time and said "what do you need? What are your aspirations? Not from us, but what are you trying to get done?"

And then we would go and try to figure out how we could help them get their mission done. . . [Say] they care about affordable housing. Well, we can work on that. Well they care about transportation modal splits, well we can work on that. (ibid.)

As Latour argued, this strategy of catering directly to others' interests is the most basic form of translation (Latour 1987). Summarizing this approach, OSD staff and senior officials describe the department as a "facilitator" or a "convener," even a "concierge."

In this early stage of their work, this supportive role positioned OSD as a hub within the municipal bureaucracy (see Aylett 2013). It had partners in all the city's major bureaus and worked hard to maintain open 
communication and collaborative relationships between them. In exchange, OSD began to see its own objectives of promoting energy efficiency and emissions reductions finding their way into other departments' work. They acted as a facilitator guiding creation and implementation, but the departments themselves did much of the work, provided funds, and received most of the public credit. OSD in fact strategically avoided claiming ownership of the projects.

Latour identified this kind of marginalization as one of the dangers of pursuing translation by catering to others' interests: "will [the contender's efforts] not be appropriated by others who say they did most of the work" (Latour 1987, 110)? Yes. But in this case it served OSD's larger goals to avoid the spotlight. Placing the focus on the bureaus helped develop their own internal capacities and slowly began to change their organizational culture. Mike O'Brien, of OSD's Green Building Program, described this shift: "Once they have to start thinking about sustainability as part of their job, it starts to change the culture of the agency. It starts to be OK to be concerned about sustainability" (Interview, O'Brien, 4 November 2008).

Starting with the 1993 City Energy Challenge that she ran while heading up what was then Portland's Energy Office, Anderson had successfully coordinated energy efficiency and building retrofit programs within the other municipal bureaus. This gave the bureaus hands-on experience with a concrete sustainability project that had tangible economic benefits.

This kind of concrete project opened the door to introducing the more complex synergies and overlaps between environmental objectives and other municipal priorities like health, walkable neighborhoods, and job creation. At a departmental level, OSD was then able to move beyond serving established priorities and to begin to more openly advocate for its own interests, but always on the basis of shared interests. Describing her current approach, Anderson explained that:

I don't feel like I need to convince everyone that global warming is real. I have to convince them that it is in their self-interest to take this action that I want them to take. (Interview, Anderson, 29 October 2008)

Initially OSD's work depended on its ability to cater to existing departmental needs. But here, Anderson is describing in general terms a shift towards a strategy of "displacing" established goals by showing that climate-relevant policies had redefined the strategies that bureaus needed to use to achieve their goals. This process of translation helped established climate change as a bridge issue that brought together various departments on the ground of common interest (see March and Olsen 1989, Callon 1986, Latour 1987, Rutland and Aylett 2008). Anderson's basic appeal to institutional self-interest managed, at least superficially, to lift the issue out of a narrowly environmental category and establish its broader relevance (Interviews, Armstrong, 11 June 2008, Anderson, 29 October 2008). 


\section{Alexander Aylett}

\section{INTERNAL POLYCENTRIC GOVERNANCE AND OPEN INNOVATION}

By 2008 the end result of OSD's work had been that engagement with climate change extended across the municipality as a whole. Tom Osdoba, who worked as a consultant for OSD and is currently director of the Centre for Sustainable Business Practices at the University of Oregon, summarized his view of this shift:

It is all very delicate, and it is all about relationships. I think Susan [Anderson] has a lot of success in figuring out those relationships and navigating that water from a position of relative weakness from an organizational perspective, to be able to put [ideas and policies] forward. (Interview, Osdoba, 22 October 2008)

Concretely this meant that OSD had strong working relationships with most of the municipality's major capital departments. For key relationships-such as those with the Planning Bureau, the permitting function at the Bureau of Development Services, and the Portland Development Commission-fulltime staff were hired (occasionally at OSD's expense) to work within those bureaus to design and implement specific climate-related projects (Interviews, Debbie Cleek, Bureau of Development Services, 15 October 2008, Chris Dearth, Bureau of Planning 17 October 2008).

Overall, OSD's facilitative approach played a supportive role in a spectrum of projects that ran from the initiatives of single individuals (like Tom Ullman in the Maintenance Bureau, who installed solar panels on his own van to power his tools and then converted the Bureau's entire fleet) to large collaborative projects (like the Clean Energy Works energy retrofit and job creation program that involved OSD, the Portland Development Commission, and 12 other public, private, and non-profit partners in a city-wide effort to improve home energy efficiency). Crucially, none of these projects are the sole property of OSD. Rather they were created with OSD support, but are managed and operated by other units throughout the municipal bureaucracy.

All these cases demonstrate a form of relational, collaborative, and emergent agency where climate-relevant policies and programs are driven forward by coalitions of multiple different actors. Each individual initiative has a dominant public face-often the Bureau most directly responsible for the sector in question-but beneath the surface action is made possible by a network of actors. OSD fostered this open and unconstrained engagement with climate-relevant policies by feeding departments with a variety of sustainability options, and providing support and recognition for their accomplishments.

This is the antithesis of a centralized and hierarchical Weberian approach to creating and implementing climate policies (see Aylett 2011a) (vis. 
Schoenberger 1997). The result is a body of projects that are innovative and varied, but also wildly uneven in terms of their scope and scale.

Mike Armstrong, OSD's deputy director and the principal coordinator of Portland's Climate Change Action Plan, spoke positively of what he called a state of "creative chaos" that surrounded sustainability initiatives in the city. He credited it for having encouraged broad and creative engagement with climate change across the municipality (Interview, Armstrong, 6 November 2008).

But successful as this approach has been, it also has an important weakness. This open facilitative approach comes at the expense of the ability to successfully establish an overarching strategy to guide the municipality's climate change efforts, and to ensure that these multiple atomized initiatives align to significantly reduce the city's emissions. Armstrong was open about this as well:

Portland is a cautionary tale of how you can do the right things for ten years, and still be nowhere near where you need to be. We are only just barely making our 1990 targets and that is a joke compared with where we really need to be. (Interview, Armstrong, 6 November 2008)

\section{THE LIMITS OF “STRATEGIC GRABBING”}

Rather than "strategic planning," OSD's head Susan Anderson calls the department's approach "strategic grabbing": finding ideas and projects that at specific moments have traction with specific politicians or departments and facilitating their implementation. All of this depended on a relatively limited refocusing of various bureaus' attention on the financial rewards of energy efficiency and green building policies and programs. These approaches were designed to win general support for the issue of climate change within the municipality, and help nurture and support individual departmental policies. This facilitative approach had benefitted OSD, winning it internal recognition within the municipality, and allowing it to expand to the point where it had over 30 staff, and showcase offices within a prestigious green redevelopment in the city's Pearl district.

What this approach had not done was allow OSD to coordinate the strategic integration between the municipality's climate change goals and operational practices and plans in other departments. The relationship between OSD's climate objectives and the plans and the objectives of the Portland Bureau of Transportation (PBOT) for the period under study are a case in point.

Between 1990 and 2008, transportation-related emissions have remained stable for roughly $40 \%$ of the city's overall emissions (see Figure 9.1 on sources for Portland's emissions). ${ }^{10}$ To tackle this, OSD's 2001 Global Warming Action Plan set out to reduce transportation-related emissions by 
Portland GHG Emissions by Sector 1990

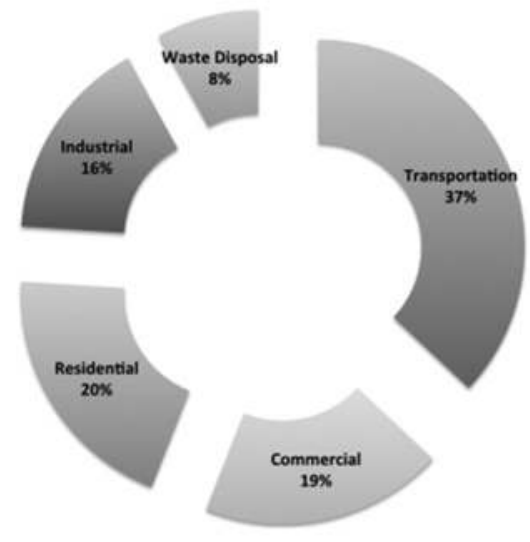

Portland GHG Emissions by Sector 2008

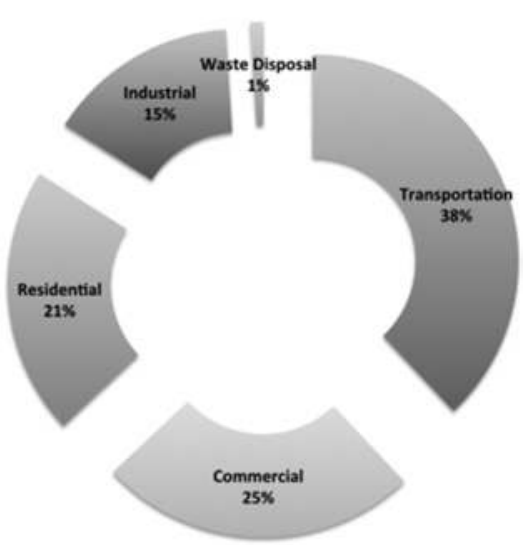

1990 Data: PEO 2000 : 2008 Data: BPS 2009

Figure 9.1 Portland GHG emissions by sector, 1990 and 2008.

Source: 1990 data: PEO (2000); 2008 data: BPS (2009).

roughly one third by 2010 . But by 2008 , rather than a decrease, we in fact see a slight increase in transportation-related emissions. The bureau with the most direct influence over these emissions is PBOT, and a closer look at its own objectives for this period go some way towards explaining why emissions in the sector failed to decline.

Commuters in Portland (as in all North American cities) are overwhelmingly dependent on their cars. A total of $62 \%$ of commuters drove to work alone in their cars in 1994, and this figure stayed almost unchanged into the early 2000s. To reach OSD's goal of a one-third reduction in transportation emissions, reducing the number of single-occupancy vehicle (or SOV) trips would be crucial. But PBOT's 2006 Transportation Systems Plan proposed something much more modest: a reduction of 5 percentage points (from $62 \%$ to $57 \%$ ) in SOV trips by 2020 . This is a far cry from what OSD's emissions reduction goals would require.

It is clear elsewhere in the 2006 plan that PBOT is generally supportive of the role that transportation planning can play in reducing the city's environmental impact and its GHG emissions. Other documents (PBOT 2009) also show that the PBOT had engaged in many of the types of operational energy efficiency actions promoted by OSD (installing high-efficiency lighting, for example). But the disparity between the objectives proposed by OSD and PBOT shows to what extent OSD's facilitative approach could fail to effectively coordinate a unified municipal response to climate change, or to influence the plans and objectives of key municipal agencies when it 
came time to go beyond minor efficiency gains and to modify their core strategic decisions.

\section{AIMING FOR “INDISPENSABLE”}

From Armstrong's frank appraisal of OSD's work up to that point, quoted earlier, it is clear that by 2008 OSD was keenly aware of a need to adjust its strategy. Somehow, in the transportation sector and elsewhere, OSD needed to provide stronger direction and more effective support in a way that could spark a deeper operational engagement with climate change among the city's key bureaus. But it needed to do so while maintaining its facilitative role as a hub within multiple networks of relational agency. It needed to find a way, in Latour's language, to move closer to being "indispensable." To spark that transition, OSD centered its strategy around the creation of the 2009 Climate Change Action Plan.

Portland's third CAP, released in 2009, was dramatically different in both its content and-crucially-the process through which it was created than those that came before it. Committing the city and county to reduce their overall emissions by $80 \%$ below 1990 levels by 2050, the plan remains one of the most ambitious municipal climate change action plans in North America. ${ }^{11}$ To implement such an ambitious plan, its targets needed to be supported by the departments and staff who would be responsible for enacting them. Pursuing what Armstrong called "a tricky balance between too much control and not enough," it needed to create a document that was both ambitious enough to address the true scope of the climate challenge, and also widely supported.

To achieve that, OSD designed a process for drafting the plan that-as well as creating the text of the plan-built and maintained collaborative relationships across departments that would enable implementation. Michelle Crim, a program manager within OSD, described the type of shift that was involved:

The other two [earlier Climate Action Plans] were essentially OSD plans. It was the carbon and climate plan for the city but other bureaus didn't have ownership over it. They probably didn't even know it existed. ... It was very much: "That's what OSD does."

[This time] we had a lot of city staff involvement. We were purposely really responsive [to internal feedback]. . . . Ultimately what ended up happening is a lot of the actions that are in that strategy helped to further the bureaus' own priorities. (Interview, Crim, 29 June 2010)

In this, Portland is a leading example of a more general finding from the UCGS. A majority of cities $(61 \%)$ reported that their plans were created with regular input by other municipal agencies throughout the planning 


\section{Alexander Aylett}

process. More specifically, over one third of respondents (37\%) report that the person/unit specifically tasked with climate planning oversees a collaborative planning process that extensively involves other multiple local government agencies/departments. ${ }^{12}$

Working with a Latourian logic, Armstrong and Crim used the process of creating the CAP to translate climate change in such a way that it "displaced" already established goals within major municipal departments (cf. Latour 1987). This time, however, this process of translating climate change had to engage with more complex processes of coalition building than simply showing that changing light bulbs would save departments money.

To achieve this, technical groups were assembled for each of CAP's eight key subject areas. ${ }^{13}$ These were made up of both municipal employees and outside experts. These groups created individual action plans in each subject area. The plan could therefore not be narrowly pigeon-holed as "what OSD does." This approach also ensured that multiple perspectives would be incorporated into the finished document, and helped avoid a plan which reflected only the situated knowledge of a limited constituency within the city (vis. Haraway 1991, Schoenberger 1997).

At the same time, a more informal process vetted each action with the bureaus that would be most impacted by it. For each area of the CAP, Armstrong, Crim, and John Tydlaska (from the Portland Development Commission) would identify the most relevant program managers within municipal bureaus and work with them personally on the objectives and the text of the plan. The goal of this process was to ensure that both the objectives and the way in which the objectives were expressed resonated with established institutional priorities and discourse.

Interestingly, the tactics employed during the CAP process also figured prominently in the responses captured by the UCGS. As was noted earlier, a majority of cities reported an increase in the integration of climate change into the plans of multiple municipal departments. Respondents were asked which strategies had been most effective in promoting this cross-departmental mainstreaming. ${ }^{14}$ Tactics for building internal networks between departments dominated the strategies that were identified as most effective. Among these were more formal interventions such as creating climate change or sustainability-focused working groups that brought together staff from various agencies (ranked fourth). But even more effective were informal interventions based on person-to-person exchanges and trust. Specifically, the top two strategies were:

- "creating informal channels of communication between the person/ team responsible for climate planning and staff within other local government agencies" and

- "cultivating personal contacts and trust between the person/team responsible for climate planning and staff within other local government agencies." 
These results confirm the role of personal networks and relationships of trust in creating the conditions necessary for shifts in policy direction within complex urban systems that has been noted in other research (see Campbell 2012). They also echo Anderson's personal approach to building connections within Portland's bureaucracy, and the less formal vetting process that the OSD team built into the process of creating the CAP.

But this should not downplay the importance of more formal interventions that aim to directly build bridges between the climate planning team (and the climate plan) and other local government agencies. The third-ranked strategy was to address the issue directly by hiring or designating staff within local government agencies to coordinate that department/ agencies' engagement with climate responses. The fifth-ranked strategy approached the same issue through the planning process by creating climate policies and programs that also help meet the existing (non-climate related) priorities, goals, and core mandates of local government agencies.

As we have seen, all of these tactics featured prominently in Portland's approach to mainstreaming engagement with climate change.

\section{THE UCGS: CHALLENGES OF UNEVEN ENGAGEMENT}

But the Portland case study and the results of the UCGS both bring to light other more complex and problematic aspects of this collaborative and relational approach to climate change planning. In the UCGS, as mentioned above, a strong majority report that their climate plans are created with significant input from other municipal agencies. While this may be the case, this participation is in fact highly uneven.

To understand the engagement of different local government agencies in greater detail, respondents were asked to rank the degree to which specific agencies contributed to designing and/or implementing climate change adaptation and mitigation plans. ${ }^{15}$ What emerged was a portrait of deep divisions. The agencies that contributed most heavily were those responsible for environmental planning, land-use planning, solid waste management, water, and transportation. Those that contributed the least were the locally operated electrical utility (where these existed), and the agencies responsible for health, and economic development. These agencies were also those where respondents reported the least alignment between climate change mitigation plans and the existing objectives of the government agencies responsible for those issues. The distance between high- and low-ranking agencies was considerable, with $61 \%$ of respondents reporting that land-use planning agencies contributed significantly, in contrast to only $29 \%$ for health agencies.

In other words, while local governments are reporting a general turn towards collaborative climate planning and a mainstreaming of climate change across municipal affairs, this movement is distributed unevenly across the institutional landscape. In some areas collaborations have been 
effectively built around common interests. But in others processes of translation have yet to effectively build the necessary foundations for joint action.

\section{PORTLAND: THE VALUE OF INTERNAL CONFLICT}

This unevenness seen in the UCGS manifests itself in a different way when you scratch beneath the surface of the Portland story to get to a second grittier dimension of the 2009 CAP planning process.

The objectives proposed in the CAP are a significant diversion from the standard approaches of the city's bureaus. Practices like a modal shift in transportation from private vehicles towards public transit and cycling had their supporters. But they were still the subject of internal debate and conflict.

The CAP played into these conflicts. It provided an opportunity for staff already engaged in efforts to change bureau practices to gain legitimacy and leverage by embedding their position in a high-profile city-wide policy. OSD therefore also tactically applied the CAP process to support contested processes of organizational transformation already taking place within other municipal agencies. As Crim explains:

[Within the Transportation Bureau there is] an internal struggle that they have had around the priority of cars versus other modes of transportation. . . Their traditional mission is to make sure that cars can get from A to B and as quickly and efficiently as possible. But there's another segment there that needs to get people from A to B in something other than a car. [Transportation planners trying to reduce the role of the private automobile] came to a place where they saw the Climate Action Plan as a tool that can help to strengthen their side of the argument.

There were disagreements like these within other bureaus as well. By having this longer process we were able to deliver what's essentially a policy document for the city that furthered these priorities at least among certain programs and staff within those bureaus and added [to their] legitimacy. As a result of that I would say this plan has tons of shared ownership. I've constantly been amazed to hear not only other city bureaus talking about the Climate Plan as their plan-not just the city's plan. (Interview, Crim, 29 June 2010)

The presence of internal conflict meant that the CAP was valuable to those pushing to shift the organizational culture and technical practices of their bureaus. The situation within the Transportation Bureau appears to have been similar to accounts of "guerrilla warfare" within private corporations, where internal factions fight to shift the established methods and organizational culture of the organization (see Schoenberger 1997, for example). 
New Instititionalist research has also called attention to the dynamic but contested process through which bureaucratic organizations respond to changing circumstances (cf. March and Olsen 1989, 2004).

Recognizing the significance of these moments of contestation, OSD allied itself with key actors in those internal conflicts. It presented the CAP as a powerful overarching municipal document, which could provide legitimacy for the changes that departmental "guerillas" were seeking to create. Bringing together these two bodies of theory expands on Latour's original conception of the function of processes of translation. It highlights the fact that acts of translation can target counter-cultures within existing organizational cultures, not only dominant actors and established objectives. ${ }^{16}$

\section{DISCUSSION}

[When I started] I was still not really hired by the city or anything. I was this little intern person who was walking around and talking to city council members saying 'global warming is real' and they began to really believe that it was too.... I wouldn't say 'sustainability', no one knew what it meant, it had too many syllables.

- Susan Anderson, Head, Portland Office of Sustainable Development, Interview, 29 October 2008

Anderson's experience of trying to create significant change from a marginal position within municipal structures is not unique. Other researchers have also called attention to the fact that the people or teams tasked with climate planning are often marginal players within municipal structures, and are rarely directly in control of key policy areas (such as transportation, or spatial planning) needed to respond effectively to the problem (Bulkeley 2010, Alber \& Kern 2008, Bulkeley et al. 2009). Fully 63\% of cities in the UCGS report that they have only a single staff member or a small team of $1-5$ people in charge of their climate change planning. Given the cross-cutting nature of climate change, effective urban responses therefore rest on the ability of small teams on the sidelines of municipal structures to mainstream and coordinate engagement with climate change across the various departmental silos that control individual pieces of a larger coordinated response.

The story of the first period of Portland's engagement with climate change is one of important institutional successes. Anderson built up a highly skilled team to carry Portland's climate and sustainability work. But beyond that OSD succeeded in gradually integrating awareness and engagement with the climate issue across the municipality's key bureaus. OSD staff achieved this through perceptive and persistent networking and facilitation within the municipal bureaucracy.

Beginning with its early work on energy efficiency through to the collaborative approach it adopted for the 2009 CAP, OSD's work was rooted in 


\section{Alexander Aylett}

an understanding of the necessity to coordinate collaborative relationships with other municipal departments. Portland's experiences are mirrored in the results of the UCGS, which shows a more general shift towards integrated, collaborative and inter-departmental approaches to climate change planning.

What impact does this have on the way in which we think about the governance of climate change at the urban scale? What does it say about the dynamics and processes of urban climate governance?

Mirroring Latour's arguments on the nature of agency, the material presented here is a strong argument for conceptualizing urban climate governance as a relational, collaborative, and emergent process. A process where no single team or department possesses exclusive agency to act. Rather, governance relationships are made up of coalitions of multiple different actors that together are able to push climate-relevant policies and programs forward.

From an internal institutional perspective, this highlights the role of the core climate planning team as a strategic convener and facilitator. Rather than simply determining technically sound policies, they have the added work of negotiating a place for the climate agenda within the context of multiple pre-existing urban priorities, and building internal coalitions of support for climate action. In Latour's vocabulary, they are a contender who must first cater to, then displace, and finally become indispensable to the established interests and goals of existing municipal agencies.

Likewise, climate change plans themselves are re-imagined. Rather than focus solely on the technical merits of the final plan, this analysis highlights the importance of the planning process itself in creating and maintaining connections between climate policy supporters across the municipality, and creating a document that enables their work and that is aligned with their specific institutional contexts. The plan as process becomes as important as the plan as document. It is not something created in isolation-rather, it is itself a result of the relational form of agency needed for its implementation.

This has implications for the conceptualization of climate change itself as an issue. There are very real ethical and technical reasons to approach climate change in relationship to other pressing local priorities. To these, this analysis adds a clearer understanding of the institutional importance of identifying synergies and co-benefits to help climate policies negotiate the complex political economy of municipal decision making, and to provide the foundation for cross-departmental coalitions of support. Climate change itself becomes a relational issue, an issue that acts as a nexus for the intersection of multiple other institutional interests.

Latour's work on the relational nature of agency, and the processes of translation through which coalitions of support can be created for new policies or technologies is particularly useful here. Latourian analysis can help make clear crucial aspects of the internal institutional work that surrounds designing and enacting urban climate change policies. As has been argued 
elsewhere, the complexity of governance relationships that surround climate change at the urban level requires a broad-based theoretical armory (vis. Bulkeley 2010). Very different theoretical tools are necessary to study the interaction between the local state and other levels of government (for example), and those that structure the relationships between actors within the local state. In this chapter I have continued my work to synthesize a set of critical concepts appropriate to understanding the internal governance relationships within municipal institutions that surround urban responses to climate change (Aylett 2010a, 2010b, 2011a, 2011b, 2013).

But calling attention to the increasingly relational and networked nature of urban climate governance within local government institutions is as much a question as it is an answer. Techniques like collaborative planning, translation, and facilitative network building have their uses. But they also clearly have their limitations. This is apparent in the unevenness of internal governance relationships highlighted by the UCGS. It is also a key aspect of the Portland story.

How to build coalitions of support that more evenly engage all municipal agencies is one key question that emerges from this analysis. Are there strategies of translation that would allow agencies so far only tenuously engaged in climate planning and implementation (such as health or economic development) to be enrolled more effectively?

Where basic support has been won, how can it be amplified to engage even more meaningfully with the operational practices and planning processes that guide the development of our cities? How can climate change "contenders" strike the tricky balance needed to establish institutional networks of urban climate governance that are broadly inclusive, widely supported, and open, but also coherent, strategic, and ambitious enough to have a significant impact? Future research in these areas would contribute significantly to this conversation.

\section{NOTES}

1. This mirrors a more general shift in the treatment of climate change as a policy issue at the national and international level (see, for example, Banuri et al., 2001).

2. See, for example, eThekwini 2007, New York, City of 2012, Portland 2009, Toronto 2007, Vancouver 2009.

3. Good examples of this policy coordination include coordinating transportation and land use planning; or effectively incentivizing green building practices through permitting practices, taxation, and education.

4. The case study that follows is built from interview material gathered as part of a larger comparative study focused, in part, on the institutional dynamics that affect a municipality's capacities to design and implement ambitious climate policies (Aylett, 2011a). In Portland, I conducted 63 semi-structured qualitative interviews spread across two field seasons during the period from Autumn 2008 to Spring 2010. These interviews (lasting between 45 minutes 


\section{Alexander Aylett}

and 1 hour 15 minutes) were conducted with expert and elite respondents from the municipal, civil society, research, and private sectors. These included high-ranking municipal officials and political staff, the heads of local NGOs, community groups, and businesses. A selection of relevant middle management and project-level staff and community members were also interviewed. This broad sample allowed me to triangulate responses and attempt to correct for any biases in individual accounts. In preparation for these interviews, I read extensively within the municipal reports, best-practice notes, and other publications produced by municipal staff (for a complete list of interviewees, see Aylett, 2011c).

Interviews began with municipal officials from Portland's Office of Sustainable Development (OSD) who were most directly engaged with climate policies and programs. Subsequently, I pursued respondents in municipal departments that, while not tasked with climate policy, controlled key portfolios related to urban form, energy use, and emissions. Specifically, this meant the heads, middle and project-level managers from the departments dealing with the Planning, Water, Development and Permitting, and Economic Development. I also conducted interview with a small number of key political respondents who oversaw OSD, or who worked in the mayor's office.

Interviews often centered on specific projects, ranging from campaigns to reduce industrial emissions to large residential green energy projects. These individual projects were used as concrete examples around which to structure questions covering the institutional dynamics that surrounded attempts to integrate and mainstream climate change across municipal institutions.

5. The UCGS was conducted in partnership with ICLEI-Local Governments for Sustainability. It ran from May to August 2013. In total 736 cities were contacted via the ICLEI member contact database. Respondents were primarily the municipal officials most directly responsible for climate change planning. Participants were contacted via e-mail with correspondence being conducted in English, French, Spanish, and Korean. The survey was conducted online and was composed of approximately 64 questions (length varied slightly depending on respondents' answers). The response rate was $48 \%$, with $36 \%$ completing the survey in full.

6. ICLEI, formerly the International Coalition for Local Environmental Initiatives, is the largest non-governmental organization working on local responses to climate change. ICLEI counts over 1,000 local government members worldwide, and its Cities for Climate Protection Program (CPP) and emissions inventorying software are among the most widely used tools for structuring and guiding local climate change planning.

7. It carried out a second one in 2000, and began annual inventories in 2005. Its inventories follow guidelines and employ emissions tracking software developed by ICLEI.

8. Also sometimes called the "Carbon Dioxide Reduction Strategy."

9. In 2002, for example, of the US\$3million received into the Solid Waste Management Fund, roughly US\$600,000 $(20 \%)$ was transferred to activities outside of OSD's waste management division (OSD 2002).

10. That the city has held transit stable at a time when there has been a general increase in transit-related emissions in the U.S. is itself an accomplishment.

11. While not unique, that target places them among a small group of climate leaders (including the states of California and Florida, as well as the E.U.) that were considering or had adopted the same target. This target was also endorsed by President Obama and proposed by the (now failed) federal Global Warming Pollution Reduction Act (Sanders-Boxer) S.309 and Safe Climate Act of 2007 (Waxman) H.R.1590. 
12. This leaves $32 \%$ of cities reporting that mitigation planning is conducted in a more isolated fashion either by core climate planning staff or among individual agencies/departments within their own silos (7\% report carrying out their planning in other ways).

13. The eight focus areas of Portland's 2009 CAP are: Buildings and Energy, Urban Form and Mobility, Consumption and Solid Waste, Urban Forestry and Natural Systems, Food and Agriculture, Community Engagement, Climate Change Preparation, Government Operations.

14. Respondents were presented with a list of 14 commonly employed strategies that covered educational outreach, network building, and formal institutional reforms and interventions. They were then asked to identify the strategies that their local governments had employed and to rank their effectiveness on a scale from 0 "not effective" to 4 "highly effective".

15. Respondents were presented with a list of 11 key sectors (listed below) and asked to rank how the agency responsible for that sector in their municipality contributed to designing and/or implementing climate change policies and programs, ranked on a scale from 0 "no contribution" to 4 "contributes heavily." This question was asked twice, once for mitigation and once for adaptation. The sectors listed where: land-use planning, water, waste water, solid waste, transportation, economic development, health, local publicly owned electrical utility (where applicable), zoning, building codes, and environment.

16. This argument needs to be qualified, given that I was not able to secure an interview with a representative from the Transportation Bureau before the end of my field work.

\section{BIBLIOGRAPHY}

Alber G, Kern K, 2008, “Governing climate change in cities: Modes of urban climate governance in multi-level systems." OECD International Conference, Competitive Cities and Climate Change, Second Annual Meeting of the OECD Roundtable Strategy for Urban Development, 9-10 October, Milan, Italy. http://www.oecd. org/document/32/0,3343,en_21571361_41059646_41440096_1_1_1_1,00. html (accessed 15 January 2009).

Aylett A, 2010a, "Participatory planning, justice and climate change in Durban, South Africa." Environment and Planning A 42(1): 99-115.

Aylett A, 2010b, "Conflict, collaboration, and climate change: Participatory democracy and urban environmental struggles in Durban, South Africa." International Journal of Urban and Regional Research 34(3): 478-495.

Aylett A, 2011a, "Bureaucracies and low carbon transitions," in Cities and low carbon transitions. Eds. H Bulkeley, V Castan Broto, M Hodson, S Marvin (Routledge, London), pp. 142-158.

Aylett A, 2011b, "Changing perceptions of climate mitigation among competing priorities: The case of Durban, South Africa." UN-HABITAT Cities and Climate Change: Global Report on Human Settlements 2011 (UN-Habitat, New York).

Aylett A, 2011c, "The urban governance of climate change: A comparative socio-institutional analysis of transformative urban responses to climate change in Durban (South Africa) and Portland (OR, USA)." PhD dissertation, Department of Geography, University of British Columbia.

Aylett A, 2013, "The socio-institutional dynamics of urban climate governance: A comparative analysis of innovation and change in Durban (KZN, South Africa) and Portland (OR, USA)." Urban Studies special issue on "Cities, Urbanization, and Climate Change,” eds. Mark Whitehead, Aidan While 50(7): 1386-1402. 


\section{Alexander Aylett}

Banuri T, Weyant, J, Akumu, G, Najam, A, Rosa, LP, Rayner, S, Sachs, W, Sharma, R, Yohe, G, 2001, "Setting the stage: Climate change and sustainable development." Climate change 2001: Mitigation, report of Working Group III, Intergovernmental Panel on Climate Change (Cambridge University Press, Cambridge).

Betsill M, 2001, "Mitigating climate change in US cities: Opportunities and obstacles." Local Environment 6: 393-406.

Bulkeley H, 2010, "Cities and the governing of climate change." Annual Review of Environment and Resources 35: 229-253.

Bulkeley H, Schroeder H, Janda K, Zhoa J, Armstrong A, Chu SY, Ghosh S, 2009, "Cities and climate change: The role of institutions, governance and urban planning." Report prepared for the World Bank Urban Symposium on Climate Change.

Bureau of Planning and Sustainability (BPS), 2009, "Climate Action Plan: Summary of public comments and resulting revisions." http://www.portlandonline.com/ bps/index.cfm? a=269115\&c=49989 (accessed 24 July 2011).

Bureau of Planning and Sustainability (BPS), 2012, "Climate Action Plan: Year Two Progress Report, April 2012.” https://www.portlandoregon.gov/bps/arti cle/393345 (accessed 24 July 2011).

Bureau of Transportation (PBOT), 2006, "Transportation Systems Plan.”

Bureau of Transportation (PBOT), 2009, "Sustainability Plan and Summary of Sustainable Practices."

Callon M, 1986, "Some elements of a sociology of translation: Domestication of the scallops and the fishermen of Briuc Bay," in Power, Action, and Belief. Ed. J Law (Routledge, New York), pp. 196-233.

Campbell T, 2012, Beyond Smart Cities: How Cities Network, Learn, and Innovate (Earthscan/Routledge, New York).

Collier U, 1997, "Local authorities and climate protection in the European Union: Putting subsidiarity into practice?" Local Environment 2(1): 39-57.

eThekwini Municipality (Durban), 2007, "GHG Data Collection and Emissions Inventory Report," prepared by ECOSERV (Pty) Ltd.

Gibbs D, Jonas A, While A, 2002, "Changing governance structures and the environment: Environment-economic relations at the local and regional scale." Journal of Environmental Policy and Planning 45(4): 123-138.

Haraway D, 1991, Simians, Cyborgs, and Women: The Reinvention of Nature (Free Association, London).

Johnson SR, 2008, "Building sustainable communities through community governance: The story of Portland, Oregon,” self-published manuscript. http://www. stevenreedjohnson.com/stevenreedjohnson/PdxDownloads_files/Participation. and.sustainability.docx (accessed 24 July 2011).

Latour B, 1987, Science in action: How to follow scientists and engineers through society (Harvard University Press, Cambridge).

March JG, Olsen JP, 1989, Rediscovering institutions: The organizational basis of politics (The Free Press, New York).

New York, City of, 2012, "Inventory of New York City Greenhouse Gas Emissions."

Office of Sustainable Development (OSD), 2002, "Solid Waste and Recycling Division, 2002 Management Report."

Pielke AR, 2005, "Misdefining 'climate change': Consequences for science and action." Environmental Science and Policy 8: 548-561.

Portland Energy Office (PEO), 2000, "Carbon Dioxide Reduction Strategy: Success and Setbacks."

Portland, City of, 1993, "Global Warming Reduction Strategy," Municipal Publication. http://www.portlandonline.com/bps/index.cfm?c=41917\&a=112110 (accessed 24 July 2011). 
Portland, City of, and Multnomah County, 2009, "Climate Action Plan."

Rutland T, Aylett A, 2008, "The work of policy: Actor-networks, governmentality, and local action on climate change in Portland, Oregon." Environment and Planning $D$ 26: 627-646.

Schoenberger E, 1997, The cultural crisis of the firm (Blackwell, Oxford).

Swart R, Robinson J, Cohen S, 2003, "Climate change and sustainable development: Expanding the options." Climate Policy 3(S1): S19-S40.

Toronto, City of, 2007, "Greenhouse Gasses and Air Pollutants in the City of Toronto: Towards a Harmonized Strategy for Reducing Emissions," prepared by ICF International.

Van Asselt H, Gupta J, Biermann F, 2005, “Advancing the climate agenda: Exploiting material and institutional linkages to develop a menu of policy options." Review of European Community and International Environmental Law 14(3): 255-263.

Vancouver, City of, 2009, “2008 Green House Gas Emissions Inventory: Summary and Methodologies."

Wilbanks T (2003), "Integrating climate change and sustainable development in a place-based context.” Climate Policy 3(S1): S147-S154. 
$\Longrightarrow$ Taylor \& Francis

Taylor \& Francis Group

http://taylorandfrancis.com 


\section{Part IV}

\section{Regional Policy Perspectives}

Comparing Policies and Outcomes across Regional Policy Regimes 
$\Longrightarrow$ Taylor \& Francis

Taylor \& Francis Group

http://taylorandfrancis.com 


\title{
10 Multilevel Governance and Institutional Capacity for Climate Change Responses in Latin American Cities
}

\author{
Patricia Romero-Lankao, Jorgelina \\ Hardoy, Sara Hughes, Angélica \\ Rosas-Huerta, Roxana Bórquez \\ and Daniel M. Gnatz
}

\section{INTRODUCTION}

Urban populations, economic activities and infrastructure are responsible for between 71 and $75 \%$ of global anthropogenic GHG emissions (Seto et al., 2014). However, often only a small fraction of emissions produced within a city is under the direct control of local governments, and while cities are vulnerable to a suite of negative impacts that climate change is projected to aggravate, many adaptation options are also out of local reach. In these cases, other jurisdictions and actors, such as national governments or the private sector, may have control over regulations, investments and programs that drive and manage emissions and risk. Hence, in order to mitigate GHG emissions and adapt to the impacts of climate change a range of actors, across sectors and levels of government, will need to create multilevel and multisectoral coalitions for effective urban climate governance. And indeed cities are "repositioning themselves in relation to the global climate regime" (Johnson et al., Chapter 1 this volume) through climate relevant actions such as energy efficiency plans and infrastructure investments seeking to reduce emissions and adapt to climate change.

Although mitigation and adaptation goals are, often of necessity, pursued in tandem by local governments, and urban climate policies are the product of multiscale influences, the relationship between multilevel governance and urban institutional capacity for mitigation and adaptation policies has only recently received attention (Hamin and Gurran 2009), and studies focused on cities from Latin American countries are often missing altogether (Johnson et al., this volume).

In this chapter, we build on prior work conducted through the ADAPTE project $^{1}$ to explore some of the key factors or drivers shaping the development and implementation of mitigation and adaptation policies in the Latin American cities of Buenos Aires, Argentina, Mexico City, Mexico and 


\section{Patricia Romero-Lankao et al.}

Santiago, Chile. These cities have been molded by similar urbanization processes, neoliberal reforms, urban and environmental policies, and by the presence of scientific groups and multinational networks (i.e., ICLEI, World Mayors Council on Climate Change and Climate Adaptation Santiago) that have been instrumental in putting climate change on their policy agendas. Comparatively speaking, Mexico City is a regional frontrunner, launching its first Climate Action Plan in 2008, while Santiago de Chile and Buenos Aires are at later stages in the development of their climate change policy agendas. Comparing two late arrivals to the climate change policy arena with a frontrunner allows us to explore the components of institutional response capacity, and to ask whether being a frontrunner is an indicator of greater institutional capacity to respond to climate change and whether barriers to creating institutional response capacity operate similarly across cities regardless of the status of their policy development.

Our framework identifies the components of institutional response capacity and allows us to compare them across cities. We use interviews with governmental and nongovernmental actors, and secondary data sources from the cities, to explore the political-economic construction of and barriers to institutional response capacity: the actor-networks involved across sectors and local, state, national and international levels, the effectiveness of the regulations and laws (legal framework), the mechanisms by which scientific information is created and communicated, and the nature and level of participation of nongovernmental actors.

\section{DEFINING RESPONSE CAPACITY AND BARRIERS TO CLIMATE RESPONSES}

For many reasons, there has historically been an institutional division of adaptation and mitigation policies and actions, with the former referring to measures aimed at reducing greenhouse gas emissions and the latter referring to actions aimed at managing the impacts of climate change, before or after those impacts are experienced. Research has helped to identify adaptive capacity and barriers (Moser and Ekstrom 2010) and generic metrics of good governance and economic development that enable effective response actions (i.e., Engle et al., 2011; Measham et al., 2011). However, there has been relatively little study of how these may translate to capacity to take steps to address climate change more broadly. The notions of response and response capacity are alternative options for defining and measuring both the capacity for and actual climate change-related actions. Response refers to any action taken by governmental, private and civil society actors to manage environmental change, in anticipation of that change or after it has happened (Tompkins and Adger 2005). We opt for this more general definition because urban actors frame many climate change actions in the context of other environmental concerns (e.g., energy, air pollution and disaster risk 
management), development pressures and goals, such as economic growth and human well-being, and in pursuit of a range of often conflicting values and priorities. For example, in Latin America connecting climate change to local conditions and goals may help to build public support. As stated by an Argentinean respondent, "there is a problem [with the public perception of climate change in urban Latina America]: the when you try to embed climate change into land use planning, you realize that adaptability and territorial sustainability are not yet perceived as key priorities, but rather as concerns developed countries should address, because they have the necessary resources.”

Response capacity relates to the pool of resources governmental and nongovernmental actors can use to manage environmental change (Burch and Robinson 2007), while attending to other development needs. The notion of response capacity is a useful tool for exploring the relationship between a city's capacity to effect change and its climate change actions because it rests on the view that adaptive and mitigative capacities are mostly shaped by the same factors (Yohe and Tol, 2002; Klein et al., 2007; Burch and Robinson 2007; Romero-Lankao et al., 2013). Response capacity also makes explicit the connection between the resources a city is able to draw on for climate change response and the underlying socioeconomic, physical and political contexts that give rise to those resources.

\section{A Framework}

Because climate change is a pervasive phenomenon affecting and being affected by different actors, who have diverse and changing values and priorities, urban climate change governance is a multi-actor and multilevel issue (Schroeder et al., 2013; Sassen, Chapter 2, this volume). In the three Latin American countries, climate change actions have been led by state governments, sometimes in spite of the lack of comprehensive or ambitious climate change policy at the national level. Urban actors, however, are constrained in their capacity to influence national policies that affect urban GHG emissions and risk. For instance, in the three cities discussed in this chapter, energy systems are shaped by national policies and priorities. This complex set of multilevel and multisectoral actor interactions (networks) then requires coordination across levels and sectors as a means of achieving more effective responses (Fisher 2013). There is no agreement on what type of relationship works "best" between, for example, local and national governments, or governmental and private actors. Yet, it has been found that climate policy frequently remains fragmented or narrowly focused on the interests of a few key issues such as energy, technological fixes or infrastructural investments, creating problems of institutional fit and lack of effectiveness.

Urban actors face other barriers. Some are related to lack of adequate buman and financial resources, fundamental for supporting climate change 


\section{Patricia Romero-Lankao et al.}

policies, for fostering inclusive economic development and investing in low-carbon and climate-resilient infrastructures and safety nets for risk mitigation and disaster response such as emergency and recovery systems, and insurance. Other barriers result from path-dependencies following from large investments of time, money and political capital in land use patterns, infrastructure and long-term engineering projects. Such investments can make it increasingly difficult to change directions.

By defining responsibilities, resources, decision-making power and planning mechanisms, laws and regulations embodying the legal framework can facilitate effective and inclusive climate action if they include principles of equity and participation, promote information exchange across cultural values, and have the flexibility to deal with uncertain climate futures (Measham et al. 2011). However, in the absence of these qualities, the legal framework may also hinder actors in their pursuit of effective climate policies.

Community engagement and participation of governmental and nongovernmental actors is critical to response capacity (Aylett 2013a). However, as will be shown in this chapter, participatory mechanisms can range from instrumental approaches focused on increasing compliance, to community and local engagement (Aylett 2013a, "Networked urban climate governance"), to efforts seeking to address risk and vulnerability by empowering poor communities (Hardoy et al., 2014), thus allowing them to address large and complex issues such as climate change in a more effective way. A lack of participatory mechanisms, or poorly executed participation methods, can reinforce inequities and undermine efforts to address climate change (Hughes 2013).

Finally, attitudes toward climate uncertainty and risk, and the availability, transmission and use of actionable scientific information on climate change are clearly factors affecting response capacity. It has been found, however, that information about the risks and options presented by climate change may not always be used in decision making due to competing and conflicting priorities, and the manner in which information is actually presented (Morss et al., 2005). The availability of information and its relevance to decision making are shaped by a number of socio-political factors such as lay perceptions, the way climate information is conveyed, political and policy cycles and the media. As a result, this information is a politically contested and bureaucratically managed component of urban climate responses (Hughes and Romero-Lankao, 2014).

\section{RESEARCH SETTING}

The climates of Buenos Aires, Mexico City and Santiago are very diverse. Buenos Aires has a humid subtropical climate, Santiago has a Mediterranean climate and Mexico City has a subtropical highland climate. While none of these cities experiences extreme variations in temperature (Table 10.1), the 
Table 10.1 Selected socioeconomic, demographic and climatic indicators

\begin{tabular}{|c|c|c|c|}
\hline Indicator & Buenos Aires & México & Santiago \\
\hline Latitude & $34^{\circ} 35 \mathrm{~S}$ & $9^{\circ} 26 \mathrm{~N}$ & $33^{\circ} 28 \mathrm{~S}$ \\
\hline Average annual temperature & 17.96 & 15.0 & 14.0 \\
\hline Population ${ }^{2}$ & $12,828,669$ & $17,946,313$ & $5,392,804$ \\
\hline GDP per capita in US\$ $(p p p)^{1, a}$ & 19,098 & 17,552 & 16,826 \\
\hline Elderly $(64 \text { and over })^{2}$ & $15 \%$ & $3.9 \%$ & $6.4 \%$ \\
\hline Electricity consumption $(k w h / c a p / y e a r)^{1, \mathrm{e}}$ & 3465 & 1534 & 2315 \\
\hline $\begin{array}{l}\mathrm{CO}_{2}(\text { million } \mathrm{t} / \text { year })^{1, \mathrm{e}} \text { and }\left[\mathrm{CO}_{2} \text { per }\right. \\
\text { capita }]^{2}\end{array}$ & $23.0[1.8]$ & $37.7[2.1]$ & $13.9[2.5]$ \\
\hline $\begin{array}{l}\text { Carbon intensity economy }(\mathrm{kg} \mathrm{CO} / \\
\quad 1000 \text { US\$ GDP })^{1}\end{array}$ & 460 & 172 & 440 \\
\hline Persons without high school education ${ }^{2}$ & $22.8 \%$ & $45.7 \%$ & $35 \%$ \\
\hline GINI coefficient ${ }^{1, b}$ & 0.44 & 0.56 & 0.55 \\
\hline $\begin{array}{l}\text { Informal employment ( } \% \text { of total } \\
\text { workforce) })^{1, \mathrm{c}}\end{array}$ & 44 & 45.7 & 34 \\
\hline Informal settlements ( $\%$ of inhabitants $)^{1, d}$ & 26.2 & 14.4 & $5-9$ \\
\hline
\end{tabular}

Sources: 1. ${ }^{\mathrm{a}}$ The year for Santiago is 2008 and for the other cities is 2005 ; ${ }^{\mathrm{b}}$ The year for Mexico is 2005; for Santiago and Buenos Aires is 2006. 'The years for the Metropolitan Areas of the three cities are 2002-2003. ${ }^{\mathrm{d}}$ The year for Buenos Aires and Mexico is 2005; and for Santiago 2006. ${ }^{\mathrm{e} T h e}$ year for Buenos Aires and Mexico is 2006; and for Santiago 2005. 2. Own calculations based on census data for the Metropolitan Area of each city.

annual precipitation rates vary from $312.5 \mathrm{~mm}$ in Santiago to $1200 \mathrm{~mm}$ in Buenos Aires. Precipitation in Mexico City varies between 700 and $900 \mathrm{~mm}$ with large interannual variations (Table 10.1).

According to current models, changes in climate parameters are projected to alter the existing environmental conditions and climate hazards in the three cities. Studies suggest there will be increases in mean temperatures in all cities; decreases in mean precipitation in Santiago and Mexico, and increases in mean precipitation in Buenos Aires (Universidad de Chile, 2006; INE 2008; Camilloni, 2006). Changes in extremes that differ from known weather patterns are also expected in the three cities and include more intense droughts, a decrease in the number of areas experiencing freezing temperatures $\left(0^{\circ} \mathrm{C}\right.$ or less), increasing floods from more intense precipitation and more frequent heat waves (Magaña 2010; Barros, 2006). An expected sea level rise of between 0.50 and 1 meter is predicted to affect low-lying areas in Buenos Aires and interact with precipitation events and sudestadas (strong winds from the southeast that push river water toward the coast) to produce urban floods.

These changes will likely result in development challenges. For instance, decreases in the Andean snowpack, resulting from changing precipitation 
and temperature regimes, might impact Santiago's water resources (Universidad de Chile, 2006), and increases in mean temperatures in Mexico City might affect water resource availability while increasing the number of extreme rain events and the severity of floods (INE, 2009). Such changes are likely to affect urban development and energy, land use and disaster planning.

Economic growth and policy have shaped urban GHG emissions and environmental risk in the cities. Many development policies of carbon and climate relevance (e.g., transportation, housing) have been undertaken without any urban planning, let alone a sustainability approach. As stated by respondents in all three cities, rather than by planning and the rule of law, land uses have been driven by market mechanisms, thereby creating limits to what can currently be done by local authorities to regulate the use and occupation of the land. For instance, in Argentina housing construction has been a fundamental national policy tool for "job creation, demand support and economic recovery," and "provinces implement" such policies with virtually no consideration given to "energy-saving technologies, bioclimatic, adaptation and other climate issues" (respondent, Province of Buenos Aires).

Energy use in the three cities is dominated by transportation and electricity generation. For instance, around $50 \%$ of the total energy consumption is dedicated to transport (Mexico City in 2004, 53\%; Buenos Aires in 2000, $49 \%$; Santiago in $2006,41 \%$ ). While the carbon intensity of the economy in Buenos Aires and Santiago is twice as high as in Mexico City, and $\mathrm{CO}_{2}$ emissions per capita are low in the three cities, total $\mathrm{CO}_{2}$ emissions are high in all three cities (Table 10.1). The cities all struggle with education (with socially segregated school systems), inadequate housing stock, informal settlements (with the exception of Santiago) and problems of housing affordability (Table 10.1). Although the three cities (or national governments) have implemented governmental programs to target the poor (e.g., "Oportunidades" program and food pension for the elderly, Mexico City; PROMEBA and Programa Ingreso Universal por Hijo, Argentina; Chile Solidario, Chile), economic liberalization has strengthened the market's role and privatized many components of housing, infrastructure and service provision previously in the hands of the government (with the exception of Buenos Aires, which has recently abandoned neoliberalism).

Climate change planning efforts in the cities make good case studies for analyzing response capacity because, although they have varied historical and political conditions, the cities also have many similarities. While Mexico City is an early adopter, Buenos Aires and Santiago are in the early stages of climate action. The three cities are capitals of countries characterized by a high degree of urban primacy, with each of the cities, historically, having outstanding political and economic importance within its country. While Mexico City (specifically the Federal District or Distrito Federal) and the Autonomous City of Buenos Aires (CABA), with their own executive and 
legislative branches, act as quasi-states within the policy arena, the city of Santiago has relatively less autonomy, as it must act within a more centralized, unitary Chilean state, where local governments function as administrators of national policies (Gajardo, 2013). All three countries have systems of government with executive, legislative and judicial branches and federated state, provincial and local tiers of government. Historically the cities have all operated within centralized systems, but the historical relationship between the capitals and their national governments has changed over time as they have suffered from periodic political upheavals (e.g., military dictatorships) and, during the 1980s and 1990s, experienced movements toward decentralization, liberalization and democratization (Seoane and Taddei, 2002).

\section{METHODS}

In consultation with local experts and decision makers, we compiled a list of three groups of potential respondents: decision makers in the areas of vulnerability and risk within the three tiers of government (local, state and federal); members of universities, research centers and science advisory organizations, and representatives from community and nongovernmental organizations. To gather a broad range of responses across vertical and horizontal networks, we targeted different levels of government, including local governments (e.g., San Fernando, Xochimilco and La Florida in the Metropolitan areas of Buenos Aires, Mexico and Santiago), city governments (for the City of Buenos Aires, Federal District and City of Santiago), state governments (Province of Buenos Aires, State of Mexico and Metropolitan Region of Santiago) and federal level governments (Argentina, Mexico and Chile). We conducted 20 interviews in Buenos Aires between July 2011 and June 2012, 18 in Mexico between July 2011 and March 2012, and 22 in Santiago between July and August 2011. The interviewees were asked questions about attributes of institutional response capacity such as the effectiveness of the legal framework, their networks and sources of information, and the mechanisms through which they engage with communities (participation). The interviews were then transcribed and translated into English by the research team. The data sets were analyzed using qualitative analysis software (NVIVO) to identify the levels and sources of institutional response capacity.

\section{CLIMATE CHANGE RELEVANT POLICIES}

The three Latin American cities are at different stages in their efforts to mitigate and adapt to climate change, as are their national governments. The governments of Mexico, Chile and Argentina have, respectively, conducted 
four, two and two "National Communications" to the United Nations Framework Convention on Climate Change and have National Climate Action Programs in place (Secretaria del Medio Ambiente y Recursos Naturales [SEMARNAT] 2007; Ministry of Environment, 2011; SADS 2007). The Secretariat of Environment and Sustainable Development of Argentina has been working in the preparation of the National Climate Change Strategy and an Action Plan since late 2011, with no relevant progress. Likewise, there have been efforts between various ministries and secretariats in Argentina to work jointly toward the design and implementation of a vulnerability manual, but this has not gone beyond the publication of the manual and the pilot implementation in one municipality. Chile developed the National Action Plan (2008-2010), but without clear budgets. As a national health authority from Santiago put it: "Although we passed a climate change plan in January, we have no budget associated with it." Among the three countries, only Mexico's federal government passed a Climate Change Law with a 2012 bill that seeks to (a) reduce greenhouse gas emissions $30 \%$ by 2020 and $50 \%$ by 2050 , based on levels from the year 2000; (b) create a new institutional system with clear mandates to the three tiers of government (e.g., in the use of financial and market instruments); and (c) foster adaptation through diagnostic tools, such as National Risk Atlas 2013, urban planning instruments and natural disaster prevention.

National-level policies create frameworks within which state and local governments can act. However, in Latin America, state authorities have frequently been responsible for incorporating climate into their instruments and investments (CEPAL 2009). Mexico City has undertaken a series of actions to institutionalize its climate agenda. It launched a Local Climate Strategy (2000), and has a Program of Climate Action 2008-2012 (PAC) and the 2011 Law for Mitigation and Adaptation to Climate Change. The city currently has a Climate Action Strategy (2014-2020), a document designed to guide climate mitigation and adaptation actions within the Climate Action Plan (2014-2020). In contrast to Mexico City, climate actions in Santiago and Buenos Aires are in their very initial stages. Although the Province of Buenos Aires, where the municipalities of the metropolitan area are located, created a Climate Change Office in 2005 within its Provincial Organization for Sustainable Development, a couple of individuals work in this office with responsibilities in outreach and capacity building (respondent, Buenos Aires Office of Climate Change). The City of Buenos Aires has its Buenos Aires 2030 Climate Change Plan, but it lacks specificity (i.e., budgets and timelines). Although Santiago has its Climate Adaptation Santiago program, no adaptation plan with budgets and precise goals has yet been launched.

While both the Buenos Aires Climate Change Plan and the Climate Adaptation Santiago program (CAS) were initiated only recently, in 2009, by the Interministerial Climate Change Team and the Helmholtz Centre for Environmental Research (UFZ), in Mexico City authorities have embarked 
since 2000 on a more aggressive institutionalization process (Hughes and Romero-Lankao 2014). In that year, the Minister of Environment, Claudia Scheinbaum, developed the Local Strategy of Climate Action that included a greenhouse gas (GHG) emissions inventory, scenarios and an identification of synergies between climate change and existing actions targeting air pollution (Romero-Lankao 2007). In 2006, the mayor of Mexico City, Marcelo Ebrard, became a climate champion locally and internationally, as did his Secretary of Environment, Martha Delgado. Meanwhile, a group of environmental experts took high-level positions within the administration. One of these was Oscar Vazques, who still holds a key position within the Ministry of Environment as director of the Mexico City Climate Change Program.

The first climate change responses in all three cities focused mainly on mitigation actions, beginning with the collection of emissions inventories in the three cities and with an emphasis on energy use as a main concern. Climate adaptation policies have since been built on existing development policies, such as urban land management, that have historically driven growth into risk-prone areas and responded to hazards in a reactive way. As recognized by one official from the national disaster management agency in Chile: "rather than being preventive, our policies respond to phenomena that have already occurred." Similarly, a State authority from Mexico City held a dim view of the present state of disaster risk management in Mexico: "We think that because we can simulate evacuations, we are doing what we need to address hazards. That doesn't work. What we need is a process for evaluating vulnerabilities and to train people to perceive and address these vulnerabilities."

Only some policies are focused on informal settlement regularization and upgrading programs that have improved populations' living conditions through the provision of services and infrastructure in health and housing. The municipality of San Fernando, Buenos Aires offers a promising example of risk management policies undertaken through development programs aimed at improving the living conditions of poor people. Although these policies did not explicitly target climate change, they reduced vulnerability and risk and, hence, enhanced populations' response capacities. Ironically, the current administration of San Fernando, elected at the end of 2011, replaced the administration that had designed this project, stopped supporting participatory budgeting programs, and no longer considers interventions and urban reorganization through inclusive, participatory policies. Furthermore, it has left communities without public support that would address and eradicate the root causes of their vulnerability.

These examples of disconnect between planning and consistent execution highlight failures in institutional response capacity in our study cities. More evidence of these, as well as some clues to their causes, can be gleaned when we examine some of the features and determinants of response capacity, 
which are highlighted in many of the insights we received from respondents in our study cities.

\section{MULTILEVEL ACTORS AND NETWORKS}

The diversity of governmental and nongovernmental actors required for urban climate change governance creates challenges to and opportunities for achieving effective policy responses. In general, the higher the political alignment between different levels of government, the greater the possibilities for coordination, support and resources transferred from one (national) to the other level (state and local). In addition, horizontal coordination and alignment within a level of government (i.e., within city government) can also facilitate institutional response capacity. However, within our three cities, there is a tension and interplay between centralized control structures and siloed, fragmented and uncoordinated structures and responses by departments and local jurisdictions. For instance, four levels of government are involved in the management of the area of Greater Buenos Aires: the national; the state, with two jurisdictions including the Province of Buenos Aires and the Autonomous City of Buenos Aires (a quasi-state); the partidos equivalent to wards or boroughs within the Autonomous City; and the municipal, including 24 suburban municipalities that comprise the rest of the metropolitan area located within the province of Buenos Aires. Similarly, the management of the Metropolitan Area of Mexico City is scattered between the federal government with its seat in the Federal District, authority delegated to national ministries, the State of Mexico with its governor and 35 conurbanized municipalities, and the 16 delegations of the Federal District, which functions as a quasi-state with its own governor. The delegations, partidos and conurbanized municipalities can be thought of as analogous to boroughs or wards of a city, each with its own city councilman, and the state governors roughly analogous to mayors. Neoliberal reforms in Mexico and Argentina have devolved some additional responsibilities to the state and local levels. While this allowed state and local authorities to begin planning and undertaking actions to deal with environmental issues, overall coordination and central execution and authority has been lacking. In contrast, centralized control in Chile has been less fully devolved from the federal government to state and local authorities. The Metropolitan Area of Santiago is managed by national ministries, a governor, 6 lieutenant-governors and 52 communes. It can be concluded, therefore, that based on different levels of commitment to actions seeking to decentralize responsibilities, our cities have been faced with varying levels of centralized control by their federal governments, while state and local institutional structures and political participation are fragmented in all three. Among other causes, this fragmentation may be due to the effects of a culture of lack of cooperation and the lack of any common and broadly shared metropolitan vision. In Mexico, governing of different 
levels by different parties has also played a role, but the overriding problem is based on a lack of integration of efforts between different jurisdictions and levels of government. As stated by a state level authority:

... It is not a question of whether political parties are blue [National Action Party, PAN], green [Institutional Revolution Party, PRI] or yellow [Democratic Revolution Party, PRD], but rather a problem of political and administrative culture. Authorities at one level do not cooperate with the other level. ... We would achieve much more if we able to sit at the same table to do planning together, if we were able to get input from other levels involved in the management [of climate change]. This would create a true construction of national climate change plans based on an effective inter-institutional coordination. (Federal District authority, Mexico City)

During the 1980 and 1990s, decentralization, democratization and devolution of responsibility exerted an influence on the cities' governance structures, particularly on democracy and political rights. For example, populations of the cities of Buenos Aires and Mexico can now elect their executive and legislative authorities (Pirez 2002; Nava-Escudero 2001). However, despite these reforms, state and local authorities, particularly in Buenos Aires and Santiago, have limited jurisdiction, even more limited human resources and funding, and are often left out of planning processes. This has impeded their governance of key emitting sectors and drivers of urban risk and vulnerability such as transportation, energy and land use. For instance, while Mexico City has a Climate Change Division, with a legal mandate, dedicated funds in its budget and a handful of people exclusively responsible for this issue, the Office of Climate Change of Buenos Aires has a staff of one, has been shifted three times from department to department and lacks dedicated funds in its budget (respondents from the Office of Climate Change of Buenos Aires and the Climate Change Division of the Federal District).

Authorities from the cities are seeking to expand their climate-action jurisdictions by various means, many of which rely on multilevel and multisectoral networks. As stated by the Officer of Climate Change in Buenos Aires: "I am a facilitator and opportunity taker. ... I identify what can work and has potential. When we did the emissions inventory, I knew researchers, people in the National Institute of Agricultural Technology and universities that could calculate the carbon footprint. I convinced the Minister of Environment to authorize me to get funds from the Federal Investment Council to make that study, and we created a system to calculate the carbon footprints." In Mexico City, officials seek to influence the priorities of higher levels of government. For example, one state-level authority in Mexico tries to "make sure that higher level decision makers are the ones who include climate change in their actions." In Santiago, local officials rely heavily on outside funding, but these resources are often deployed in response to an 
event that has already happened. One official says, "Because of the flood we had external resources," while another states that, " $60 \%$ or $70 \%$ of all projects here are funded by the regional fund, that is, the money is not from here but from the regional government."

As for horizontal networks, while environment agencies at national and subnational levels retain a position as central actors, they are often unable to affect proactive change because they lack power and connections to actors in other divisions whose policies exert more direct influence on the drivers of emissions and risks. For instance, environmental authorities have been able to include climate considerations such as energy savings and bioclimatic technologies in pilot programs that built a handful of houses in Buenos Aires and Mexico City. However, housing policies have mostly been shaped by housing authorities, with little concern for environmental considerations. After the 2001 economic crisis, housing construction became a key sector for economic reactivation in Argentina and soon housing programs centrally designed by the national state outnumbered those implemented by the province through the National Housing Fund (FONAVI). As housing in Buenos Aires became increasingly dependent on national moneys and guidelines, local authorities lost autonomy to introduce environmental considerations into their programs (respondent, Institute of Housing of the Province). While the government of Mexico City had more autonomy to create environmental strategies, many of its housing investments were channeled into new middle-rise flats for middle- and high-income households; it also subsidized the construction of flats for low-income families within the central city, and provided credits for low-income residents to make home and land improvements, with the goal of fostering consolidation of existing informal settlements.

Within our study cities, as in other cities, research groups and transnational organizations such as the School of Sciences of the University of Buenos Aires, Atmospheric Sciences Center of the Autonomous University of Mexico (UNAM), University of Chile, Helmholtz Centre for Environmental Research, ICLEI, the C40, the World Bank and the Economic Commission for Latin America (ECLA) have been key players in the introduction of climate change into the policy arena. By taking part in transnational networks, local officials, such as Mexico City Mayor and Chair of the World Mayors Council, Marcelo Ebrard, were able to advance the climate efforts and showcase their climate action policies internationally. Respondents in the three cities pointed to the relevance of having access to resources and learning opportunities through transnational networks and other entities.

\section{THE ROLE OF LEGAL FRAMEWORKS}

National legal frameworks, when they can lay the foundation for climate action without being too restrictive, have been shown to favor the 
development of climate change policies at the urban level. These become the medium on which each city can develop its own strategies for mitigation and adaptation (Measham et al., 2011). For instance, Mexico has a federated system with free and sovereign states to operate, subject to the rules imposed by the Constitution and the supreme legal order that creates two subordinated and coexisting legal systems: the national and state (Rosas-Huerta 2011). This legal structure has opened opportunities for states and municipalities to design policies at the local level. The current federal system offered Mexico City (i.e., the Government of the Federal District) a unique opportunity to create its own climate legislation, even prior to the national climate bill of 2012. Still under the national climate bill, the federal government retains significant legal powers over the political life of the Federal District, approves its borrowing limit and affects the power of the City to issue market instruments (Rosas-Huerta, 2011). Conversely, Argentina has not made great strides to put in place a legal framework in which local governments can introduce urban mitigation and adaptation. In Chile, the relevant legislation originates from the central government (unitary system) and is set by the Ministry of Environment, created in 2010 with the responsibility to develop and implement climate change policies and action plans in coordination with other levels of government (Article $70 \mathrm{~h}$ ) of Law 20,417). Even with this law, however, climate change policies in Chile are national and sectoral but do not connect with territorial or regional concerns nor with the place-based nature of climate change issues.

Within the bounds of legal frameworks, State and local authorities are responsible for diverse climate-relevant nonregulatory services such as water and sanitation (Secretaria del Ambiente del Gobierno del Distrito Federal [GDF] 2007). However, they have more limited influence on key drivers of emissions and risks such as housing, energy and transportation where they must often tap national sources of power and funding. City authorities are charged with authorizing development, redevelopment, housing and other changes to the landscape and built environment that are crucial land use or territorial planning drivers of emissions and climate risk; however, they have done so with varying levels of success, often due to differences in their access to and alignment with other levels of power or with conflicting interests and goals. In fact, metropolitan expansion in the cities entails two parallel processes, which are often in direct conflict. One consists of market arrangements, heavily planned and oriented to the upper-middle and higher-income families. The other lies mostly in the informal sector, outside the market and meets the needs of low-income groups. The cities are, hence, shaped by the growth of private enclaves, such as Puerto Madero and Nord Delta (Buenos Aires), Perisur and Santa Fe (Mexico City) and Las Condes, Nuñoa, Providencia and Vitacura in Santiago, where the market logic provides a guide to the private production and operation of the city. Local governments are often unable to meet the demands of the upper-middle and higher-income groups, while simultaneously seeking to meet social, 
environmental or climate policy goals, such as avoiding the social exclusion of lower-income groups, avoiding urban sprawl and urban growth into risk-prone areas, or emphasizing the creation of conservation areas or the provision of ecosystems-services.

A key issue is that all these environmental, climatic and social priorities compete for regulatory space within a policy agenda that is already coping with a very wide range of demands and economic drivers of development. This conflict is manifested in competing discursive or material constructions of urban development policies evident in our interviews, as respondents discussed a divergence between what is needed in land use planning, housing provision and other policy interventions to more effectively prepare for climate change and what is actually being done:

The concepts of climate change, adaptation and sustainability are not yet rooted in the policies of territorial planning. ... Land use planning in Buenos Aires and in Argentina has become an unfettered extension of the private market into the city. (Respondent, Institute of Housing, Province of Buenos Aires)

There is momentum for the creation of the Climate Change Act. Still many questions have not been addressed, such as why our legislation continues favoring the use of fossil fuels to produce electricity, and what the legal goals are for reducing GHG emissions in key sectors. (Scientist, Mexico)

I greatly doubt that you can find any (climate considerations) in the land use planning tools that can give hope for better property regulations in the communal, sectional, or regional urban land development plans that exist in the Country. (Santiago authority)

The importance of an effective legal framework can be illustrated by the fact that while Mexico is a leader in Latin America in relation to the development of legislation and strategies to mitigate and adapt to climate change, many key drivers of institutional capacity are still lacking there. In fact, it has been the case in other cities that many features of legal frameworks that were not directly designed for climate action may become relevant to climate policy (see for Manizales Colombia, Hardoy et al., 2014).

\section{PARTICIPATION}

Urban authorities in the cities have followed the international trend of involving private sector and civil society actors in the design of plans and programs at various levels (Garfin et al., 2013; Carmin et al., 2012). Such participatory exercises have posed additional challenges and opportunities in the development of climate-relevant policies and actions. As these policies are developed, various levels of planning include spaces and mechanisms 
for participation and coordination between sectors and actors, especially in the stages of diagnosis, policy design and planning, and universities and research organizations at the national, state and local level have traditionally been a source of knowledge and innovations for municipal and state governments. In Santiago and Mexico City, academics, specialists, nongovernmental actors and various sectoral and administrative levels of government (including the general public in Mexico City) have been involved in consultation processes. Both Mexico City and Santiago have held participatory consultation processes in the preparation of their respective climate adaptation efforts (respondent, Mexico City and ECLA). These efforts were designed to raise awareness and elucidate the priorities of stakeholders in relation to climate change.

Although Buenos Aires has not yet embarked on such a consultation process, the municipality of San Fernando implemented a comprehensive project in coordination with national and provincial authorities, and with the participation of poor communities, to improve living conditions in many of the barrios we visited. The actions included: a project of urbanization and urban renewal supported by the National Neighborhood Improvement Program (PROMEBA), the Housing Improvement Program (Mejor Vivir) and a Subprogram of Private Villas and Slums (municipal authority, San Fernando). While these policies were not designed with climate change considerations in mind, they have strengthened the response capacity of local neighborhoods. In these initiatives, local authorities formed alliances with neighborhood populations and fostered a process of self-organization and empowerment. In total, these projects helped reduce vulnerability not only in material terms but also in terms of responsiveness to floods resulting from sudestadas, but failed to address long-term needs and growth. As one resident put it, "the governments that planned to build the houses where we live now had a long term vision. I mean ... at that time [they] thought of building high [to withstand the storm-surges]. . . . Yet the houses are very small and they didn't realize that our families grow. Our children start having children and they need a place to live. That is why we occupy the ground floor" (respondent from San Fernando, Buenos Aires). The housing program which the respondent was referring to includes an empty ground floor and two higher floors for living space. These accommodations were supposed to provide protection from flooding. However, as it often happens with housing plans, "they address a family's need for a point in time, . . . but when the family grows ... the initial solution is exceeded and outdated" (respondent, municipality of San Fernando, Buenos Aires).

In our visits to the barrios of San Fernando, we were able to observe the capacities fostered by these programs but also witnessed gaps in the programs. For instance, $81 \%$ of neighbors were unaware of the existence of a system of formal disaster risk response to storm surges (Romero-Lankao, et al., 2014). Still, the residents had their own local response strategies in place. As stated by a barrio leader, if family members receive warnings or 


\section{Patricia Romero-Lankao et al.}

"call the coast guard number, and one from the barrio calls and informs the rest" (e.g., in Buenos Aires), then together they move their belongings to the upper level if the house has two floors. These strategies are creating social capital based on local networks and organizations and are fostered by the municipality of San Fernando and civil society organizations. The emergence of social capital was also exemplified in forms of auto-organization and collaboration we found when we visited La Florida, Santiago, where a neighborhood leader described an avalanche hitting the neighborhood in 1993:

The first thing we did was to take care of our homes, because this population had no casualties, but did have flooding in several homes, like 5 or 6 houses. Then, as people were scared, they left their homes alone, even where nothing had happened. The first step we took was to make a permanent duty team, for security reasons, to avoid that somebody would steal. And there we had the very, very successful collaboration with the police.

Participation is, of course, not without its challenges, and many of these challenges were also reflected in our interviews. In our study cities, with some exceptions, informants reported that the mechanisms for interaction between government and communities tended to be technocratic, authoritarian and paternalistic. For instance, one national civil protection authority reported that it is commonly thought that the management strategies are appropriate only if "drafted by technicians who know their implications." Such opinions, however, ignore structural differences and power relations that restrict the access of urban populations to the processes of diagnosing climate change problems and defining the most appropriate management measures, thereby creating the very incompetence they seek to redress by using experts to develop solutions.

Community leaders had mixed opinions on the mechanisms in place for community involvement. Independently of socioeconomic status, they often referred to the dominance of political or economic interests over technical considerations and to the lack of attention to citizen requests. "Neither the municipality, nor the Government ... they do absolutely nothing, they don't care. They only care about downtown and about barrio alto" (inhabited by high-income populations) (Santiago neighborhood leader). "Sometimes I am in Tigre," an upper-class neighborhood where there are "such houses and I say, here they won't get flooded, and yes, they do, I never thought about it ... but the difference is that they are in another situation, they build the house high. It's all a money issue" (community leader, San Fernando, Buenos Aires).

Respondents from local organizations and municipal governments often expressed that they lack the power or financial and human resources that would allow them to participate in defining both the climate issues and the 
response strategies to mitigate and adapt. A key step to solve water and flooding issues in the barrio of San Luis, Mexico City "would be to include the affected population in the decision making process; we would need to improve the communication between the government and various sectors of the community" (community leader, Mexico City).

Participation in all of our cities, therefore, seemed to be limited by imbalances in access to resources and decision-making power, which in turn limited response capacity. The implication here is that to shore up institutional capacity, it is essential that climate change decision making be broadly participatory and that local and cross-sectoral participation and accountability be part of the decision-making process during all stages of policy implementation and evaluation.

\section{SCIENTIFIC INFORMATION}

Generation of and access to scientific information in decision making build on past policies and are in different stages of development in the three cities. For example, while Mexico City has built on a three-decade-long tradition of collecting and analyzing data to create relevant information on air pollution, all three cities have had longer traditions in the management of disaster risk information even if other areas (such as air pollution) are more recent.

Specific to climate change, Chile and Argentina are in the initial phases of creating energy inventories and vulnerability assessments of relevance to their capital cities. According to a national official from Chile, "We are in such a very preliminary stage that what we have done first is to see what information we have internally and secondly what basic knowledge is being created." The Government of the Federal District presents a different situation. Mexico City has been enhancing its institutional response capacity by maintaining its own emissions inventory for over a decade, and the Ministry of Environment and the Institute of Science and Technology have created a science policy interface, the Virtual Climate Change Center, established in collaboration with the National University of Mexico (UNAM). Its goal is to serve as a repository of knowledge, models and data on climate change impacts, vulnerability and on areas of relevance to urban sustainability, such as water and air pollution. With financing from the World Bank, Mexico City has also subcontracted two studies, one on poverty and climate vulnerability and the other on the economics of climate change (Leon and Neri., 2001). According to a Mexico City state official, all these efforts "will give governmental authorities the tools they need to develop their long term planning."

It is common practice in Buenos Aires and Santiago that scientific information on emissions inventories, natural resources, hydro-meteorological disasters is created by the national levels of government in collaboration with national universities, and in the case of urban sustainability and climate 
change with supra-national and international organizations such as ICLEI (city of Buenos Aires) and the Helmholtz Center, Germany (Santiago). In Mexico City, on the other hand, information has been generated at the state level through an expert network (with strong participation of the Mario Molina Center) able to support its goal of presenting climate change as a problem for the city. The city also recently created its boundary organization, the Climate Virtual Center. In Chile, climate change-relevant information is developed sector by sector: "decision making with information, as understood by us in our planning exercise, should be taken on by the sectors involved. In other words, it is the Ministry of Housing and Urban Development who must incorporate climate change and generate useful information and introduce it into land use planning. ... Therefore, the creation of information has to be sectoral, but with the support of the Ministry of Environment" (national official, Chile).

This top-down approach to creating information seemed to be efficient and effective to many of our respondents. "Of course the information goes from the national to the state to the local level. We don't use information from the municipality. Many environmental organizations within the municipality have different levels of capacity, they are very unequal. We have public servants who are very engaged and responsible in some, but in others people just don't care, they don't have the idea of climate change. We provide the municipalities with our information" (Federal authority, Mexico). National or regional scientific assessments are often used to validate plans or are involved throughout the process of plan development, sometimes to the point of exclusion of local voices and concerns; "they don't really want your opinion" (respondent from University of Buenos Aires). For instance, within metropolitan areas, scientific information exchange and support seldom occurs with the smaller municipalities, who usually have less access and less capacity to interpret specific scientific information or to make it useful for local decision making.

The capacity of city and municipal governments to request specific information, to drive research, and be able to use it to draft sound local policies is often very limited. In fact, much of the scientific information generated is so disconnected from what city and municipal authorities need that it makes little contribution to policy making, and these local governments are seldom clear about what information they need to demand. Even when they collaborate with various governmental levels, there is often a gap between the type of information produced by academia and research institutes and what local governments need. Conversely, information collected and produced at the local level, by the local communities, seldom reaches higher-level policy-making circles.

Access to information within the local community is of paramount importance and is often dependent on the mode of transmission. Within the three cities, when decision makers relayed information to the public, they often relied on press releases or radio broadcasts for disaster emergency 
alerts coming from national sources (e.g., National Office of Emergency of the Interior Ministry in Chile and the National System of Civil Protection in Mexico), and on the Internet for sharing information between agencies or with the public. Reports, plans and data were often published on an agency website and then considered to be in the public domain, with little regard for how often they were read. For example, one official from Mexico states, "we make a follow up on our climate change program every two months." These information distribution strategies falsely assume that individuals will be at the right place and the right time to receive pertinent information or that they are active seekers that will find the information they need to respond to emergencies, or to introduce changes in their behavior. In many cases, however, information users, particularly community members, may not be actively looking for information or may not be looking for it on the Internet, or they might not understand, or be able to interpret, any information they do encounter. According to our research, TV and radio provide the most common sources of information (Romero-Lankao et al., 2014), but this information is not necessarily of use for individuals as it can be inconsistent and sometimes contradictory. As stated by one community leader in Santiago: "The only thing I know is what is on television . . . when it is made public." This finding points to an additional disconnect in the transmission of information and forgets that communities might recall much of the information they receive as nonspecific or ambiguous, and that as found in Buenos Aires and Santiago, communications of friends, family, neighbors and church members play a fundamental role in populations' responses.

In our study cities, both production and access to quality scientific information was often limited to a select group of government and nongovernmental actors (academics, private sector and civil society organizations), and our surveys indicated that scientific information was seldom produced with the idea of sharing it with different actors, including the local communities. Evidence of this could be seen in attitudes of deliberate exclusion in some of our respondents. For instance, one national authority from Santiago commented that involvement by communities was not "part of the solution, but rather of the problem."

\section{CONCLUSION: IS FRONTRUNNER STATUS ENOUGH? INSTITUTIONAL CAPACITY IN CITIES FROM LATIN AMERICA}

This chapter has explored institutional response capacity in the governance of carbon emissions and climate resilience in the Latin American cities of Buenos Aires, Mexico and Santiago. However, rather than a given set of dimensions and attributes, institutional response capacity is a dynamic process, historically constructed through the multilevel interaction of governmental and nongovernmental actors. We used a comparative case study approach to evaluate response capacity in three cities from the South, and to 
explore whether being a frontrunner in the climate change arena is an indicator of greater institutional response capacity, or whether barriers operate similarly across cities regardless of the level of institutionalization of their climate policies.

Our findings suggest that the level of authority provided to Mexico City within Mexico's legal framework to take steps to address climate change, and the city's extended experience with monitoring and tracking environmental hazards (e.g., air pollution), have enhanced institutional response capacity and likely help to explain why Mexico City is a regional frontrunner in responding to climate change. Buenos Aires and Santiago face greater restrictions on their authority in areas such as energy use and land use planning and are often left out of planning decisions taking place at higher levels. These findings point to the importance of multilevel legal frameworks in shaping the response capacity of urban areas, and may explain the variations we observe in the actions of cities that may otherwise appear quite similar.

Regardless of Mexico City's regional frontrunner status, however, we also found that respondents in all three cities described many similar challenges and opportunities in their efforts to effectively respond to climate change. In all three cities, for instance, the design of climate responses was contingent upon existing development pressures and priorities, and these conditions were often driven and perpetuated by the underpinnings of prior land use practices and housing and infrastructural investments that would be difficult and costly to change (path-dependency). Furthermore, the case studies shed light on the challenge of embedding climate considerations not only into sectoral policies such as housing and energy, but also into regional or territorial planning.

Coordination across levels of governance is a crucial determinant of institutional capacity as it reduces transaction costs and facilitates communication (Fisher 2013). It also enhances access to and learning from resources at national and international levels. Running counter to this generally accepted practice of good governance, a tension exists in our three studied cities, between centralized administrative structures and top-down transmission of climate-relevant information and siloed, fragmented and uncoordinated structures and responses by departments (e.g., housing) and jurisdictions at different levels. While this tension is being navigated in Mexico City relatively proactively (e.g., by seeking to align federal and municipal climate change laws and plans), it is a greater challenge for Buenos Aires and Santiago.

Scholarship has found that in the face of uncertainty, the most successful way to generate capabilities and provide relevant solutions is to develop policies, plans and programs that start with the integration of diverse knowledge systems (academia, public sector, private sector, civil society). A lack of or poorly executed participatory mechanisms and methods, as we found in our cities, can create inequities and undermine efforts to address climate change 
In many instances, information in the three cities comes from universities, research centers and even a virtual center, but a good working connection between government and academia is generated only sporadically. Furthermore, municipal authorities have limited capacities to drive climate research and to request and use locally relevant scientific information. The gap between the type of scientific information produced and the information that will be required by government politicians and bureaucrats to create effective policies is often vast and each community has its own set of priorities and pressures.

In order to improve institutional response capacity, the question of how cities coordinate across levels of governance becomes a much more intractable problem than it may first appear. After all, each department, level of government and urban actor has different values, imperatives and priorities, and the question may begin and end in conflicts over what to coordinate rather than how. Any examination of urban climate change planning in isolation from other institutions is likely to provide a false sense of a city's institutional response capacity. This is the case in Mexico City, where climate change laws have been enacted and where there is a legacy of state support for climate offices and policies. In this case, while a greater institutional response capacity might be assumed, conflicts between the areas of concern, values, needs and priorities of levels of government and urban actors have reduced the overall effectiveness of climate policy and action. We observed these conflicts in the attitudes of respondents in all three cities as they described how economic imperatives and policies fostering economic growth have taken priority over environmental protection and risk reduction. Ultimately, this becomes a matter of public perception as well. Climate change issues can seem a distant concern when urban residents are worrying about how to put the evening bread on the table. Our research suggests that increasing institutional response capacity for climate action will require an alignment of climate concerns with many currently competing development goals and priorities.

This study suggests some interesting possibilities for further exploration: to investigate the roles the private sector plays, both in driving emissions and risk, and in shaping institutional capacity; and to assess the effects of interactions between different governmental tiers and between different attributes of intuitional response capacity.

\section{NOTE}

1. This chapter is an outcome of the project 'Adaptation to the Health Impacts of Air Pollution and Climate Extremes in Latin American Cities' (ADAPTE) that investigates risks, vulnerabilities and capacitiesin four Latin American cities (Buenos Aires, Bogotá, Mexico City, and Santiago). ADAPTE has been financed by the Inter American Institute of Global Environmental Change and the National Science Foundation. Participants include (1) Patricia Romero-Lankao, 
Hua Qin, Mercy Borbor Cordova, Melissa Haeffner, Sara Hughes, Olga Wilhelmi, Steve Sain, Raphael Nawrotzky, and Kevin Sampson from NCAR, United States; (2) Eduardo Behrenz and Daniela Parra from the Universidad de los Andes, Colombia; (3) Alejandro Leon, Patricia Matus, Paulina Aldunce, and Karla Caneo from Universidad de Chile; (4) Laura Dawidowski and Rosana Abrutsky from CNEA, Argentina; and (5) Angélica Rosas and Griselda Günther from Autonomous Metropolitan University, Mexico City.

\section{BIBLIOGRAPHY}

Aylett, A. "Networked urban climate governance: Neighborhood-scale residential solar energy systems and the example of solarize Portland." Environment and Planning C: Government and Policy 31, no. 5 (2013a): 858-75.

—. "The socio-institutional dynamics of urban climate governance: A comparative analysis of innovation and change in Durban (KZN, South Africa) and Portland (OR, USA)." Urban Studies 50, no. 7 (2013b): 1386-1402.

Barros, V. "Introducción," chapter 1, in Barros, V. et al., El Cambio Climático en la Cuenca del Plata. CIMA - UBA, CONICET, Buenos Aires (2006): 11-18.

Burch, Sarah, and John Robinson. "A framework for explaining the links between capacity and action in response to global climate change." Climate Policy 7, no. (4) (2007): 304-16. doi:10.1080/14693062.2007.9685658

Camilloni, I. "Tendencias Climáticas." Impactos del Cambio Global en las áreas costeras del Río de la Plata. AIACC LA 20 (2006): 13-19.

Carmin, J., I. Anguelovski, and D. Roberts. ":Urban climate adaptation in the Global South planning in an emerging policy domain." Journal of Planning Education and Research, 32, no. 1 (2012): 18-32.

CEPAL. La Economia del Cambio Climatico en Chile, United Nations Economic Commission for Latin America and the Caribbean, Santiago: CEPAL. (2009).

Engle, Nathan L., Owen R. Johns, Maria Carmen Lemos, and Donald R. Nelson. "Integrated and adaptive management of water resources: tensions, legacies, and the next best thing." Ecology and Society 16, no. 1 (2011): 19.

Fisher, Dana R. "Understanding the relationship between subnational and national climate change politics in the United States: Toward a theory of boomerang federalism." Environment and Planning C: Government and Policy 31, no. 5 (2013): 769-84. doi:10.1068/c11186

Gajardo, J. "Rol Normativo del Municipio en la Protección del Medio Ambiente." In: Chacón, A. (Ed.), Análisis y Perspectivas del Derecho Municipal Chileno. Santiago, Chile: Instituto Chileno de Estudios Municipales (ICHEM) (2013), pp. 80-97.

Garfin, G., P. Romero-Lankao, and R. Varady. "Rethinking integrated assessments and management projects in the Americas." Environmental Science \& Policy 26 (2013): 1-5.

Gore, C. "The limits and opportunities of networks: Municipalities and Canadian climate change policy." Review of Policy Research 27, no. 1 (2010): 27-46.

Hamin, Elisabeth M., and Nicole Gurran. "Urban form and climate change: Balancing adaptation and mitigation in the U.S. and Australia." Habitat International, Climate Change and Human Settlements, 33, no. 3 (2009): 238-45. doi:10.1016/j.habitatint.2008.10.005

Hardoy, J. y L.S.V. Velásquez Barrero. "Re-thinking 'Biomanizales' to address climate change adaptation in Manizales, Colombia." Environment and Urbanization 26, no. 1 (April 2014): 53-68. 
Hughes, Sara. "Justice in urban climate change adaptation: Criteria and application to Delhi." Ecology and Society 18, no. 4 (2013): 48.

Hughes, Sara and Patricia Romero Lankao. "Science and institution building in urban climate change policy making." Environmental Politics. Preview View full text Download full text, Access options DOI: 10.1080/09644016.2014.921459, Sara Hughesa* \& Patricia Romero-Lankaoa, pages 1023-1042, Publishing models and article dates explained, Published online: 21 Jul 2014

INE. Mexico's Third National Communication to the United Nations Framework Convention on Climate Change. Mexico: National Institute of Ecology. (2007).

- Climate Change: A View from México. National Institute of Ecology (2008). http://www.ine.gob.mx/cclimateico/edo_sector/estados/futuro_mexico.html

- Fourth National Communication of Mexico to the United Nations Framework Convention on Climate Change. Ministry of Environment and Natural Resources, National Institute of Ecology. Mexico City, Mexico. (2011).

INE. 2009. México. Cuarta Comunicación Nacional ante la Convención Marco de las Naciones Unidas sobre el Cambio Climático. INE, México

Johnson C., H. Schroeder and N. Toly (2015) "Introduction: Urban Resilience, Low Carbon Governance and the Global Climate Regime,” in Johnson et al. (eds.) The Urban Climate Challenge: Rethinking the Role of Cities in the Global Climate Regime New York and London: Routledge, pp. 1-23.

Klein, R., S. Huq, F. Denton, T. Downing, R. Richels, J. Robinson, and F. Toth. "Interrelationships between adaptation and mitigation." In: Parry, M. L., Canziani, O. F., Palutikof, J.P., van der Linden, P. J., and Hanson, C. E.(Eds.), Climate Change 2007: Impacts, Adaptation and Vulnerability (Contribution of Working Group II to the Fourth Assessment Report of the Intergovernmental Panel on Climate Change). Cambridge, Cambridge University Press (2007), pp. 745-77.

Leon, C., and C. Neri. Study on Climate Change, Disaster Risk Management and the Urban Poor Mexcio City Case Study (WB-GDF unpublished report) (2010), pp. 72-114.

Magaña, Victor. "Estudio de Vulnerabilidad Diferenciada Ante Eventos Extremos Del Clima En La Zona Metropolitan de La Ciudad de México: Aspectos Climáticos.” In: Baker, J.L. (Ed.), Study on Climate Change, Disaster Risk Management and the Urban Poor Mexico City Case Study. Washington, DC: World Bank (2010), 72-114.

Measham, Thomas G., Benjamin L. Preston, Timothy F. Smith, Cassandra Brooke, Russell Gorddard, Geoff Withycombe, and Craig Morrison. "Adapting to climate change through local municipal planning: Barriers and challenges." Mitigation and Adaptation Strategies for Global Change 16, no. 8 (2011): 889-909.

Ministry of Environment. Chile-Second National Communication. Chile: Ministry of Environment. (2011). http://www.undp-alm.org/resources/assessments-andbackground-documents/chile-second-national-communication-2011-english

Morss, Rebecca E., Olga V. Wilhelmi, Mary W. Downton, and Eve Gruntfest. 2005. "Flood risk, uncertainty, and scientific information for decision making: Lessons from an interdisciplinary project." Bulletin of the American Meteorological Society 86, no. 11 (2005): 1593-601.

Moser, Susanne C., and Julia A. Ekstrom. "A framework to diagnose barriers to climate change adaptation." Proceedings of the National Academy of Sciences 107, no. 51 (December 21, 2010): 22026-31.

Nava-Escudero, César. Urban Environmental Governance: Comparing Air Quality Management in London and Mexico City. Aldershot, UK: Ashgate. (2001).

Pirez, Pedro. "Buenos Aires: Fragmentation and privatization of the metropolitan City." Environment and Urbanization 14, no. 1 (2002): 145-58. 
Rehner, J., J. Samaniego, and R. Jordán. "Regional panorama Latin America." Megacities and Sustainability. Economic Commission for Latin America and the Caribbean (ECLAC). Santiago de Chile (2010).

Romero-Lankao, Patricia. "How do local governments in Mexico City manage global warming?" Local Environment 12, no. 5 (2007): 519-35.

Romero-Lankao, Patricia, Sara Hughes, Angelica Rosas-Huerta, Roxana Borquez, and Daniel M. Gnatz. "Institutional capacity for climate change responses: An examination of construction and pathways in Mexico City and Santiago." Environment and Planning C: Government and Policy 31, no. 5 (2013): 785-805.

Romero-Lankao, P., Hughes, S., Qin, H., Hardoy, J., Rosas-Huerta, A., Borquez, R., Lampis, A., 2014: Scale, urban risk and adaptation capacity in neighborhoods of Latin American cities. Habitat International, 42 (0), 224-235.

Rosas-Huerta, A. "La capacidad administrativa del gobierno del Distrito Federal y el cambio climático." Política y Cultura, 36 (2011): 177-203.

SADS. 2da Comunicación Nacional de La República Argentina a La Convención Marco de Las Naciones Unidas Sobre Cambio Climático. Argentina: Secretaria del Ambiente y Desarrollo Sustentable. (2007). http://unfccc.int/resource/docs/ natc/argnc2s.pdf

Schroeder, H., S. Burch, and S. Rayner (guest Eds.). "Novel multi-sector networks and entrepreneurship in urban climate governance." Environment and Planning C: Government and Policy 31, no. 5(2013): 761-8.

Secretaria del Ambiente del Gobierno del Distrito Federal (GDF). Mexico City Climate Action Program 2008-2012. (2007) www.mexicocityexperience.com/ documents/climate_change

Secretaria del Medio Ambiente y Recursos Naturales (SEMARNAT). “Mexico's Third National Communication to the United Nations Framework Convention on Climate Change", Secretaría de Medio Ambiente y Recursos Naturales, Mexico City. (2007).

Seoane, J., and E. Taddei. "Movimientos sociales, conflicto y cambios políticos en América Latina.” En: OSAL: Observatorio Social de América Latina. No. 9 (ene. 2003): 67-72. Buenos Aires: CLACSO, 2003-. (Sept.-Dec. 2002).

Seto, K. C., S. Dhakar, A. Bigio, H. Blanco, G. C. Delgado, D. Dewar, L. Huang, A. Inaba, A. Kansal, S. Lwasa, J. McMahon, D. Mueller, J. Murakami, H. Nagendra, and A. Ramaswami. "Chapter 12, Human settlements, infrastructure and spatial planning." In Intergovernmental Panel on Climate Change (Ed.), Climate Change 2014: Mitigation of Climate Change. Contribution of Working Group III to the Fifth Assessment Report of the Intergovernmental Panel on Climate Change. (2014). New York: Cambridge University Press.

Tompkins, E. L., and W. Neil Adger. "Defining response capacity to enhance climate change policy.” Environmental Science \& Policy 8, no. 6 (2005): 562-71.

Universidad de Chile. ESTUDIO DE LA VARIABILIDAD CLIMÁTICA EN CHILE PARA EL SIGLO XXI INFORME FINAL. Chile: Universidad de Chile. (2006). http://www.dgf.uchile.cl/PRECIS/articles-39442_pdf_Estudio_texto.pdf

Yohe, G., and R. S. Tol. "Indicators for social and economic coping capacity-moving toward a working definition of adaptive capacity." Global Environmental Change 12, no. 1 (2002): 25-40. 


\title{
11 Climate Change Adaptation and African Cities
}

\author{
Understanding the Impact of \\ Government and Governance \\ on Future Action
}

Christopher Gore

\section{INTRODUCTION}

Some residents of Tandale Ward, in the city of Dar es Salaam, Tanzania, have made significant investments in their homes to respond to weather events exacerbated by climatic change. Like other low-income areas in the city (see Kiunsi 2013), Tandale is in a very low-lying area and is vulnerable to flooding. As a result, many households have built secondary walls around the base of their houses to prevent water and associated debris from entering their homes when flooding occurs. Figure 11.1 shows a wall built around the base of a home in Tandale, and Figure 11.2 shows the proximity of houses to a river that is prone to flooding during extreme rain events.

While some might suggest that the actions of Tandale residents illustrate grassroots climate adaptation, a more accurate description for these activities is 'coping'. Far from semantics, the distinction between 'coping' and 'adaptation' is important when thinking about a long-term and institutionalized response to climate change in cities (Bulkeley \& Tufts 2013). Coping mechanisms represent any actions that respond to potential disaster or impending shocks; adaptation refers to the deliberate, intended and purposeful actions of governments and formal institutions to respond to climate risks and vulnerabilities - the kind of action that is thought necessary for resilience (see Bulkeley \& Tufts 2013; Pelling 2011). Thus, when discussing climate change adaptation or mitigation, formal international, national and local institutions and organizations must be considered: the formal entities that can leverage financial resources to invest in climate adaptation and mitigation measures; that can engage with citizens that are coping with risks to best respond to their needs; and that, in theory, have tools and mechanisms to support (and enforce) actions to improve resilience.

International reports on climate change impacts and adaptation are replete with statements emphasizing the role that local and urban governments should play in successful adaptation and the need for vertical and horizontal coordination and collaboration between governments, civil society and the private sector (see section 8.4, IPCC WG II, 2014). The 


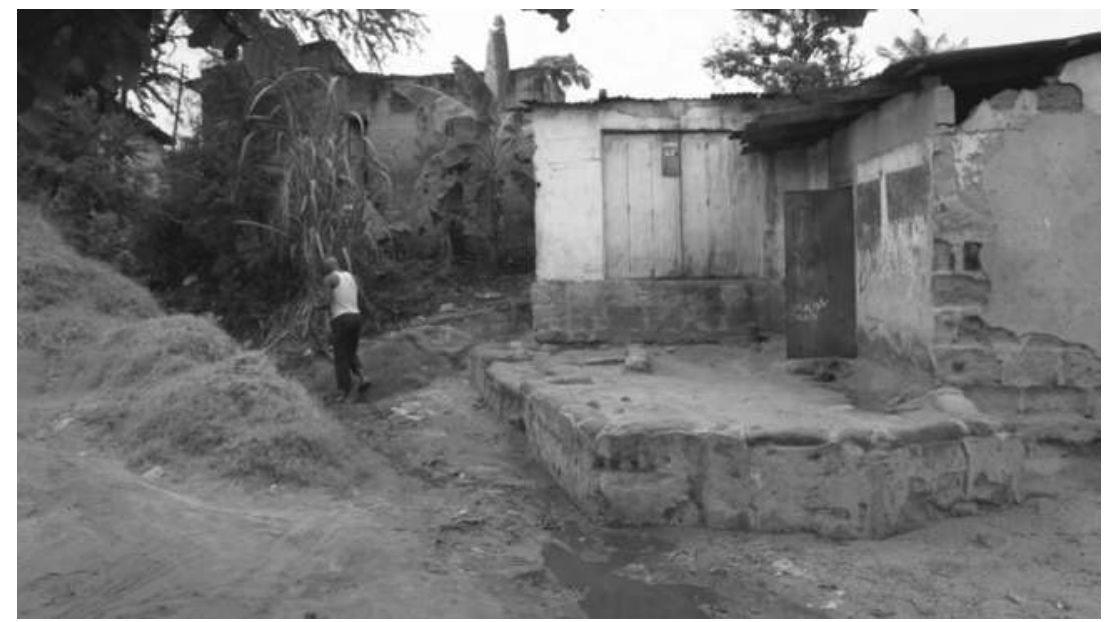

Figure 11.1 Home with secondary wall, Tandale Ward, Dar es Salaam.

Photo by Christopher Gore.

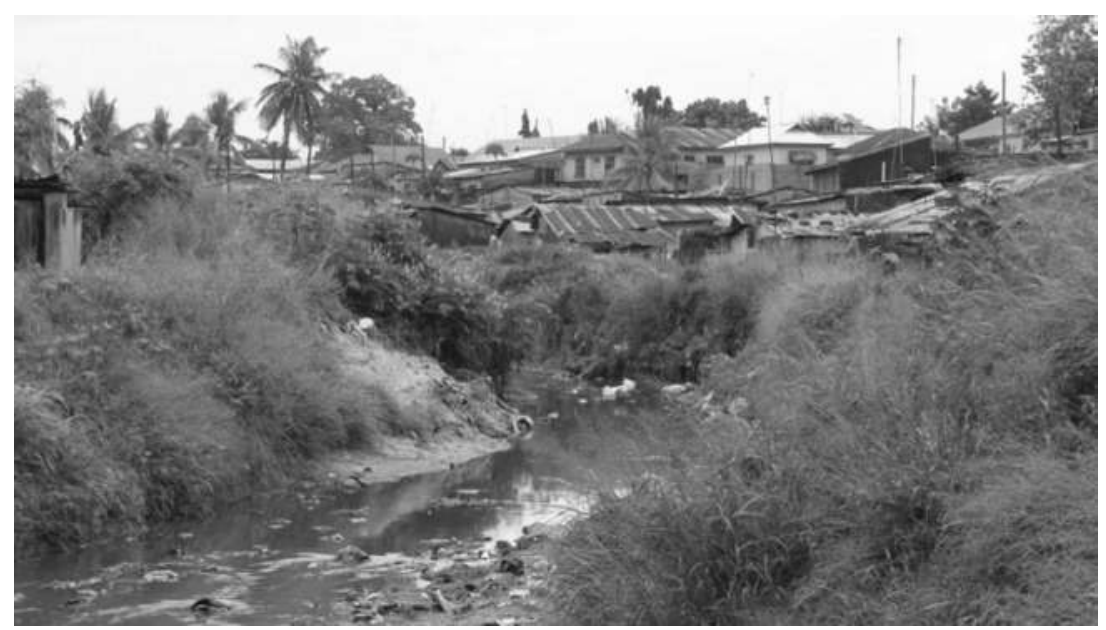

Figure 11.2 River in Tandale Ward, with houses near river.

Photo by Christopher Gore.

2014 IPCC Working Group II report on impacts, adaptation and vulnerability states that there is evidence that 'well-governed cities have a strong basis for building climate resilience' (IPCC 2014, 4; 49). The emphasis on the role of local governments and multilevel governance is long standing and important. Naturally, however, these prescriptions under-emphasize 
the stark, historic and present challenges that local governments in poor countries confront in leveraging resources to respond to climate risks, and in working with citizens and national governments in ways necessary to produce resiliency. Most critically, these observations under-emphasize the political sensitivity of climate adaptation strategies (see Bulkeley \& Tufts 2013); "addressing climate change in the city provokes fundamental political tensions over how and for whom environmental protection ... should be pursued" (Bulkeley 2010, 15). Resiliency depends on "effective political organization and receptive political systems with the capacity both to respond positively to citizen demands and to learn" and "... the quality of governance, especially local governance” (Satterthwaite 2013, 388). Yet cities in sub-Saharan Africa ${ }^{1}$, are known for limited financial resources, tense relations with national governments, and inadequate services and support for citizens. Hence, to reflect and theorize on cities and climate change in Africa means to undertake a deeply political exercise; what is needed for resiliency is daunting for many reasons explained below, but most fundamentally, requires an ambitious agenda that is likely to generate conflict.

With respect to financial resources, for example, in many countries, annual city expenditures per person are extremely low. A study of ten African cities between 2007 and 2009 showed that when Johannesburg was excluded, the average expenditure per person was U.S. \$32.93 (Stren 2014, 24). Adding to this lack of resources is an historic tension between urban and national governments and a general lack of national-urban cooperation to respond to the rapid population changes in African cities and the associated infrastructural and housing shortages (Gore \& Muwanga 2013; Goodfellow \& Titeca 2012; Resnick 2011). Thus, for resource poor and underserviced cities in Africa, the space between what experts and the international community say is needed to produce resiliency and the reality of urban conditions, management and governance is wide. This observation is not intended to underestimate the importance of African cities' engagement in climate knowledge networks, international conferences and debates, or their own knowledge of the challenges they confront. Research on cities and climate change clearly acknowledges that the diffusion of information and ideas through transnational networks are important in prompting city initiatives (Carmin, Anguelovski \& Roberts 2012; Schreurs 2008; Bulkeley \& Betsill 2005). But in recognizing the international engagement of African urban leaders, it is imperative to recognize the importance of endogenous factors as motivators for city climate response and how domestic governance-the character of the relationship between city governments and citizens and city governments and national governments- has an indelible impact on a city's capacity to respond to the climate risks it confronts. One of the best examples of the importance of endogenous leadership in Africa comes from the city of Durban, where climate leadership came from within the city (Carmin, Anguelovski \& Roberts 2012). Outside Africa, research has shown how the internal institutional structure of cities affects 
climate activities (Burch 2010a; 2010b; Dannevig, Hovelsrud, \& Husabø 2013; Meijerink \& Stiller 2013). Thus, this chapter argues that to understand how African cities are responding and may respond to climate change, how they engage in national and international processes, and their prospects for responding to the global climate challenge, there is a need to get 'back to basics': there is a need to understand how and why city governments are structured and function the way they are; how these characteristics shape response to urban challenges generally and climate risks specifically; and the implications of altering these structures and functions. The chapter argues that a central goal of future research on African cities and climate change must be to understand how the structure of city governments in Africa and the character of their relationship with citizens, other governments and the international community-the character of governance-will affect future climate adaptation and resiliency.

The chapter continues by first discussing some central challenges in African cities today, particularly in relation to their rapid change. The relationship between these changes and general expected effects of climate change are also highlighted. Then, two examples of cities in East Africa are presented and contrasted: Kampala, Uganda, and Dar es Salaam, Tanzania. The cases have similar general challenges with respect to urban management and climate change, but the structure of each city government is very different, and each city's relations with its citizens and the national government are also very different. Thus, while both cities are engaged in activities responsive to climate risks, the structure of government and character of governance in each city has historically and is presently going to produce significant challenges in establishing long-term institutionalized and sustained climate adaptation. The chapter concludes by making some observations about the future of African cities in climate action and governance in light of the emphasis on the structure and function of city governments.

Following in the spirit of the central questions this book takes up, the chapter reveals that African cities are engaged formally in local, national and global climate processes, and they are learning how to engage with international networks and communities in seeking both resources and support, and to advocate for action. As a result, the prospect of crafting responses to the global climate challenge and local climate risks is high. The challenge that remains is whether the current political context of African cities and structure of city governments can adapt in a manner and pace that is deemed necessary to respond to climate risks. For theory, the implications are significant and raise questions about the conditions when international learning and knowledge generation can or do translate into political and policy change domestically. Equally, if the change can take place, what concerns and implications of that change will arise, particularly for the populations most vulnerable. This chapter argues that there is a significant need to return to 'first principles' when considering city climate governance and theory in Africa: the structure of city governments, their relationship with 
national governments, and their capacity to implement climate resilient actions will depend on a national enabling environment that is fiscally and politically supportive of city climate leadership and action.

\section{AFRICAN CITIES AND CLIMATE CHANGE: THE EFFECT OF GOVERNMENT AND GOVERNANCE}

For several important reasons, African cities are anomalous globally. Compared to other regions of the world, the national percentage of African urban populations is lower than any other region. According to the UN Population Division, approximately 36.7 percent of Africans live in urban areas (UN Population Division 2012). This comparatively low total population of urban residents, however, is changing rapidly. Compared to other regions of the world, the average annual rate of urban growth is one of the highest in the world: from 2005 to 2010 average annual urban growth was estimated to be 3.71 percent, which was higher than China, Latin America, Europe and North America (Stren 2014, S20). While migration to cities contributes to population increase it is the not the dominant reason city populations are growing rapidly (see Potts 2009). The most dominant contributor to population growth is due to natural increase.

One dominant concern amongst African urban scholars is the globally and historically unprecedented disconnect between urban population growth and economic growth in many African countries. Population growth is not consistent with economic growth in African cities, leading some international agencies to argue that "the wisdom of seeking economic survival in the largest cities has become doubtful" (UN-Habitat 2008, 106). Given this context, it is not surprising to learn that service delivery and housing have not met need and demand. While the total African urban population living in informal settlements or 'slums' is expected to decrease over time, by 2030 still over 50 percent of urban residents are expected to be living in areas that are un- or under-serviced, that lack secure tenure or property rights, that are dominated by unregulated structures, and where formal physical planning is difficult to implement (Stren 2014, S22).

The challenge of urban development and management in the majority of large, medium and small African cities is ongoing and will persist for the medium to long term. Given this, for the foreseeable future African city governments will remain deeply dependent on national financing and collaboration, along with international financing, to respond to basic service needs as well as climate-specific needs. Improvements in infrastructure and housing for climate resiliency, for example, will depend on leveraging financial resources. Yet, national governments in many countries have been very slow to react to rapid urban change and there exists deep acrimony between many African city governments and national governments historically and today (see Resnick 2011; Esser 2012; Gore \& Muwanga 2013). This has left 
an indelible impact on the quality of service delivery and urban governance generally. When the complexity of climate change is added into this mix, the conclusion is not positive: "The multi-dimensional complexities of urban form, urbanization and urban governance in Africa have left city authorities and governments unprepared for climate change" (Lwasa 2010b, 20). The recent IPCC, Working Group II, report Climate Change 2014: Impacts, Adaptation, Vulnerability provides detailed information on why the link between climate and urbanization in Africa warrants significant attention.

For the continent as a whole, the IPCC reports general impacts that are alarming: general warming across the continent; likely reductions in precipitation in North and southwest Africa, while producing general water stress throughout the continent; increases in intensity of rainfall events, with a corresponding negative impact on crop production due to increasing temperatures and changes in precipitation. One of the most challenging climate change impacts in Africa, as well as globally, is that climate change is expected to exacerbate vulnerability, particularly by increasing the burden or multiplying existing health vulnerabilities, such as safe water, sanitation, and food insecurity.

For urban areas in Africa specifically, the IPCC report highlights the vulnerability of populations living in coastal areas that may be displaced due to storm events and sea level rise. Heavy rain events and poor urban infrastructure have and will continue to produce concerns about flooding and general infrastructure damage, particularly the households of poor and vulnerable populations. The report also notes that these vulnerabilities will be accentuated by the low adaptive capacity of local governments:

Weak local government creates and exacerbates problems including the lack of appropriate regulatory structures and mandates; poor or no planning; lack of or poor data; lack of disaster risk reduction strategies; poor servicing and infrastructure (particularly waste management and drainage); uncontrolled settlement of high-risk areas such as floodplains, wetlands, and coastlines; ecosystem degradation; competing development priorities and timelines; and a lack of coordination among government agencies. (IPCC WG II, 2014, Chapter 22, 28)

Owing to this long list of concerns, in the last decade or more, multilateral, bilateral and international non-government organizations have invested heavily in risk assessments and planning for adaptation to climate change in the sub-continent. But while financing for climate adaptation projects exist, the success and effect of these initiatives cannot be considered in the absence of understanding how the very authorities and institutions on the front line of climate response do function and may function to address risks; that is, the structure and capacity of city governments and their relations with citizens and governments will have a significant bearing on the potential to produce effective climate governance nationally and at the city level. How cities 
function, what national governments are doing to support or undermine city policy, and how city and national governments engage with citizens will have a bearing on future climate resiliency (Satterthwaite 2013).

Two cases of cities in East Africa are now presented to highlight the relationship between the structure of urban government (the formal administrative structure inclusive of elected office holders and the bureaucracy), the character of urban governance (the character or relations between governments and non-government entities), and climate response. Two cases are presented rather than one longer case in order to contrast how the structure of government in two African cities has an immediate, direct and potentially different effect on urban policy and engagement with national governments and citizens-conditions deemed necessary for future climate resiliency. The case of Kampala, Uganda, is first presented, followed by Dar es Salaam, Tanzania. General information about the cities is presented first, followed by a brief review of climate-specific issues affecting the cities. This climate context is followed by an explanation of the political and administrative structure of the cities and how this has historically effected policy action and what it suggests for future climate action.

\section{KAMPALA, UGANDA}

The city of Kampala is the capital of the East African country of Uganda. It is a relatively small country of about 236,000 square kilometers, on the northern shore of Lake Victoria, bordering South Sudan to the north, Kenya to the east, Tanzania and Rwanda to the southwest, Rwanda and the Democratic Republic of the Congo to the west. Despite its small geographic size, it has one of the fastest-growing populations in the world, at near 5 percent per year (Lambright 2014).In 2002, the national census revealed that the population was 23 million. In late August 2014, the latest national census took place. As of October 2014, the results of the census were still being compiled. In 2012, the UN Population Division estimated that the national population would be near 40 million, and by 2025 near 55 million people (UN Population Division 2012). In 2002, Kampala had an estimated population of about 1.2 million; by 2011 the Uganda Bureau of Statistics projected the population to be 1.7 million (Kasaija \& Lwasa 2014). Depending on how you define 'Kampala' and with whom you are speaking, the daytime population of the city and its environs may increase to 2.5 or 3 million people. The population changes in Uganda generally and Kampala specifically will be exacerbated in future by the very low national urban population-approximately 15 percent of the total population - and the very young population, thereby creating a scenario where natural increase is a central driver of population change. The speed of population change, combined with problems with urban management and service delivery (discussed more below), has left the city with large deficits 


\section{Christopher Gore}

in housing, infrastructure and general service delivery. In addition, there is a historical and colonial legacy of water, waste collection and sewerage serving high-income areas of the city leaving low-income areas under-serviced and vulnerable (Gore \& Gopakumar, forthcoming). This service deficit is amplified by the physical location of low-income settlements in Kampala. The formal city of Kampala surrounds several large hills, with corresponding valleys in between. Generally, as is common in East Africa, low-income residential areas dominate low-lying areas. Not surprisingly, these areas are more vulnerable to flooding and heavy rainfall events, which themselves are expected to increase and intensify under future climate change.

The most serious and often quoted climate change impacts on Kampala relate to rainfall and flooding (see Lwasa 2010a). Lwasa (2010a) reports that over the last twenty years, the frequency of flooding events in Kampala due to more intense rainfall has increased. Conversely, there is also a concern that under climatic change sources of drinking water could decrease, which could compromise water supply, or at minimum require new investments in infrastructure to access new water sources. Flooding and high volumes of runoff produce other environmental and health stresses, including destruction of homes and potential for exposure to waterborne diseases, such as malaria, dysentery and cholera, which result from stagnant water and untreated sewage. High levels of poverty in the city make these conditions worse. While Kampala generated 42 percent of national economic growth between 2005-2009, and poverty in rural areas decreased during this time, inequality nationally, and poverty in Kampala, increased during this period (World Bank 2013, 29). Kampala's estimated poverty level was about 30 percent of the population in 2010 (Lwasa 2010a, 167).

In light of these challenges and climatic conditions, it has been argued that "Kampala city requires restructuring of spatial planning and urban governance systems by making plans responsive to current and future [climate] challenges" (Lwasa 2010a, 168). In late 2010, a new 'governance system' did arise in Kampala. But the reason for this change was not climate-related (as would be expected). Change came as a result of a long history of conflict and tension between the national and city government, and the Kingdom of Buganda (see Goodfellow \& Lindemann 2013), which owns approximately half of the land in Kampala city proper. The question that is most relevant when thinking about the city and climate change is whether the changes in the structure of urban government and the character of governance align with characteristics deemed necessary for urban climate resilience.

Until late 2010, Kampala had been governed like most cities, with a popularly elected mayor and council responsible for policy and program implementation. Like many cities in Africa, there had been a tendency, however, for a majority of Kampala elected officials, including mayors, to represent political parties in opposition to the President's (see Resnick 2011; Esser 2012). Adding to this, cases of corruption and poor service delivery in the city were common, and overall, despite some very positive environmental 
initiatives relating to urban food production and security (see Cole et al. 2008), the city was largely seen as being ineffectual. The national government, however, did not help to minimize this image. Despite the size of the city relative to any other urban area in the country, its dominance or primacy in terms of economic contributions to national wealth, and the challenges it encountered in responding to rapid urban change, it was funded in the same manner as any other district in the country (see Gore \& Muwanga 2013). In addition, urban areas and Kampala specifically, had never been prioritized or generally referenced in national poverty or development strategies (Mitlin 2004; Gore 2008); there was no national urban policy; and the dramatic urban change that was befalling the country was not well recognized by national leadership until almost 2010 (Gore \& Muwanga $2013,3)$. Thus, infrastructure and service quality in the city prior to the national government's takeover was poor and generally deteriorating, making it somewhat easy to convince the public that a national takeover of the city was in the best interest of citizens and the country. Indeed, just after the formal takeover of the city, national and local candidates aligned with the President's political party, the National Resistance Party, and President Yoweri Museveni himself, received more support from Kampala voters than ever previously.

Thus, in late 2010, the national government passed the Kampala Capital City Bill, which transferred authority for the city directly to the national government.

The new bill produced a dramatic change in the structure of capital city government and urban governance, vesting authority for planning and development decisions in an Executive Director and ten Directors. While popular local elections remain in place, the popularly elected mayor and council have no direct authority over spending, therefore lacking "... fiscal autonomy-a de facto unfunded mandate” (Gore \& Muwanga 2013, 12). The Executive Director is appointed by the President and accountable to Cabinet and a Minister responsible for Kampala. The Kampala Capital City Authority (KCCA) has replaced the former city council. The KCCA consists of elected councillors but the Directors of various city departments, such as Physical Planning and Physical Services and the Environment, take direction from the Executive Director and not the KCCA. As a result, while the elected councillors make recommendations for city programs, the Directors are ultimately accountable to the Executive Director and not to individuals popularly elected.

In 2014, Kampala City is a much different organization than previously. Annual reports to Parliament take stock of activities and expenditures, along with future initiatives. A majority of technical city staff has changed, with bureaucratic leaders clearly aligned with the mandates set out by the Executive Director. Further, while there have been many controversies relating to city government policy decisions, such as relating to petty street traders and illegal buildings, the general sentiment in the city is that roads and 


\section{4}

infrastructure have improved and self-monitoring by the city suggests that waste collection has increased; revenue generation has increased; social development activities are documented, such as support for urban farmers; and enforcement of laws has increased (Government of Uganda 2014).

With respect to climate change specifically, the Executive Director, Ms. Jennifer Musisi, has also spoken openly and directly about taking actions to respond to climate change. At the 2014 Technical Experts Meeting on the Urban Environment in Bonn, Germany, Musisi announced several initiatives she connected to climate change and improved resiliency: solar-powered street lighting along all new road lighting systems in the city; construction of new channels to minimize flooding in city suburbs; new electricity generation using solid waste from the municipal landfill site; and the promotion of new stoves to reduce charcoal and wood consumption and reduce particulate matter in the city. These announcements, including the Executive Director's direct participation in an international meeting and networking with organizations like the Global Environment Facility and UN-Habitat, clearly reveal that climate change and financing for climate resiliency are priorities. But do these actions suggest a positive path for climate resiliency?

One of the critical needs for low-income cities is support and collaboration with national governments and international institutions. Previously, the relationship between Kampala and the national government was poor and the city had a poor record of performance, which together had a negative indirect effect on the capacity for the city to attract international finance and support. Hence, from a positive perspective, the city seems engaged in a multilevel process of upward vertical collaboration with the national government and international actors. Horizontal collaboration, networking and knowledge sharing at international events are also evident, which, as earlier noted, is always important in city climate action. One large uncertainty that remains, however, is how and if the city will and can build bridges with citizens and civil society organizations and begin to establish and reinvigorate the conditions necessary for urban climate governance that responds to citizen needs and distributes action and benefits equitably. Acknowledging the improvements to the city since the KCCA came into being, we note that one of the biggest challenges in Kampala will be how to move beyond a piecemeal approach to city development and begin to work with the many civil society organizations engaged in such things as housing, flood response and slum upgrading as real partners (Kasaiji and Lwasa 2014). Further, it remains that the technical arm of the city must overcome deeply rooted public suspicion and concern that the takeover of the city was as much a political maneuver of the President to undermine opposition as it was a decision deemed necessary to respond to the failures of city governance and service improvement (see Lambright 2014). Indeed, whether one of the outcomes of the new structure of city government produces more programs to address climate risks, these cannot be equated with a city that is climate adaptive or resilient. The national government's takeover of the city was deeply political 
and built on a history of conflict between citizens and levels of government. It will take time before the actions of the new city government will be able to show that environmental and climate policies and programs are sensitive to the city as a whole, and not reasserting political tensions or conflicts that hold a lasting legacy in the city. So while the new city government of Kampala does seem to be moving in a direction that is illustrative of a city with the resources and relations needed for climate adaptation, climate resilience will remain dependent on how the new structure of the city government engages in the social and political task with its citizens and civil society organizations that are necessary for future resilience. Further, both pragmatically and theoretically, if the national government's takeover of the city does produce positive outcomes for climate resiliency, then very careful and challenging debates will need to unfold about whether the risks of climate are urgent enough in some cities to accept or endorse a limit on local democracy and the influence of popularly elected councillors on projects and funding in the city. It is important to remember that many of the most popular and beautifully planned cities in the world, like Paris, or cities deemed 'successful' in the developing world, like Curitiba, Brazil, owe their 'success' to national leaders that took power undemocratically and had a vision for city development that was facilitated by their power. Is climate resiliency in poor urban environments worthy of these national interventions? Clearly authoritarian interventions are not necessary for city climate adaptation; but for future research, it is incumbent to try to understand the conditions (political, social and administrative) that lead to positive initiatives, such as in Durban, South Africa, where endogenous leadership was critical (see Carmin, Anguelovski \& Roberts 2012).

Turning to a different example, the city of Dar es Salaam similarly shows evidence of engagement with climate issues internationally, but here the fragmented model of city government produces different concerns about the capacity of the city-region to produce climate actions that will produce resiliency.

\section{DAR ES SALAAM, TANZANIA}

Dar es Salaam, Tanzania, is an historic port city on the east coast of Africa. Tanzania, bordered by Kenya to the north, Uganda, Burundi, Rwanda to the northwest, Democratic Republic of Congo to the west, and Zambia, Malawi, and Mozambique to the south, is about 945,000 square kilometers, over three times the geographic size of Uganda. The population of Tanzania, like Uganda, is also increasing very rapidly. According to the United Nations Population Division (2012), in 2005, the national population was estimated at almost 38.8 million people. By 2010, the population had increased to 45 million. By 2015, it is estimated that the population will reach 52 million, and by 2025 almost 70 million. 
Dar es Salaam is the dominant, primate city in Tanzania, but functions with a fragmented government structure. When people discuss the city of Dar es Salaam, they are actually referring to the formal Region of Dar es Salaam-a national region. This region is made up of three national districts, which are also three independent municipalities-Illala, Kinondoni and Temeke. Each of these municipalities has an independent mayor and council. The city/region as a whole is overseen by a nationally appointed Regional Commissioner, but there also exists a Dar es Salaam City Council and Mayor of Dar es Salaam. The Dar es Salaam City Council is supposed to help coordinate activities for the city/region as a whole, although it has no legislative authority to do so. This administrative context is significant when thinking about climate action in the city and will be discussed further below.

While the political capital of Tanzania was formally moved from Dar es Salaam to Dodoma in 1973, and the National Assembly opened there in 1996, many central government offices remain in Dar es Salaam, and the city remains the economic center of the country. Dar es Salaam generates over 70 percent of the national gross domestic product (UN-Habitat 2009, 6). In 2011, Dar es Salaam's population was estimated to be around 4 million people, "which is approximately ten percent of the country's total population and 50 percent of its urban population. With a population growth of 4.3 percent per year, Dar es Salaam has become the third fastest growing city in Africa and among the ten fastest growing cities in the world" (World Bank 2011). Not surprisingly, this speed of growth, combined with the size of the city, has produced serious challenges in service delivery.

Some of the most regularly cited environmental service provision challenges in Dar es Salaam are drinking water provision, housing and housing quality, and general infrastructure quality. The infrastructure for water provision dates back almost fifty years; the quality of the infrastructure has been so poor in the recent past that 60 percent of water pumped is lost; and it is estimated that only 30 percent of city residents have access to tap water (Kyessi 2005, 3). Financing service provision is also a major problem. A 2004 report by ActionAid revealed that only 26 percent of people receiving water were being billed for it, and even those connected to the city's water system regularly went weeks without water (Dill 2009, 614). Further, only about 10 percent of the population is connected to the sewer system (Kiunisi 2013, 323). The health outcomes from these conditions are predictable: "cholera, dysentery and other gastrointestinal diseases are commonplace in Dar es Salaam" (Dill 2009, 614).

The number of people living in informal or unplanned settlements in Dar es Salaam is also very high, with the percentage of households categorized as 'slum households' ranging between 65-80 percent (UN-Habitat 2008; Kiunsi 2013). The physical quality of these dwellings combined with their location in low-lying areas, often near water courses, in valleys, or near coastal wetlands, means that they are very vulnerable to extreme weather 
events such as heavy rainfall, which cause flooding, erosion and land degradation. Conversely, in the past ten years, the city has also experienced drought and increases in mean temperatures, which are expected to continue (World Bank, n.d.). In short, climatic change is expected to exacerbate already difficult infrastructure and human welfare challenges: "Dar es Salaam is a city where urban poverty and climate variability-floods as well as drought-jointly create a situation of high vulnerability for the poor that affects crucial aspects of their lives, e.g., health, sanitation and access to clean water, and safety of housing and property" (START et al. 2011). More generally,

Tanzania is predicted to become warmer by $2.5^{\circ}$ to $4.5^{\circ} \mathrm{C}$ by the year 2080 . . . Precipitation is projected to increase in all rainfall seasons, with coastal and southern parts experiencing the greatest increases. Dar es Salaam has already become warmer-data from the TMA indicate an increase in both minimum and maximum temperatures over the last four to five decades. The data also show a decrease in the number of rainfall days and mean annual rainfall, and increased variability in rainfall intensity. (Kiunsi 2013, 325)

The costs of responding to these climatic challenges are enormous. The stormwater drains in Dar es Salaam were constructed in the 1950s and are deemed largely dysfunctional; the estimated cost of building a sea wall along the $100 \mathrm{~km}$ coastline of Dar es Salaam to protect it from rising sea levels has been put at $\$ 270$ billion; when the cost of upgrading housing is added to some of these projected costs and needs, then it is clear that costs of responding to climate risks are well beyond the national and local economies (Kithiia 2011, 177).

The real and expected effects of climate change on Dar es Salaam are well known. The city has been studied extensively, partly due to the many additional risks it confronts due to being on a coast as opposed to inland, like Kampala, and partly due to the speed of change it has experienced as an urban agglomeration. There are also many projects underway in the city to upgrade services, infrastructure, and housing, and to reduce congestion, such as the Dar es Salaam Rapid Transit (DART) system. Many other mitigation activities exist, such as: "... tree planting; the protection of coral reefs and mangrove vegetation; using more efficient cooking stoves; promoting the use of natural gas instead of oil and coal or using briquettes (to cut down on fuelwood/charcoal use); using energy-saving street lights; an improved public transport system; and methane gas capture at waste disposal sites" (Kiunsi 2013, 331). Funding for these activities and risk assessments have come from various international sources such as the European Union, the World Bank, UN-Habitat, Cities Alliance, and the International Council for Local Environmental Initiatives (ICLEI). Many of these international funding initiatives will benefit Dar es Salaam directly, but, importantly, the funds 
generally move through national ministries, particularly the Prime Minister's Office, which signs off on international project funding. Hence, Dar es Salaam is formally engaged in multilevel climate actions and clearly connected to the international system through funding and knowledge sharing.

Linkages between Dar es Salaam and the international community and knowledge networks also come about through local representatives. As a reminder, the City of Dar es Salaam is formally governed through a fragmented administrative structure-three independent municipalities, each with a popularly elected council and mayor; a city mayor and council that aims to coordinate city activities and initiatives but without legislative authority to do so; and a nationally appointed Regional Commissioner. One of the outcomes of this structure is that there are situations where the mayor of Dar es Salaam will participate in international meetings, while the mayor of one of three Dar es Salaam municipalities will participate in a different meeting or network. For example, the World Mayors Council on Climate Change has two mayors from the Region of Dar es Salaam as members-the mayor of the Municipality of Kinondoni and Temeke. Meanwhile, the mayor of Dar es Salaam-the city as a whole-represented the city on the World Bank's Mayor's Task Force on Climate Change, Disaster Risk and the Urban Poor and has represented the city as a whole at the C40 Cities Climate Leadership Group. Yet, the Dar es Salaam mayor has no authority to implement a city-wide agenda without the support of the three other mayors and therefore must rely on cooperation, coercion or financial incentives from that national government or international sources to produce city-wide actions. Thus, city political leaders are engaged in knowledge sharing and networking internationally. But this engagement does not mean that the character of the relations between the city, citizens and government and non-government entities-the character of multilevel or local climate governance-will produce the conditions necessary for climate adaptation and resiliency.

The structural complexity of Dar es Salaam has challenged and does challenge the capacity for city-wide actions that are deemed necessary to adapt to climate change successfully and to make climate adaptation institutionalized in city administration. Dar es Salaam City Council staff, for example, have no authority to implement physical planning standards for the city as a whole and have not been engaged in the development of a much anticipated Master Plan (Author's observation, June 2014). Further, it is important to remember that the structure of the city highlighted here masks the other layers of authority and representation at lower levels in the city, such as the street-level elected committees (mtaa committees) and the divisions that make up districts. Hence, while the lowest levels of local authority may have long-held systems of engagement with citizens through a history of decentralization-a case similar in Uganda-and therefore the quality of relations at this scale may be strong, these connections cannot be 
considered independent of the vertical relations and collaboration deemed necessary for climate resilience. Once again, a scenario arises where the very conditions deemed important for citizen engagement and democracy may also prove to be-and often do prove to be-impediments to the kind of city-wide, rapid, institutionalized response to climate change that is needed. The pragmatic steps needed to respond to climate adaptation and produce resiliency are deeply political (see Bulkelely \& Tufts 2013): in Dar es Salaam, to move people away from low-lying areas and into new housing settlements or for the national government to restructure the city to provide more authority to the City Council would have significant political fallout. These challenges are amplified by a history of low national attention to urban issues, such as in Uganda. Cities and national urban centers have not received a lot of prominence in national development and climate strategies in the country-something similar in Uganda; the country's 2007 National Adaptation Programme of Action, for example, emphasized rural and natural resource issues, with human settlements listed as the ninth of eleven priority sectors (Kiunsi 2013, 321-322).

Unlike Kampala, no large national intervention in the structure of government in Dar es Salaam has occurred to date. Local political and technical leaders from both cities are engaged in international climate forums and have received funding for risk assessments and improvements in physical infrastructure that are necessary in the face of climate risk. Further, as should be expected in poor urban settings, both cities depend on their national governments to facilitate international financial transfers and for the legislative authority to implement climate-responsive changes in their cities. While both cities are structured differently, the same questions linger about the effect of those structures on climate adaptation. While Kampala's structure of government has changed and become more professionalized, having stronger technical capacity, and having the mandate of the President to implement changes and improvements, its success in fostering and building relations with Kampala citizens will be tested in the years to come owing to long-standing political conflict in the city. Conversely, while Dar es Salaam's government structure, like Kampala's old structure, is rooted in an ethos of democratic decentralization, it is now proving to be a point of clear debate, frustration and contention in urban management for the city-the structure that was created and lingers due to assumptions of better local representation produces extremely large challenges for city and region-wide coordination. In both cities, the central point that must be considered is the relationship between the structure of government, the character of governance and the effect of both of these on the capacity of the cities to respond to the looming challenge of climate change. How the structure of government affects the ability, willingness and necessity of governments at multiple levels to engage with citizens will have a lasting impact on the capacity of cities to respond to climate change. 


\section{CONCLUSION}

This chapter has examined two cities in East Africa that are both affected by and attempting to respond to quite significant challenges exacerbated by climatic change. In both cases, the cities are clearly planning for a future where the cities want to be part of an international community of cities engaged in climate activities. As other chapters in this book highlight, Dar es Salaam and Kampala, like other cities throughout Africa, are engaging with the international system through knowledge sharing, networking and financial opportunities. This is significant: African cities may be poor, lack capacity and are struggling with extraordinarily rapid change, but they are not disconnected from the debates taking place internationally and from the networks of cities that have materialized in the last two decades to respond to climate change. Given this, it is important to recognize the potential for African cities to play an important role in the future of international climate governance. African cities are not passive bystanders to the global climate challenge. While this observation is important in order to combat the mainstream perception of African cities as being directionless and bastions of violence or poverty, a more important observation for international climate governance is whether and how the complexity of African urban government and governance can and will impact pragmatic responses to climate change and theory of cities and climate change.

Pragmatically, projects and programs to respond to climate risks in African cities must be cognizant of the history and power dynamics of city governments and city politics. Climate risks may produce some isolated impacts in cities, but overall climate impacts will be at a regional and city-wide scale. For this reason, lack of attention to past political debates, conflicts and problems in cities, particularly national-local relations, and the effect of these relations on project implementation, has the potential to reproduce inequities in the city and to miss critical points of administrative leadership that may not be apparent from an organizational chart. Understanding why a government is structured the way it is, the past and present outcomes of that structure, and how to work within that structure to produce broad benefits in project implementation is essential for the institutionalization of climate adaptation.

Theoretically, the fact that African cities are engaged in international climate networks and domestic climate activities produces an exciting opportunity for future research and knowledge generation. It has only been in recent years that scholars globally have begun to examine the correlation between city structure and climate actions. This, however, will be a critical undertaking in the years to come. As the case of Durban, South Africa, revealed, internal bureaucratic leadership can produce significant city climate response (see Carmin, Anguelovski \& Roberts 2012). Further, international research reveals that the structure of government seems to affect urban climate and environmental initiatives (Bae and Feoick 2013), as does 
the relationships within government (Burch 2010a; 2010b). Given this, and recognizing one of the central questions in this book, there is a significant need to better understand how city governments are using climate change to justify policy development; the democratic and policy implications of doing this; and, whether cities are (re)asserting their political and policy importance nationally and internationally due to their front-line role in responding to climate change.

African cities are acting and want to act to respond to climate change. In supporting these actions and following their trajectory, it is imperative not to lose sight of the foundations of urban policy and response- the people, structures and relations that are in theory, and increasingly in practice, vested with the moral if not legal authority to minimize climate vulnerability and to improve human welfare at the urban scale: the city government.

\section{NOTE}

1. For the remainder of this chapter, 'Africa' will be used instead of 'sub-Saharan Africa'. The author is conscious of the serious problems and potential perils with generalizing for approximately 50 countries in the region and that the distinction between North Africa and sub-Saharan Africa has disciplinary and historic rationales that do not always hold merit. For this reason, the chapter tries to be generalize minimally and to use specific examples where possible.

\section{BIBLIOGRAPHY}

Bae, Jungah \& Richard Feiock. 2013. Forms of Government and Climate Change Policies in US cities. Urban Studies 50 (4), 776-788.

Bulkeley, Harriet. 2010. Governing Climate Change in the City. Urbanization and Global Environmental Change Viewpoints 4 (October), 15-19.

Bulkeley, Harriet \& Michele Betsill. 2005. Rethinking Sustainable Cities: Multilevel Governance and the 'Urban' Politics of Climate Change. Environmental Politics 14 (1), 42-63.

Bulkeley, Harriet \& Rafael Tufts. 2013. Understanding Urban Vulnerability, Adaptation and Resilience in the Context of Climate Change. Local Environment 18 (6), 646-662.

Burch, Sarah. 2010a. In Pursuit of Resilient, Low Carbon Communities: An Examination of Barriers to Action in Three Canadian Cities. Energy Policy 38, $7575-7585$.

Burch, Sarah. 2010b. Transforming Barriers into Enablers of Action on Climate Change: Insights from Three Municipal Case Studies in British Columbia, Canada. Global Environmental Change 20, 287-297.

Carmin, JoAnn, Isabelle Anguelovski, \& Debra Roberts. 2012. Urban Climate Adaptation in the Global South: Planning in an Emerging Policy Domain. Journal of Planning Education and Research 32 (1), 18-32.

Cole, D., D. Lee-Smith, \& G. Nasinyama (eds.) 2008. Healthy City Harvests: Generating Evidence to Guide Policy on Urban Agriculture. Lima and Kampala: Urban Harvest and Makerere University. 
Dannevig, Halvor, Grete K. Hovelsrud, \& Idun A Husabø. 2013. Driving the Agenda for Climate Change Adaptation in Norwegian Municipalities. Environment and Planning C: Government and Policy 31, 490-505.

Dill, Brian. 2009. The Paradoxes of Community-based Participation in Dar es Salaam. Development and Change 40 (4), 717-743.

Esser, D. 2012. 'When We Launched the Government's Agenda . . .': Aid Agencies and Local Politics in Urban Africa. Journal of Modern African Studies 50 (3), 397-420.

Goodfellow, Tom \& Stefan Lindemann. 2013. The Clash of Institutions: Traditional Authority, Conflict and the Failure of 'Hybridity' in Buganda. Commonwealth and Comparative Politics 51 (1), 3-26.

Goodfellow, Tom \& K. Titeca. 2012. Presidential Intervention and the Changing 'Politics of Survival' in Kampala's Informal Economy. Cities 29 (4), 264-270.

Gore, C. 2008. Healthy Urban Food Production and Local Government. In D. Cole, D. Lee-Smith, \& G. Nasinyama (eds.), Healthy City Harvests: Generating Evidence to Guide Policy on Urban Agriculture. Lima and Kampala: Urban Harvest and Makerere University, 49-65.

Gore, Christopher \& Govind Gopakumar. Forthcoming. Infrastructure and Metropolitanization: Understanding and Comparing the Relationship in Cities of Africa and India. Journal of Urban Affairs.

Gore, Christopher \& Nansozi K. Muwanga. 2014. Decentralization Is Dead, Long Live Decentralization! Capital City Reform and Political Rights in Kampala, Uganda. International Journal of Urban and Regional Research 38 (6), 2201-2216.

Government of Uganda. 2014. Ministerial Policy Statement, Financial Year 2014/2015, Vote 122. Presented to the Parliament of Uganda by Frank Tumwebaze (MP), Minister for the Presidency and Kampala Capital City Authority. Kampala, Uganda.

IPCC, 2014. Climate Change 2014: Impacts, Adaptation, and Vulnerability. Part B: Regional Aspects. Contribution of Working Group II to the Fifth Assessment Report of the Intergovernmental Panel on Climate Change [Barros, V.R., C.B. Field, D.J. Dokken, M.D. Mastrandrea, K.J. Mach, T.E. Bilir, M. Chatterjee, K. L. Ebi, Y. O. Estrada, R. C. Genova, B. Girma, E. S. Kissel, A. N. Levy, S. MacCracken, P.R. Mastrandrea, \& L.L. White (eds.)]. Cambridge and New York: Cambridge University Press.

Kasaija, Peter \& Shuaib Lwasa. 2014. The Role of Civil Society Organizations in Shaping Adaptation Capacities of the Urban Poor in Kampala, Uganda. Urbanization and Global Environmental Change 10 (May), 13-16.

Kithiia, Justus. 2011. Climate Change Risk Responses in East African Cities: Need, Barriers and Opportunities. Current Opinion in Environmental Sustainability 3, 176-180.

Kiunsi, Robert. 2013. The Constraints on Climate Change Adaptation in a City with a Large Development Deficit: The Case of Dar es Salaam. Environment and Urbanization 25 (2), 321-337.

Kyessi, Alphonce. G. 2005. Community-based Urban Water Management in Fringe Neighbourhoods: The Case of Dar es Salaam, Tanzania. Habitat International $29,1-25$.

Lambright, Gina. 2014. Opposition Politics and Urban Service Delivery in Kampala, Uganda. Development Policy Review 32 (S1), S39-S60.

Lwasa, Shuaib. 2010a. Adapting Urban Areas in Africa to Climate Change: The Case of Kampala. Current Opinion in Environmental Sustainability 2, 166-171.

Lwasa, Shuaib. 2010b. Urban Vulnerabilities and Adaptation in Low Income Countries: Perspectives for Future Research in Africa. Urbanization and Global Environmental Change Viewpoints 4 (October), 20-23. 
Meijerink, Sander \& Sabina Stiller. 2013. What Kind of Leadership Do We Need for Climate Adaptation? A Framework for Analyzing Leadership Objectives, Functions, and Tasks in Climate Change Adaptation. Environment and Planning C: Government and Policy 31, 240-256.

Mitlin, Diana. 2004. Understanding Urban Poverty: What the Poverty Reduction Strategy Papers Tell Us. Working Paper on Poverty Reduction in Urban Areas 13. London: International Institute for Environment and Development.

Pelling, M. 2011. Adaptation to Climate Change: From Resilience to Transformation. London: Taylor \& Francis.

Potts, Deborah. 2009. The Slowing of Sub-Saharan Africa's Urbanization: Evidence and Implications for Urban Livelihoods. Environment and Urbanization 21 (1), 253-259.

Resnick, Danielle. 2011. In the Shadow of the City: Africa's Urban Poor in Opposition Strongholds. Journal of Modern African Studies 49 (1), 141-166.

Satterthwaite, David. 2013. The Political Underpinnings of Cities' Accumulated Resilience to Climate Change. Environment and Urbanization 25 (2), 381-391.

Schreurs, Miranda. A. 2008. From the Bottom Up. Local and Subnational Climate Change Policies. Journal of Environment and Development 17 (4), 343-355.

START Secretariat, Tanzania Meteorological Agency, Ardhi University. 2011. Urban Poverty and Climate Change in Dar es Salaam, Tanzania: A Case Study. March 10. Retrieved June 15, 2012 from http://start.org/download/2011/dar-case-study.pdf

Stren, Richard. 2014. Urban Service Delivery in Africa and the Role of International Assistance. Development Policy Review 32 (S1), S19-S37.

UN Population Division of the Department of Economic and Social Affairs of the United Nations Secretariat. World Population Prospects: The 2012 Revision. Retrieved June 25, 2013 from http://esa.un.org/unpd/wpp/index.htm

UN-Habitat. 2008. The State of African Cities. Nairobi, Kenya.

UN-Habitat. 2009. Tanzania: Dar es Salaam City Profile. Nairobi, Kenya.

World Bank, n.d. Dar es Salaam Case Study Overview: Climate Change, Disaster Risk and the Urban Poor: Cities Building Resilience for a Changing World. Retrieved June 17, 2014 from http://siteresources.worldbank.org/INTURBANDEVELOP MENT/Resources/336387-1306291319853/CS_Dar_Es_Salaam.pdf

World Bank. 2008. Citizen's Report Card on Urban Water, Sanitation and Solid Waste Services in Kenya. Summary of Results from Nairobi. Washington, DC: World Bank.

World Bank. 2011. Tanzania-Dar es Salaam Metropolitan Development Project. Washington D.C.-The World Bank. Retrieved June 17, 2014 from http:// documents.worldbank.org/curated/en/2011/04/14238032/tanzania-dar-es-salaammetropolitan-development-project

World Bank, 2013. Africa's Pulse. An Analysis of Issues Shaping Africa's Economic Future. October, Vol. 8. Washington, DC: World Bank. 
$\Longrightarrow$ Taylor \& Francis

Taylor \& Francis Group

http://taylorandfrancis.com 


\section{Part V}

\section{Governing the Urban Climate Challenge \\ New Directions in Theory, \\ Policy and Research}


$\Longrightarrow$ Taylor \& Francis

Taylor \& Francis Group

http://taylorandfrancis.com 


\title{
12 Conclusion \\ Governing the Urban Climate Challenge
}

\author{
Craig Johnson, Heike Schroeder \\ and Noab Toly
}

\section{INTRODUCTION}

The chapters in this volume raise a number of critical questions about the study of cities in global climate governance regimes. Principal among these are factors affecting climate policy formation and implementation at the urban scale, the ways in which cities are engaging with global environmental governance processes and systems, the impact of international norms on urban and domestic climate politics and, more generally, the ways in which cities, transnational urban networks, national governments and global governance institutions may address the urban climate challenge.

In this final chapter, we identify four central themes that emerge from close examination of the contributions to this volume: building capacity for urban climate governance, understanding the role of cities in global climate regimes, evaluating what constitutes successful urban climate governance and identifying questions for future research.

\section{BUILDING CAPACITY FOR URBAN CLIMATE GOVERNANCE}

One core theme that emerges from the volume is the challenge of integrating climate change priorities into urban policy and planning. As noted in Chapter 1 , the ability of cities to invest in long-range adaptation and mitigation measures is often constrained by a lack of sufficient resources, limited timelines and the perceived need to address more pressing demands. For older cities, the costs of repairing and retrofitting aging infrastructure can be prohibitively expensive. For newer ones, especially ones in emerging economies, the ability of formal urban institutions to coordinate and contain rapid and unplanned urban growth is often constrained by issues such as a lack of resources, weak institutions and policies governing land and concerns for health, energy, housing, transportation, disaster risk reduction.

A second challenge stems from the fact that many factors influencing urban carbon emissions and vulnerability are often well beyond the reach of urban authority structures. In many cases, cities lack the formal authority 
to enact legislation governing energy, transportation, infrastructure and so on. Even when cities do have the requisite formal authority, they often lack the financial and human resources. In Christopher Gore's words, African cities are often "deeply dependent on national financing and collaboration, along with international financing, to respond to basic service needs as well as climate-specific needs." The same can be said about many of the cities covered in this volume.

A third issue concerns the challenge of coordinating across the multiple administrative channels and "silos" (Aylett, Chapter 9) that have a role in the formation and implementation of urban climate policy. Although many cities are now speaking the language of climate change, the ability of urban planners and politicians to implement policies that regulate emissions and vulnerability is highly dependent upon the administrative channels that govern a wide range of sectors, including transportation, water and sanitation, health, housing and emergency services. In some cases (e.g., North Vancouver, Chapter 7; Portland, Chapter 9), municipal authorities have been able to incorporate climate change into their operational and planning structures. In many others, however, (e.g., Mumbai, Chapter 8) municipal authority is fragmented by a combination of bureaucratic politics and administrative path-dependence. To take but one example:

... the management of the Metropolitan Area of Mexico City is scattered between the federal government with its seat in the Federal District, authority delegated to national ministries, the State of Mexico with its governor and 35 conurbanized municipalities, and the 16 delegations of the Federal District, which functions as a quasi-state with its own governor. (Romero-Lankao et al., Chapter 10)

A final and related issue concerns the political costs and benefits of taking action on climate change. As noted in Chapter 1, the ability of urban leaders to invest in climate change adaptation and mitigation entails a timeline that often far exceeds the fiscal and political shelf life of most urban planners and politicians. The professional and political benefits of investing in climate change are therefore minimal, especially when they come at the expense of other pressing urban needs. As we shall see, some of the most successful efforts at incorporating climate change into urban policy and planning occurred when urban planners and politicians were able to situate climate change into a broader agenda of urban sustainability.

\section{Core Themes and Findings}

Recent empirical work on urban climate governance has shown that cities can achieve greater autonomy when they are "nested" within a federal system that specifies and guarantees these rights to autonomous municipal bodies (Tanner et al., 2009). However, reconciling the formal distribution 
of power with the informal dynamics of urban and environmental change is a difficult undertaking. The chapters in this volume suggest that higher-level authorities can build the capacity of urban institutions in a number of ways. First, they can provide the financial resources that are essential for developing or upgrading services in transportation, healthcare, energy, housing and other relevant sectors. Second, they can provide a legal framework that allows municipalities to legislate and enforce new rules and by-laws governing urban emissions and vulnerability.

Chapter 6, by Joana Setzer and colleagues, shows that São Paulo was able to enact its own climate change legislation, building upon the "shared jurisdiction that exists between the national government, subnational states, the Federal District and municipalities, to protect the environment and fight pollution in any form." Chapter 7, by Sarah Burch and colleagues, finds that municipal efforts to integrate climate change into urban policy were directly influenced by the incentives put in place by British Columbia's Climate Action Charter. Alexander Aylett's analysis in Chapter 9 suggests that Portland's ability to enact climate change policies was dependent upon a constitutional system that recognizes the authority of municipalities to regulate water and waste management, energy efficiency and land use. Chapter 10, by Patricia Romero-Lankao and colleagues, finds that Mexico City's constitutional status as a Federal District conferred a special authority that enabled it to enact its own climate change legislation, in advance of Mexico's national climate bill in 2012.

What this suggests is that urban climate policy innovations are to a large degree dependent upon larger political systems that drive and divide the power to regulate energy, transportation, health, infrastructure and other relevant sectors at multiple levels of governance. This is not to suggest that cities are irrelevant to governing climate change, but that they are important, if often dependent, actors with contingent effectiveness. In some instances (e.g., in Mexico and Canada), the separation of formal, constitutional powers appears to have facilitated a coordination of effort that appears to be lacking in unitary regimes, such as Chile (Chapter 10) or Tanzania (Chapter 11).

In others, city-state relations appear to have created a dynamic in which urban and provincial leaders were able to frame their efforts to tackle climate change in relation to the perceived failures and shortcomings of national policy. In Brazil, for instance, São Paulo's municipal climate initiative was inspired largely in response to the federal government's inability to implement effective climate legislation of its own. In Mexico, Argentina and Chile, municipal climate change actions were "led by state governments, sometimes in spite of the lack of comprehensive or ambitious climate change policy at the national level." Finally, in British Columbia (the CAC) and Portland, policy innovations were framed in relation to their federal governments' failed effort to follow through on national commitments to the Kyoto Protocol and the UNFCCC. 
Drawing upon "constructivist" traditions in policy studies and political science, framing theories help to highlight the idea that policy decisions are not necessarily the result of rational decision making (e.g., cost-benefit analysis) or interest group formation, and that the power that is used to influence policy decisions may reflect the popularity of a particular narrative "whose time has come" (e.g. Kingdon, 2003; cf. Finnemore and Sikkink, 1998; True et al., 2007). Bulkeley (2000: 734), for instance, argues that policy networks can be usefully understood in relation to "the shared terms and concepts through which meaning is assigned to social and physical processes and the nature of the policy problem." Central to this conceptualization is the idea that "discourse coalitions" construct storylines whose actors and adherents articulate a shared understanding of policy problems and agendas (Hajer, 1995; Bulkeley, 2000). Discourse coalitions and policy networks are by no means "fixed" in this process; rather, the assumption is that actors may draw upon a variety of different storylines, highlighting the role of power and conflict in discursive politics (Hajer, 1995; Bulkeley, 2000).

A number of chapters highlight the role of policy frames in facilitating the formation and implementation of urban climate change initiatives. Burch and colleagues (Chapter 7), for instance, found that political consensus about the need to incorporate climate change into urban planning was more effective when it was framed in relation to a broader "sustainability approach," as opposed to a more limiting climate change agenda:

One key finding from all four cities is that integrating climate change planning in a broader sustainability framework increases the breadth of actors/stakeholders enrolled in planning (e.g. transportation, energy, water, etc.), and it is expected that with implementation, more actors will also be engaged in the process of operationalizing climate action in practice.

Similarly, Aylett found that Portland's Office of Sustainable Development (OSD) played a critical role in facilitating support for climate policy initiatives across a number of municipal bureaucracies (Chapter 9). In Aylett's words, climate change became "a relational issue, an issue that acts as a nexus for the intersection of multiple other institutional interests."

What this suggests is that ideas, goals and language may be "framed" in a way that fosters a wider constituency of support for new climate policy initiatives. Beyond the (relatively inconsequential) act of incorporating "climate-smart" terms and priorities into urban policy discourse, a critical point here is that greenhouse gas emissions and vulnerability to climatic hazards are being established as a central part of operational and planning structures (cf. Chapter 7). As with other concerns that are central to municipal operational and planning structures, there will be variance in 
the effectiveness of planning efforts. But this variance does not diminish the importance of bringing the concern into cities' most basic governance structures.

\section{GOING GLOBAL: UNDERSTANDING THE ROLE OF TRANSNATIONAL NORMS AND NETWORKS}

A second theme in the volume concerns the ways in which cities are engaging with global climate governance processes and systems. As noted in the introductory chapter, urban engagement in global climate politics has evoked two particular lines of inquiry. First, how are cities affecting global climate politics? Second, how are global climate norms and networks influencing climate change policies and priorities at the urban scale? Each of these we now address in turn.

\section{How Are Cities Affecting Global Climate Politics?}

As noted in Chapter 1, considerable attention has been paid to the agency of cities in affecting global environmental governance regimes. Gordon and Acuto's chapter on the C40 (Chapter 4) suggests that city networks have played a key role in advocating and facilitating changes in policy and in technical cooperation among member cities. At the heart of their analysis is a critical reflection about the "discursive, tactical and organizational" strategies cities and city networks have used in legitimating their place within the global climate regime. "Discursive strategies" entail the political terms and discourses used to reposition "cities as 'leaders' and as central points through which both the causes and solutions to climate change must pass." Tactical strategies include efforts to "supplement, augment, or enhance governance capacity" through strategic alliances with corporations (such as Siemens and ARUP), multilateral donors (such as the World Bank) and other urban climate alliances (such as ICLEI and the Clinton Climate Initiative). Finally, organizational strategies are conscious efforts to reconfigure the network by strengthening internal rules and procedures, encouraging and reviewing the performance of the membership.

As Bulkeley (2000: 744) argues, "Networks provide structured social relations and rules, which enable and constrain policy change, through allowing some actors, and some ideas into the policy process while excluding others." Gordon and Acuto suggest that the C40 has been able to establish itself as a legitimate actor both in terms of influencing urban climate policy (see below) and in shaping global climate governance. However, like any large network, it also faces the challenge of balancing the coherence that is necessary for pushing an ambitious climate agenda while at the same time maintaining the flexibility that is essential for maintaining membership 
within the network. More broadly, the chapter highlights the challenges of working within the confines of an inter-state system:

On one hand, cities may be co-opted back into the status quo system of state-centric governance and attempt to either reproduce inter-state relations or be swallowed up by them. On the other, the structural imperative to legitimate claims to governance authority has the potential to crush the innovative, locally adaptive nature of city-network governance thus robbing them of their capacity for innovation and experimentation.

To what extent are cities and transnational urban networks able to transcend these pervasive structural and geopolitical constraints? In one sense, cities and networks like ICLEI and the C40 are clearly bound by the rules of an international system (e.g., the UNFCCC) that affords ultimate sovereignty and authority to individual nation-states. In another, they are part of a larger dynamic that is itself reconfiguring the nature of geographical and temporal scales.

In Chapter 2, Saskia Sassen argues that cities have created (and are continuously creating) new forms or "articulations" of human-environment interaction that transcend pre-existing scales of analysis and interaction. On one hand, cities produce "ruptures" in the "biospheric cycles" that underlie the global climate system. On another, they are "a frontier space for new types of environmentally sustainable energy sources, construction processes, and infrastructures." Understanding and reconciling these seemingly contradictory forces, she argues, entails recognizing the fact that cities are operating at multiple scales that frequently transcend the administrative boundaries of municipal governance. In her own words,

the city ... functions both at the diverse scales that constitute the city (for instance, household, neighborhood, city center) and at a planetary scale insofar as all cities share certain features (vast numbers of buildings, vast amounts of garbage, mass-transport, and so on).

A key point here is that new flows of finances, resources, technologies and populations create new forms of temporal and spatial connections that change the scale at which cities interact with wider, planetary systems, highlighting an important distinction between levels and scales:

What is sometimes described as a change of scales may merely be a change of level. A change of scale results in new interactions and relationships, often a different organization. Level, on the other hand, is a relative position in a hierarchically organized system.

Distinguishing between the multilevel and multi-scalar dimensions of urban climate governance provides an important means of understanding the role of cities in the global climate regime. Conceptually, it helps to differentiate 
between the formal power that local authorities are able to exercise in relation to land use and transportation (these are primarily questions of multilevel governance) and the wider scales that affect and are affected by resource needs and decisions at different scales of interaction. Theoretically, the emphasis on the spatial and ecological dimensions of scale also provides an important means of conceptualizing change. As Sassen and Dotan (2011: 832) have argued, interactions across scales are:

... not only a question of larger or smaller, but rather that the phenomenon itself changes. Unstable systems become stable, bottom-up control incorporates elements of top-down control as it shifts scales upward, and what is competition at a lower scale may become less important and interactions of differences more important at a larger scale.

What this implies is that cities have internal dynamics and global interactions that transcend conventional forms of governance and analysis. According to Sassen, existing modes of understanding and governing global climate challenges (e.g., adaptation, mitigation and the UNFCCC) are ill equipped to address the complexities of urban and global environmental change.

Building upon Sassen's analysis, De Flander (Chapter 3) focuses on the ability of cities to close urban resource cycles (i.e., the connections between urban consumption and resource flows and production) as a means of restoring planetary ruptures in the Earth's climate system. At the heart of her analysis is a conceptual framework that explores different scenarios involving variations in urban resource production, resource consumption, scale of the (closed) resource cycle area and population density. The ability of cities to close existing resource cycles, she argues, entails an integrated effort to modify urban lifestyles and consumption.

An important point that emerges from De Flander's analysis is the impact of theoretical plans and models on urban policy and practice. As noted in Chapter 1 , there is now a growing body of evidence to suggest that cities and transnational urban coalitions have used the language of the Kyoto Protocol and of climate change more generally to justify new forms of policy and investment at the urban scale (Bulkeley and Broto, 2012; Bulkeley and Betsill, 2013). However, the dissemination of climate policy norms is uneven (Acuto, 2013), reflecting large disparities in the size, capacity and leadership of urban governance institutions. Moreover, the geographical, institutional and discursive ties that connect cities and urban actors with global environmental regimes vary enormously, suggesting considerable room for empirical research.

\section{How Are Global Regimes Affecting Urban Climate Policies and Priorities?}

Many of the chapters in this volume provide evidence to suggest that transnational urban climate networks, particularly ICLEI and the C40, have been 
instrumental in shaping urban responses to climate change. For instance, São Paulo's participation in ICLEI's Cities for Climate Protection (CCP) campaign entailed the development of a GHG emissions inventory, the establishment of emissions reductions targets and the development of a Local Action Plan for climate change mitigation (Chapter 6). On the basis of its early involvement, the city also participated in a number of seminal international climate change discussions, including the annual Conference of Parties to the UNFCCC and the launch of the C40 in 2005. With the benefit of international funding, São Paulo introduced a number of innovative mitigation measures, including landfill methane gas recovery projects, a clean fuel program for public transit and an automobile emissions inspection program. Although its involvement was far less extensive than São Paulo, Mumbai is currently working with the India-based TERI and the UK Meteorological office in preparing a strategy for adaptation and disaster risk reduction in the context of urban flooding (Chapter 8). Finally, Santiago and Buenos Aires both developed emissions inventories with the assistance of ICLEI technical cooperation and funding (Chapter 10).

What this suggests is that access to the aid and technical assistance of transnational urban networks, donors and UNFCCC mechanisms was instrumental in the development of innovative urban climate policy initiatives.

Chapter 5, by Sofie Bouteligier, explores another vital source of influence: the role of multinational corporations. As noted in Chapter 1, companies like Cisco, Siemens and ARUP have become increasingly active in developing climate-smart policies for cities around the world. In Chapter 5, Bouteligier argues that growing demand for corporate urban planning services reflects both a lack of knowledge and capacity on the part of many municipalities and the growing field of urban environmental engineering and consulting. In so doing, she raises interesting questions about the impact of MNCs on urban plans and priorities, the nature of these plans and priorities and the implications for the study of corporate power in global governance regimes.

On the question of impact, Bouteligier's analysis suggests that MNCs are now shaping a wide range of urban climate policy initiatives, from writing and advising urban climate plans (e.g., ARUP in Ho Chi Minh City and Melbourne) to harmonizing urban transportation systems (e.g., Siemens in London) and developing applications for reducing carbon footprint (e.g., Cisco in Amsterdam). According to Bouteligier, the plans and priorities being developed by MNCs like Siemens and ARUP are primarily "market-based" in the sense that they are working with the private sector in the development of systems and infrastructure that can be replicated and conceivably sold to municipalities around the world. At the heart of many corporate models (and ability to create markets for urban climate consulting) is an ability to diagnose the problems for which MNCs are able to prescribe and implement policy solutions.

One important theme that emerges from the analysis of MNCs (Chapter 5) and transnational urban networks (Chapter 4) is the standardization 
and possible homogenization of urban climate policy. Insofar as cities are buying or receiving technical assistance from companies, transnational networks, donors and the UNFCCC it appears likely that many of these policies will replicate the practices (and limitations) of generic approaches to urban climate governance. The development of greenhouse gas emission inventories is a popular case in point.

Is this necessarily a problem? On one hand, corporations, networks, donors and the UNFCCC are clearly filling a need that stems from a lack of domestic urban capacity (cf. Chapters 6 and 11). On the other, they are perhaps working at odds with the processes of innovation and experimentation that are often ascribed to urban systems (cf. Chapters 1 and 2). If cities are simply adopting corporate packages and policies, the scope for experimentation appears limited, although this of course is an empirical question (see below). Moreover, the profile of mitigation opportunities and adaptation needs may differ significantly from one city to the next, limiting the effectiveness of one-size-fits-all policy development.

A broader question concerns the impact of urban climate governance models on the distribution of power and influence within the international system. As noted in Chapter 1, cities occupy an ambiguous place in the study of global governance regimes, reflecting their lack of formal political authority in relation to sovereign nation-states. A number of chapters in this volume (e.g., Chapters 2, 3, 4 and 5) raise the possibility that climate change (as a phenomenon and a realm of political agency) is changing the relative power of cities within the international system. Here a number of interesting questions can be raised about the extent to which global norms and priorities (including urban climate planning models) are affecting this equation.

Drawing upon Finnemore and Sikkink's distinction between "regulative norms, which order and constrain behavior and constitutive norms, which create new actors, interests, or categories of action" (Finnemore and Sikkink, 1998: 891), there is ample evidence to suggest that the UNFCCC, the Kyoto Protocol and-critically-the perceived failure of the Kyoto Protocol have created the conditions for new forms of regulative and constitutive norm formation. In Chapters 4, 5, 6, 8, 10 and 11, we can see that cities and transnational urban networks, such as ICLEI and the C40, have used the terms and norms of UNFCCC targets to "order and constrain" the behavior of individual member cities, even while operationalizing these norms in new ways. We can also see that local efforts to engage with climate change have occurred in response to a perceived failure of the Kyoto Protocol. At the same time, there is evidence to suggest that urban officials have used the norms and terms of the UNFCCC to justify inaction on climate change issues and priorities. For example, urban planners in Mumbai expressed strong reservations about investing in adaptation measures, arguing it was instead "an international responsibility to provide resources" (Boyd et al., Chapter 8).

What this suggests is that global norms and institutions are being used strategically to justify various forms of action and inaction (cf. Boyd 
et al., Chapter 8). Whether these norms have force-and whether they actually encourage efforts to curb emissions and vulnerability to climate change-depends on the strength of networks and global governance institutions in organizing, enforcing and implementing global environmental regimes.

This brings us to the terms on which we evaluate policy.

\section{WHAT CONSTITUTES SUCCESS?}

The chapters in this volume examine a wide array of policies, decisions and outcomes that may be loosely associated with successful urban climate governance. Making sense of these initiatives is a complex undertaking-measuring their effectiveness is fraught with difficulty. Indeed, as Bouteligier points out in Chapter 5, the cities that are typically characterized as "exemplars" in the field of urban climate governance (e.g., London, New York) are also the ones with the largest ecological footprints.

As noted in Chapter 1, the development of roads, suburbs and public services, the consumption of food and energy and the production of goods, services and sectors all create potential rigidities that have strong bearing on the ability of urban systems to act and react to changing environmental conditions (cf. Sassen and Dotan, 2011; Kennedy, 2011). Overcoming the rigidities put in place by years of investment (or lack thereof) in particular modes of transportation, electricity generation, sanitation, water treatment, and so on entails an ability to understand the costs and potential risks of maintaining the status quo and an ability to mobilize (public and private) resources in the name of (long-term) infrastructural development (cf. Ostrom, 1990; Moser and Luers, 2008; World Bank, 2010; Kennedy, 2011).

Theories of adaptive social learning identify three inter-related aspects of what these challenges may entail:

- Path-dependence, which implies the existence of rules, norms and associated cultural practices that prevent social actors from acting in ways that might reduce vulnerability to undesirable environmental change (cf. North, 1990)

- A failure to learn from past experiences and events, highlighting the ability of institutions to build knowledge and experience for the purposes of future action (Armitage et al., 2008; Pahl-Wostl, 2009; Tschakert and Dietrich, 2010)

- A failure to anticipate future scenarios, highlighting the extent to which social actors are able to question norms, challenge rules and change destructive patterns of behavior (Armitage et al., 2008; Pahl-Wostl, 2009; Tschakert and Dietrich, 2010).

In conceptualizing adaptive social learning, Pahl-Wostl (2009: 358-9) employs the idea of "triple-loop learning" to conceptualize the ways in which new 
ways of acting and thinking may be able to challenge past path-dependencies (cf. Armitage et al., 2008). "Learning," she contends, "is assumed to be an exploratory, stepwise search process where actors experiment with innovation until they meet constraints and new boundaries" (Pahl-Wostl, 2009: 358). Framed in this way, single-loop learning implies an incremental refinement of established routines aimed at improving performance without necessarily challenging or changing potentially destructive human practices. Double-loop learning involves an effort to question and reframe the assumptions on which past practices have been based. Finally, triple-loop learning implies a substantive transformation in which dominant and potentially destructive practices are overturned in favor of new institutional norms and practices.

To understand the various measures being used to reduce emissions and vulnerability to climate change, we characterize policy changes in relation to these three forms of learning. For simplicity, we will call them adoption (single-loop learning), experimentation (double loop) and transformation (triple loop).

Perhaps the most common form of policy change being documented in this volume falls under the heading of adoption. If adoption implies an incremental refinement of established routines aimed at improving performance, many of the global norms being put in place by local municipalities entailed the adoption or expansion of UNFCCC targets or the implementation of international metrics for measuring greenhouse gas emissions. Portland, for instance, expanded upon the Kyoto target by aiming to reduce overall emissions by $80 \%$ below 1990 levels by 2050. Similarly, cities like Ho Chi Minh City (Chapter 5), São Paulo (Chapter 6) and Mumbai (Chapter 8) adopted plans and codes that were developed in collaboration with MNCs, transnational networks and international bodies.

Far less common was the kind of experimentation being discussed in the comparative literature on urban climate policy innovation (e.g., Bulkeley and Broto, 2012). If experimentation involves an effort to question and reframe the assumptions on which past practices have been based, there is limited evidence to suggest that urban planners and politicians in cities like Portland, São Paulo and Mexico City recognized the need to introduce measures aimed at reducing emissions and vulnerability to climate change, but that their ability to reframe the assumptions of urban development was constrained by their lack of capacity and authority to regulate the myriad factors influencing rapid and often unplanned urban growth.

Notably some of the most important assumptions being questioned in the volume relate to two central terms in the UNFCCC: adaptation and mitigation. Both Sassen (Chapter 2) and De Flander (Chapter 3), for instance, contend that efforts to address urban emissions and vulnerability to climate change will entail an ability to move beyond the technocratic discourse of the UNFCCC and the IPCC in favor of a substantive change in urban consumption and living.

Finally, a number of chapters in the volume focus on the possibilities of urban transformation. Here, the chapters by Sassen and De Flander offer 
a number of normative insights about the nature of sustainable urban climate governance. At the heart of their analysis is the notion that sustainable urban transformation will entail a wholesale change in the ways in which cities understand, govern and consume resources and energy. Beyond the role that planning and experimentation can play in this process are the systems of knowledge that inform our understanding of urban-climate dynamics. A number of chapters highlight the importance of science and data in developing urban climate policies (e.g., Chapter 10).

That said, participation in global climate governance institutions does appear to provide opportunities for incremental learning that may lead to longer-term policy change. As Bouteligier (Chapter 5) points out,

Sustainability transitions ideally consist of long-term, mid-term and short-term horizons, suggesting changes in culture, structures, and practices . . . short-term, small-scale projects can be part of broader sustainability transitions. They are important sources of inspiration for other cities and even governments at other levels, as they are often used as laboratories to experiment with new technologies and approaches. They can also generate support for a broader policy within one city.

Here the analysis of policy changes in Portland (Chapter 9) and in British Columbia (Chapter 7) suggests that smaller incremental changes can lead to more dramatic organizational and institutional transformations. As Burch and colleagues (Chapter 7 ) point out,

The urban scale becomes an interesting test-bed to investigate the co-benefits of embedding climate change into broader sustainability goals.

And in more detail, Sassen identifies the "multiple ecologies that enable the mixing of diverse forms of knowledge and diverse technologies."

Cities are sites where these challenges can be studied empirically and where policy design and implementation often is more feasible than at the national level, partly because it comes down to a kind of practical engagement, rather than, for instance, law-making as is often the case at the national level.

Here it is also worth noting that many of the cities being documented in these chapters were also international leaders in urban climate governance. Portland, for instance, was "the first city in the United States (and among the first in the world) to enact a climate change strategy" (Aylett, Chapter 9). Mexico City was one of the first Latin American cities to adopt its own climate change plan. Portland and São Paulo were two of the earliest members of ICLEI.

A related theme concerns the role of sequencing. Contrary to the intuitive assumption that cities will be more likely to prioritize adaptation measures that arguably have more direct bearing on urban priorities, such as health, 
flood control and disaster management, the cases in this volume suggest that municipalities were actually more likely to introduce mitigation measures in advance of adaptation. In Latin America, for instance, all three cities introduced emissions inventories long before incorporating what appears to have been a relatively weak form of adaptation for disaster risk reduction (Chapter 10). Similarly, municipalities in BC adopted mitigation measures in advance of adaptation (Chapter 7).

One possible explanation for sequencing mitigation in advance of adaptation is that it is less costly for cities to legislate energy efficiency and transportation reforms than it is to invest in aging infrastructure. Another possibility is that, until recently, mitigation has traditionally been promoted more forcefully and with more funding (e.g., through the CDM) than has adaptation. Whatever the case, exploring the balance of sequencing mitigation and adaptation provides an interesting field for future research.

A final and critical issue relates to what we might call the political ecology of urban climate governance. Assuming that the spatial distribution of environmental externalities can often be highly uneven, questions can be raised about the extent to which marginal populations are being affected by urban climate policy. Here the chapters on India and Africa (Chapters 8,10 and 11) provide the most compelling evidence that policies aimed at curbing emissions and vulnerability to climate change are also affected by questions of power and socio-economic status. According to Boyd and colleagues (Chapter 8), "climate change governance (in Mumbai) is at present still an elite issue," highlighting the relationship between environmentalism and socio-economic status. Similarly, making reference to Europe, Bouteligier points out that the most innovative policy experiments and projects "are often limited to privileged neighborhoods in cities" (Chapter 5).

A number of chapters also highlight the fact that increasing emissions and vulnerability to climate change are also occurring in a context of globalization and neo-liberal policy reform (e.g., Chapter 2, 3, 5, 8, 10). As Romero-Lankao and colleagues point out (Chapter 10), economic liberalization in Mexico, Argentina and Chile has led to the privatization of housing, infrastructure and public services, thereby exacerbating the vulnerability of poor and marginal populations to a wide range of environmental and economic stressors. Similarly, Gore (in Chapter 11) highlights the vicious cycle of poverty, weak governance capacity and climate vulnerability in African cities like Dar es Salaam.

Insights about the distributional consequences of urban climate policy raise larger questions about the ways in which past struggles, decisions, changes and "ruptures" affect contemporary development pathways.

\section{NEW DIRECTIONS FOR FUTURE RESEARCH}

By way of conclusion, this section now identifies a number of areas of interest for future empirical research. As noted earlier, the chapters in this 
volume highlight four sets of questions about the study of cities in global climate governance regimes. First, under what conditions are cities incorporating climate change into urban planning and policy? Second, how and in what ways are cities engaging with global environmental governance processes and systems? Third, what is the impact of international climate change norms on urban and domestic climate politics? And fourth, what are the implications for the study of international relations and global environmental governance?

On the first question, a number of questions present themselves. First, what are the constituencies of support that facilitate effective policy change? Several chapters in the volume (e.g., Chapters 5, 8, 10 and 11) highlight the class dimensions of urban climate policy formation. Others (e.g., Chapters 7 and 9) highlight the importance of institutions and discourses. A more general question concerns the factors affecting successful implementation of climate policy objectives. As Burch and colleagues point out, more needs to be known about the conditions under which plans and stated policies are turned into tangible actions on the ground.

The second question is about the ways in which cities and city networks are engaging in global environmental governance regimes. Here important questions can be raised about the factors affecting participation, the strategies networks are using to organize and effect policy and the extent to which networks are addressing free riding among members. Questions can also be raised about the normative goals of transnational urban agency, and the extent to which transnational urban alliances are crafting an alternative to the UNFCCC.

The third set of questions is about norm diffusion within the international system. To what extent is participation in international networks, such as ICLEI and the C40, effecting tangible changes at the urban scale? Through what mechanisms are these changes occurring? What role do multinational corporations play in this process? As noted in Chapter 1, the geographi$\mathrm{cal}$, institutional and discursive ties that connect cities and urban actors with global environmental regimes vary enormously, suggesting considerable room for empirical research. How, for instance, do geopolitical spheres of influence affect the adoption of urban climate governance norms and policies? To what extent do geopolitical ties facilitate other policy channels?

Finally, the last set of questions is about the ways in which we theorize the role of cities in the international system. A number of chapters in this volume (e.g., Chapters 2 and 4) highlight the idea that existing theories of international relations and global governance are inadequate for understanding the role of cities in global climate governance regimes. Because they play such a large role in global emissions and because they are particularly vulnerable to the effects of climate change, cities have assumed, or have at the very least been associated with, responsibility for taking action on climate change. Whether cities are adopting, experimenting with or transforming global governance mechanisms, more can be written and said about 
the ways in which cities and city networks affect our understanding of the international system.

\section{BIBLIOGRAPHY}

Acuto, Michele (2013) “The New Climate Leaders?" Review of International Studies 39: 835-7.

Amen, Mark, Noah J. Toly, Patricia McCarney, and Klaus Segbers, eds. (2011) Cities and Global Governance: New Sites for International Relations. London: Ashgate.

Armitage, D., M. Marschke, and R. Plummer (2008) "Adaptive Co-management and the Paradox of Learning." Global Environmental Change 18: 86-98.

Berkes, Fikret (2009) "Evolution of Co-management: Role of Knowledge Generation, Bridging Organizations and Social Learning." Journal of Environmental Management 90 (5): 1692-1702.

Berkes, F. and C. Folke (1998) "Linking Social and Ecological Systems for Resilience and Sustainability." In F. Berkes and C. Folke (Eds.), Linking Social and Ecological Systems. Cambridge: Cambridge University Press, 1-26.

Betsill, M. \& H. Bulkeley (2004) "Transnational Networks and Global Environmental Governance: The Cities for Climate Protection Program." International Studies Quarterly 48: 471-93.

Betsill, M. \& H. Bulkeley (2006) "Cities and the Multilevel Governance of Global Climate Change." Global Governance 12: 141-59.

Bhagat, R. B. and Soumya Mohanty (2009) "Emerging Pattern of Urbanization and the Contribution of Migration in Urban Growth in India." Asian Population Studies 5 (1): 5-20.

Bouteligier, Sofie (2012) Cities, Networks, and Global Environmental Governance. New York: Routledge.

Bulkeley, H. (2000) "Discourse Coalitions and the Australian Climate Change Policy Network." Environment and Planning C: Government and Policy 18: 727-48.

Bulkeley, H. (2010) "Cities and the Governing of Climate Change." Annual Review of Environment and Resources, 229-53.

Bulkeley, H. and M. Betsill (2005) "Rethinking Sustainable Cities: Multilevel Governance and the 'Urban' Politics of Climate Change." Environmental Politics 14 (1): 42-63.

Bulkeley, H. and M. Betsill (2013) "Revisiting the Urban Politics of Climate Change." Environmental Politics 22 (1): 136-54.

Bulkeley, H. and V. Broto (2012) "A Survey of Urban Climate Change Experiments in 100 Cities." Global Environmental Change 23 (1): 92-102.

Curtis, S. (2011) "Global Cities and the Transformation of the International System." Review of International Studies 37 (4): 1923-47.

Finnemore, M. and K. Sikkink (1998) "International Norm Dynamics and Political Change." International Organization 52 (4): 887-917.

Folke, C. (2006) "Resilience: The Emergence of a Perspective for Social-Ecological Systems Analysis." Global Environmental Change 16: 253-67.

Folke, C., T. Hahn, P. Olsson, and J. Norberg (2005) "Adaptive Governance of Social-Ecological Systems." Annual Review of Environment and Resources 30: $441-73$.

Hajer, M. (1995) The Politics of Environmental Discourse: Ecological Modernization and the Policy Process. Oxford: Clarendon Press.

IPCC (Intergovernmental Panel on Climate Change, WG II) (2014) "Chapter 8: Urban Areas." Retrieved 5 August 2014 from http://ipcc-wg2.gov/AR5/images/ uploads/WGIIAR5-Chap8_FGDall.pdf 
Kennedy, C. (2011) The Evolution of Great World Cities: Urban Wealth and Economic Growth. Toronto: University of Toronto Press.

Kingdon, J. (2003) Agendas, Alternatives and Public Policies. 2nd ed. Toronto: Longman Press.

Moser, S. and A.L. Luers (2008) "Managing Climate Risks in California: The Need to Engage Resource Managers for Successful Adaptation to Change." Climatic Change 87 (Supplement 1): S309-S322.

North, D. (1990) Institutions, Institutional Change and Economic Performance. Cambridge: Cambridge University Press.

Ostrom, Elinor (1990) Governing the Commons: The Evolution of Institutions for Collective Action. Cambridge: Cambridge University Press.

Ostrom, Elinor (2010) "Polycentric Systems for Coping with Collective Action and Global Environmental Change." Global Environmental Change 20: 550-7.

Pahl-Wostl, C. (2009) “A Conceptual Framework for Analysing Adaptive Capacity and Multi-level Learning Processes in Resource Governance Regimes." Global Environmental Change 19: 354-65.

Romero-Lankao, P. and D. Dodman (2011) "Cities in Transition: Transforming Urban Centers from Hotbeds of GHG Emissions and Vulnerability to Seedbeds of Sustainability and Resilience." Current Opinion in Environmental Sustainability 3: 113-20.

Romero-Lankao, P. and Hua Qin (2011) “Conceptualizing Urban Vulnerability to Global Climate and Environmental Change." Current Opinion in Environmental Sustainability 3: 142-9.

Sabatier, P. A. and C. M. Weilbe (2007) “The Advocacy Coalition Framework: Innovations and Clarifications." In P. Sabatier (Ed.), Theories of the Policy Process. Boulder: Westview Press, 189-222.

Sassen, S. (2001) The Global City. 2nd ed. Princeton: Princeton University Press.

Sassen, S. (2006) “Chicago's Deep Economic History: Its Specialized Advantage in the Global Network.” In R.P. Greene, M. J. Bouman, and D. Grammenos (Eds.), Chicago's Geographies: Metropolis for the 21st Century. Washington, DC: American Association of Geographers, 75-86.

Sassen, S. and N. Dotan (2011) "Delegating, not Returning, to the Biosphere: How to Use the Multi-scalar and Ecological Properties of Cities." Global Environmental Change 21: 823-34.

Tanner, T., T. Mitchell, E. Polack, and B. Guenther (2009) "Urban Governance for Adaptation: Assessing Climate Change Resilience in Ten Asian Cities." IDS Working Paper 315. Brighton: Institute of Development Studies.

Toly, Noah J. (2008) "Transnational Municipal Networks in Climate Politics: From Global Governance to Global Politics.” Globalizations 5 (3): 341-56.

Toly, Noah J. (2011) "Cities, the Environment, and Global Governance: A Political Ecological Perspective.” In Mark Amen, Noah J. Toly, Patricia L. McCarney, and Klaus Segbers (Eds.), Cities and Global Governance: New Sites for International Relations. Burlington, VT: Ashgate, 137-50.

Toly, Noah J., Sofie Bouteligier, Graham Smith, and Ben Gibson (2012a) "New Maps, New Questions: Global Cities beyond the Advanced Producer and Financial Services Sector." Globalizations 9 (2): 289-306.

Toly, Noah J., Sofie Bouteligier, Graham Smith, and Ben Gibson (2012b) “American Cities, Global Networks: Mapping the Multiple Geographies of Globalization in the Americas." URBE: Revista Brasiliera de Gestao Urbana 4 (1): 73-86.

True, J., B. Jones, and F. Baumgartner (2007) "Punctuated Equilibrium Theory: Explaining Stability and Change in Public Policy Making.” In P. Sabatier (Ed.), Theories of the Policy Process. Boulder: Westview Press, 155-88.

Tschakert, P. and K.A. Dietrich (2010) "Anticipatory Learning for Climate Change Adaptation and Resilience.” Ecology and Society 15 (2). Retrieved 31 August 2014 from http://www.ecologyandsociety.org/vol15/iss2/art11/ 
Viotti, P. and M. Kaupi (2010) International Relations Theory. 4th ed. Toronto: Longman.

Weible, C. M., P. A. Sabatier, and K. McQueen (2009) "Themes and Variations: Taking Stock of the Advocacy Coalition Framework." Policy Studies Journal 37 (1): 121-40.

World Bank (2010) Cities and Climate Change: An Urgent Agenda. Washington, DC: World Bank. 
$\Longrightarrow$ Taylor \& Francis

Taylor \& Francis Group

http://taylorandfrancis.com 


\section{Contributor Bios}

\section{EDITORS}

Craig Johnson is Associate Professor of Political Science and International Development Studies at the University of Guelph in Canada. His research focuses on questions of land and resource governance in the context of urbanization, globalization and climate change. Dr. Johnson holds a $\mathrm{PhD}$ in International Development from the London School of Economics, and has taught at the London School of Economics, the School of Oriental and African Studies, University College London and the University of Oxford. In 2009, he was an ESRC-SSRC Visiting Fellow with the Tyndall Centre for Climate Change Research and the Environmental Change Institute, both at the University of Oxford. In 2013, he was a Senior Visiting Fellow with the Institute for Advanced Sustainability Studies (IASS) in Potsdam, Germany. Dr. Johnson is currently leading an international team of researchers investigating the globalization of urban land markets in India, Bangladesh and Viet Nam. He has published widely in the field of development, focusing primarily on questions of governance, livelihoods and the environment. He is the author of Arresting Development: The Power of Knowledge for Social Change (Routledge, 2009) and co-editor of Policy Windows and Livelihood Futures: Prospects for Poverty Reduction in Rural India (Oxford University Press, 2006).

Heike Schroeder is a Senior Lecturer in Climate Change and International Development at the School of International Development, University of East Anglia. Her areas of work include global environmental politics, urban climate governance, the role of non-state actors in international cooperation on climate change and forest governance. She is also a coordinator of the governance theme in the Tyndall Centre for Climate Change Research and a member of the Scientific Steering Group of the long-term international research project on Earth System Governance under the auspices of the International Human Dimensions Programme on Global Environmental Change (IHDP). From 2007 to 2011, she was a 
Tyndall Senior Research Fellow and a James Martin Senior Research Fellow in forest governance at the Environmental Change Institute, University of Oxford. From 2003 to 2007, she was at the Bren School of Environmental Science and Management, University of California, Santa Barbara.

Noah Toly is Director of Urban Studies and Associate Professor of Politics and International Relations at Wheaton College in the United States (IL). His research and teaching interests are at the intersections of urban and global environmental governance, with particular interests in the participation of cities as sites and municipalities as actors in climate governance regimes. He holds the PhD in Urban Affairs and Public Policy from the University of Delaware. Before joining the faculty at Wheaton College, he worked as a Policy Fellow at the Center for Energy and Environmental Policy. In addition to urban and global environmental governance, he has substantial interests in religion and globalization and was appointed as a Senior Fellow at the University of Chicago's Martin Marty Center for the Advanced Study of Religion for the 2012-2013 academic year. He has also been named an Emerging Leader by the Chicago Council on Global Affairs. He has co-edited or co-authored five books and numerous articles, book chapters and essays. He is also the editor of the Routledge Series Cities and Global Governance.

\section{CONTRIBUTORS}

Michele Acuto is currently Research Director, and Senior Lecturer in Global Networks and Diplomacy, in the Department of Science, Technology, Engineering and Public Policy (STEaPP) at University College London. $\mathrm{He}$ is also a Fellow of the Institute for Science, Innovation and Society (InSIS) at the University of Oxford. Dr. Acuto is the author of The Urban Link (Routledge), editor of Negotiating Relief (Hurst), co-editor of Global City Challenges (with Wendy Steele) and Reassembling International Theory (with Simon Curtis) and of the series Cities and the Global Politics of the Environment (with Sofie Bouteligier), all for Palgrave Macmillan.

Alexander Aylett is an Assistant Professor in the Centre for Urbanization, Culture and Society at the Université INRS in Montreal. He was formerly a Banting Postdoctoral Fellow at the Massachusetts Institute of Technology and the Research Director at Sustainable Cities International. He holds a PhD in urban geography and sustainability planning from the Department of Geography of the University of British Columbia. He has worked as a sustainability researcher and consultant in North America and overseas and has strong policy analysis and project management 
skills. Dr. Aylett has expertise in integrated long-term climate and sustainability planning. He also has extensive experience studying the governance of urban sustainability transitions, institutional barriers to change and organizational innovation, as well as participatory sustainability planning and community-led program design and implementation. Mobilizing crosscutting sustainability transitions in complex urban systems has been the focus of both his research and consulting work.

Roxana Bórquez is a researcher at the Center for Climate and Resilience Research. She has a degree in Renewable Natural Resources Engineering (2007) and a Master in Management and Public Policy (2011) from University of Chile. Her research focuses on adaptation to global change, vulnerability of communities, environmental conflict and science-public policy interface. For ten years she has worked as a researcher in different international projects between Latin American countries, related to resilience to climate change, institutional adaptations, vulnerability of communities in rural and urban contexts on different levels (local, regional and national), capacity building in local governments to design measures to tackle climate change. She was part of the Expert Committee formed to participate in the elaboration of Chile's National Action Plan on Climate Change (2006) and participated in the Technical Committee of the "Glacier Protection Law Project in Chile" (2006).

Sofie Bouteligier is a policy advisor to the Government of Flanders, an Associate Fellow of the Leuven Centre for Global Governance Studies (KULeuven, Belgium) and a Senior Research Fellow with the City Leadership Initiative at University College London. She holds a $\mathrm{PhD}$ from the Faculty of Social Sciences at KULeuven and is the author of Cities, Networks, and Global Environmental Governance: Spaces of Innovation, Places of Leadership (Routledge, 2012), which is part of the Routledge series on Cities and Global Governance. Prior to taking up her current appointments, Dr. Bouteligier was a doctoral researcher at the Global Environmental Governance and Sustainable Development Research Group of the Faculty of Social Sciences at KULeuven (Belgium) (October 2006 until August 2011). From September 2011 until October 2012 she was a postdoctoral researcher at the Environmental Policy Group of Wageningen University.

Emily Boyd is a Professor in Resilience Geography at the Department of Geography and Environmental Science, University of Reading. She is also an Affiliated Senior Research Associate at the Stockholm Resilience Centre. She has a background in Development Studies (PhD, UEA) and Forestry and Land Use Change (MSc, Oxon). Emily's current research is focused on rethinking development under climate futures, in particular focusing on the politics of urban adaptation and the new carbon economy, 
and of ecosystem services and poverty alleviation. In particular, she is interested in the dynamics of change, question of scale, network linkages between local and global institutions, and the roles that are played by science, state, private and community actors in adaptive governance and livelihood transformations. Her previous research has centered on South America; currently she has projects ongoing in India and Africa.

Maxwell T. Boykoff is an Associate Professor in the Center for Science and Technology Policy, which is part of the Cooperative Institute for Research in Environmental Sciences at the University of Colorado-Boulder. He teaches in the Environmental Studies program and is Adjunct Faculty in the Geography Department. In addition, Max is a Senior Visiting Research Associate in the Environmental Change Institute at the University of Oxford. He holds a PhD in Environmental Studies from the University of California-Santa Cruz and Bachelor of Sciences in Psychology from the Ohio State University. Max has ongoing interests in climate adaptation, cultural politics and environmental governance, creative climate communications, science-policy interactions and political economy and the environment, and he has experience working in North America, Central America, South Asia and Europe. Max's research has concentrated on interactions between state and non-state actors at the interface of environmental science, policy and practice. He has been working in two primary research areas: (1) issues in the cultural politics of climate change, and (2) transformations of carbon-based economies and societies.

Sarah Burch is an Assistant Professor in the Department of Geography and Environmental Management, University of Waterloo, Canada. She holds a PhD in Resource Management and Environmental Studies from the University of British Columbia, Canada. Dr. Burch writes and speaks widely on processes for visualizing climate change at the community scale, barriers to effective climate change responses and sources of sustainability innovation. She is a Coordinating Lead Author in the Assessment Report on Climate Change in Cities (ARC3-2), and North American coordinator of the Earth System Governance network of Research Fellows.

Ann Dale, a Trudeau Fellow Alumna (2004), a Fellow of the World Academy of Art and Sciences, was recently awarded the 2014 CUFA Paz Buttedahl Distinguished Academic Career Award and in 2013, the Canada Council of the Arts Molson Prize for the Social Sciences.

Katleen De Flander a Research Fellow at the Institute for Advanced Sustainability Studies in Potsdam, Germany, and is a $\mathrm{PhD}$ candidate at the Institute for Urban and Regional Planning at the TU-Berlin. She holds an Architect degree from the University of Art and Science in Ghent, 
Belgium, and a Master's degree in Urban Environmental Management from Wageningen University, the Netherlands. Her research focuses on the relationship between cities and resources and how to bring about a transformation thereof.

Aditya Ghosh works at South Asia Institute, Heidelberg University, Germany, as a Research Associate pursuing his $\mathrm{PhD}$ after having worked for twelve years as a full-time journalist, editor and researcher with organizations such as Hindustan Times, The Times of India-two of India's and the world's largest English-language newspapers-and Centre for Science and Environment, India's premier think-tank. He contributes regularly to The Guardian and Reuters Alert Net on environmental issues as well. In his $\mathrm{PhD}$ project, he is attempting to develop a framework of climate-resilient development in the vulnerable ecosystem of Indian Sundarbans, the world's largest and a critically endangered mangrove ecosystem, by examining the existing adaptation discourse, their drivers and existing barriers in development policies, the socioeconomic, political constraints and existing climate governance. He has Master's degrees in Environment and Development (University of Sussex, UK, 2010) and in journalism (University of Calcutta, India, 1999).

Daniel M. Gnatz has a Master's in Coastal Management from the NOVA University. His work focuses on urban coastal development, vulnerability and risk. He has also done research on governance as it affects the capacity to mitigate and adapt to climate change in coastal areas.

David Gordon is a PhD candidate in the Department of Political Science at the University of Toronto conducting doctoral research on the internal dynamics of transnational urban climate governance networks. David has published on topics including intergovernmental coordination in federated states, domestic climate policy and the dynamics of network-city relations.

Christopher Gore is an Associate Professor in the Department of Politics and Public Administration, Ryerson University, and a Graduate Associate of the Environmental Applied Science and Management program. He holds a PhD in Political Science and Environmental Studies from the University of Toronto. Chris's research and teaching focuses on the politics, policy and administration of environmental and urban affairs, as well as technology and infrastructure. In recent years he has focused on cities and climate change in North America, and energy access, food security and natural resources in East Africa. He is currently engaged in a multiyear comparative research project in East Africa focused on urban food security and production. In East Africa he also continues to study energy policy, climate adaptation, urban governance and the politics of 
infrastructure access, including cyberinfrastructure. Chris is the editor of the journal Review of Policy Research: The Politics and Policy of Science and Technology, the official journal of the Science, Technology and Environmental Politics section of the American Political Science Association, and is co-editor of a new book series by Palgrave Macmillan, Urban Politics in a Global Society.

Jorgelina Hardoy has a degree in Geography from the University of Buenos Aires and an MA from Rutgers, the State University of New Jersey. She is a Senior Researcher at IIED-America Latina. Her work focuses on developing multi-stakeholder processes to improve environmental conditions and reduce social vulnerability and risk in low-income neighborhoods, including those related to climate change.

Sara Hughes is an Assistant Professor of Political Science at the University of Toronto. Her research focuses on urban politics, the institutions of local government, urban environmental policy and the politics of local climate change response. Prior to joining the University of Toronto Sara worked as a postdoctoral fellow at the U.S. Environmental Protection Agency and the National Center for Atmospheric Research. In 2013 she was named a Clarence N. Stone Scholar by the urban politics section of the American Political Science Association. Sara's current projects include a book examining the politics of urban sustainability in the U.S. and co-editing a collection of papers that explore the implications of climate change adaptation for urban governance globally. Recent publications include "Authority Structures and Service Reform in Multilevel Urban Governance: The Case of Wastewater Recycling in California and Australia," in Urban Affairs Review; "Science and Institution Building in Urban Climate Change Policy Making," in Environmental Politics; and "Voluntary Environmental Programs in the Public Sector: Evaluation of an Urban Water Conservation Program in California," in Policy Studies Journal.

Freya Kristensen is a $\mathrm{PhD}$ candidate in the Department of Geography at Simon Fraser University and holds a fellowship from the Pacific Institute for Climate Solutions (PICS). She has an MA in International Studies from the University of Northern British Columbia.

Fernando Rei is Professor of Environmental Law at Fundação Armando Alvares Penteado (FAAP) in São Paulo, Brazil, and Assistant Professor of International Environmental Law at the Catholic University of Santos (UNISANTOS). Fernando holds a PhD in state-environmental law from the Alicante University and a PhD in international law from the University of São Paulo. He is scientific director of the Brazilian Society of 
International Law of the Environment (SBDIMA). He was twice CEO of São Paulo’s Environmental Agency (CETESB).

John Robinson In his role as Associate Provost-Sustainability, Prof. Robinson is responsible for leading the integration of academic and operational sustainability on the University of British Columbia's Vancouver campus. His own research focuses on the intersection of sustainability, social and technological change, behavior change and community engagement processes at the community and building scale.

Patricia Romero-Lankao is an "interdisciplinary sociologist" and a Scientist at NCAR currently leading the "Urban Futures" initiative. Her research explores the dynamics of urbanization that shape urban emissions, vulnerabilities and risk. She has also analyzed why and how urban populations and decision makers attempt to meet the challenges of reducing emissions while improving their resilience to floods, air pollution and other environmental impacts. Along with other scientists, she is designing urban interdisciplinary studies that inform and are informed by global interdisciplinary research. She has participated in global and local endeavors promoted by UNDP and UN-HABITAT. She was co-leading author to Working Group II of the Nobel prize-winning IPCC AR4 and is currently convening author of IPCC: AR5, North American chapter. She is passionately engaged in finding options to move humankind toward a more sustainable and fair future.

Angélica Rosas-Huerta has a degree in Social Sciences from Universidad Autónoma Metropolitana. She is an Associate Professor at the Department of Policy and Culture of this university. She specializes on public policies, institutional capabilities and the public policy-science interface in the climatic change arena. She also focuses on the institutional dimensions of social vulnerability and adaptation to climatic change. She has authored and co-authored research papers and chapters of books related to evaluation policies of high-level education and institutional capabilities of governments attending to climatic change. She has also authored books on capabilities and weaknesses of local governments dealing with climatic change.

Saskia Sassen is the Robert S. Lynd Professor of Sociology and Co-Chair, The Committee on Global Thought, Columbia University (www.saskiasassen. com). Her recent books are Territory, Authority, Rights: From Medieval to Global Assemblages (Princeton University Press, 2008); A Sociology of Globalization (W. W. Norton, 2007); and the fourth fully updated edition of Cities in a World Economy (Sage, 2012). Among older books is The Global City (Princeton University Press, 1991/2001). Her books 
are translated into more than twenty languages. She has received diverse awards, from multiple doctor honoris causa to being chosen as one of the Top 100 Global Thinkers by Foreign Policy and as the 2013 winner of the Principe de Asturias Prize for the Social Sciences.

Joana Setzer is a post-doctoral researcher at the Grantham Research Institute on Climate Change and the Environment. She is currently working on the new edition of the GLOBE Climate Change Legislation Study, a compilation of climate legislation in 100 countries. Joana holds a $\mathrm{PhD}$ in Environmental Policy and Development from the London School of Economics and Political Science (LSE). Her research focused on the international environmental relations undertaken by subnational governments. She also holds an MSc in Environmental Policy and Regulation from the LSE. Prior to that, Joana obtained an MSc in Environmental Science from the University of São Paulo, a LLB in Law from Pontificia Universidade Catolica of São Paulo, and she worked for eight years as an environmental lawyer in Brazil.

Alison Shaw is Principal at FlipSide Sustainability, a climate change and sustainability consulting and coaching firm. Her expertise combines two decades of sustainability research with professional coaching techniques to co-create, mobilize and embed cutting-edge sustainability knowledge. She leads, designs and manages social learning processes that help to transition organizations and networks of practice toward greater sustainability outcomes.

Laura Valente de Macedo is a $\mathrm{PhD}$ candidate at the University of São Paulo (PROCAM/IEE-USP). Her research investigates climate change policies and measures at the local level. She has an MSc degree in environmental change from the University of Oxford, and an MSc in environmental science from the University of São Paulo. Laura is an architect and city planner by training, and has been working as a consultant and a lecturer in sustainability policies and management. She was the national director for Sustainable Production and Consumption at the Brazilian Ministry of Environment (2011-2012), and regional director of ICLEI-Local Governments for Sustainability for Latin America and the Caribbean (2002-2011). Between 2000-2002 she was a coordinator of the Brazilian Climate Change Forum, and between 1991-1997 she worked as an advisor to environmentalist Congressman Fabio Feldmann. She co-authored and edited several publications in sustainability management related fields. 


\section{Index}

actor network theory 159-60; see also Latour

adaptation 1, 12-13, 16, 82, 238-9; critique of $28-9,33,119-20$, 139-40, 204-7

adaptive capacity 140, 151, 182-3, 210 adaptive social learning 236

Addis Ababa 11

advocacy 10, 66, 69

AECOM 84

agriculture 18, 55, 143, 150; effects of urbanization on rural livelihoods $1-3,7$

air quality 83,111

Alexander, C. 46-53

ALGA (Australian Local Government Association) 64

Amsterdam 83, 143, 234

architecture see urban design

articulations between cities and the biosphere 15, 28-9, 33-4, 38, 232

ARUP 10, 50, 57, 68-9, 71, 73, 83, 85, $92,231,234$

A.T. Kearney 68

Atkins Report 13: "Future Proofing Cities" 13

automobile 38, 54, 112, 170, 234: Dependence on 14, 38, 50, 54, 165-7

Autonomous University of Mexico (UNAM) 192, 197

Bangkok, Thailand 142, 143

Barcelona 56

Betsill, M. 5, 9, 10, 11, 64, 66, 67, 103,

biogas 110 $105,119,129,142,158,207,233$

Bloomberg, M. 11, 63, 68, 74, 76-8
Bloomberg Philanthropies 69, 73

Brazil 6, 68: National Climate Change Policy 109; Municipal Climate Law 109

British Columbia 121: "Meeting the Climate Challenge" 121, 123-4; provincial targets for emissions reductions 123-4; Climate Action Charter 129

Buenos Aires, Argentina 17, 181, 234; economic, demographic and climatic conditions 184-6; constitutional status 186-7; climate change policies 187-90; administrative structure 190-2; decentralization 191-2; legal support for 192-4; housing policy 195 ; community engagement 195; emissions inventories 197-9

Bulkeley, H. 5, 8-11, 63-7, 101-3, $105,114,119,129,142,171$, 173, 205, 207, 230-1, 233, 237

Burundi 215

C40 (Cities Climate Leadership Group) 5, 10, 15-6, 24, 64-5, 67-71, 78, 83, 102, 107-10, 142, 192, 218, 231-5, 240; history of $64-5,67-70$; role in advocacy 69; organization and administration of 74-5; critical interpretations of 75-7

Canada 121, 229

Carbon Disclosure Project (CDP) 73

cars see automobile

CCI (Clinton Climate Initiative) 11, $67,69,72-3,78,107,110$, 142,231 
CCP (Cities for Climate Protection) 27, 64-6, 106-8, 142, 218, 234; see also ICLEI $27,64-5$

CDM (Clean Development Mechanism) 10, 106, 110, 239

Children's Investment Fund Foundation (CIFF) 73

China 6-7, 50, 86, 89, 112, 141-2, 209: urban population growth 6-7

cholera 212, 216

Cisco 83, 234

cities 3: as sites of vulnerability 3 ; as sources of greenhouse gas emissions 3, 141; challenge of acting autonomously 5, 181, 183, 229; challenge of reducing emissions and vulnerability 5 , 229; theories of urban climate engagement $8-15,240$; as complex adaptive systems 9 , 39,141 ; as actors in global climate politics $10-12 ; 24-5$, 63-4, 69, 106-8; as sites of struggle 27,229 ; as sites of capital accumulation and investment 1-8, 29-34, 87; as sites of experimentation 8-9, 29-33, 82, 240; as exemplars 86 ; in relation to nation-states 8-15, 29, 66-7, 108-9, 183, 217-19, 229, 240; challenge of conceptualizing 14-15; 29-30, 240 ; in the study of international relations 64-7, 240; as actors in global climate politics $8-15$, 29-30, 64-7; 102-3, 147, 218, 233-5, 240; legal framework for governance 183

Cities Alliance 217

Cities Climate Leadership Group see C40

City Climate Leadership Awards 73

\section{CITYNET 64}

city networks 68

Clean Development Mechanism see CDM

Clinton Climate Initiative see CCI

Complex adaptive systems 9, 39, 44, 46,56

Conference of Parties (COP) 6, 27, 34, $68,71,78,106-8,142$

consumption $3,5,14,17,31,35$, 38-42, 47, 53-4, 56, 82, 86-90, $110,130,141,185-6,214$
Copenhagen 26, 34

Copenhagen Conference of Parties (COP 15) 6, 34, 71, 107-8

corporations see MNCs

Curitiba, Brazil 215

Dar es Salaam, Tanzania 17, 205, 208, 211, 215-20, 239; population 215-17; administrative structure 216; climate change vulnerability 216-17; climate change initiatives 217-19

Democratic Republic of Congo (DRC) 211, 215

"dense sprawl" 45

densification strategies 6,14 , 17,45

Department for International Development, (DFID) UK 10

development pathways $14,46,63,82$, 119-20, 122-3, 125, 134-5, 236, 239

Dhaka, Bangladesh 86, 142 discourses see discursive strategies discursive strategies 70-1, 122, 159-60, 231; see also policy framing

disease 3, 7, 32-3, 88, 111, 212, 216

Dongtan 49-50, 57, 85

Durban, South Africa 207, 215, 220

eco-cities 48-9: Dongtan eco-city 49-50

Economic Commission for Latin America (ECLA) 192, 195

energy 6, 13-16, 24, 34, 39-40, 43-5, 50, 54-5, 69, 74, 83, 86-91, 104-7, 109-11, 113, 120, 128-34, 141, 143, 157-66, 171, 174-5, 181-3, 186, 189, 191-3, 197, 200,

Eurocities 64

European Union 217

Finnemore, M. 9, 230, 235

floods 142, 144, 212

footprints, urban carbon and ecological $3,11,65,82-3,86,88-9,111$, 191, 234, 236

G20 67

Gavron, N. 67

Gleneagles 67; see also G20

global climate governance 8-15: role of norms in shaping dissemination 
of urban climate policy 9-10; 235-6, 240

global climate regime 4-5, 8, 10-11, 16, 27, 37, 64, 109, 181, 227, 231-2; definition of 5

Global Environment Facility (GEF) 214 globalization 15, 45, 68, 239

Green Climate Fund 5, 10

Guangzou, Chona 142

health $7,13,27,38,83,111,122,129$, $156,163,169,173,175,188-9$, 201, 210, 212, 216-17, 227-9, 238

Helmholtz Center, Germany 198

Ho Chi Minh City 83, 143, 234, 237

Hong Kong 68, 78

housing 7-10, 13, 56, 111, 144-5, $162,186,189,192-5,198,200$, 207, 209, 212, 214, 216-7, 219, 227-9, 239

IBM 84

ICLEI 5, 10-11, 16, 27, 34, 65-6, 73, 102-3, 106-8, 110, 130, 142, 156, 161, 174, 182, 192, 198,

IKEA 84 $217,231-5,238,240$

India 6: projected population growth in $7,68,142$, responsibility for adaptation 146-7; disaster mitigation 149; see also Mumbai

Indian Meteorological Department (IMD) 144-45

Indonesia 7, 68

infrastructure $5,8-9,12-13,24,31-2$, $45,50,54-5,83,86-7,90,120$, 130-4, 142-5, 147, 149, 181, 184, 186, 189, 209-10, 212-14, 216-17, 219, 227-9, 232, 234, 239

Intergovernmental Panel on Climate Change see IPCC

International Council on Local Environmental Initiatives see ICLEI

International Energy Agency (IEA) 1, 3,14

International Institute for Environment and Development (IIED) 35

International regimes 3: definition of 11

IPCC (Intergovernmental Panel on Climate Change) 3, 5-6, 8, 105, $119,121,139,205-6,210,237$
Joint Implementation 10

Kampala, Uganda 17, 208, 211-15, 219-20; population 211-12; climate change vulnerability 212; administrative structure 212-14; climate change initiatives 214; political history 214-15

Kenya 211, 215

Kolkata, India 142-3

Kyoto Protocol 9, 11, 27, 63, 233; perceived failure of $10,68,229$, 235

Lagos 110

Lake Victoria 211

Landprop see IKEA

land use $7,8,14,46,130-2,143,169$, 173, 175, 183-4, 186, 191, 193-4, 198, 200, 229, 233; land-use planning 46

Latour, B. 159-60, 162-3, 167-8, 171-2

Lefebvre, H. 39, 54-5

LEED Gold Standard 130, 132

lifestyle 12, 56, 86, 88-92, 134, 233

Lima 11

livelihood 7, 14, 139, 143, 150

Livingstone, K. 11, 68, 78

Local Government and Municipal Authority Constituency 27

Local Government Climate Roadmap 27

London 10, 11, 49, 67, 76-7, 83-4, 107; Abercrombie Plan for 49; Greater London Authority 67; involvement in the formation of the C40 67; climate leadership 67

Los Angeles 11, 27, 77

Mahatma Gandhi National Rural Guarantee Act (MNREGA) 147

Malawi 215

Manila, Philippines 142

market environmentalism 151

Marx, K. 50: idea of "Utopian Cities" 50

Masdar City (United Arab Emirates) $29,50,52$

mayors $11,26,63-4,91-2,107-8$, 126, 142, 182, 190, 192, 212, 218: growing profile of 26,63

Mayors for Peace 64 
McKinsey Global Institute 6

Medellin (Colombia) 55

Melbourne 83, 234

methane gas recovery 110, 217, 234

Mexico City 17, 110, 181, 228-9, 237-8; economic, demographic and climatic conditions 184-6; constitutional status $186-7$; climate change policies 187-90; administrative structure 190-2; decentralization 191-2; legal support for 192-4; water and sanitation 196; community engagement 196; emissions inventories 197-9

Miller, D. 68, 78

MIT-ICLEI Urban Climate Change Governance Survey 157-8

mitigation $5-6,8,10,12-13,16,28-9$, $33,38,55,82-4,102,104-5$, 109-10, 112-13, 119-25, 127-35, 139, 142-5, 147-8, 152, 157, 169, 175, 181-2, 184, 188-9, 193, 205, 217, 227-8, $233-5,237,239$

MNCs 16, 82-5, 87-8, 91-2; 234, 237; and urban design 84-5; and the study of urban climate governance $84-5$; and policy diffusion 85

mobility $38,54,56,83,85,88,91$, 111,175

modernist planning 50-2

Mozambique 215

multilevel governance 105, 114, 181, 206, 233

multinational companies see MNCs multinational corporations see MNCs multi-scalar systems $12,28-9,31-3$, 139-40, 158: in contrast to multi-level systems $32-3,232-3$

Mumbai, India 16, 139-55, 228, 234-5, 237, 239: vulnerability to climate change 143 ; automobile dependence 143; 2005 floods 144-6; impact on the poor 148-9

Mumbai Disaster Management Plan 145

Mumbai Metropolitan Region 143

Mumbai Metropolitan Regional Development Authority (MMRDA) 143
Nagoya 143

neoliberal environmentalism 88; see also market environmentalism

neoliberalism 45, 75-6, 87-8, 186, 239

networks see transnational urban networks

New Orleans 143

New York 5-6, 10-11, 26, 63, 67, 70, $74,76,78,107,173,236$

NGOs 24, 101, 145, 174

Nigeria 7

Ningbo 143

nongovernmental organizations see NGOs

non-state actors 5, 10-12, 72, 101-2, $119,121,150$

North-South politics 6, 33, 102-3, 152: and the C40 76

North Vancouver, City of (CNV) 125 , 130-2, 134, 228

Oregon, USA 17, 156-77

Organization for Economic

Cooperation and Development

(OECD) 110, 143

Ostrom, E. 108, 236

Pahl-Wostl, C. 236-7

Paris 26, 215

path dependence 228, 236

planetary ruptures $9,14-15,28,37-8$, 232-3, 239

planning $4,8-10,14,16,35,46$, $50,56-7,74,78,83,89-90$, 104-5, 110, 120, 122-3, $125-6,128-35,144-5,148$, $152,156-8,160-1,164-75$, 183-4, 186, 188-91, 193-5, 197-8, 200-1, 209-10, 212-3, 218, 220, 227-8, 230-1, 234-5, 238, 240

policy see urban climate policy policy framing 133-4, 151, 172-3, 230-1

political ecology 14, 239

polycentric governance 164-5

population density 39-45, 233

Portland, Oregon 17, 156-77, 228-30, 237-8: Office of Sustainable Development 160, 162-3; history of urban climate policy change 161-9; transportation 165-7; Climate Change Action 
Plan 167-9; municipal politics $170-1$

poverty $7-8,13-4,55,122,147,150$, $197,212-3,217,220,239$

privatization $16,91,239$

public-private partnerships 110, 239

\section{Realdania 73}

Recife (Brazil) 56

resilience 3, 5-6, 8-9, 13-14, 46, 54, $65,91,120,131,142,147,151$, 158

resource cycles 39-45, 56-7, 233

response capacity $123,182-4,186-7$, 189-90, 195, 197, 199-201

Revi, A. 7, 37, 144, 148

Romero-Lankao, P. 3, 7-9, 13-14, 17, 103, 195, 199, 229, 239

Rotterdam 6, 78, 143

rural displacement $1-3$

rural-urban migration 1-3, 56

Rwanda 211, 215

sanitation $6-7,13,90,123,193,210$, 217, 228, 236

Santiago, Chile 17, 182, 234; economic, demographic and climatic conditions 184-6; constitutional status 186-7; climate change policies 187-90; administrative structure 190-2; decentralization 191-2; legal support for 192-4; emissions inventories 197-9

São Paulo 16, 77, 78, 101-4, 229, 234, 237-8: evolution of urban climate policy 104-5; transnational engagement 106-8; municipal-federal relations 108-9; and the National Climate Change Policy 109; Biogas recovery project 110; and municipal transportation 110-11; challenges in enforcement 111-12; increasing car ownership 112; policy integration 112

Sassen, S. 6-9, 12, 14-5, 18, 37-8, 46, $54,70,77,183,232-3,236-8$

Satterthwaite, D. 3, 7-9, 14, 18, 34-5, $120,207,211$

scale $12-13 ; 26-7$ scaling 30-1

Seattle 5, 142

Shanghai 141, 143

Siemens 10, 16, 69, 73, 83-6, 231, 234; Siemens Centre for Urban Sustainability 84

Sikkink, K. 9, 66, 230, 235

Singapore 6

Smarter Cities Challenge see IBM

South Africa 6, 68

South Sudan 211

Soviet planning 54

space as a concept 30-3, 54; and the work of Lefebvre 54-5

Stockholm 26

Surrey, British Columbia 125, 130-1, 134

sustainability 28-31, 33, 67, 85-9, 91, 119-35, 160, 162-5, 168, 171, 183, 186, 194, 197, 228, 230, 238; as a framework for integrating adaptation and mitigation 131-3

techno-fixes 87

TERI (The Energy Research Institute, India) 143

\section{Tianjin 143}

Tokyo 26, 27, 143

Toronto 5, 68, 78, 173

transnational urban alliances $27,64-5$ : history of 64-5; "first" and "second wave" of transnational urban climate alliances; see also Bulkeley, H. 65; evolution of scholarship on 66-7

transnational urban networks 64-5, 231-2; evolution of scholarship on $66-8,106-8$

transportation 5-6, 8-10, 13-14, 25, $35,37-8,43,49,51,54,74,77$, 83, 86, 90, 103-4, 106, 110-14, $120,128,130-4,143,162$, 165-7, 169-71, 173, 175, 186, 191, 193, 217, 227-30, 232-4, 236, 239

UNDP (United Nations Development Programme) 10

UNFCCC (United Nations Framework Convention on Climate Change) 5-6, 9-11, 27, 34, 65, 76, 
101-2, 104-7, 229, 232-5, 237,240

UN-Habitat 209, 214, 216-17

UNISDR (UN International Strategy for Disaster Reduction) 13

United Nations Framework Convention on Climate Change see UNFCCC

United Nations Sustainable Development Knowledge Platform 110

United States 7, 108

University of Buenos Aires 192

University of Chile 192

urban climate policy 5 : challenges of reducing emissions 5-8; urban climate experiments $8-9$; defining success $8-15$; and transnational urban alliances 64-7; and MNCs 84-5; challenges of policy integration 112, 200-1, 227-8; human and financial resource needs; 183 , 207, 227-8; legal support for 183; the role of climate science 183

urban design 30

urban ecological footprint $1-3 ; 28-30$; 37-8, 236

urban population 1: growth trends 1-3; exposure to climate hazards 1 ; in coastal and low elevation areas 17

urban vulnerability 1 : conceptualizations of 13-14; political economy of $149-52$; in Africa 210-11 urban greenhouse gas emissions 1: challenges in measuring 14-15, 30

urbanization 1: projected growth rates 1 ; explanations for 7 ; environmental impact of 7 ; in Africa 209

urban transformations $28-32 ; 37-8$ : nature of 46, 238-9

Utopian Cities 50-4: "Lilypad Floating Ecopolis" 51

Vancouver 26, 120, 125, 130-4

Victoria, British Columbia 125, 130-2 vulnerability 1 : in an urban context 1 , $3,13-14$; theories of $13-14$; 142; urban floods 142; and poverty 147-9; political economy of 149-52

waste disposal 8, 37, 54, 217

water $3,6-7,13,15,28,30,32,35$, $37-9,45,54-5,74,83,86-8$, $90,106,120,122,128,130-1$, 133, 143-4, 146, 148-50, 164, $169,174-5,185-6,193,197$, 205, 210, 212, 216-7, 228-30, 236; "right to water" 55

World Bank 3, 5-6, 8, 10, 12, 14, 17, 68, 110, 192, 197, 212, 216-18, 236 ; as an actor $67,73,231$

World Bank Institute 69

World Mayors Council 182, 192, 218

World Resources Institute 73

Zambia 215

ZEIS (Special Zones of Social Interest) 56 